\author{
Universidade de São Paulo \\ Instituto de Astronomia, Geofísica e Ciências Atmosféricas \\ Departamento de Ciências Atmosféricas
}

Ana Carolina Nóbile Tomaziello

\title{
Influências da temperatura da superfície do mar e da umidade do solo na precipitação associada à Zona de Convergência do Atlântico Sul
}



Ana Carolina Nóbile Tomaziello

\title{
Influências da temperatura da superfície do mar
}

\author{
e da umidade do solo na precipitação associada
}

\section{à Zona de Convergência do Atlântico Sul}

Dissertação apresentada ao Departamento de Ciências Atmosféricas do Instituto de Astronomia, Geofísica e Ciências Atmosféricas da Universidade de São Paulo como requisito parcial para obtenção do título de Mestre em Ciências.

Área de Concentração: Meteorologia Orientador: Prof. Dr. Adilson Wagner Gandu

São Paulo 

Às pessoas mais maravilhosas que poderiam existir em minha vida... Minha mãe, Maria Cida, a quem devo todas as minhas conquistas, por toda paciência, apoio e infinito amor. Meus avós, Shirlei e Augusto, por todo apoio, amor e carinho. 



\section{Agradecimentos}

Em primeiro lugar a Deus pelo dom e privilégio da vida, por ter me concedido o livrearbítrio para que eu escolhesse meu caminho e por ter colocado em minha vida pessoas tão maravilhosas e incomparáveis. A Jesus por velar por mim e proteger a todos que amo.

Ao meu orientador desde os meus primeiros passos na iniciação científica, Prof. Dr. Adilson Wagner Gandu, por ter me apresentado e me conduzido ao fascinante mundo da pesquisa, pela oportunidade, orientação, sugestões e apoio neste trabalho, principalmente pela confiança, paciência, grande incentivo, otimismo, amizade e por acreditar em mim sempre.

À minha mãe, Maria Cida, mulher guerreira e meu amor eterno, pelo apoio em todas as etapas de minha vida, carinho, amor, força, incentivo, por todo esforço que realizou para que eu tivesse uma boa formação, pelo exemplo de vida, confiança, paciência, enfim, por tudo que fez e faz por mim sempre e incondicionalmente.

Aos meus avós, Shirlei e Augusto, pelo apoio, amor, carinho, incentivo, pelos esforços que fizeram por mim durante toda minha vida e pela confiança que sempre em mim depositaram.

A uma pessoa maravilhosa, Paulo, pelo carinho, amizade e principalmente por toda paciência ao longo desses anos.

Ao meu pai, Rogério Achilles, e aos meus avós, Elisa (in memoriam) e Rogério (in memoriam), pela confiança que depositaram em mim e por todo o carinho.

Ao meu amigo Márcio pelo incentivo. 
Aos membros da banca do Exame de Qualificação, Profs. Drs. Ricardo de Camargo e Tércio Ambrizzi (IAG-USP), pelas críticas e sugestões, que contribuíram para o desenvolvimento deste trabalho.

Ao Prof. Dr. Edmilson Dias de Freitas (IAG-USP) pelos seus ensinamentos, atenção, consideração, paciência, dicas, incentivo e amizade.

Ao Prof. Dr. Pedro Leite da Silva Dias (IAG-USP) pelas sugestões de grande valia, dicas e auxílio sempre que possível.

Ao Prof. Dr. Dirceu Luis Herdies (CPTEC/INPE) pela disponibilização dos dados das reanálises utilizados neste estudo.

Ao meu amigo Dr. Ricardo Hallak (IAG-USP) pela disponibilidade e inúmeros auxílios durante a realização deste trabalho.

À Profa. Dra. Leila Maria Véspoli de Carvalho (IAG-USP) pelas dicas e sugestões.

Aos professores do IAG-USP pela dedicação, acompanhamento durante todo o curso e ensinamentos que muito contribuíram para meu crescimento científico.

À equipe que mantém o Laboratório MASTER (IAG-USP) pela infraestrutura que possibilitou a realização deste trabalho.

Aos técnicos de informática, Samuel e Sebastião, e às secretárias do Departamento de Ciências Atmosféricas do IAG-USP, Ana, Bete e Sônia, pela atenção.

Aos meus amigos Meteorologistas do IAG-USP pela grande amizade, companheirismo, apoio e bons momentos que passamos juntos ao longo desses anos.

Ao IAG-USP (Instituto de Astronomia, Geofísica e Ciências Atmosféricas da Universidade de São Paulo) pela oportunidade de realização do curso de Mestrado.

À FAPESP (Fundação de Amparo à Pesquisa do Estado de São Paulo) pela concessão da bolsa de Mestrado e pelo apoio financeiro através do processo nº 2007/57101-2. 
“Aprender é a única coisa de que a mente nunca se cansa, nunca tem medo e nunca se arrepende". 



\section{Resumo}

NÓBILE TOMAZIELLO, A. C. Influências da temperatura da superfície do mar e da umidade do solo na precipitação associada à Zona de Convergência do Atlântico Sul. 2010. 166 f. Dissertação (Mestrado em Meteorologia) - Instituto de Astronomia, Geofísica e Ciências Atmosféricas, Universidade de São Paulo, São Paulo, 2010.

Durante o verão austral, diversas regiões do Brasil, como a Sudeste, porções das Regiões Sul e Nordeste e o Brasil central, sofrem períodos de intensa precipitação, geralmente associados à Zona de Convergência do Atlântico Sul (ZCAS), o que ocasiona sérios problemas econômicos e sociais nessas regiões. Assim, o objetivo geral deste trabalho foi estudar as principais características da ZCAS, sendo que, do ponto de vista de modelagem numérica, pretendeu-se estudar as influências da temperatura da superfície do mar (TSM) e da umidade do solo (US) principalmente na precipitação associada ao sistema. Esse estudo foi realizado através de simulações com o modelo regional BRAMS (Regional Atmospheric Modeling System with Brazilian Developments), para dois casos de ZCAS, ocorridos em 1998 e 1999, períodos, respectivamente, com TSM's do Pacífico leste e central anomalamente quentes (El Niño) e anomalamente frias (La Niña). Através de índices estatísticos foi verificado o desempenho do modelo, usando TSM's com resoluções espaciais e temporais diferentes, na previsão de precipitação nas regiões que compõem a ZCAS (oceânica, costeira e amazônica). O pior e o melhor desempenhos do modelo BRAMS se deram quando do uso de TSM's com resoluções espacial e temporal menos e mais refinadas, respectivamente, para o caso de ZCAS de 1998. Para o caso de 1999 não foram observadas diferenças significativas no desempenho 
do modelo. Grande parte do erro do modelo na previsão de chuva é devida ao viés do próprio modelo, que é melhor em identificar a ocorrência/não-ocorrência de chuva do que em localizar núcleos mais intensos. No entanto, o BRAMS apresenta alto skill no que se refere à quantidade de chuva. Com respeito à simulação de precipitação nas regiões que compõem a ZCAS, o melhor e o pior desempenhos do modelo se deram nas regiões amazônica e oceânica, respectivamente. Com relação à US verificaram-se as influências da condição de solo mais seca possível, aplicada às regiões de ZCAS continental, em características do sistema como convergência de umidade e precipitação. De maneira geral, a quantidade de precipitação acumulada nas regiões onde se aplicou a condição seca foi maior do que no experimento controle devido à convergência de umidade, que é transportada das regiões circunvizinhas para a região de solo mais seco por circulações de meso e grande escalas geradas por heterogeneidades na superfície. Analisaram-se ainda diferenças nas características da ZCAS observada e simulada em diferentes fases do El Niño-Oscilação Sul (ENOS). Os casos de ZCAS de 1998 e 1999 se apresentaram mais alongado sobre o Atlântico e predominantemente continental, respectivamente, o que confirma que períodos de El Niño (La Niña) favorecem a ocorrência de ZCAS oceânica (continental). Nos testes de sensibilidade do BRAMS à US foi observado provável efeito do ENOS sobre a ZCAS simulada, uma vez que o movimento ascendente na ZCAS amazônica foi menos intenso do que na costeira em 1998, ocorrendo o oposto em 1999. A fase quente (fria) do ENOS favorece a subsidência (ascendência) na região amazônica, podendo ter contribuído para enfraquecer (intensificar) o movimento vertical nessa região em 1998 (1999).

Palavras-chave: ZCAS, modelagem, precipitação, TSM, umidade do solo, convergência. 


\section{Abstract}

NÓBILE TOMAZIELLO, AC. Influences of the sea surface temperature and of the soil moisture upon the precipitation associated with South Atlantic Convergence Zone. São Paulo: Institute of Astronomy, Geophysics and Atmospheric Sciences, University of São Paulo, 2010, 166 p. Masters Dissertation in Meteorology.

During austral summer, several regions of Brazil, as Southeast, portions of South and Northeast Regions and central Brazil, suffer periods of intense precipitation, generally associated with South Atlantic Convergence Zone (SACZ), which causes serious economic and social problems in those regions. Notwithstanding, the general objective of this work was to study the main features of SACZ, and in terms of numerical modeling, it intended to study the influences of the sea surface temperature (SST) and of the soil moisture (SM) mainly upon the precipitation associated with the system. This study was carried out through simulations with BRAMS (Regional Atmospheric Modeling System with Brazilian Developments) regional model, to two SACZ cases, occurred in 1998 and in 1999, periods, respectively, with SST's of Eastern and central Pacific abnormally warm (El Niño) and abnormally cold (La Niña). Through statistical indices it was verified the model performance, using SST's with different spatial and temporal resolutions, upon the precipitation's forecasting in the regions that compound SACZ (oceanic, coastal and Amazon). The worst and the best performances of BRAMS model occurred when using SST's with less and more refined spatial and temporal resolutions, respectively, to the SACZ case of 1998. To the case of 1999 it was observed no significant differences in the model's performance. Much of the model's error in rain's 
forecasting is due to the bias of the model itself, which is better in identifying the occurrence/non-occurrence of rain than in locate more intense nuclei. However, the BRAMS has high skill regarding to the amount of rain. About the precipitation's simulation in the regions that compound SACZ, the best and the worst model's performances occurred in the Amazon and oceanic regions, respectively. Concerning the SM it was verified the influences of the driest possible soil condition, applied to continental regions of SACZ, upon system's features such as moisture convergence and precipitation. In general, the amount of rainfall in regions where the dry condition was applied was higher than in the control experiment due to the moisture convergence, which is transported from surrounding regions to the one of drier soil by meso and large scale circulations generated by heterogeneities on the surface. It was also analyzed differences in the characteristics of observed and simulated SACZ at different phases of El Niño-Southern Oscillation (ENSO). The SACZ cases of 1998 and of 1999 were presented more elongated over the Atlantic and predominantly continental, respectively, confirming that periods of El Niño (La Niña) favor the occurrence of oceanic (continental) SACZ. In the BRAMS' sensibility tests to SM it was observed probable effect of ENSO upon simulated SACZ, as the upward motion in Amazon SACZ was less intense than in the coastal one in 1998, occurring the opposite in 1999. The warm phase of ENSO favors the subsidence (rising) on Amazon region, which may have contributed to weaken (intensify) the vertical motion on the region in 1998 (1999).

Keywords: SACZ, modeling, precipitation, SST, soil moisture, convergence. 


\section{Lista de figuras}

Figura 1. Topografia (intervalo de $500 \mathrm{~m}$ ). A região sombreada representa os limites da grade, com espaçamento horizontal de $32 \mathrm{~km}$, utilizada nas simulações numéricas com o BRAMS. Os retângulos representam os limites das distintas regiões, utilizadas neste trabalho, que compõem a ZCAS: oceânica (azul), costeira (vermelho) e amazônica (verde)

Figura 2. Imagens do satélite GOES-8 no canal do infravermelho para os dias (a) $11 / 02 / 98$ às $18 Z$, (b) $12 / 02 / 98$ às $18 Z$, (c) $14 / 02 / 98$ às $21 Z$ e (d) $16 / 02 / 98$ às 18Z. Fonte: DSA/INPE.

Figura 3. Precipitação diária acumulada pelo GPI (intervalo de $5 \mathrm{~mm} \mathrm{dia}^{-1}$ ) nos dias (a) 11/02/98, (c) 12/02/98, (e) 14/02/98 e (g) 16/02/98. Divergência do fluxo horizontal de umidade integrado na atmosfera, da pressão reduzida ao nível médio do mar ao nível de $100 \mathrm{hPa}$ (intervalo de $1,5 \times 10^{-4} \mathrm{~kg} \mathrm{~kg}^{-}$ ${ }^{1} \mathrm{~s}^{-1}$ ), para as $18 \mathrm{Z}$ dos dias (b) $11 / 02 / 98$, (d) $12 / 02 / 98$, (f) $14 / 02 / 98$ e (h) 16/02/98. O tracejado em preto representa a localização das seções verticais das Figuras 7 e 8

Figura 4. Idem à Figura 3 mas para escoamento horizontal $\left(\mathrm{m} \mathrm{s}^{-1}\right)$ e temperatura do ar (sombreado com intervalo de $2{ }^{\circ} \mathrm{C}$ ) em $1000 \mathrm{hPa}$ (a, c, e, g) e para escoamento horizontal $\left(\mathrm{m} \mathrm{s}^{-1}\right)$ e umidade específica (sombreado com intervalo de $1 \mathrm{~g} \mathrm{~kg}^{-1}$ ) em $1000 \mathrm{hPa}(\mathrm{b}, \mathrm{d}, \mathrm{f}, \mathrm{h})$.

Figura 5. Idem à Figura 3 mas para linhas de corrente e magnitude do escoamento horizontal (intervalo de $2 \mathrm{~m} \mathrm{~s}^{-1}$ ) em $500 \mathrm{hPa}$ (a, c, e, g) e para altura geopotencial (contorno com intervalo de $15 \mathrm{~m}$ ) e advecção de vorticidade relativa (sombreado com intervalo de $1 \times 10^{-9} \mathrm{~s}^{-2}$ ) em 500 $\mathrm{hPa}(\mathrm{b}, \mathrm{d}, \mathrm{f}, \mathrm{h})$

Figura 6. Idem à Figura 3 mas para linhas de corrente e magnitude do escoamento horizontal (intervalo de $5 \mathrm{~m} \mathrm{~s}^{-1}$ ) em $200 \mathrm{hPa}$.

Figura 7. Seções verticais da divergência do fluxo horizontal de umidade (intervalo de $1 \times 10^{-4} \mathrm{~kg} \mathrm{~kg}^{-1} \mathrm{~s}^{-1}$ ) para as $18 \mathrm{Z}$ dos dias (a) $11 / 02 / 98$, (c) $12 / 02 / 98$, (e) $14 / 02 / 98$ e (g) 16/02/98. Seções verticais da velocidade vertical omega (intervalo de $0,1 \times 10^{-2} \mathrm{hPa} \mathrm{s}^{-1}$ ) para as $18 \mathrm{Z}$ dos dias (b) $11 / 02 / 98$, (d) 12/02/98, (f) 14/02/98 e (h) 16/02/98. No eixo das abscissas está representada a distância em $\mathrm{km}$, a partir do ponto mais ao norte, ao 
longo da linha tracejada em preto nas Figuras anteriores. A linha em verde representa, aproximadamente, o limite entre continente e oceano, que se localizam à esquerda e à direita da mesma, respectivamente. No eixo das ordenadas estão representados os níveis de pressão em $\mathrm{hPa}$.

Figura 8. Idem à Figura 7 mas para as componentes zonal (intervalo de $\left.5 \mathrm{~m} \mathrm{~s}^{-1}\right)(\mathrm{a}$, $\mathrm{c}, \mathrm{e}, \mathrm{g})$ e meridional (intervalo de $\left.5 \mathrm{~m} \mathrm{~s}^{-1}\right)(\mathrm{b}, \mathrm{d}, \mathrm{f}, \mathrm{h})$ do vento.

Figura 9. Imagens do satélite GOES-8 no canal do infravermelho para os dias (a) $06 / 01 / 99$ às $18 \mathrm{Z}$, (b) 09/01/99 às $18 \mathrm{Z}$, (c) $12 / 01 / 99$ às $21 \mathrm{Z} \mathrm{e}$ (d) $17 / 01 / 99$ às 21Z. Fonte: DSA/INPE.

Figura 10. Precipitação diária acumulada pelo GPI (intervalo de $5 \mathrm{~mm} \mathrm{dia}^{-1}$ ) nos dias (a) 06/01/99, (c) 09/01/99, (e) 12/01/99 e (g) 17/01/99. Divergência do fluxo horizontal de umidade integrado na atmosfera, da pressão reduzida ao nível médio do mar ao nível de $100 \mathrm{hPa}$ (intervalo de $1,5 \times 10^{-4} \mathrm{~kg} \mathrm{~kg}^{-1} \mathrm{~s}^{-1}$ ), para as $18 \mathrm{Z}$ dos dias (b) 06/01/99, (d) 09/01/99, (f) 12/01/99 e (h) 17/01/99. O tracejado em preto representa a localização das seções verticais das Figuras 14 e 15 .......

Figura 11. Idem à Figura 10 mas para escoamento horizontal $\left(\mathrm{m} \mathrm{s}^{-1}\right)$ e temperatura do ar (sombreado com intervalo de $2{ }^{\circ} \mathrm{C}$ ) em $1000 \mathrm{hPa}(\mathrm{a}, \mathrm{c}, \mathrm{e}, \mathrm{g})$ e para escoamento horizontal $\left(\mathrm{m} \mathrm{s}^{-1}\right)$ e umidade específica (sombreado com intervalo de $1 \mathrm{~g} \mathrm{~kg}^{-1}$ ) em $1000 \mathrm{hPa}(\mathrm{b}, \mathrm{d}, \mathrm{f}, \mathrm{h})$.

Figura 12. Idem à Figura 10 mas para linhas de corrente e magnitude do escoamento horizontal (intervalo de $2 \mathrm{~m} \mathrm{~s}^{-1}$ ) em $500 \mathrm{hPa}$ (a, c, e, g) e para altura geopotencial (contorno com intervalo de $15 \mathrm{~m}$ ) e advecção de vorticidade relativa (sombreado com intervalo de $1 \times 10^{-9} \mathrm{~s}^{-2}$ ) em 500 $\mathrm{hPa}(\mathrm{b}, \mathrm{d}, \mathrm{f}, \mathrm{h})$.

Figura 13. Idem à Figura 10 mas para linhas de corrente e magnitude do escoamento horizontal (intervalo de $5 \mathrm{~m} \mathrm{~s}^{-1}$ ) em $200 \mathrm{hPa}$.

Figura 14. Seções verticais da divergência do fluxo horizontal de umidade (intervalo de $1 \times 10^{-4} \mathrm{~kg} \mathrm{~kg}^{-1} \mathrm{~s}^{-1}$ ) para as $18 \mathrm{Z}$ dos dias (a) 06/01/99, (c) 09/01/99, (e) 12/01/99 e (g) 17/01/99. Seções verticais da velocidade vertical omega (intervalo de $0,1 \times 10^{-2} \mathrm{hPa} \mathrm{s}^{-1}$ ) para as $18 \mathrm{Z}$ dos dias (b) 06/01/99, (d) 09/01/99, (f) 12/01/99 e (h) 17/01/99. No eixo das abscissas está representada a distância em $\mathrm{km}$, a partir do ponto mais ao norte, ao longo da linha tracejada em preto nas Figuras anteriores. A linha em verde representa, aproximadamente, o limite entre continente e oceano, que se localizam à esquerda e à direita da mesma, respectivamente. No eixo das ordenadas estão representados os níveis de pressão em $\mathrm{hPa}$.

Figura 15. Idem à Figura 14 mas para as componentes zonal (intervalo de $5 \mathrm{~m} \mathrm{~s}^{-1}$ ) $(\mathrm{a}, \mathrm{c}, \mathrm{e}, \mathrm{g}) \mathrm{e}$ meridional (intervalo de $\left.5 \mathrm{~m} \mathrm{~s}^{-1}\right)(\mathrm{b}, \mathrm{d}, \mathrm{f}, \mathrm{h}$ ) do vento. 
Figura 16. Umidade inicial do solo no nível de solo mais próximo à superfície (0,10 $\mathrm{m}$ abaixo da superfície) nos três experimentos realizados com o BRAMS (SEM025, SEM1 e DIA025) para (a) ZCAS-98 e para (b) ZCAS-99 (intervalo de $0,05 \mathrm{~m}^{3} \mathrm{~m}^{-3}$ ).

Figura 17. Diferença da média de TSM de todo o período de integração do modelo (08/02/98 às $00 \mathrm{Z}$ a 19/02/98 às $00 \mathrm{Z})$ entre os experimentos numéricos SEM025 e SEM1 (SEM025-SEM1) (intervalo de 0,5 ${ }^{\circ} \mathrm{C}$ ).

Figura 18. Idem à Figura 17 mas para temperatura do ar em $1000 \mathrm{hPa}$ (intervalo de $\left.0,2^{\circ} \mathrm{C}\right)$

Figura 19. Diferença da média de umidade específica de todo o período de integração do modelo (08/02/98 às 00Z a 19/02/98 às 00Z) entre os experimentos numéricos (a) SEM025 e SEM1 (SEM025-SEM1) e (b) SEM025 e DIA025 (SEM025-DIA025) (intervalo de 0,5 x 10-3 $\mathrm{g} \mathrm{kg}^{-1}$ ) e diferença da divergência média do fluxo horizontal de umidade, do mesmo período de integração, integrado na atmosfera, da pressão reduzida ao nível médio do mar ao nível de $100 \mathrm{hPa}$ entre os experimentos numéricos (c) SEM025 e SEM1 (SEM025-SEM1) e (d) SEM025 e DIA025 (SEM025-DIA025) (intervalo de 0,5 x 10 $0^{-4} \mathrm{~kg} \mathrm{~kg}^{-1}$ $\left.\mathrm{S}^{-1}\right)$

Figura 20. Diferença da média do fluxo de calor sensível à superfície de todo o período de integração do modelo (08/02/98 às 00Z a 19/02/98 às 00Z) entre os experimentos numéricos (a) SEM025 e SEM1 (SEM025-SEM1) e (b) SEM025 e DIA025 (SEM025-DIA025) (intervalo de $2 \mathrm{~W} \mathrm{~m}^{-2}$ ) e diferença da média do fluxo de calor latente à superfície, do mesmo período de integração, entre os experimentos numéricos (c) SEM025 e SEM1 (SEM025-SEM1) e (d) SEM025 e DIA025 (SEM025-DIA025) (intervalo de $2 \mathrm{~W} \mathrm{~m}^{-2}$ ). Os valores em (c) devem ser multiplicados por 4 .

Figura 21. Diferença da precipitação acumulada no final do período de integração do modelo (08/02/98 às 00Z a 19/02/98 às 00Z) entre os experimentos numéricos (a) SEM025 e SEM1 (SEM025-SEM1) e (b) SEM025 e DIA025 (SEM025-DIA025) (intervalo de $10 \mathrm{~mm} \mathrm{dia}^{-1}$ ).

Figura 22. Diferença da média de TSM de todo o período de integração do modelo (02/01/99 às $00 \mathrm{Z}$ a 18/01/99 às $00 \mathrm{Z})$ entre os experimentos numéricos SEM025 e SEM1 (SEM025-SEM1) (intervalo de 0,5 ${ }^{\circ} \mathrm{C}$ ).

Figura 23. Idem à Figura 22 mas para temperatura do ar em $1000 \mathrm{hPa}$ (intervalo de $\left.0,2^{\circ} \mathrm{C}\right)$

Figura 24. Diferença da média de umidade específica de todo o período de integração do modelo (02/01/99 às $00 \mathrm{Z}$ a 18/01/99 às 00Z) entre os experimentos numéricos (a) SEM025 e SEM1 (SEM025-SEM1) e (b) SEM025 e DIA025 (SEM025-DIA025) (intervalo de $0,5 \times 10^{-3} \mathrm{~g} \mathrm{~kg}^{-1}$ ) e 
diferença da divergência média do fluxo horizontal de umidade, do mesmo período de integração, integrado na atmosfera, da pressão reduzida ao nível médio do mar ao nível de $100 \mathrm{hPa}$ entre os experimentos numéricos (c) SEM025 e SEM1 (SEM025-SEM1) e (d) SEM025 e DIA025 (SEM025-DIA025) (intervalo de $0,5 \times 10^{-4} \mathrm{~kg} \mathrm{~kg}^{-1}$ $\left.\mathrm{s}^{-1}\right)$

Figura 25. Diferença da média do fluxo de calor sensível à superfície de todo o período de integração do modelo (02/01/99 às $00 Z$ a 18/01/99 às 00Z) entre os experimentos numéricos (a) SEM025 e SEM1 (SEM025-SEM1) e (b) SEM025 e DIA025 (SEM025-DIA025) (intervalo de $2 \mathrm{~W} \mathrm{~m}^{-2}$ ) e diferença da média do fluxo de calor latente à superfície, do mesmo período de integração, entre os experimentos numéricos (c) SEM025 e SEM1 (SEM025-SEM1) e (d) SEM025 e DIA025 (SEM025-DIA025) (intervalo de $2 \mathrm{~W} \mathrm{~m}^{-2}$ ). Os valores em (c) devem ser multiplicados por 4 .

Figura 26. Diferença da precipitação acumulada no final do período de integração do modelo (02/01/99 às $00 Z$ a 18/01/99 às $00 Z)$ entre os experimentos numéricos (a) SEM025 e SEM1 (SEM025-SEM1) e (b) SEM025 e DIA025 (SEM025-DIA025) (intervalo de $10 \mathrm{~mm} \mathrm{dia}^{-1}$ ). 104

Figura 27. Umidade inicial do solo no nível de solo mais próximo à superfície (0,10 m abaixo da superfície) nos três experimentos realizados com o BRAMS (a) AMAZ, (b) COST e (c) CTRL (intervalo de $0,01 \mathrm{~m}^{3} \mathrm{~m}^{-3}$ ). Os retângulos verde, vermelho e azul representam as regiões que compõem a ZCAS (vide Figura 1). O retângulo amarelo representa a região equatorial.

Figura 28. Seção vertical da umidade inicial do solo (intervalo de $0,05 \mathrm{~m}^{3} \mathrm{~m}^{-3}$ ) em (a) AMAZ e (b) COST. Umidade do solo no final do período de integração (intervalo de $0,05 \mathrm{~m}^{3} \mathrm{~m}^{-3}$ ) em (c) AMAZ para ZCAS-98, (d) COST para ZCAS-98, (e) AMAZ para ZCAS-99 e (f) COST para ZCAS-99. As seções foram realizadas em latitudes constantes, $7^{\circ} \mathrm{S}$ e 20 ${ }^{\circ} \mathrm{S}$ em AMAZ e COST, respectivamente. No eixo das ordenadas estão representados os níveis do solo abaixo da superfície $(\mathrm{m})$ definidos no modelo numérico

Figura 29. Diferença da média de temperatura do ar de todo o período de integração do modelo (08/02/98 às 00Z a 19/02/98 às 00Z) em $1000 \mathrm{hPa}$ entre os experimentos numéricos (a) AMAZ e CTRL (AMAZ-CTRL) e (b) COST e CTRL (COST-CTRL) (intervalo de $0,4{ }^{\circ} \mathrm{C}$ ).

Figura 30. Diferença da média de umidade específica, em $1000 \mathrm{hPa}$, de todo o período de integração do modelo (08/02/98 às 00Z a 19/02/98 às 00Z) entre os experimentos numéricos (a) AMAZ e CTRL (AMAZ-CTRL) e (b) COST e CTRL (COST-CTRL) (intervalo de $1,5 \times 10^{-3} \mathrm{~g} \mathrm{~kg}^{-1}$ ) e diferença da divergência média do fluxo horizontal de umidade, do mesmo período de integração, integrado na atmosfera, da pressão 
reduzida ao nível médio do mar ao nível de $100 \mathrm{hPa}$ entre os experimentos numéricos (c) AMAZ e CTRL (AMAZ-CTRL) e (d) COST e CTRL (COST-CTRL) (intervalo de $1 \times 10^{-4} \mathrm{~kg} \mathrm{~kg}^{-1} \mathrm{~s}^{-1}$ ).

Figura 31. Diferença da média do fluxo de calor sensível à superfície de todo o período de integração do modelo (08/02/98 às 00Z a 19/02/98 às 00Z) entre os experimentos numéricos (a) AMAZ e CTRL (AMAZ-CTRL) e (b) COST e CTRL (COST-CTRL) (intervalo de $10 \mathrm{~W} \mathrm{~m}^{-2}$ ) e diferença da média do fluxo de calor latente à superfície, do mesmo período de integração, entre os experimentos numéricos (c) AMAZ e CTRL (AMAZ-CTRL) e (d) COST e CTRL (COST-CTRL) (intervalo de $10 \mathrm{~W}$ $\left.\mathrm{m}^{-2}\right)$.

Figura 32. Diferença da precipitação acumulada no final do período de integração do modelo (08/02/98 às $00 Z$ a 19/02/98 às 00Z) entre os experimentos numéricos (a) AMAZ e CTRL (AMAZ-CTRL) e (b) COST e CTRL (COST-CTRL) (intervalo de $10 \mathrm{~mm} \mathrm{dia}^{-1}$ ).

Figura 33. Perfis verticais da média da temperatura do ar e do ponto de orvalho (intervalo de $2{ }^{\circ} \mathrm{C}$ ) de todo o período de integração do modelo (08/02/98 às $00 \mathrm{Z}$ a 19/02/98 às 00Z) e das regiões (a) amazônica e (b) costeira, sendo que as linhas preta e azul representam a temperatura do ar e do ponto de orvalho em CTRL, respectivamente, e as linhas verde e magenta representam as mesmas variáveis em AMAZ (a) e em COST (b). No eixo da ordenadas estão representados os níveis de pressão em hPa.

Figura 34. Perfis verticais da média da temperatura potencial (intervalo de $1{ }^{\circ} \mathrm{C}$ ) de todo o período de integração do modelo (08/02/98 às 00Z a 19/02/98 às 00Z) e das regiões (a) amazônica e (b) costeira, sendo que a linha preta representa a temperatura potencial em CTRL e a linha verde representa a mesma variável em AMAZ (a) e em COST (b). No eixo da ordenadas estão representados os níveis de pressão em $\mathrm{hPa}$.

Figura 35. Idem à Figura 34 mas para componente vertical do vento (intervalo de $\left.0,2 \times 10^{-2} \mathrm{~m} \mathrm{~s}^{-1}\right)$.

Figura 36. Perfis verticais da divergência média do fluxo horizontal de umidade (intervalo de $0,01 \times 10^{-6} \mathrm{~kg} \mathrm{~kg}^{-1} \mathrm{~s}^{-1}$ ) de todo o período de integração do modelo (08/02/98 às $00 \mathrm{Z}$ a 19/02/98 às $00 \mathrm{Z})$ e para as regiões (a) amazônica e (b) costeira e perfis verticais da divergência média horizontal (intervalo de $1 \times 10^{-6} \mathrm{~s}^{-1}$ ), do mesmo período de integração, para as regiões (c) amazônica e (d) costeira. A linha preta representa a variável em CTRL e a linha verde representa a variável em AMAZ (a, c) e em $\operatorname{COST}(b, d)$. No eixo da ordenadas estão representados os níveis de pressão em $\mathrm{hPa}$. 
Figura 37. Diferença da média de temperatura do ar de todo o período de integração do modelo (02/01/99 às $00 \mathrm{Z}$ a 18/01/99 às 00Z) em $1000 \mathrm{hPa}$ entre os experimentos numéricos (a) AMAZ e CTRL (AMAZ-CTRL) e (b) COST e CTRL (COST-CTRL) (intervalo de $0,4^{\circ} \mathrm{C}$ ).

Figura 38. Diferença da média de umidade específica de todo o período de integração do modelo (02/01/99 às $00 \mathrm{Z}$ a 18/01/99 às 00Z) entre os experimentos numéricos (a) AMAZ e CTRL (AMAZ-CTRL) e (b) COST e CTRL (COST-CTRL) (intervalo de $1,5 \times 10^{-3} \mathrm{~g} \mathrm{~kg}^{-1}$ ) e diferença da divergência média do fluxo horizontal de umidade, do mesmo período de integração, integrado na atmosfera, da pressão reduzida ao nível médio do mar ao nível de $100 \mathrm{hPa}$ entre os experimentos numéricos (c) AMAZ e CTRL (AMAZ-CTRL) e (d) COST e CTRL (COST-CTRL) (intervalo de $1 \times 10^{-4} \mathrm{~kg} \mathrm{~kg}^{-1} \mathrm{~s}^{-1}$ ).

Figura 39. Diferença da média do fluxo de calor sensível à superfície de todo o período de integração do modelo (02/01/99 às $00 \mathrm{Z}$ a 18/01/99 às 00Z) entre os experimentos numéricos (a) AMAZ e CTRL (AMAZ-CTRL) e (b) COST e CTRL (COST-CTRL) (intervalo de $10 \mathrm{~W} \mathrm{~m}^{-2}$ ) e diferença da média do fluxo de calor latente à superfície, do mesmo período de integração, entre os experimentos numéricos (c) AMAZ e CTRL (AMAZ-CTRL) e (d) COST e CTRL (COST-CTRL) (intervalo de $10 \mathrm{~W}$ $\left.\mathrm{m}^{-2}\right)$.

Figura 40. Diferença da precipitação acumulada no final do período de integração do modelo (02/01/99 às $00 \mathrm{Z}$ a 18/01/99 às $00 \mathrm{Z})$ entre os experimentos numéricos (a) AMAZ e CTRL (AMAZ-CTRL) e (b) COST e CTRL (COST-CTRL) (intervalo de $10 \mathrm{~mm} \mathrm{dia}^{-1}$ ).

Figura 41. Perfis verticais da média da temperatura do ar e do ponto de orvalho (intervalo de $2{ }^{\circ} \mathrm{C}$ ) de todo o período de integração do modelo (02/01/99 às $00 \mathrm{Z}$ a 18/01/99 às 00Z) e das regiões (a) amazônica e (b) costeira, sendo que as linhas preta e azul representam a temperatura do ar e do ponto de orvalho em CTRL, respectivamente, e as linhas verde e magenta representam as mesmas variáveis em AMAZ (a) e em COST (b). No eixo da ordenadas estão representados os níveis de pressão em $\mathrm{hPa}$

Figura 42. Perfis verticais da média da temperatura potencial (intervalo de $1{ }^{\circ} \mathrm{C}$ ) de todo o período de integração do modelo (02/01/99 às $00 \mathrm{Z}$ a 18/01/99 às 00Z) e das regiões (a) amazônica e (b) costeira, sendo que a linha preta representa a temperatura potencial em CTRL e a linha verde representa a mesma variável em AMAZ (a) e em COST (b). No eixo da ordenadas estão representados os níveis de pressão em $\mathrm{hPa}$.

Figura 43. Idem à Figura 42 mas para componente vertical do vento (intervalo de $0,2 \times 10^{-2} \mathrm{~m} \mathrm{~s}^{-1}$ ). 
Figura 44. Perfis verticais da divergência média do fluxo horizontal de umidade (intervalo de $0,01 \times 10^{-6} \mathrm{~kg} \mathrm{~kg}^{-1} \mathrm{~s}^{-1}$ ) de todo o período de integração do modelo (02/01/99 às $00 \mathrm{Z}$ a 18/01/99 às $00 \mathrm{Z})$ e para as regiões (a) amazônica e (b) costeira e perfis verticais da divergência média horizontal (intervalo de $1 \times 10^{-6} \mathrm{~s}^{-1}$ ), do mesmo período de integração, para as regiões (c) amazônica e (d) costeira. A linha preta representa a variável em CTRL e a linha verde representa a variável em AMAZ (a, c) e em $\operatorname{COST}(b, d)$. No eixo da ordenadas estão representados os níveis de pressão em $\mathrm{hPa}$. 



\section{Lista de tabelas}

Tabela 1 - Principais características das simulações numéricas, comuns a todos os experimentos realizados com o BRAMS neste trabalho.

Tabela 2 - Diferenças entre os experimentos numéricos realizados com o BRAMS para verificação do impacto das resoluções espacial e temporal dos dados de TSM.

Tabela 3 - Comparações entre os experimentos numéricos realizados com o BRAMS e impacto de qual resolução está sendo verificado em cada comparação.

Tabela 4 - Tabela de contingência 2 X 2 sim/não para dado evento.

Tabela 5 - Classificação da intensidade da precipitação e limiares de precipitação acumulada diária $\left(\mathrm{mm} \mathrm{dia}{ }^{-1}\right)$.

Tabela 6 - DPO para cada limiar de precipitação do NCEP (mm dia $\left.{ }^{-1}\right)$, para todo domínio e cada região que compõe a ZCAS (oceânica, costeira e amazônica) separadamente. DPS, EM, RMSE e RMSE $U$, para cada limiar de precipitação do NCEP ( $\mathrm{mm} \mathrm{dia}^{-1}$ ), para todo domínio e cada região que compõe a ZCAS (oceânica, costeira e amazônica) separadamente e para cada um dos experimentos numéricos (SEM025, SEM1 e DIA025) realizados com o BRAMS para ZCAS-98.

Tabela 7 - TSA para cada dia de simulação para os limiares de precipitação do NCEP (mm dia $\left.{ }^{-1}\right)$, para todo o domínio e cada região que compõe a ZCAS (oceânica, costeira e amazônica) separadamente para SEM025 para ZCAS-98. Os valores destacados em vermelho e sombreados em cinza representam os cinco melhores valores de TSA em cada limiar e os cinco melhores valores de TSA em cada região, respectivamente.

Tabela 8 - Idem à Tabela 7 mas para SEM1

Tabela 9 - Idem à Tabela 7 mas para DIA025.

Tabela 10 - Idem à Tabela 6 mas para ZCAS-99. 
Tabela 11 - Idem à Tabela 7 mas para SEM025 para ZCAS-99.

Tabela 12 - Idem à Tabela 7 mas para SEM1 para ZCAS-99.

Tabela 13 - Idem à Tabela 7 mas para DIA025 para ZCAS-99.

Tabela 14 - Tipos de solo disponíveis no modelo BRAMS e respectivos pontos de saturação $\left(\mathrm{m} \mathrm{m}^{-3}\right)$ e pontos de murcha permanente $\left(\mathrm{m} \mathrm{m}^{-3}\right)$.

Tabela 15 - Níveis do solo (metros abaixo da superfície) e fração inicial de umidade do solo em cada nível com relação à saturação de cada tipo solo (Tabela 14).

Tabela 16 - Volume de precipitação $(\mathrm{mm})$ e número de pixels "positivos" e "negativos" para as diferenças AMAZ-CTRL e COST-CTRL para cada região que compõe a ZCAS e para a região equatorial. Os valores se referem à precipitação acumulada no final do período de integração do modelo (08/02/98 às 00Z a 19/02/98 às 00Z) para ZCAS-98.

Tabela 17 - Idem à Tabela 16 mas para ZCAS-99 e período de integração do modelo de 02/01/99 às $00 \mathrm{Z}$ a 18/01/99 às $00 \mathrm{Z}$ 


\section{Lista de abreviaturas e siglas}

AB

AMAZ

ASAS

BRAMS

CAPE

CF

CLP

CN

COLA

COST

CPTEC

CTRL

DIA025
Alta da Bolívia

Teste de sensibilidade do BRAMS a US inicial com a condição inicial de umidade mínima aceitável pelo modelo (PMP) na região de ZCAS amazônica

Alta Subtropical do Atlântico Sul

Regional Atmospheric Modeling System with Brazilian Developments

Convective Available Potential Energy (Energia Potencial Convectiva Disponível)

Condição de Fronteira

Camada Limite Planetária

Cavado do Nordeste

Center for Ocean-Land-Atmosphere Studies

Teste de sensibilidade do BRAMS a US inicial com a condição inicial de umidade mínima aceitável pelo modelo (PMP) na região de ZCAS costeira

Centro de Previsão de Tempo e Estudos Climáticos

Experimento numérico controle dos testes de sensibilidade do BRAMS a US inicial

Teste de sensibilidade do BRAMS a TSM utilizando conjunto de dados de TSM diária com espaçamento horizontal de 0,25 x 0,25 graus de latitudelongitude 
DJF

DPO

DPREP

DPS

DSA

ECMWF

EM

ENOS

ERA-40

EROS

FINEP

GOES-8

GPCP

GPI

GrADS

GRIB

IBGE

INPE

JBN

LEAF-2

MERRA

NCEP
Dezembro-Janeiro-Fevereiro

Desvio Padrão da Observação

Data Preparation

Desvio Padrão da Simulação

Divisão de Satélites e Sistemas Ambientais

European Centre for Medium-Range Weather Forecasts

Erro Médio

El Niño-Oscilação Sul

45-Year ECMWF Re-Analysis from September 1957 to August 2002

Earth Resources Observation and Science Center

Financiadora de Estudos e Projetos

Geostationary Operational Environmental Satellite 8

Global Precipitation Climatology Project

Global Precipitation Index

Grid Analysis and Display System

Gridded Binary

Instituto Brasileiro de Geografia e Estatística

Instituto Nacional de Pesquisas Espaciais

Jato de Baixos Níveis

Land Ecosystem-Atmosphere Feedback Model 2

Modern Era Retrospective-Analysis for Research and Applications

National Centers for Environmental Prediction 
NCL Nível de Condensação por Levantamento

NEB Nordeste do Brasil

NND Nível de Não Divergência

NOAA National Oceanic and Atmospheric Administration

OLAM Ocean-Land-Atmosphere Model

OMJ Oscilação de Madden-Julian

PIB Produto Interno Bruto

PMP Ponto de Murcha Permanente

RAMS Regional Atmospheric Modeling System

RMSE Root Mean Square Error (Raiz Quadrada do Erro Médio Quadrático)

RMSE $_{\mathbf{U B}} \quad$ Root Mean Square Error Unbiased (Raiz Quadrada do Erro Médio Quadrático com remoção do viés ou bias)

RMSP Região Metropolitana de São Paulo

ROL Radiação de Onda Longa

SEM025 Teste de sensibilidade do BRAMS a TSM utilizando conjunto de dados de TSM semanal com espaçamento horizontal de $0,25 \times 0,25$ graus de latitude-longitude

SEM1 Teste de sensibilidade do BRAMS a TSM utilizando conjunto de dados de TSM semanal com espaçamento horizontal de 1 x 1 grau de latitudelongitude

SMAS Sistema de Monção da América do Sul

SP $\quad$ Estado de São Paulo

SSiB Simplified Simple Biosphere

STM Secretaria dos Transportes Metropolitanos 
TEB

TRMM

TSA

TSM

US

USGS

VCAN

ZCAS

ZCAS-98

ZCAS-99

ZCIT

ZFB
Town Energy Budget

Tropical Rainfall Measuring Mission

Bias-Adjusted Threat Score

Temperatura da Superfície do Mar

Umidade do Solo

United States Geological Survey

Vórtice Ciclônico de Altos Níveis

Zona de Convergência do Atlântico Sul

Evento de ZCAS ocorrido em fevereiro de 1998

Evento de ZCAS ocorrido em janeiro de 1999

Zona de Convergência Intertropical

Zona Frontal de Baiu 


\section{Lista de símbolos}

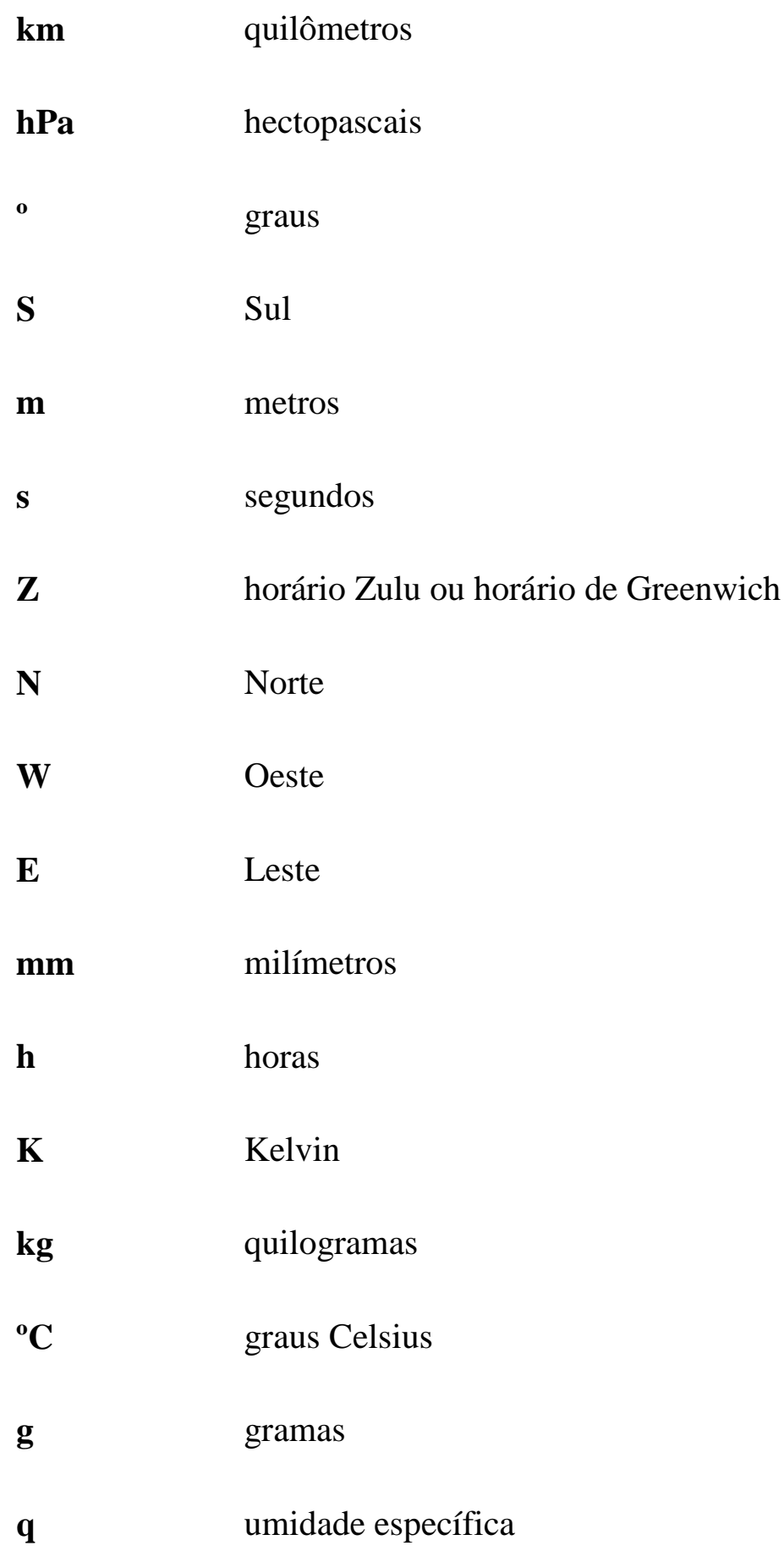




\begin{tabular}{|c|c|}
\hline $\mathbf{r}_{\mathbf{v}}$ & razão de mistura de vapor \\
\hline $\mathbf{n}$ & número de instantes da análise/observação \\
\hline $\mathbf{y}_{\mathbf{i}}$ & valor simulado \\
\hline $\mathbf{o}_{\mathbf{i}}$ & valor observado \\
\hline $\bar{y}$ & média no tempo dos valores simulados para cada ponto de grade \\
\hline $\bar{o}$ & média no tempo dos valores observados para cada ponto de grade \\
\hline $\mathbf{a}$ & $\begin{array}{l}\text { número de pontos observados e previstos pelo modelo com precipitação } \\
\text { acima de determinado limiar (previsão correta) }\end{array}$ \\
\hline c & $\begin{array}{l}\text { número de pontos observados mas não previstos pelo modelo com } \\
\text { precipitação acima de determinado limiar (surpresa) }\end{array}$ \\
\hline B & bias ou viés \\
\hline b & $\begin{array}{l}\text { número de pontos previstos pelo modelo mas não observados com } \\
\text { precipitação acima de determinado limiar (alarme falso) }\end{array}$ \\
\hline $\mathbf{H}$ & $\begin{array}{l}\text { hits, isto é, número de pontos previstos corretamente pelo modelo com } \\
\text { precipitação acima de determinado limiar }\end{array}$ \\
\hline d & $\begin{array}{l}\text { número de pontos não observados e não previstos pelo modelo com } \\
\text { precipitação acima de determinado limiar (previsão correta) }\end{array}$ \\
\hline $\mathbf{F}$ & $\begin{array}{l}\text { forecasts, isto é, número de pontos previstos pelo modelo com precipitação } \\
\text { acima de determinado limiar }\end{array}$ \\
\hline $\mathbf{O}$ & $\begin{array}{l}\text { observations, isto é, número de pontos observados com precipitação acima } \\
\text { de determinado limiar }\end{array}$ \\
\hline $\mathbf{W}$ & watts \\
\hline
\end{tabular}




\section{Sumário}

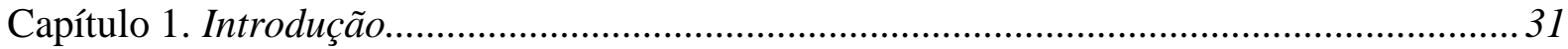

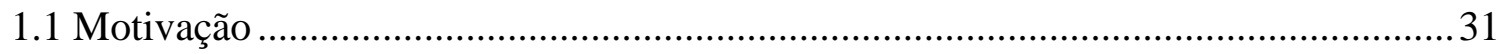

1.2 Zona de Convergência do Atlântico Sul e precipitação ..............................................34

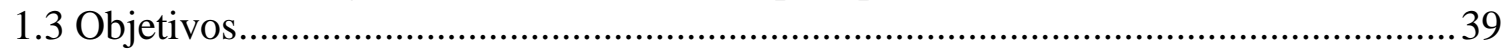

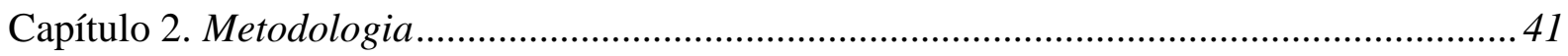

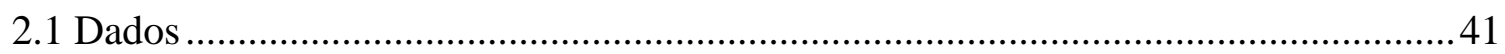

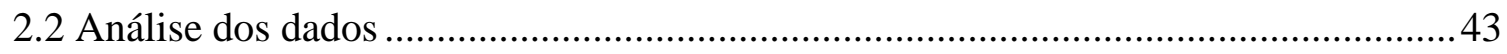

2.3 O modelo BRAMS ..................................................................................... 44

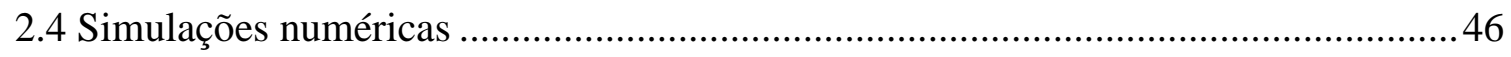

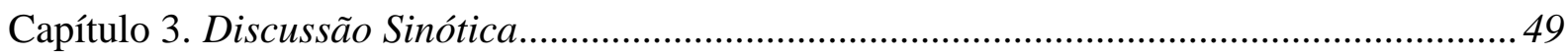

3.1 ZCAS-98

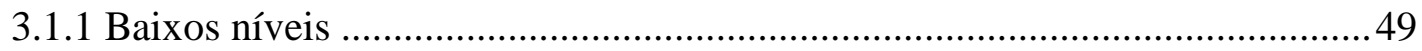

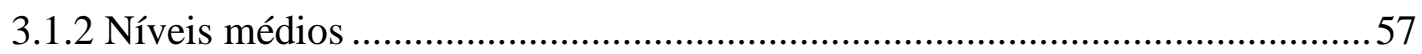

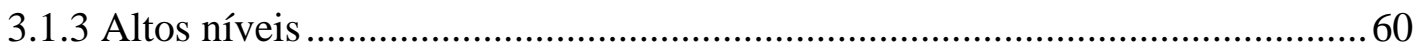

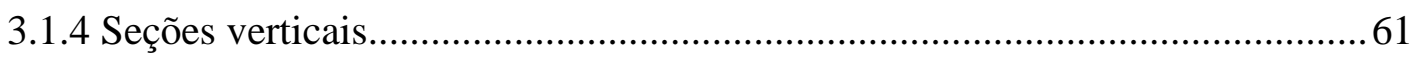

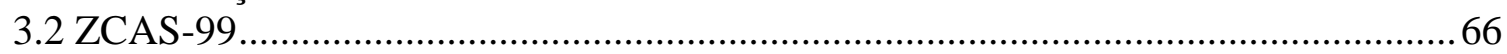

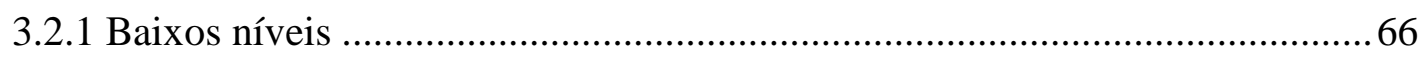

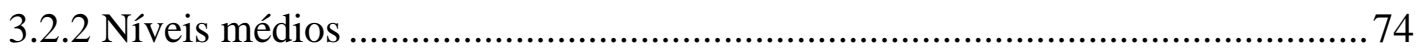

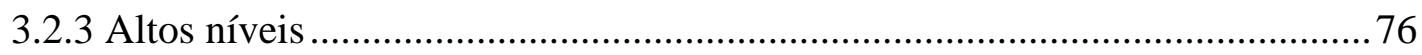

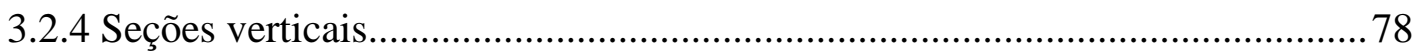

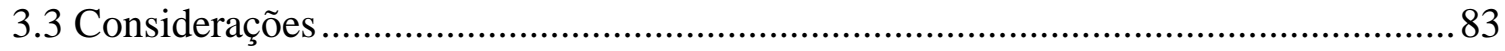

Capítulo 4. Influências da temperatura da superfície do mar na ZCAS ..................................85

4.1 Características específicas dos testes de sensibilidade a TSM ...................................8 88

4.1.1 Verificação das simulações de precipitação ..................................................90

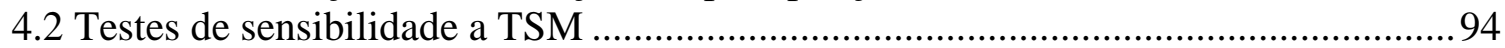

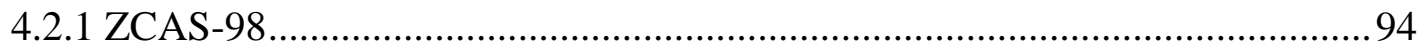

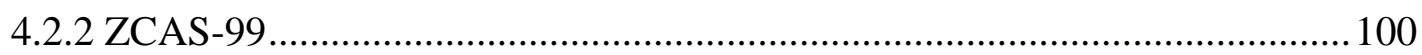

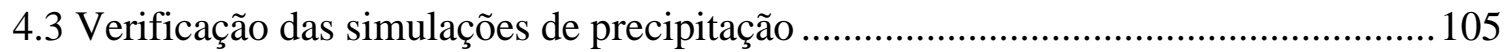

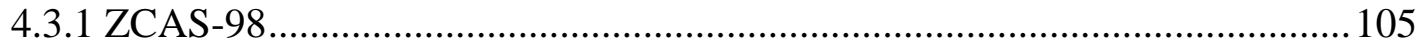

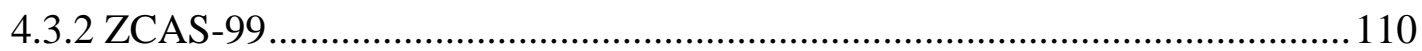

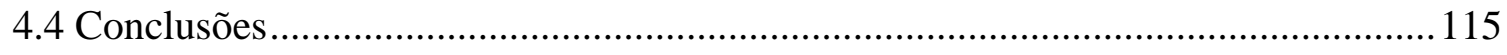

Capítulo 5. Influências das condições inicias de umidade do solo na ZCAS.......................... 119

5.1 Características específicas dos testes de sensibilidade a US ................................... 122

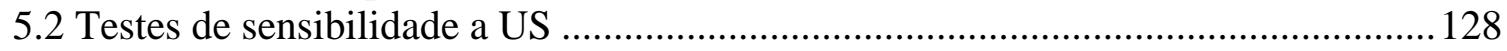

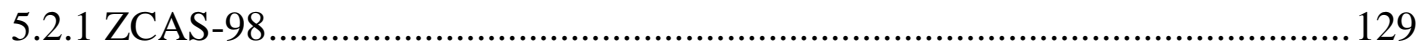

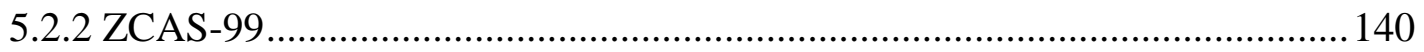


5.3 Conclusões

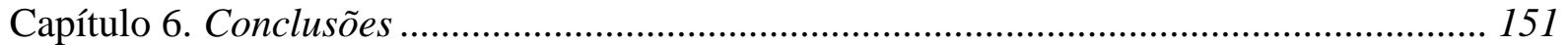

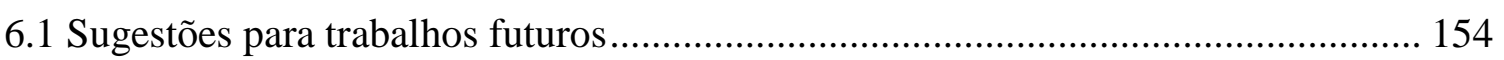

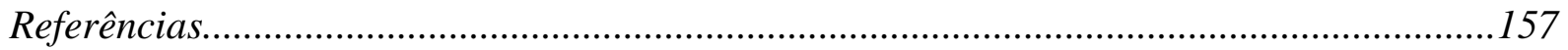




\section{Capítulo 1}

\section{Introdução}

\subsection{Motivação}

Diversas regiões do Brasil sofrem períodos de intensa precipitação, principalmente durante o verão austral, o que ocasiona sérios problemas, desde sociais até econômicos, nas cidades e no campo.

A população total do Brasil, segundo estimativas do Instituto Brasileiro de Geografia e Estatística (IBGE) para 2009, é de cerca de 191,5 milhões de habitantes, sendo que mais de 80 milhões concentram-se na Região Sudeste. A grande quantidade de habitantes no Sudeste se deve ao fato de que nele localizam-se diversas regiões metropolitanas como, por exemplo, a Região Metropolitana de São Paulo (RMSP), também conhecida como Grande São Paulo, que é, segundo a Secretaria dos Transportes Metropolitanos (STM), um dos maiores aglomerados urbanos do mundo, abrangendo a Capital do Estado e mais 38 municípios vizinhos. Sua área, de $8051 \mathrm{~km}^{2}$, corresponde a menos de 1 milésimo da superfície do território brasileiro e a menos de $4 \%$ do território do Estado, mas nela concentram-se, segundo as estimativas do IBGE para 2009, 20 milhões de habitantes, destes, cerca de 11 milhões residem no município de São Paulo. 
Levantamentos publicados pelo IBGE para 2006 indicam que o Produto Interno Bruto (PIB) da Região Sudeste é de mais de $\mathrm{R} \$ 1$ trilhão, representando mais de $55 \%$ da riqueza nacional, e que o PIB da RMSP corresponde a mais de 50\% do total estadual.

Além das regiões metropolitanas, as regiões rurais do Brasil também podem ser afetadas pelas chuvas intensas, o que pode impactar fortemente a economia do país. O Brasil, que em 1995 ocupava a nona posição no ranking mundial de exportações agroindustriais (com 2,8\% das exportações mundiais), foi para a quarta posição em 2005, tornando-se o quarto maior exportador mundial de produtos agrícolas, ficando atrás apenas dos Estados Unidos, França e Holanda, com 4,8\% das exportações mundiais e crescimento médio anual de 10,2\%, o maior do mundo (CHINA..., 2009).

Deve-se considerar que, devido à expansão urbana das regiões metropolitanas, realizada aleatoriamente, sem o necessário planejamento, aliada ao assoreamento da rede de drenagem natural e construída, a ocorrência de chuvas intensas, principalmente na cidade de São Paulo, e especialmente na região leste do município, desencadeia situações que, em muitos casos, beiram o caos, com ocorrências de vítimas fatais, congestionamentos, interrupção do fornecimento de energia elétrica, pontos alagados, trechos inundados, desabamentos e fechamento de aeroportos, o que compromete a rotina da população e a economia do país. Estas chuvas, ocorrentes durante os meses mais quentes do ano, estão geralmente associadas à chamada Zona de Convergência do Atlântico Sul (ZCAS). Conforme Quadro (1994), a ZCAS normalmente se estaciona sobre a Região Sudeste, sul da Bahia, norte do Paraná e Brasil Central, provocando chuvas intensas e persistentes devido à sua manutenção durante vários dias sobre essas regiões do Brasil. Brandão e Fisch (2008), por exemplo, estudaram o impacto da ZCAS na área de Guaratinguetá - SP e puderam observar que a estacionaridade e os níveis pluviométricos elevados associados a esse sistema são suficientes para provocar enchentes em diversos municípios brasileiros. 
Visto que a ZCAS é um sistema de grande escala associado a precipitação intensa e persistente, podendo assim afetar a produção agrícola e a movimentação de rotina de diferentes regiões metropolitanas do Brasil, justifica-se a necessidade de aprofundar os estudos sobre suas principais características, como sua evolução típica e condições para seu desenvolvimento e manutenção.

Diante dos diversos problemas causados pela precipitação associada à ZCAS, ressalta-se a necessidade de melhorar a previsão meteorológica do país, com a finalidade de auxiliar na mitigação dos possíveis efeitos. Vale ressaltar que, assim como mencionado por Jorgetti (2008), os modelos numéricos ainda não são capazes de representar a estrutura detalhada da ZCAS e simular a precipitação associada a ela de forma satisfatória. Cavalcanti et al. (2002), por exemplo, encontraram que o modelo global do CPTEC/COLA simula precipitação excessiva na porção mais ao sul da ZCAS e subestima a oeste e noroeste dessas áreas.

Sendo assim, estudos que envolvem modelagem numérica da atmosfera, incluindo principalmente testes de sensibilidade de modelos meteorológicos a diferentes parâmetros atmosféricos ou de superfície, podem ajudar na pesquisa e identificação dos problemas que dificultam uma representação adequada da ZCAS e contribuir consideravelmente para o serviço operacional de Meteorologia, pois fornecem um extenso embasamento teórico para a otimização dos modelos e interpretação de previsões numéricas, aprimorando a previsão de eventos extremos, permitindo a elaboração de medidas de mitigação e, muitas vezes, de prevenção das possíveis consequências desses episódios. 


\subsection{Zona de Convergência do Atlântico Sul e precipitação}

A ZCAS é genericamente descrita como região com alta variabilidade da atividade convectiva no leste da América do Sul durante o verão (CARVALHO; JONES; LIEBMANN, 2004). Em imagens de satélite é marcada por uma extensa banda de nebulosidade com orientação noroeste-sudeste, que vai desde o sul da Amazônia até o sudeste do Brasil e sudoeste do Atlântico Sul (CASARIN; KOUSKY, 1986; FERREIRA; SANCHES; SILVA DIAS, 2004; KODAMA, 1992, 1993; LIEBMANN et al., 1999; LIEBMANN; JONES; CARVALHO, 2001; QUADRO, 1994), já em campos de radiação de onda longa (ROL) média mensal é caracterizada por uma banda de ROL mínima ligada à Amazônia, onde há intensa convecção (NINOMIYA, 2007).

A ZCAS e a atividade convectiva da Amazônia compõem o Sistema de Monção da América do Sul (SMAS) (JONES; CARVALHO, 2002), sendo que a variabilidade da primeira está mutuamente relacionada ao segundo. Assim, os mecanismos responsáveis pela variabilidade na intensidade da ZCAS determinam as características de grande escala do SMAS (CARVALHO; JONES; LIEBMANN, 2004). Essa reciprocidade entre ZCAS e SMAS foi descrita também por Figueroa, Satyamurty e Silva Dias (1995), cujo trabalho mostrou que a variabilidade da precipitação no SMAS está associada a circulações de grande escala atuantes na América do Sul durante o verão austral (LENTERS; COOK, 1999).

A circulação de altos níveis sobre a região do SMAS, no verão austral, apresenta um grande anticiclone centrado sobre a Bolívia, Alta da Bolívia (AB), e um cavado próximo à costa nordeste do Brasil, Cavado do Nordeste (CN) (NINOMIYA, 2007); em baixos níveis apresenta um anticiclone sobre o Oceano Atlântico, a Alta Subtropical do Atlântico Sul (ASAS), e o Jato de Baixos Níveis (JBN) da América do Sul a leste da Cordilheira dos Andes. 
$\mathrm{A} A B$ é um anticiclone que se forma em altos níveis, geralmente na primavera, atingindo sua atividade máxima no verão austral devido à intensificação da liberação de calor latente, oriunda da convecção sobre a Amazônia, e também a partir do fortalecimento de um ciclone térmico à superfície (Baixa do Chaco), derivado do intenso aquecimento superficial na região do altiplano boliviano. A AB possui altas temperaturas desde a superfície aumentando até aproximadamente $300 \mathrm{hPa}$, tendo variação intrassazonal e interanual (ANDRADE, 2007). A $\mathrm{AB}$ favorece o $\mathrm{CN}$, cuja intensificação está relacionada ao fortalecimento da $\mathrm{AB}$. $\mathrm{O} \mathrm{CN}$ apresenta centro frio e topo quente, opostamente à AB (ANDRADE, 2007), sendo que ambos os sistemas são tipicamente observados durante eventos de ZCAS.

A ZCAS se forma quando ocorre acoplamento de sistemas frontais (processo dinâmico), que penetram na América do Sul, à $\mathrm{AB}$ (processo termodinâmico) já estabelecida (ANDRADE, 2007), o que concorda com Kodama (2002, 2003), que afirma que a formação da ZCAS se dá normalmente ao longo da corrente de jato em altos níveis e do lado leste de um cavado quase ancorado, e com Carvalho, Jones e Liebmann (2004), que destacam que ZCAS intensas são precedidas de propagação de distúrbios sinóticos nas latitudes médias, tais como as frentes frias.

A ASAS é um anticiclone formado sobre o Atlântico Sul em torno de $30^{\circ} \mathrm{S}$, devido ao ramo descendente da célula de Hadley, se estendendo até altos níveis e se inclinando para noroeste com a altura. Em baixos níveis a ASAS, ao longo de sua porção oeste, transporta vapor d'água em direção à ZCAS e ao longo de sua porção sudoeste a zona de convergência é mantida quase-estacionária durante períodos do verão austral.

O JBN ocorre com mais frequência no verão e é caracterizado por ventos intensos, com velocidade superior a $10 \mathrm{~m} \mathrm{~s}^{-1}$ (NINOMIYA, 2007), extensão horizontal (largura) de aproximadamente $500 \mathrm{~km}$ e restritos a poucos quilômetros acima da superfície. Esse jato se desenvolve devido à canalização dos ventos alísios, que adentram o nordeste da América do 
Sul, pela topografia dos Andes. Na baixa troposfera, esses ventos do Atlântico equatorial penetram na região amazônica transportando vapor d'água a leste dos Andes para as regiões subtropicais da América do Sul, o que ocorre mais eficientemente durante regimes de ZCAS (HERDIES et al., 2002). Vale ressaltar que a Cordilheira dos Andes possui importante efeito na intensidade e posicionamento da ZCAS (FIGUEROA; SATYAMURTY; SILVA DIAS, 1995), uma vez que canaliza o escoamento de baixos níveis que carrega umidade proveniente da Bacia Amazônia (LIEBMANN et al., 2004).

A circulação do SMAS e o posicionamento da ZCAS desempenham um importante papel na distribuição de chuva sobre o Brasil (DRUMOND, 2005) e trazem consequências hidrológicas principalmente para as Regiões Sul (LIEBMANN et al., 2004) e Sudeste (CARVALHO; JONES; LIEBMANN, 2002, 2004), uma vez também que a ZCAS pode persistir por 10 dias ou mais (FIGUEROA; SATYAMURTY; SILVA DIAS, 1995).

Associado ao posicionamento da ZCAS, Nogués-Paegle e Mo (1997) observaram que há uma "gangorra" de condições seca e chuvosa sobre as regiões tropicais e subtropicais da América do Sul durante o verão, mostrando que a intensificação da ZCAS está associada com divergência (HERDIES et al., 2002) e déficit de precipitação sobre as planícies subtropicais a sudoeste dessa região, concordando com os trabalhos de Gandu e Silva Dias (1998) e Liebmann et al. (2004), e, conforme Carvalho, Jones e Liebmann (2004) e Gan, Kousky e Ropelewski (2004), com escoamento de baixos níveis de noroeste e oeste a leste dos Andes convergindo no Brasil central-oeste. A intensificação da precipitação na região da ZCAS quando do enfraquecimento do escoamento de baixos níveis também foi apontada por Liebmann et al. (2004).

Por outro lado, ZCAS enfraquecida, caracterizada por anomalias positivas de ROL sobre a América do Sul e negativas sobre o sudeste do continente (CARVALHO; JONES; LIEBMANN, 2004), mostra condições de convergência (HERDIES et al., 2002) e muita 
precipitação no sul do Brasil, norte da Argentina e Uruguai, e associa-se com escoamento de baixos níveis de noroeste intensificado sobre o Paraguai e norte da Argentina (DRUMOND, 2005) e anomalias de leste sobre o Brasil central-oeste (CARVALHO; JONES; LIEBMANN, 2004; GAN; KOUSKY; ROPELEWSKI, 2004; HERDIES et al., 2002; LIEBMANN et al., 2004).

Os regimes de precipitação da América do Sul possuem variabilidade em muitas escalas de tempo e espaço: enquanto a convecção na bacia amazônica exibe variação diurna intensa e sazonal, as variações intrassazonais são mais pronunciadas no leste da América do Sul tropical e subtropical (CARVALHO; JONES; LIEBMANN, 2004). Em particular, a precipitação associada à ZCAS exibe uma variedade rica de variações intrassazonais (CARVALHO; JONES; LIEBMANN, 2002; DE ALMEIDA et al., 2007) e diversos trabalhos mostraram a influência de fenômenos atmosféricos de tal escala de tempo na variabilidade da ZCAS, por exemplo, Cunningham e Cavalcanti (2006) e De Souza e Ambrizzi (2006). Os últimos autores destacaram a persistência de um padrão de ZCAS de mais de três dias quando a Oscilação de Madden-Julian (OMJ) está em sua fase ativa sobre a América do Sul.

A ligação entre a variabilidade intrassazonal do regime de ventos em baixos níveis e a atividade convectiva em mesoescala na região tropical da América do Sul foi investigada por Jones e Carvalho (2002), que observaram que na região sudeste do Brasil (região da ZCAS) o número de sistemas convectivos, sua distribuição diurna, tamanho, duração, intensidade e organização são modulados pelas anomalias de ventos nessa região. Assim, anomalias de ventos de baixos níveis de oeste (leste) correspondem à fase ativa (inativa) da ZCAS (HERDIES et al., 2002; JONES; CARVALHO, 2002), fortalecendo (enfraquecendo) o sistema de monções sobre a América do Sul subtropical. Anomalias intrassazonais de leste dos ventos de baixos níveis significam, então, supressão da atividade convectiva na ZCAS (RICKENBACH et al., 2002). 
A influência de fenômenos atmosféricos de escala global, como o El Niño-Oscilação Sul (ENOS), na variabilidade interanual das monções, em especial da ZCAS, também foi estudada por muitos autores. Carvalho, Jones e Liebmann (2004), por exemplo, além dos estudos quanto à relação da ZCAS com distúrbios de escala de tempo intrassazonal, ainda mostraram que a frequência de ZCAS continental ou oceânica depende da fase do ENOS, porém esta não possui influência clara na intensidade da ZCAS (intensa ou fraca).

A modulação da ZCAS pelo ENOS também foi indicada por Drumond (2005), Liebmann e Marengo (2001) e Nogués-Paegle e Mo (1997). Os últimos autores apontaram que a fase quente (fria e neutra) do ENOS favorece a ocorrência de ZCAS oceânica (continental) e Liebmann e Marengo (2001) destacaram que a fase quente (fria) implica na redução (intensificação) da precipitação na região amazônica, especialmente nas porções norte e central, devido ao movimento subsidente (ascendente) anômalo a leste dos Andes, induzido pela ascendência (subsidência) no Pacífico equatorial leste. Já Drumond (2005) sugeriu que embora na maioria dos eventos a fase quente (fria) do ENOS esteja associada a anomalias positivas (negativas) de precipitação no Sudeste e negativas (positivas) nos subtrópicos, há alguns casos nos quais ocorre o oposto.

Anomalias de circulação e de chuva no SMAS durante dezembro-janeiro-fevereiro (DJF) de 1997-98 (El Niño) e 1998-99 (La Niña), períodos coincidentes com os casos estudados no presente trabalho e correspondentes ao El Niño mais intenso do século XX, foram descritas por Lau e Zhou (2003). A amplitude da anomalia de TSM do Pacífico leste equatorial foi quatro vezes o desvio padrão da variabilidade interanual para as duas décadas anteriores, com o centro quente de TSM muito mais próximo da América do Sul do que nos eventos anteriores (LAU; ZHOU, 2003). Os autores encontraram que a AB de DJF de 1997-98 foi mais intensa do que a de 1998-99, e que, durante o El Niño, o JBN intensificado causa fortalecimento do escoamento de baixos níveis noroeste-sudeste climatológico do SMAS. 
Conforme visto até agora, a ZCAS é um sistema meteorológico de escala sinótica com variabilidade em diversas escalas de tempo e espaço, está intimamente relacionado a diferentes circulações de grande escala atuantes sobre a América do Sul e é influenciada por variados distúrbios nas escalas de tempo intrassazonal e interanual. Entretanto, vale lembrar que a atmosfera e a superfície estão em constante interação, sendo que os sistemas de circulação e grande parte dos fenômenos atmosféricos, no que diz respeito à formação, desenvolvimento e manutenção dos mesmos, dependem das condições da superfície, tais como temperatura, umidade do solo (US), vegetação, topografia, TSM. Nessa interação ocorrem trocas intensas de calor, umidade e momento linear (GEVAERD; FREITAS, 2006) sendo que a umidade do solo, por exemplo, dada certa quantidade de radiação líquida incidente, afeta principalmente a partição de fluxos de calor sensível e latente à superfície (BELJAARS et al., 1996).

Desta forma, é importante o entendimento da influência das condições da superfície nas características de fenômenos atmosféricos, tais como a ZCAS, que desempenha um importante papel na distribuição de chuva sobre o Brasil. Determinadas influências da TSM e da US na precipitação associada à ZCAS foram estudadas neste trabalho, com base em experimentos numéricos, e serão apresentadas nos Capítulos 4 e 5, respectivamente.

\subsection{Objetivos}

O objetivo geral do presente trabalho foi estudar características de casos de ZCAS, tais como precipitação associada, padrões de escoamento e convergência de umidade e circulações de grande escala associadas ao SMAS. Através de experimentos numéricos com o 
modelo BRAMS sobre a América do Sul pretendeu-se verificar a influência de características da superfície, especificamente da TSM e da US, na precipitação associada à ZCAS tanto sobre o continente quanto sobre o Oceano Atlântico. Pretendeu-se ainda verificar o desempenho do modelo numérico nas simulações de precipitação nas diversas regiões que compõem a ZCAS (oceânica, costeira e amazônica) com o uso de índices estatísticos, e analisar as diferenças nas características de ZCAS (estudos de casos) em condições de El Niño e La Niña.

No Capítulo 2 são apresentados os dados e a descrição do modelo atmosférico regional utilizados neste trabalho, bem como a metodologia empregada, tanto com relação a análises observacionais de casos de ZCAS, quanto a simulações numéricas dos mesmos. No Capítulo 3 são apresentadas discussões sinóticas de dois casos de ZCAS selecionados. Influências da TSM e de condições iniciais de umidade do solo na precipitação associada à ZCAS, estudadas a partir de testes de sensibilidade do modelo BRAMS, são apresentadas nos Capítulos 4 e 5, respectivamente. Finalmente, no Capítulo 6 são apresentadas as conclusões deste estudo e sugestões para trabalhos futuros. 
Capítulo 2

\section{Metodologia}

\subsection{Dados}

Os dados de parâmetros atmosféricos (vento, temperatura, umidade etc.) utilizados foram as Reanálises ERA-40 (UPPALA et al., 2005), provindas de observações meteorológicas assimiladas no modelo global do European Centre for Medium-Range Weather Forecasts $(E C M W F)$, em pontos de grade espaçados de 1,125 x 1,125 graus de latitude-longitude, disponíveis para o globo todo, em quatro horários diários, em superfície e em 23 níveis de pressão. Esses dados foram utilizados tanto para análises diagnósticas (daqui em diante consideradas como "observações”) quanto para a inicialização e a definição das condições de fronteira (CF) do modelo regional usado nas simulações, sendo que as CF's foram atualizadas a cada seis horas (00Z, 06Z, 12Z e 18Z).

Com relação às TSM's foram utilizados dois conjuntos de dados, as análises semanais e as diárias da National Oceanic and Atmospheric Administration (NOAA), com espaçamentos horizontais de 1 x 1 e de 0,25 x 0,25 graus de latitude-longitude, respectivamente.

Os dados de tipo de solo, topografia e tipo de vegetação utilizados para alimentar o modelo regional foram baseados nos dados fornecidos pelo United States Geological Survey/Earth Resources Observation and Science (USGS/EROS) Center, e os dados diários de 
umidade do solo, utilizados quando da inicialização do modelo com umidade do solo horizontalmente heterogênea, foram os de Gevaerd e Freitas (2006), construídos a partir de dados de satélite.

As imagens de satélite utilizadas na discussão sinótica dos eventos de ZCAS foram as provenientes do satélite GOES-8 no canal do infravermelho e fornecidas pela Divisão de Satélites e Sistemas Ambientais do Instituto Nacional de Pesquisas Espaciais (DSA/INPE).

Os dados referentes à precipitação foram as precipitações diárias em grade de 1 x 1 grau de latitude-longitude, disponíveis de $40^{\circ} \mathrm{S}$ a $40^{\circ} \mathrm{N}$ e de $180{ }^{\circ} \mathrm{W}$ a $180^{\circ} \mathrm{E}$, obtidas do Global Precipitation Climatology Project (GPCP) - Global Precipitation Index (GPI) e serão consideradas neste trabalho como "observações". Esse conjunto de dados foi obtido com a técnica de Arkin e Meisner (1987) que estima a precipitação através de imagens de satélite no canal do infravermelho e de um algoritmo que adiciona $3 \mathrm{~mm} \mathrm{~h}^{-1}$ a cada pixel cuja temperatura de brilho é inferior a $235 \mathrm{~K}$, colocando $0 \mathrm{~mm} \mathrm{~h}^{-1}$ para os demais pixels da região (HUFFMAN et al., 2001).

Dentro dos períodos de estudo propostos, que se referem a dois verões austrais, um durante condições de El Niño (1997-98) e outro de La Niña (1998-99), o Climanálise Boletim de Monitoramento e Análise Climática aponta três eventos de ZCAS: (i) 12 a 16 de fevereiro de 1998 (5 dias); (ii) 6 a 18 de janeiro de 1999 (13 dias) e (iii) 19 a 28 de fevereiro de 1999 (10 dias). Dentre os três casos foram selecionados dois, um ocorrido em 1998 (i) e outro em 1999 (ii), daqui em diante ZCAS-98 e ZCAS-99, respectivamente. Para o ano de 1999, foi selecionado o caso (ii) ao invés de (iii) com base na observação das imagens de satélite, uma vez que (ii) apresenta padrão de nebulosidade associada mais característica de eventos de ZCAS (orientação noroeste-sudeste) do que (iii). 


\subsection{Análise dos dados}

A análise sinótica dos episódios de ZCAS se baseou na inspeção de imagens do satélite GOES-8 no canal do infravermelho, campos de precipitação diária acumulada (das 00Z de um dia às $00 Z$ do dia seguinte) do GPI, campos horizontais, das Reanálises ERA-40, de divergência do fluxo horizontal de umidade integrado na atmosfera, escoamento horizontal, temperatura e umidade específica em baixos níveis $(1000 \mathrm{hPa})$, escoamento horizontal, altura geopotencial e advecção de vorticidade relativa em níveis médios (500 hPa), e escoamento horizontal em altos níveis $(200 \mathrm{hPa})$.

Também foram analisadas seções verticais da divergência do fluxo horizontal de umidade, da velocidade vertical omega e das componentes zonal e meridional do vento ao longo da zona de convergência, também a partir dos dados das Reanálises ERA-40. O local das seções verticais em cada caso foi escolhido visualmente. Com base nos campos de precipitação e de escoamento horizontal procurou-se fazer o corte na direção noroeste-sudeste (coincidente com a ZCAS), que abrangesse os núcleos mais intensos de precipitação e a região de confluência do escoamento sobre o Atlântico Sul durante a maior parte do ciclo de vida do sistema.

Foi observada toda evolução de cada um dos casos de ZCAS, sendo que foram selecionados quatro dias de seus ciclos de vida para análise e apresentação dos campos, abrangendo o surgimento, o desenvolvimento e a dissipação do sistema. Foram selecionados os campos das $18 \mathrm{Z}$ para serem apresentados na discussão sinótica, pois trata-se de $15 \mathrm{~h}$ local, que dentre os quatro horários disponíveis nos dados das Reanálises ERA-40 é o de maior incidência solar e atividade convectiva. A discussão sinótica com base nos campos descritos anteriormente será apresentada no Capítulo 3. 


\subsection{O modelo BRAMS}

O BRAMS, que é derivado do Regional Atmospheric Modeling System (RAMS) versão 5.04, é um modelo de mesoescala criado pela Colorado State University, Estados Unidos (PIELKE et al., 1992; COTTON et al., 2003) e foi desenvolvido pelo Projeto BRAMS adaptação do RAMS às características brasileiras, coordenado pelo Centro de Previsão de Tempo e Estudos Climáticos do Instituto Nacional de Pesquisas Espaciais (CPTEC/INPE) e financiado pela Financiadora de Estudos e Projetos (FINEP).

É um abrangente modelo numérico da atmosfera, desenvolvido nas linguagens computacionais C e FORTRAN, baseado no esquema de diferenças finitas, não-hidrostático, elástico, compressível, de área limitada, que inclui equações prognósticas para temperatura, vapor d'água, água líquida (nuvem e chuva) e as três componentes do vento (TREMBACK, 1990; TRIPOLI; COTTON, 1982; WALKO et al., 1995, 2000), podendo ser empregado desde simulações da camada limite planetária (CLP) até de todo um hemisfério, simulando assim sistemas de meso e grande escalas. O modelo ainda possui diversas opções físicas que permitem a seleção apropriada das mesmas, pelo usuário, para diferentes escalas espaciais, fenômenos meteorológicos, localidades e aplicações (COTTON et al., 2003).

Quanto à grade horizontal, o modelo permite o aninhamento de grades, possibilitando o ajuste de malhas de maior resolução dentro de malhas de resolução inferior. Grades de resolução superior são utilizadas para modelar processos atmosféricos de pequena escala como, por exemplo, circulações termicamente induzidas pela superfície e escoamento sobre terrenos complexos, enquanto que grades de resolução inferior são aplicadas com a finalidade de modelar o ambiente desses processos de menor escala e de prover CF's para malhas de alta resolução. Além disso, as grades de menor resolução são empregadas para simular sistemas de 
grande escala que interagem com os de escala menor, resolvidos na malha de resolução mais refinada (COTTON et al., 2003).

A grade horizontal usa uma projeção rotacionada polar-estereográfica, na qual o polo da projeção é posicionado no ponto determinado pelo polo da grade, controlando assim o grau de distorção do domínio. Em relação à vertical, o modelo utiliza uma coordenada vertical do tipo sigma, que possibilita levar em conta irregularidades do terreno, acompanhando-o no limite inferior e sendo plana no limite superior (CLARK, 1977).

A parametrização convectiva utilizada nas simulações numéricas com o BRAMS realizadas no presente trabalho foi a de Cumulus de Grell (1993). Esta parametrização é uma versão simplificada de Arakawa e Schubert (1974) e a precipitação é determinada por uma condição de quase-equilíbrio, na qual a coluna é estabilizada pela convecção à mesma taxa que é desestabilizada pelo escoamento de grande escala. As propriedades das nuvens são calculadas usando uma única corrente ascendente sem entranhamento que desentranha apenas no topo da nuvem e uma única corrente descendente que começa no nível de menor energia estática úmida (nível de temperatura potencial equivalente mínima) e desentranha em uma camada de profundidade específica acima da superfície (COHEN, 2002).

A parametrização microfísica da versão do modelo BRAMS utilizada neste trabalho inclui distribuições normais (gaussianas) como função base para todas as espécies de hidrometeoros (sete classes, incluindo deferentes categorias de graupel e granizo) e a equação de balanço de calor para os hidrometeoros, permitindo armazenamento de calor e hidrometeoros em fases mistas (sólida e líquida). Ainda faz uso de coleção estocástica ao invés de aproximações de acreção contínua e o esquema de nucleação do gelo inclui nucleação homogênea a partir de gotículas de nuvem e nevoeiro (WALKO et al., 1995).

O RAMS já foi amplamente usado para simular processos atmosféricos e de superfície em escalas de tempo relativamente curtas (PIELKE et al., 1992), simulações climáticas 
(GANDU; COHEN; SOUZA, 2004; LISTON; PIELKE, 2000; LU et al., 2001) e, mais recentemente, para estudar duas importantes circulações locais atuantes na RMSP, a brisa marítima e a ilha de calor urbana (FREITAS et al., 2007), por exemplo. No presente trabalho foi utilizada a versão 4.2 do modelo BRAMS.

\subsection{Simulações numéricas}

Antes da realização das simulações prepararam-se os dados das Reanálises ERA-40 para serem lidos no modelo. Esta preparação foi efetuada através de scripts que realizam a transformação de dados no formato GRIB (Gridded Binary) em DPREP (Data Preparation), que é o formato de dados pronto para ser lido pelo BRAMS.

Na Tabela 1 estão apresentadas as características da grade utilizada nas simulações, que abrangeu todo o Brasil, parte da América do Sul e de oceanos adjacentes e cobriu uma área de $5568 \times 6080 \mathrm{~km}^{2}$ (Figura 1), e as características gerais comuns a todas as simulações realizadas no presente estudo. 
Tabela 1 - Principais características das simulações numéricas, comuns a todos os experimentos realizados com o BRAMS neste trabalho.

\begin{tabular}{|c|c|}
\hline \multicolumn{2}{|c|}{ Características da grade } \\
\hline início da integração & $\begin{array}{l}\text { ZCAS-98: 08fev1998 às 00Z } \\
\text { ZCAS-99: 02jan1999 às 00Z }\end{array}$ \\
\hline fim da integração & $\begin{array}{l}\text { ZCAS-98: } 19 \text { fev1998 às } 00 Z \\
\text { ZCAS-99: } 18 \text { jan1999 às } 00 Z\end{array}$ \\
\hline tempo de integração & $\begin{array}{l}\text { ZCAS-98: } 264 \text { horas ( } 11 \text { dias) } \\
\text { ZCAS-99: } 384 \text { horas (16 dias) }\end{array}$ \\
\hline número de pontos $(\mathrm{x}, \mathrm{y}, \mathrm{z})$ & $(191,175,34)$ \\
\hline espaçamento horizontal & $32 \mathrm{~km}$ \\
\hline espaçamento vertical no primeiro nível & $100 \mathrm{~m}$ \\
\hline razão de incremento na vertical & 1,15 \\
\hline espaçamento vertical máximo & $1000 \mathrm{~m}$ \\
\hline centro da grade & $17,5^{\circ} \mathrm{S} ; 49,5^{\circ} \mathrm{W}$ \\
\hline polo da grade & $17,5^{\circ} \mathrm{N} ; 49,5^{\circ} \mathrm{W}$ \\
\hline passo de tempo & $30 \mathrm{~s}$ \\
\hline $\begin{array}{l}\text { níveis do solo } \\
\text { (metros abaixo da superfície) }\end{array}$ & $\begin{array}{l}-4,00 ;-3,00 ;-2,00 ;-1,75 ;-1,50 ;-1,25 \\
-1,00 ;-0,75 ;-0,50 ;-0,30 ;-0,20 ;-0,10 \mathrm{~m}\end{array}$ \\
\hline \multicolumn{2}{|c|}{ Parâmetros de assimilação nas fronteiras do domínio } \\
\hline $\begin{array}{l}\text { número de pontos na fronteira lateral onde } \\
\text { é aplicado o nudging }\end{array}$ & 5 \\
\hline $\begin{array}{l}\text { escala de tempo de nudging na fronteira } \\
\text { lateral }\end{array}$ & $1800 \mathrm{~s}$ \\
\hline $\begin{array}{l}\text { escala de tempo de nudging no centro do } \\
\text { domínio }\end{array}$ & $43200 \mathrm{~s}$ \\
\hline $\begin{array}{l}\text { escala de tempo de nudging no topo do } \\
\text { domínio }\end{array}$ & $10800 \mathrm{~s}$ \\
\hline $\begin{array}{l}\text { altura a partir da qual é aplicado nudging } \\
\text { na parte superior do domínio simulado }\end{array}$ & $16000 \mathrm{~m}$ \\
\hline
\end{tabular}

\begin{tabular}{lc}
\hline \multicolumn{2}{c}{ Parametrizações } \\
\hline radiação de onda curta & Chen e Cotton (1983) \\
radiação de onda longa & Chen e Cotton (1983) \\
Cumulus & Grell (1993) \\
\hline
\end{tabular}


Tendo em vista a grande variabilidade espacial da precipitação ao longo da ZCAS, definiram-se três regiões distintas que a compõem, denominadas oceânica, costeira e amazônica (Figura 1). Essas regiões foram determinadas visualmente com base em Carvalho, Jones e Liebmann (2004) e na precipitação acumulada no final do período de integração do modelo em diferentes experimentos realizados no presente estudo para os dois casos de ZCAS. As regiões abrangem o máximo possível as porções onde há precipitação associada à ZCAS, levando-se em conta os dois casos. Evitou-se englobar a Cordilheira dos Andes na região amazônica e superpor as regiões, a fim de que sejam independentes para estudos estatísticos. Tomou-se o cuidado de definir as três regiões com áreas aproximadamente iguais, uma vez que estudos estatísticos deverão levar à comparação do skill do modelo nas diferentes regiões, sendo assim, é razoável que as áreas sejam semelhantes.

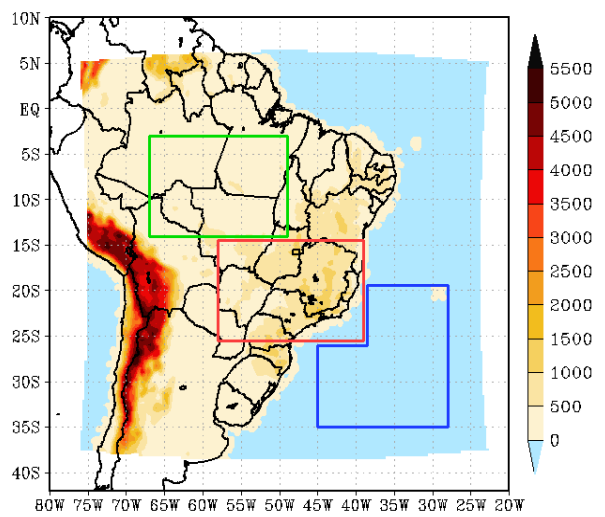

Figura 1. Topografia (intervalo de $500 \mathrm{~m}$ ). A região sombreada representa os limites da grade, com espaçamento horizontal de $32 \mathrm{~km}$, utilizada nas simulações numéricas com o BRAMS. Os retângulos representam os limites das distintas regiões, utilizadas neste trabalho, que compõem a ZCAS: oceânica (azul), costeira (vermelho) e amazônica (verde).

As características particulares de testes de sensibilidade do modelo BRAMS a TSM e a condições iniciais de US bem como os resultados dos mesmos serão apresentados nos Capítulos 4 e 5, respectivamente. 
Capítulo 3

\section{Discussão Sinótica}

\subsection{ZCAS-98}

\subsubsection{Baixos níveis}

No dia 11 de fevereiro de 1998, pode-se observar na imagem de satélite (Figura 2a) que a ZCAS já está no início de seu estabelecimento, apresentando intensa nebulosidade associada e se estendendo de forma descontínua do Sudeste do Brasil ao Atlântico Sul, com um núcleo extenso de nebulosidade também sobre a região central e oeste da Amazônia. Os dados de precipitação (Figura 3a) indicam forte atividade convectiva na região do Amazonas se estendendo ao Atlântico Sul com orientação noroeste-sudeste típica de ZCAS, intensa precipitação também nos estados de São Paulo e Paraná, e um núcleo menos intenso localizado sobre o Mato Grosso. O escoamento horizontal em baixos níveis (Figura 4a) já caracteriza uma região de convergência, porém mais restrita ao Oceano Atlântico, com ventos intensos de componente norte (ramo oeste da ASAS) e sul confluindo na direção noroestesudeste. Nesta mesma região há intensa convergência do fluxo de umidade (Figura 3b), majoritariamente sobre o Atlântico Sul, o que caracteriza a zona de convergência. Há também convergência de umidade com precipitação associada no sudeste do Brasil, porém a intensidade da convergência é menor se comparada à que ocorre no Atlântico Sul. 
(a)

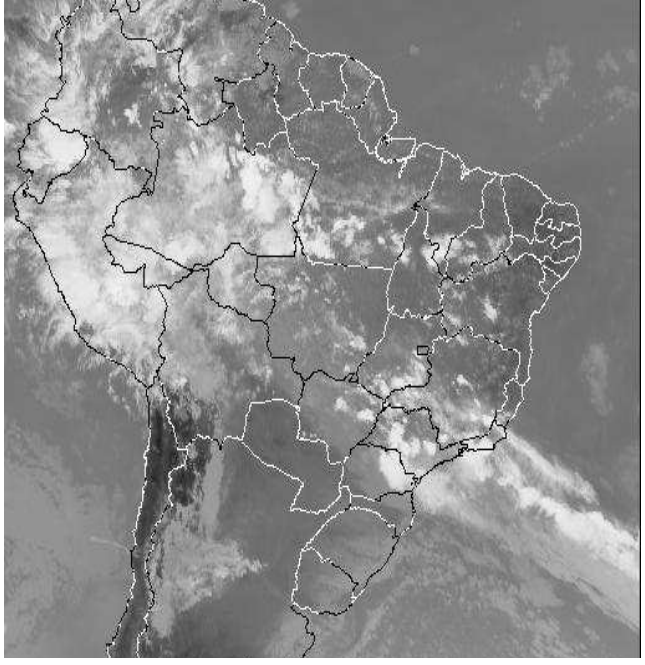

(c)

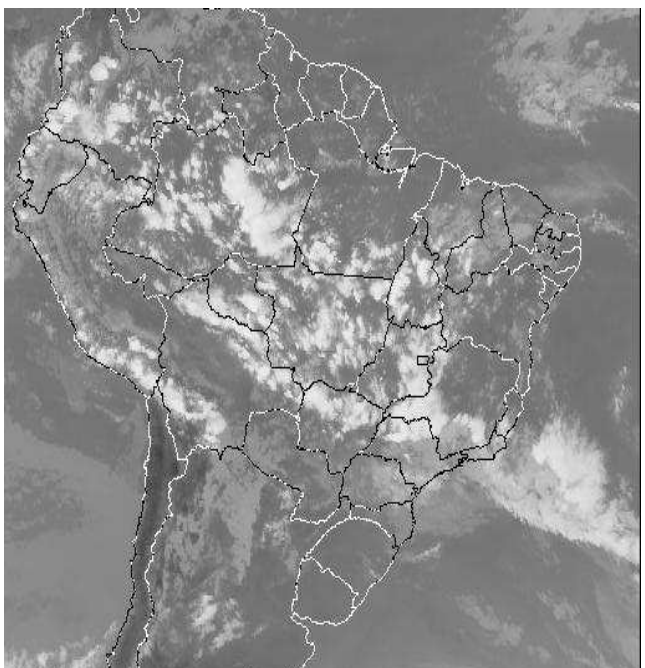

(b)

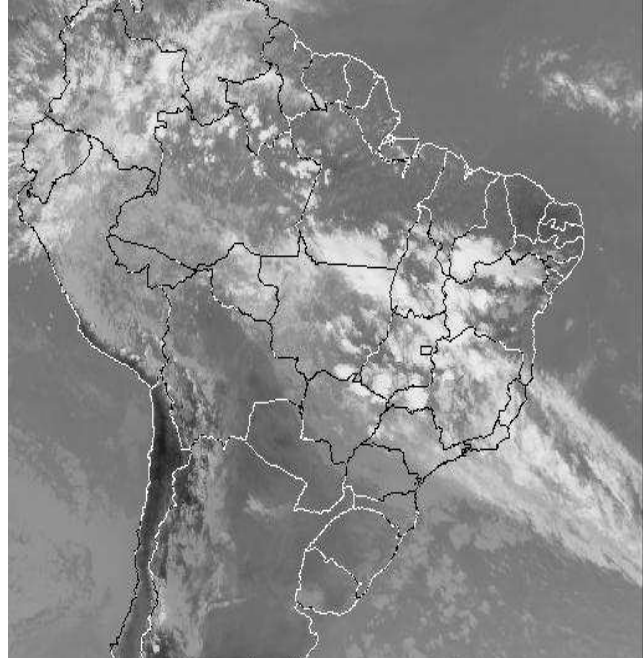

(d)

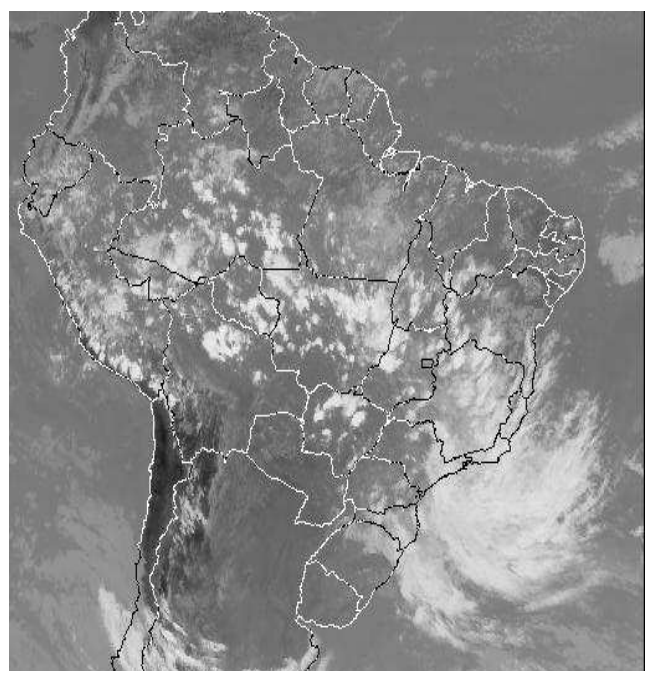

Figura 2. Imagens do satélite GOES-8 no canal do infravermelho para os dias (a) 11/02/98 às 18Z, (b) $12 / 02 / 98$ às $18 Z$, (c) $14 / 02 / 98$ às $21 Z$ e (d) 16/02/98 às 18Z. Fonte: DSA/INPE.

Os alísios adentram o continente pelas costas norte e nordeste do Brasil para trazer umidade e ar quente do equador e posteriormente da Amazônia (Figura 4a), alimentando, nos próximos dias, a convecção e a precipitação no Brasil central e sudeste. Quanto à temperatura do ar (Figura 4a), identifica-se uma fronteira entre ar quente e frio se estendendo do litoral de São Paulo ao Atlântico Sul, padrão de sistemas frontais que, conforme já apontado por Carvalho, Jones e Liebmann (2004), precedem ocorrências de ZCAS intensas. Nota-se, a partir da Figura 4b, que a ZCAS se localiza no limite polar da massa tropical úmida com intenso gradiente de umidade, conforme Ninomiya (2007). O ar mais seco das latitudes mais altas está sendo transportado para a zona de convergência havendo encontro deste com o ar 
mais úmido e quente das regiões tropicais, que é transportado principalmente pelos alísios na parte continental e pela ASAS, cujo giro anticiclônico tem um importante papel no transporte de umidade. Na região de convergência no Atlântico próximo à costa sudeste do Brasil destaca-se um núcleo com grande quantidade de umidade (Figura $4 b$ ).

$\mathrm{Na}$ imagem de satélite (Figura 2b) observa-se que no dia 12 de fevereiro já havia se estabelecido a banda de nebulosidade associada à ZCAS, mais larga do que no dia anterior, sobre o Brasil central e Região Sudeste com sua intrínseca orientação noroeste-sudeste estendendo-se do sul da Amazônia em direção ao Atlântico Sul, sendo que há enfraquecimento do núcleo de nebulosidade no oeste da Amazônia. Os dados de precipitação do GPI (Figura 3c) apontam que as áreas com maior quantidade de precipitação diária acumulada, associada ao sistema, são o noroeste do Mato Grosso, centro-sul de Minas Gerais, Rio de Janeiro, divisa entre Mato Grosso do Sul e Goiás e Atlântico Sul. Algumas áreas com menor quantidade de precipitação ocorrem na Amazônia e interior do Nordeste do Brasil (NEB). Há convergência do fluxo de umidade na região de confluência de escoamentos sobre o Atlântico Sul, Brasil central e interior da Região Nordeste (Figura 3d), porém a convergência é menos intensa do que no dia anterior. Quanto à convergência do fluxo horizontal de umidade, ressalta-se, na Figura 3d, que na região de convergência de ventos com orientação noroeste-sudeste sobre o Atlântico Sul (Figura 4c) se dá o maior fluxo de umidade.

Na Figura 4c é possível identificar confluência de ventos de componente norte provindos da porção oeste da ASAS, cujo giro anticiclônico traz vapor d'água em direção à zona de convergência, com ventos de componente sul, característicos de sistemas frontais. Também é possível notar a entrada dos alísios na costa do NEB. Nesta região esses ventos de leste adotam componente norte e adentram o continente transportando umidade do Atlântico à 
região continental. A região de escoamento horizontal mais intenso se dá ao sul da confluência de ventos sobre o Atlântico Sul.

No campo horizontal de temperatura do ar (Figura 4c) nota-se o limite do ar frio com o ar mais quente na região da convergência. Os ventos com componente sul observados nesta Figura estão advectando ar frio para a área de confluência enquanto os de componente norte transportam ar quente e úmido das regiões mais próximas ao equador para essa região. A umidade na região da ZCAS (Figura 4d) é menor do que no dia anterior, sendo que no lado equatorial da mesma na região oceânica, próximo às costas do Rio de Janeiro e Espírito Santo, há ainda grande quantidade de umidade sendo advectada para a zona de convergência, alimentando o sistema no início de seu desenvolvimento. Nesta mesma Figura é possível identificar a menor quantidade de umidade no centro de alta pressão sobre o Atlântico Sul. No noroeste da América do Sul há grande concentração de umidade e observa-se uma faixa de maior concentração ao longo da ZCAS também sobre a região continental.

Ainda há, no dia 14 (Figura 2c), persistência da zona de convergência, que apresenta características mais descontínuas, com três núcleos de precipitação distintos (Figura 3e), um localizado no Atlântico Sul, um no sul de Minas Gerais e outro no oeste da região amazônica, sendo que, com exceção da Amazônia, a quantidade acumulada de precipitação neste dia foi menor do que no dia 12. A nebulosidade na porção continental se estende mais para a Amazônia (Figura 2c) com relação ao dia 12.

A confluência do escoamento horizontal (Figura 4e) persiste no Atlântico Sul, no entanto observa-se a formação de um vórtice ciclônico no sudeste dessa região, associado a um cavado em altos níveis (Figura 6c), bem como uma deformação da Alta Subtropical, em cuja porção sudoeste a ZCAS permanece ancorada. Nota-se a penetração de escoamento de leste proveniente da porção norte da Alta Subtropical na região de Minas Gerais (Figura 4e), onde 
há um núcleo intenso de precipitação (Figura 3e), sendo que o papel desse escoamento é trazer umidade do oceano para esta região.

Pode-se notar a persistência da região úmida da ZCAS (Figura 3f), mostrada pelo campo de convergência do fluxo horizontal de umidade. Entre $37^{\circ} \mathrm{S}$ e $32^{\circ} \mathrm{S}$ e entre $25^{\circ} \mathrm{W}$ e $30^{\circ} \mathrm{W}$ aproximadamente observa-se a maior convergência umidade, coincidindo com a região ciclônica formada ao longo zona de convergência oceânica e na região de maior intensidade do vento. Sendo esta uma região de baixa pressão, a umidade tende a convergir para ela. No campo de temperatura (Figura 4e) há destaque para a região do vórtice ciclônico formado em baixos níveis, já que a temperatura aí é maior do que no dia 12. A maior temperatura nessa região causou abaixamento da pressão em baixos níveis e devido à convergência do fluxo de umidade para essa região é observado o núcleo de precipitação citado anteriormente.

Através do campo de umidade (Figura 4f) também é possível notar que a quantidade de umidade que converge na ZCAS diminui com relação dia 12. No Brasil central, principalmente na região do Mato Grosso e Pará há menos umidade do que nas regiões adjacentes. Neste campo de umidade também identifica-se a ZCAS com características mais descontínuas, pois observam-se três núcleos distintos com maior concentração de umidade, um intenso no oeste da Amazônia, um se estendendo do norte de São Paulo ao Maranhão e leste do Pará e outro no Atlântico Sul na direção noroeste-sudeste, semelhantemente ao que se observa no campo de precipitação da Figura 3e. O escoamento anticiclônico associado à ASAS enfraquece (Figura 4f) com relação ao dia 12, então sua eficiência em advectar umidade diminui. Desta forma, a quantidade de umidade na ZCAS é menor quando se compara ao início do ciclo de vida do sistema. 
(a)

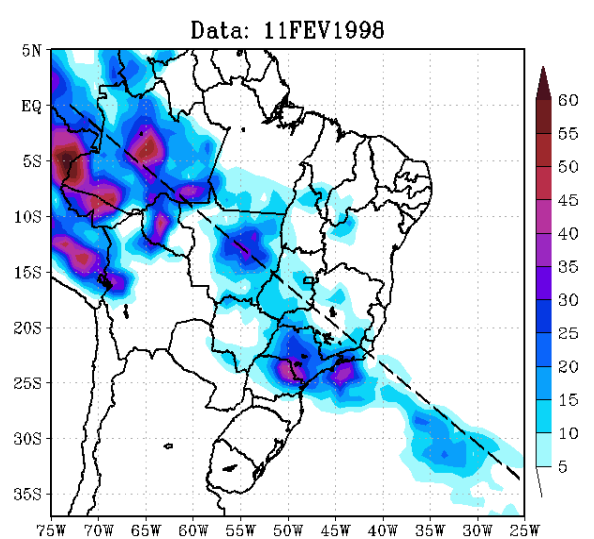

(c)

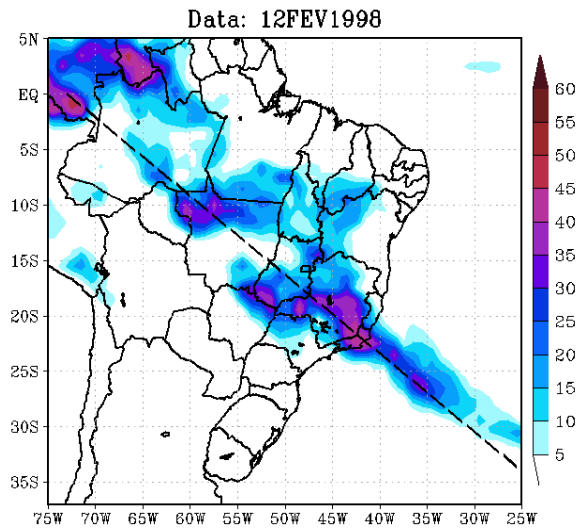

(e)

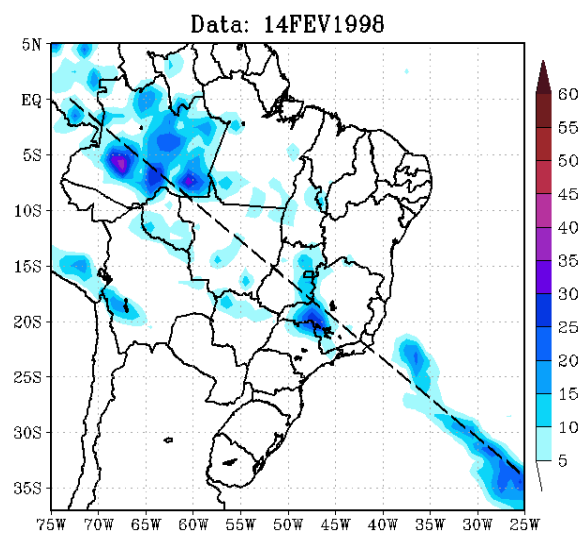

(g)

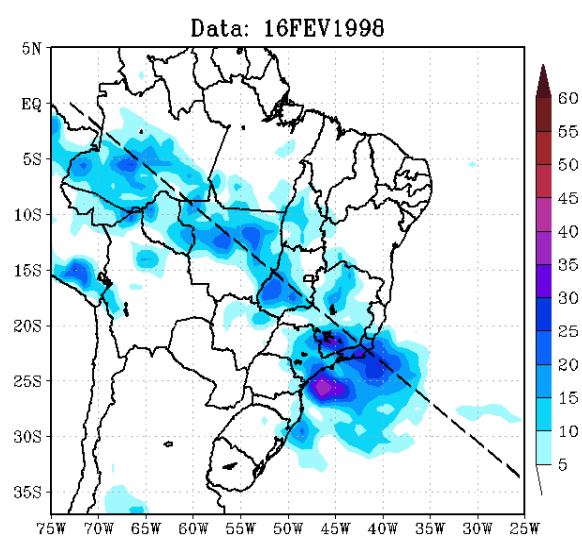

(b)

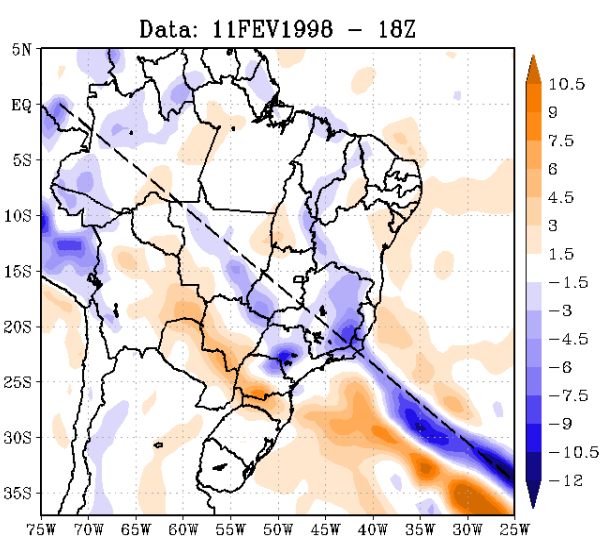

(d)

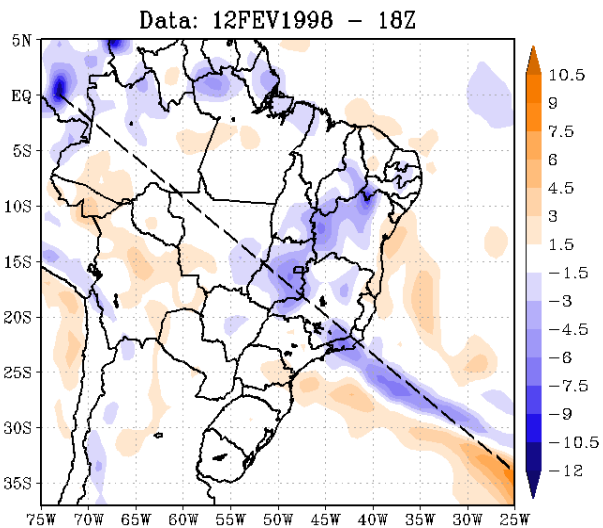

(f)

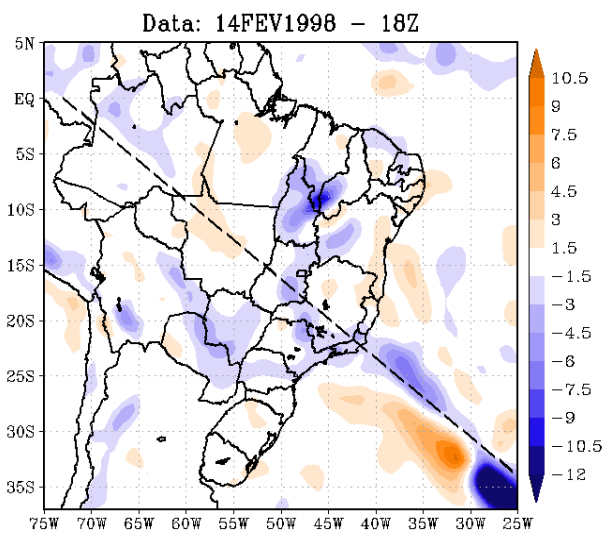

(h)

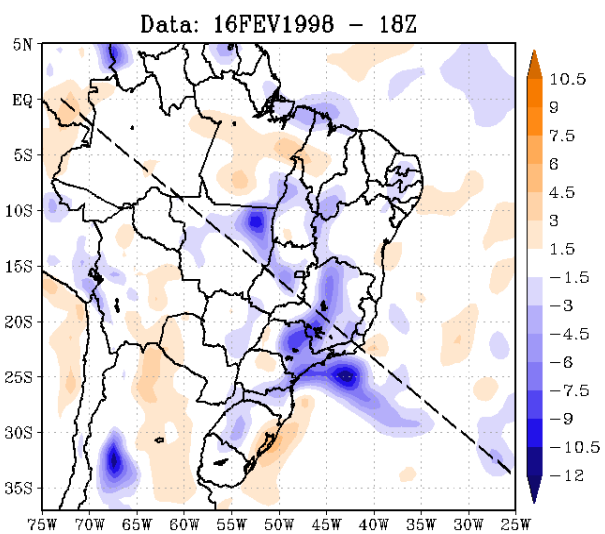

Figura 3. Precipitação diária acumulada pelo GPI (intervalo de $5 \mathrm{~mm} \mathrm{dia}^{-1}$ ) nos dias (a) $11 / 02 / 98$, (c) 12/02/98, (e) 14/02/98 e (g) 16/02/98. Divergência do fluxo horizontal de umidade integrado na atmosfera, da pressão reduzida ao nível médio do mar ao nível de $100 \mathrm{hPa}$ (intervalo de $1,5 \times 10^{-4} \mathrm{~kg} \mathrm{~kg}^{-1} \mathrm{~s}^{-1}$ ), para as $18 \mathrm{Z}$ dos dias (b) 11/02/98, (d)12/02/98, (f) 14/02/98 e (h) 16/02/98. O tracejado em preto representa a localização das seções verticais das Figuras 7 e 8. 
(a)

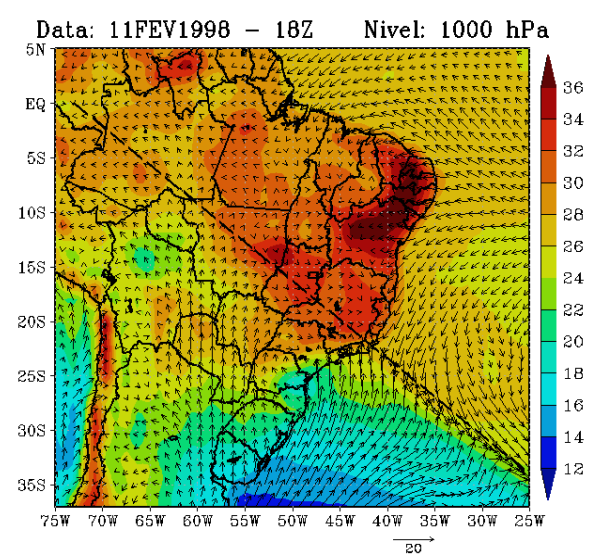

(c)

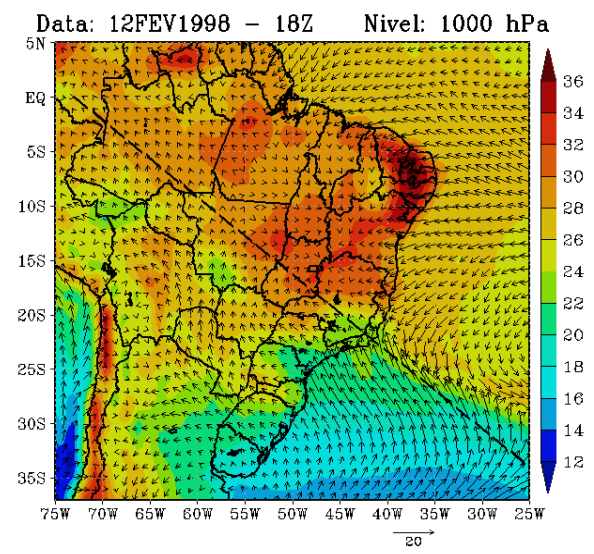

(e)

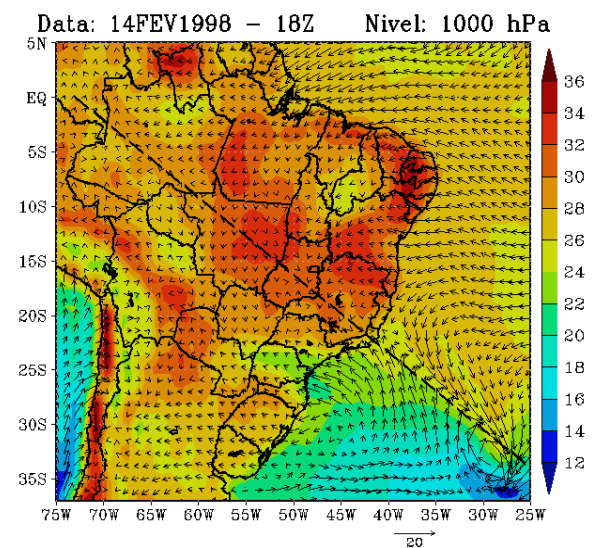

$(\mathrm{g})$

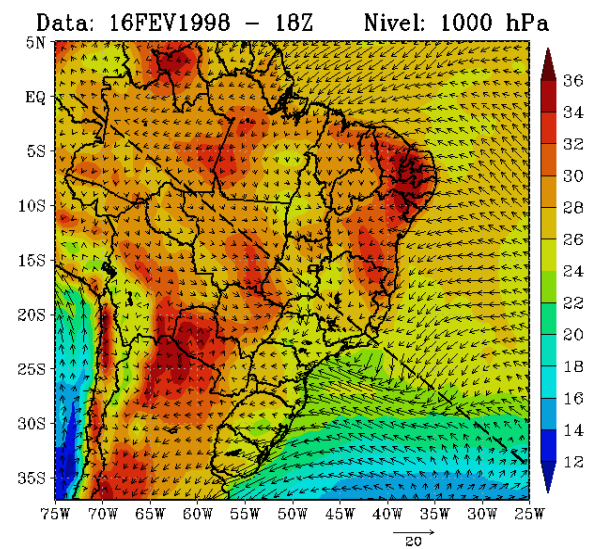

(b)

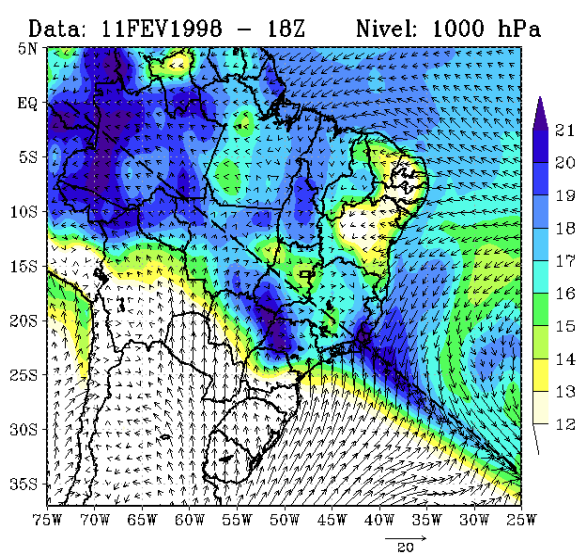

(d)

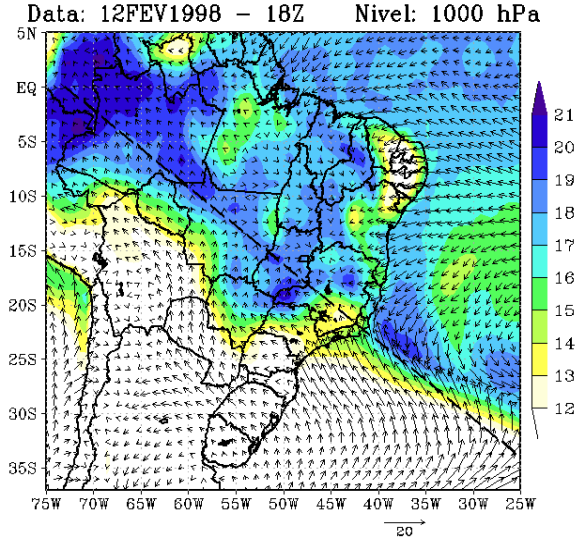

(f)

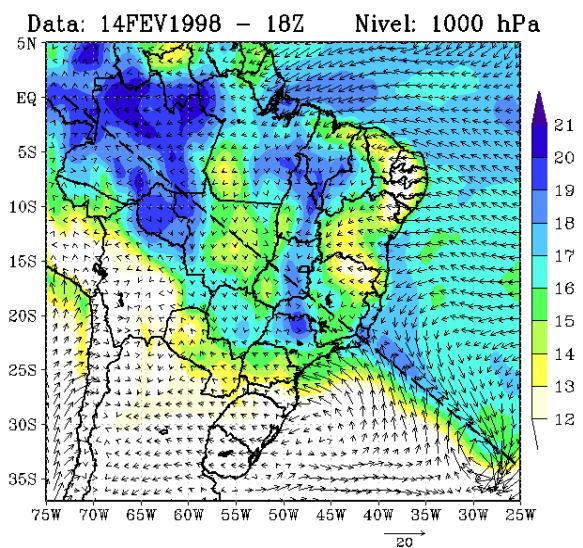

(h)

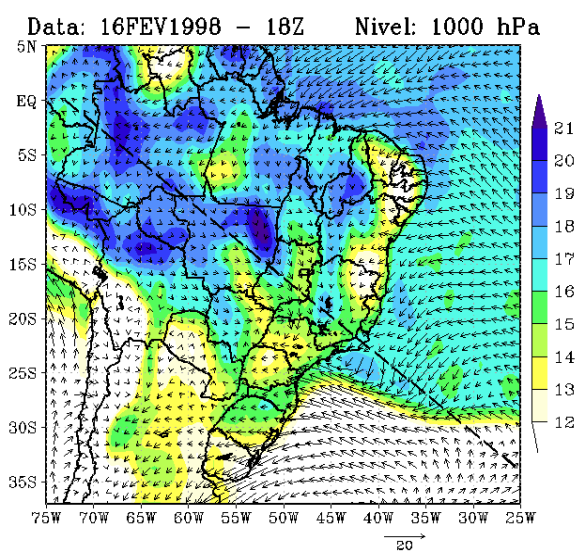

Figura 4. Idem à Figura 3 mas para escoamento horizontal $\left(\mathrm{m} \mathrm{s}^{-1}\right)$ e temperatura do ar (sombreado com intervalo de $\left.2{ }^{\circ} \mathrm{C}\right)$ em $1000 \mathrm{hPa}(\mathrm{a}, \mathrm{c}, \mathrm{e}, \mathrm{g})$ e para escoamento horizontal $\left(\mathrm{m} \mathrm{s}^{-1}\right)$ e umidade específica (sombreado com intervalo de $1 \mathrm{~g} \mathrm{~kg}^{-1}$ ) em $1000 \mathrm{hPa}(\mathrm{b}, \mathrm{d}, \mathrm{f}, \mathrm{h}$ ). 
No dia 16 de fevereiro o sistema já está se dissipando, observa-se na Figura 2d que a banda de nebulosidade noroeste-sudeste peculiar da ZCAS já não está mais tão caracterizada como nos dias anteriores. Ainda há presença de alguns núcleos convectivos no Brasil central e uma grande região de nebulosidade abrangendo as costas sul e sudeste do Brasil e o Atlântico Sul. Entretanto, neste estágio, nota-se que a banda de precipitação voltou a apresentar características mais contínuas (Figura 3g) ainda que com precipitação menos intensa ao longo da porção continental. Na região de intensa nebulosidade sobre o oceano, apresentada na imagem de satélite, há maior quantidade de precipitação diária acumulada associada com relação ao restante do domínio, principalmente na região oceânica próxima à costa de São Paulo, e intensa convergência do fluxo horizontal de umidade (Figura 3h).

No campo de escoamento horizontal (Figura 4g), nota-se que os alísios que entram no continente sul-americano pelo NEB apresentam componente norte mais intensa com relação ao dia 14. Estes ventos devem escoar em direção ao sudeste e sul da América do Sul transportando vapor d'água e ar quente da Amazônia e do Atlântico tropical para essa regiões, sendo que parte desse escoamento se dá a leste dos Andes, pois é canalizado por eles. No Atlântico Sul destaca-se uma região de ventos de sudeste mais intensos (Figura 4g), coincidindo com o núcleo mais intenso de precipitação (Figura 3g) nesse dia, esse escoamento é um ramo da porção oeste da Alta Subtropical que transporta umidade do oceano para a costa de São Paulo (Figura 4h), causando a formação de precipitação nessa região (Figura 3g). Na Figura 4h é possível notar a descaracterização da ZCAS, pois o padrão de confluência de ventos orientado na direção noroeste-sudeste não se distingue claramente, a zona de convergência se desintensifica e começa a se orientar mais zonalmente sobre o Atlântico Sul.

A convergência do fluxo horizontal de umidade (Figura 3h) mais intensa ainda permanece sobre o Atlântico Sul na região de atuação da ZCAS, porém se concentra mais na região próxima à costa de São Paulo e Rio de Janeiro, onde o escoamento proveniente do 
anticiclone do Atlântico é mais eficiente em transportar vapor d'água. Com relação ao campo horizontal de umidade (Figura 4h), nota-se que há menos quantidade de umidade na região da ZCAS. Levando em conta que a ZCAS se localiza em uma região de intenso gradiente de umidade, como apontado por Ninomiya (2007), identifica-se também seu enfraquecimento a partir deste campo, já que o gradiente de umidade é mais fraco se comparado ao que existia antes do início do desenvolvimento do sistema, no dia 11 de fevereiro. Com relação à temperatura do ar (Figura 4g) a fronteira entre ar mais frio proveniente do polo e ar mais quente da região equatorial, que caracterizava um sistema frontal, se apresenta mais zonal.

\subsubsection{Níveis médios}

No dia 11 de fevereiro, ao longo do escoamento de oeste, observa-se um cavado se aproximando da costa sudeste do Brasil (Figuras 5a e 5b), assim há um distúrbio sinótico de latitudes médias se propagando, neste caso um sistema frontal, o que segundo Carvalho, Jones e Liebmann (2004) antecede ocorrências de ZCAS intensas. Vale lembrar que, conforme Kodama (1992, 1993), a ZCAS se forma justamente do lado leste de um cavado quase ancorado. Nota-se que o eixo do cavado apresenta ligeira inclinação para oeste. É possível também identificar a alta subtropical a nordeste do cavado embebido no escoamento de oeste, já que ela é uma estrutura mais ou menos barotrópica mantendo seu giro anticiclônico em níveis médios, assim como se apresenta nos baixos níveis sobre o Atlântico Sul.

No dia 12, o cavado está posicionado mais a leste com seu eixo ainda inclinado para oeste (Figuras 5c e 5d), assim o sistema frontal está posicionado aproximadamente sobre os estados de São Paulo, Rio de Janeiro e Minas Gerais, se estendendo até o sudoeste do Atlântico Sul 
(Figura 4c). Observa-se que há advecção de vorticidade ciclônica a leste de uma região de advecção de vorticidade anticiclônica (Figura 5d), assim a tendência do sistema de cristas e cavados é se deslocar para leste.

No dia 14 (Figuras 5e e 5f), o núcleo do jato subtropical se desintensifica e o eixo do cavado apresenta ligeira inclinação para leste e comprimento de onda menor, o que torna o sistema frontal mais meridional. No campo do escoamento em baixos níveis (Figura 4e) observa-se que a ZCAS também se apresenta mais meridional do que no início de seu ciclo de vida, permanecendo desta forma ancorada ao padrão de escoamento do cavado. Na Figura 4e também se identifica o núcleo de baixa pressão em superfície associado ao sistema frontal.

Já no dia 16 o cavado se deslocou para leste em direção ao oceano (Figura 5g) e observase a aproximação de um novo sistema de cavado e crista se aproximando do sul do Brasil, com um cavado de comprimento de onda menor do que o anterior sobre a região sudeste do Brasil e uma crista com um anticiclone associado sobre o norte da Argentina, Paraguai e Bolívia (Figuras 5g e 5h). Associado ao novo cavado há a presença de um sistema com intensa nebulosidade e precipitação na região (Figuras $2 \mathrm{~d}$ e $3 \mathrm{~g}$ ) e associado à crista observa-se aumento de temperatura em superfície no norte da Argentina (Figura 4g). No sul do Atlântico Sul o escoamento de oeste em níveis médios se apresenta mais zonal e, em consequência, a ASAS sofre certa deformação, apresentando porção sudoeste com características mais zonais (Figura 5g). Desta forma, a zona de convergência, já em estado de dissipação, se apresenta mais zonalmente ancorada à ASAS. 
(a)

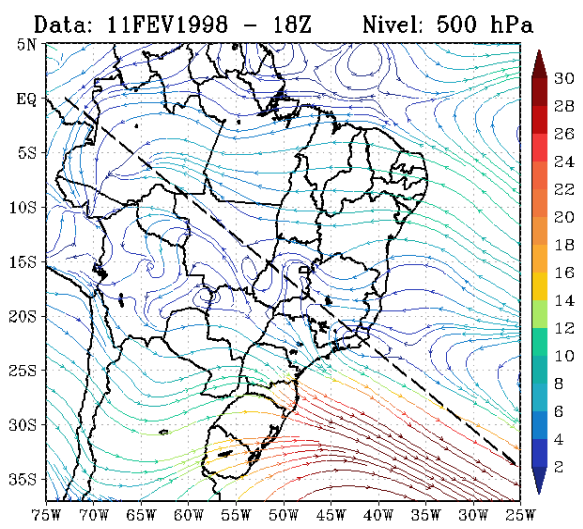

(c)

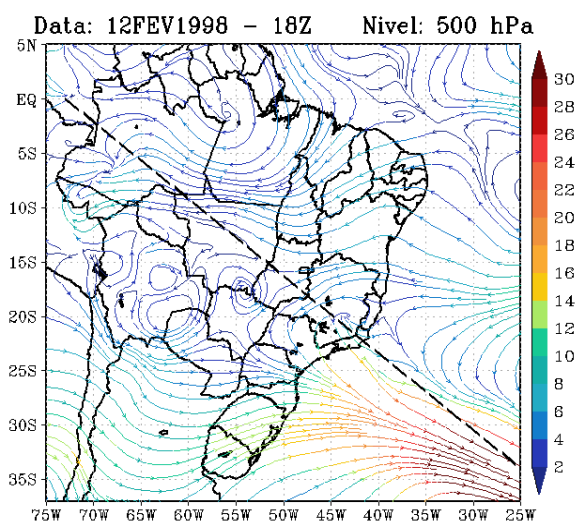

(e)

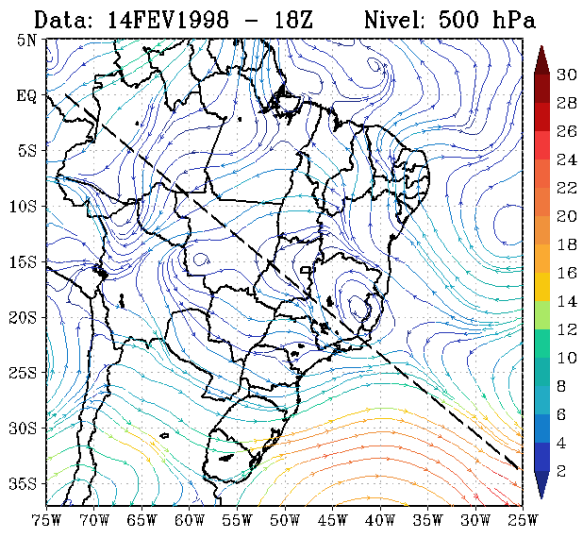

$(\mathrm{g})$

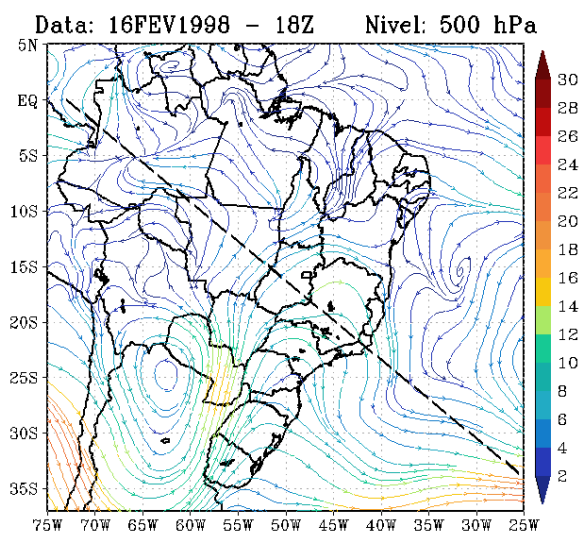

(b)

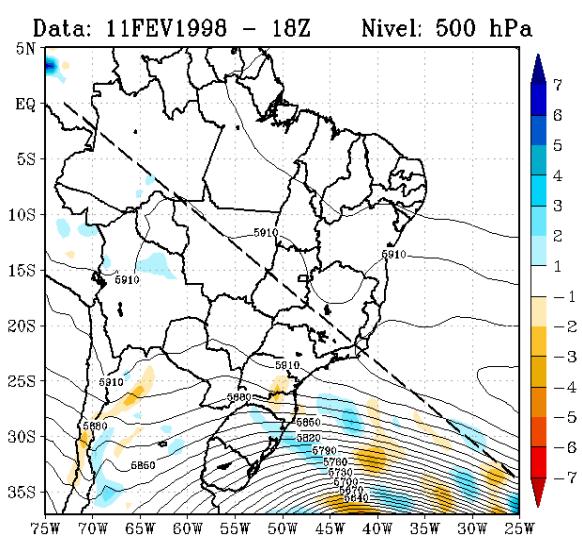

(d)

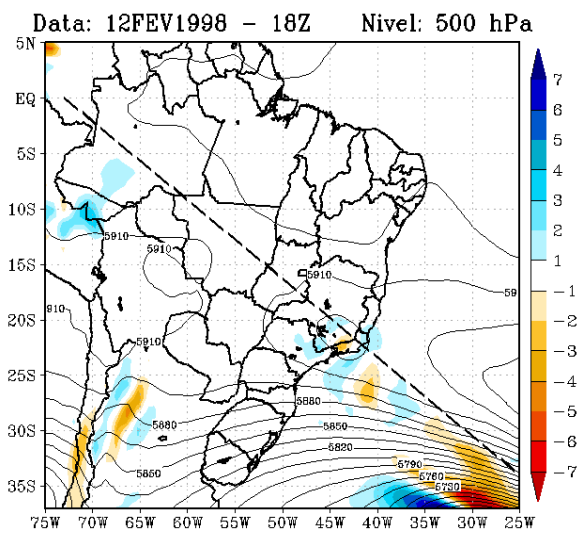

(f)

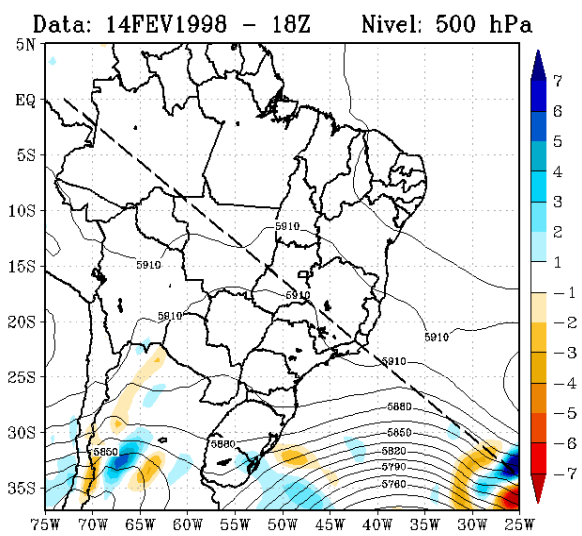

(h)

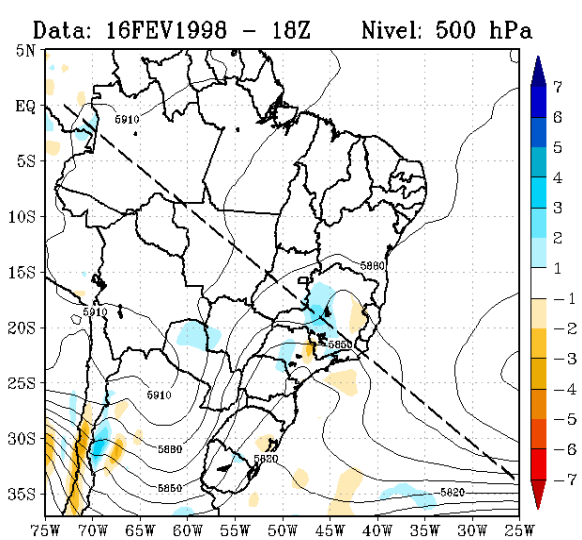

Figura 5. Idem à Figura 3 mas para linhas de corrente e magnitude do escoamento horizontal (intervalo de $2 \mathrm{~m}$ $\mathrm{s}^{-1}$ ) em $500 \mathrm{hPa}$ (a, c, e, g) e para altura geopotencial (contorno com intervalo de $15 \mathrm{~m}$ ) e advecção de vorticidade relativa (sombreado com intervalo de $1 \times 10^{-9} \mathrm{~s}^{-2}$ ) em $500 \mathrm{hPa}(\mathrm{b}, \mathrm{d}, \mathrm{f}, \mathrm{h}$ ). 


\subsubsection{Altos níveis}

Observa-se, já no dia 11 de fevereiro, padrão de circulação típico da região do SMAS durante o verão, um cavado em altos níveis próximo à costa do NEB, denominado Cavado do Nordeste (Figura 6a). Sobre o norte do estado de São Paulo há centrado um grande vórtice anticiclônico e identifica-se a corrente de jato com núcleo no sul do Atlântico Sul, em cujo lado equatorial a ZCAS deverá se desenvolver, conforme Kodama (1992, 1993).

(a)

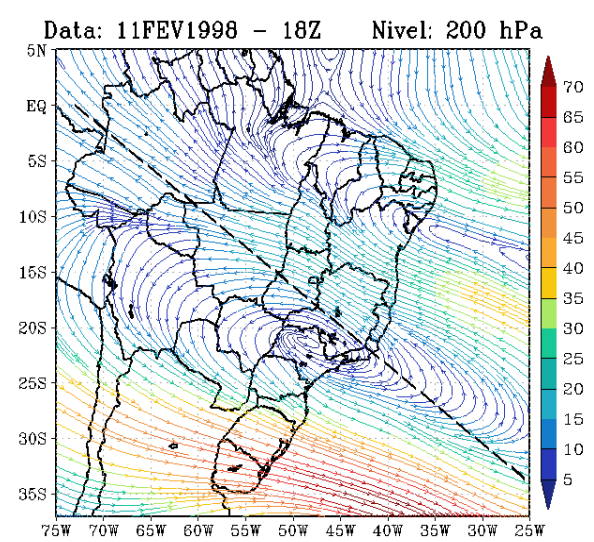

(c)

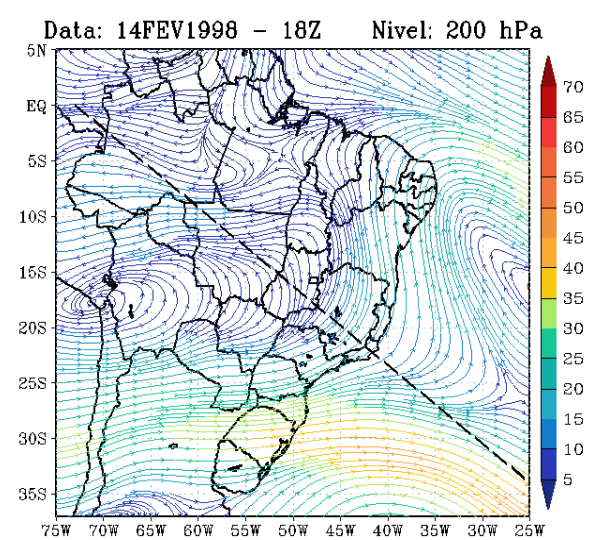

(b)

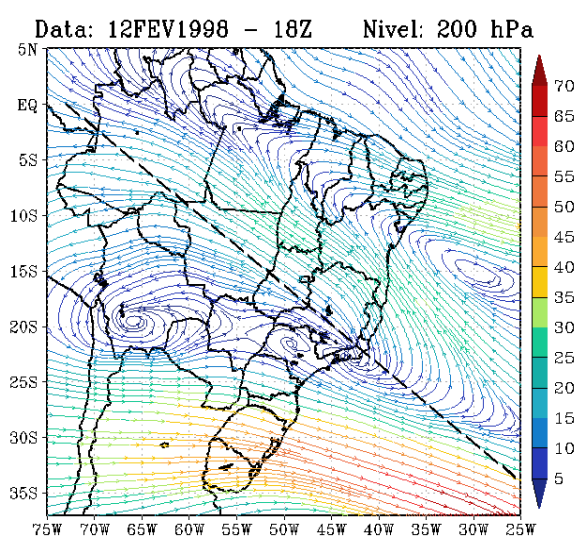

(d)

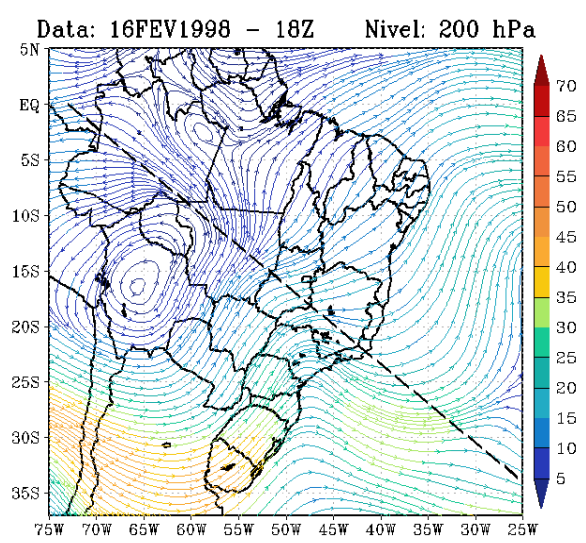

Figura 6. Idem à Figura 3 mas para linhas de corrente e magnitude do escoamento horizontal (intervalo de $5 \mathrm{~m}$ $\mathrm{s}^{-1}$ ) em $200 \mathrm{hPa}$.

No dia 12 (Figura 6b) observa-se um vórtice ciclônico de altos níveis (VCAN) tropical, associado ao escoamento do $\mathrm{CN}$, sobre o Oceano Atlântico na direção da costa da Bahia. Além do CN, observa-se um grande anticiclone centrado sobre a Bolívia, denominado Alta da 
Bolívia, que se desenvolve devido às intensificações da convecção sobre a Amazônia e de um ciclone térmico em superfície (Baixa do Chaco), conforme Andrade (2007). A AB e o CN associados atuam sobre a região do SMAS, sendo típicos durante episódios de ZCAS. Observa-se também desintensificação do núcleo do jato subtropical em 200 hPa na Figura 6b.

Nota-se certo deslocamento do VCAN ligeiramente para sudeste e da AB para noroeste no dia 14 (Figura 6c). Observa-se persistência da configuração típica de altos níveis associada à ocorrência de zona de convergência. Com relação ao dia 12, o núcleo da corrente de jato subtropical se apresenta menos intenso.

No dia 16 (Figura 6d) já ocorre certa descaracterização da circulação do CN, que se deslocou para o oceano, sendo que a $\mathrm{AB}$ ainda mantém seu padrão de vorticidade anticiclônico. Quanto à corrente de jato subtropical, o núcleo encontra-se ao longo da crista sobre o norte da Argentina.

\subsubsection{Seções verticais}

Em baixos níveis, no dia 11, observa-se convergência do fluxo de umidade majoritariamente na região do Atlântico Sul (Figura 7a), com destaque para os níveis mais próximos à superfície até aproximadamente $900 \mathrm{hPa}$. A partir do campo de velocidade vertical omega (Figura 7b), identifica-se intenso movimento ascendente sobre o Atlântico Sul que se estende até altos níveis e alguns pontos com movimento ascendente sobre o Brasil central e Amazônia, associados aos núcleos de precipitação observados na Figura 3a. 
(a)

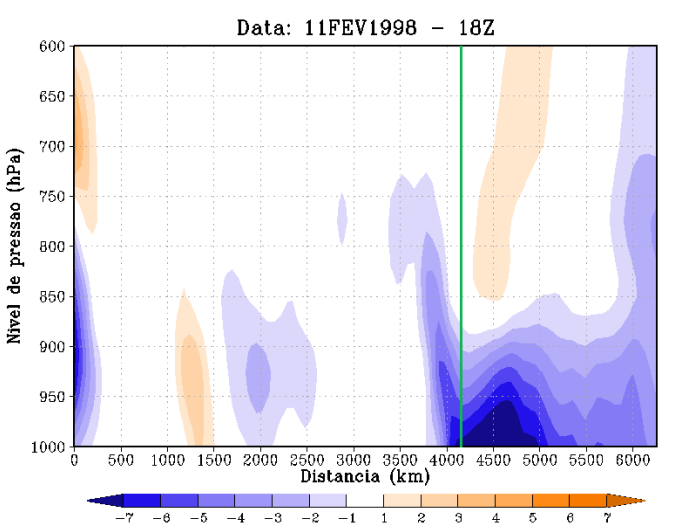

(c)

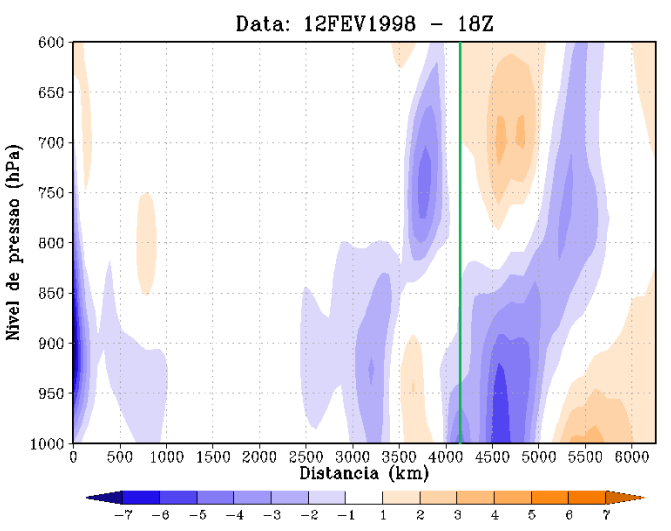

(e)

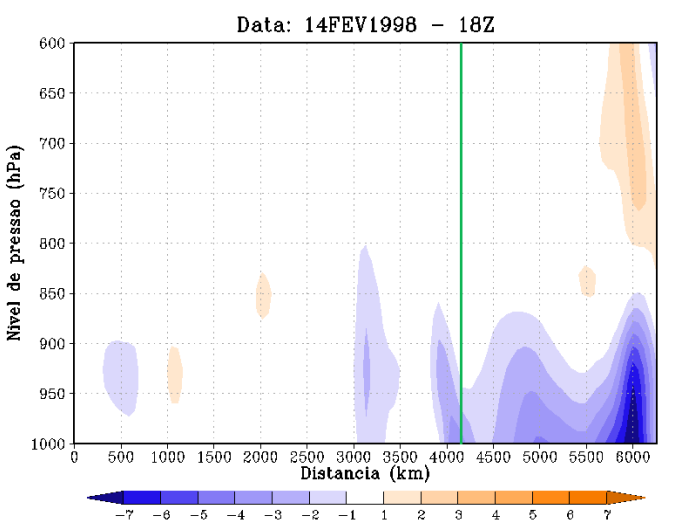

(g)

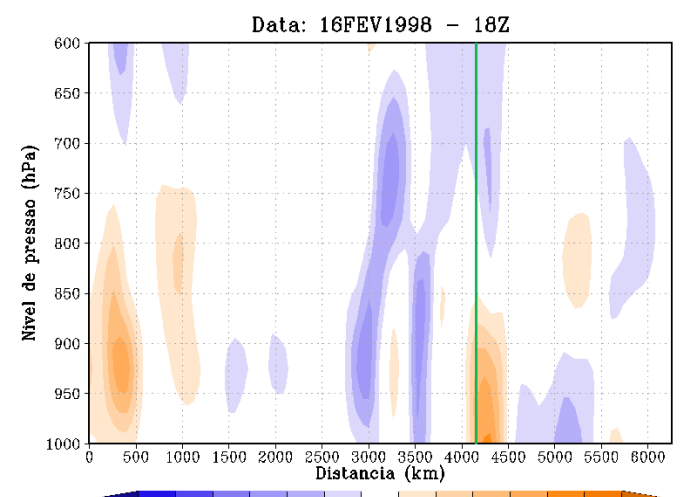

(b)

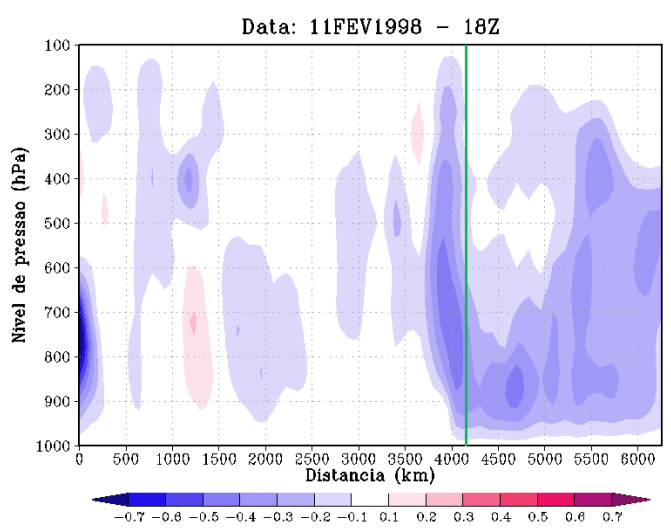

(d)

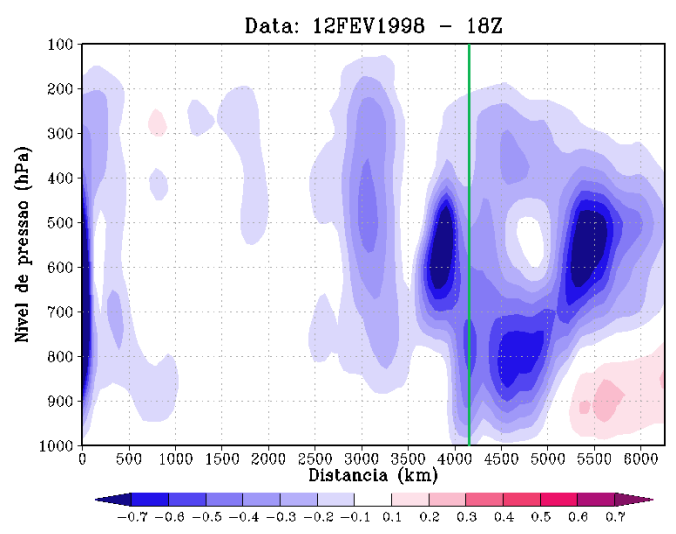

(f)

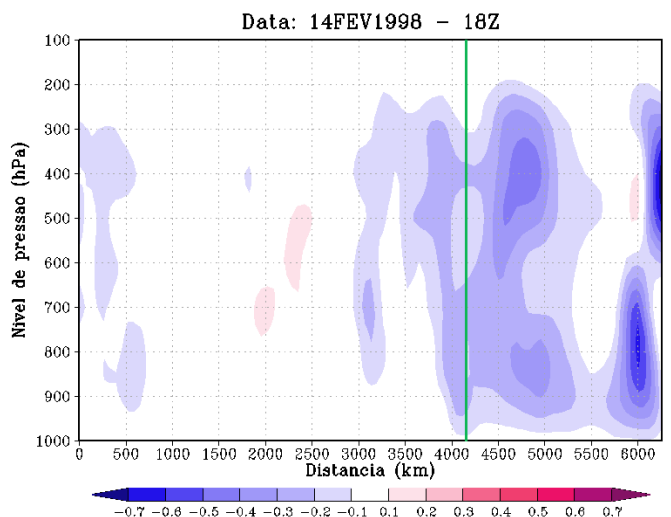

(h)

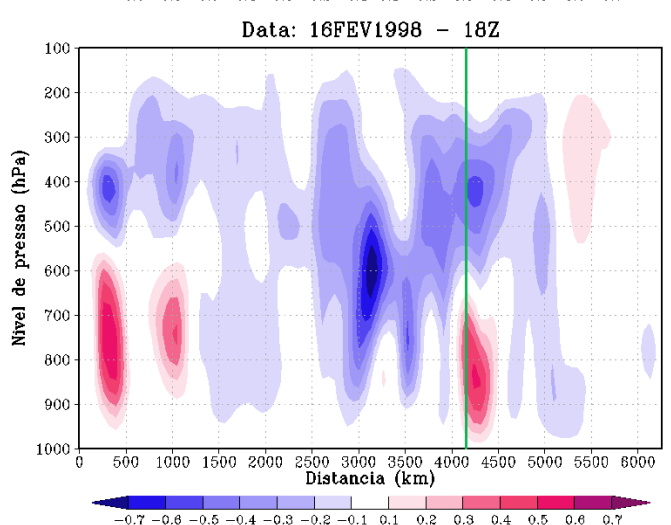

Figura 7. Seções verticais da divergência do fluxo horizontal de umidade (intervalo de $1 \times 10^{-4} \mathrm{~kg} \mathrm{~kg}^{-1.4} \mathrm{~s}^{-1.7}$ ) para as $18 \mathrm{Z}$ dos dias (a) 11/02/98, (c) 12/02/98, (e) 14/02/98 e (g) 16/02/98. Seções verticais da velocidade vertical omega (intervalo de $0,1 \times 10^{-2} \mathrm{hPa} \mathrm{s}^{-1}$ ) para as $18 \mathrm{Z}$ dos dias (b) $11 / 02 / 98$, (d) $12 / 02 / 98$, (f) $14 / 02 / 98$ e (h) 16/02/98. No eixo das abscissas está representada a distância em km, a partir do ponto mais ao norte, ao longo da linha tracejada em preto nas Figuras anteriores. A linha em verde representa, aproximadamente, o limite entre continente e oceano, que se localizam à esquerda e à direita da mesma, respectivamente. No eixo das ordenadas estão representados os níveis de pressão em hPa. 
Com relação às componentes horizontais do vento, na região continental há predominância de escoamento zonal de leste, principalmente nos altos níveis (Figura 8a). Na porção oceânica em toda coluna troposférica há escoamento zonal de oeste e meridional de norte (Figura 8b). Em baixos níveis este padrão de circulação está associado ao giro anticiclônico da ASAS, que traz umidade e ar quente das latitudes mais baixas para as latitudes médias, e em altos níveis a componente zonal de oeste está associada ao escoamento da corrente de jato.

No dia 12 (Figura 7c), observa-se convergência de umidade dos baixos aos médios níveis na região da costa sudeste. Há movimento ascendente intensificado ao longo da ZCAS nas suas porções oceânica e próxima à costa dos baixos aos níveis médios e movimento descendente em baixos níveis no Atlântico Sul (Figura 7d), este último associado à região sem nebulosidade (Figura 2b) e sem precipitação sobre o oceano ao longo da linha sobre a qual foi feita a seção vertical (Figura 3c). O padrão do escoamento horizontal (Figuras 8c e 8d) é semelhante ao do dia anterior, porém na porção oceânica observa-se vento de sul em baixos níveis. Com a aproximação do sistema frontal das latitudes mais baixas, o escoamento em baixos níveis torna-se de sul ao longo do corte vertical (Figura 4c).

A convergência do fluxo de umidade, promovida na zona de convergência, se concentra nos baixos níveis e mais sobre o oceano ainda no dia 14 (Figura 7e), à qual está associada a precipitação na região de ZCAS oceânica (Figura 3e) e onde há intensa nebulosidade (Figura 2c). Há alguma convergência de umidade (Figura 7e) associada aos outros dois núcleos de chuva ao longo da zona de convergência observados na Figura 3e, um sobre o sul de Minas Gerais e o outro na Amazônia. Ainda ocorre persistência do movimento ascendente dos níveis mais baixos aos níveis médios da troposfera sobre grande porção do oceano, onde a ZCAS continua ativa, com destaque para o núcleo mais intenso de precipitação sobre o Atlântico (Figura 3e), onde há velocidade vertical omega negativa intensa (Figura 7f). Na região desse 
núcleo de chuva observa-se convergência em níveis mais baixos (Figura 7e), já que o vórtice ciclônico promove convergência em superfície e consequente movimento ascendente nos níveis baixos e médios (Figura 7f), e divergência de massa na coluna em níveis mais altos (Figura 7e). A configuração do escoamento zonal (Figura 8e), no dia 14, se mantém, já o vento meridional (Figura 8f) no oceano é de norte, inclusive nos baixos níveis, isso se dá devido ao desenvolvimento do vórtice ciclônico (Figura 4e) na porção sul do Atlântico Sul e a certa deformação da ASAS.

Já no final do ciclo de vida da zona de convergência, no dia 16, a convergência do fluxo de umidade se desintensifica e se restringe a pontos localizados no Sudeste do Brasil e porções do Atlântico (Figura 7g), associada a uma extensa região de nebulosidade e precipitação (Figuras $2 \mathrm{~d}$ e $3 \mathrm{~g}$ ), relacionado a ela há também intenso movimento ascendente (Figura 7h). Ainda é possível observar que aproximadamente entre 600 e 500 hPa há o nível de não divergência (NND), pois abaixo e acima deste ponto há movimento subsidente e ascendente, respectivamente, em algumas regiões ao longo da seção vertical. Neste período é possível observar a permanência do escoamento de oeste nas latitudes médias (Figura 8g). A predominância de vento de componente norte na porção sul do Atlântico Sul diminui (Figura 8h), pois há descaracterização do vórtice ciclônico já mencionado e deformação da ASAS novamente (Figura 4h), fazendo com que a componente meridional desintensifique. 
(a)

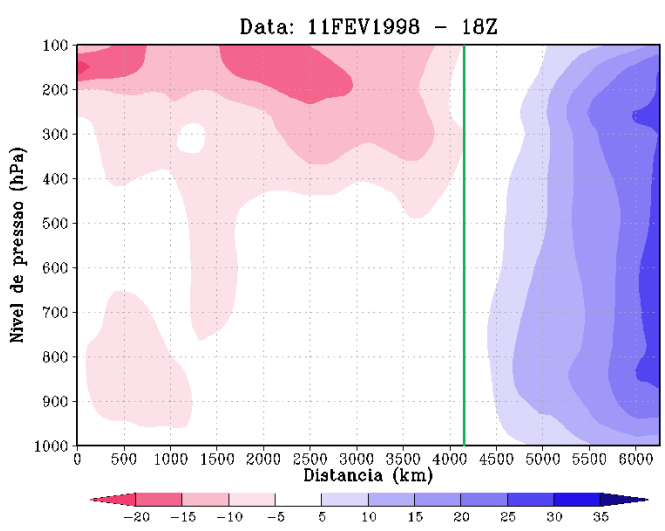

(c)

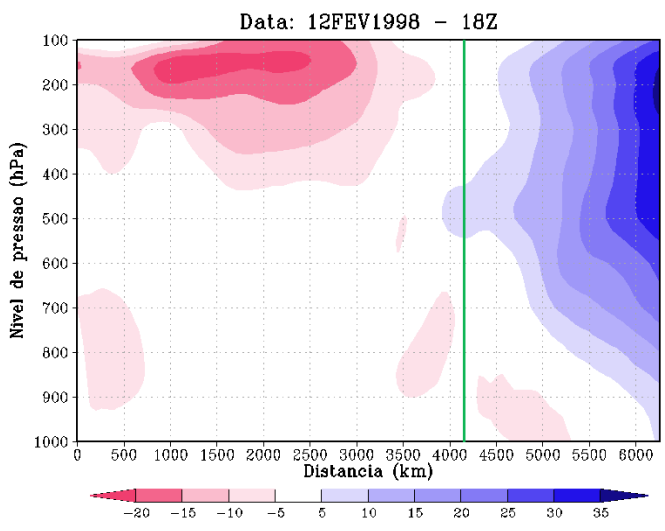

(e)

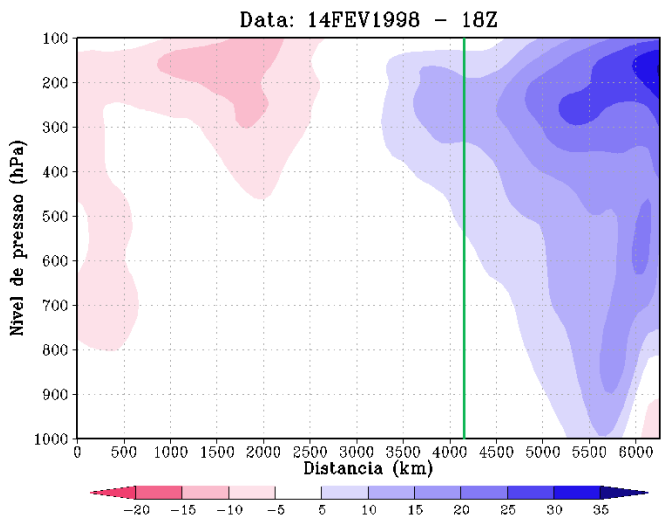

(g)

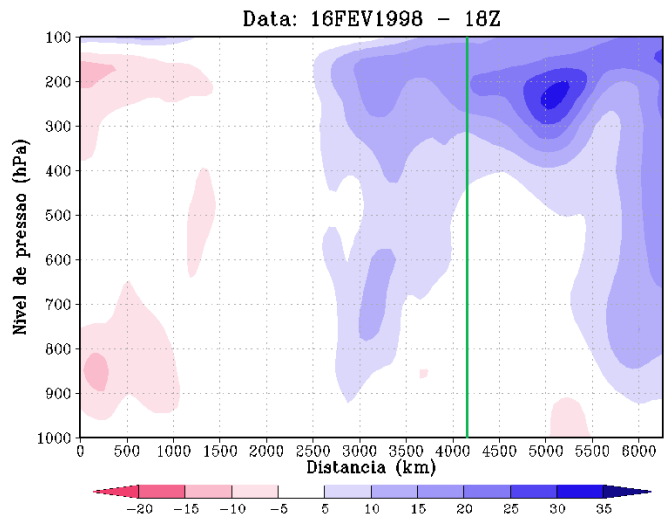

(b)

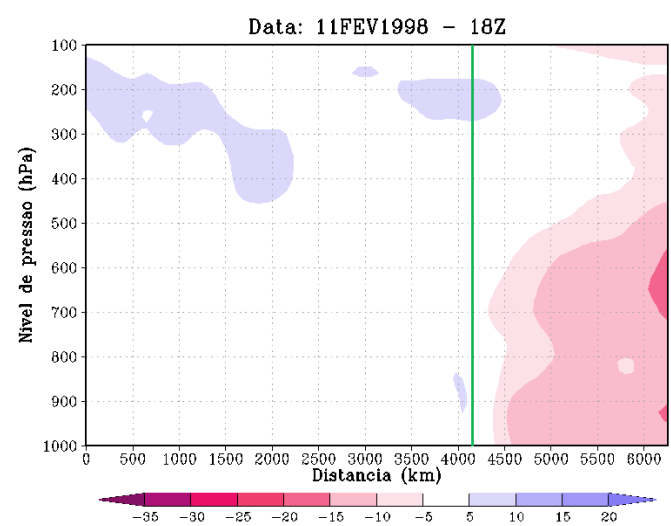

(d)

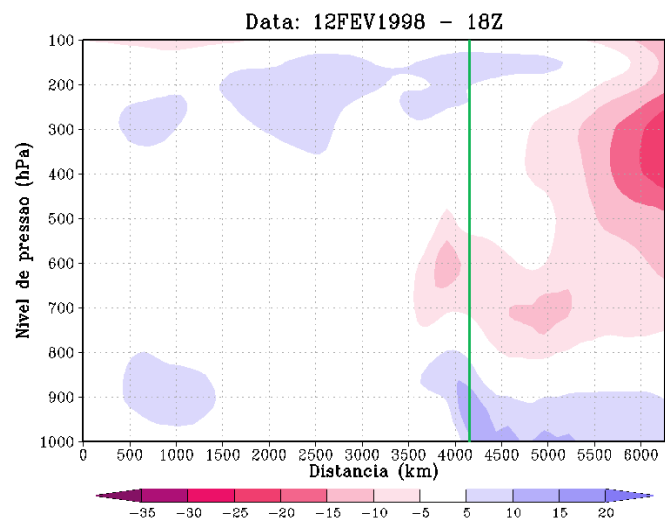

(f)

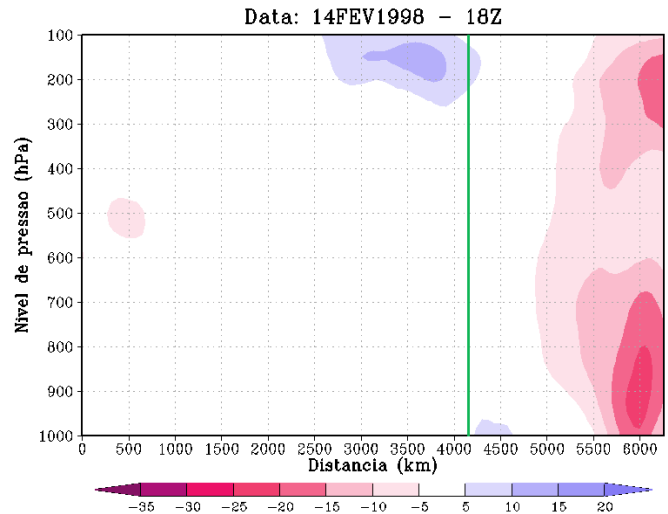

(h)

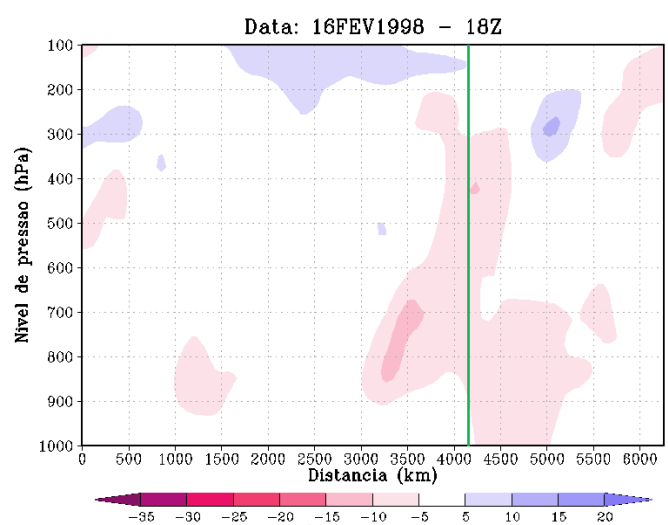

Figura 8. Idem à Figura 7 mas para as componentes zonal (intervalo de $5 \mathrm{~m} \mathrm{~s}^{-1}$ ) (a, c, e, g) e meridional (intervalo de $\left.5 \mathrm{~m} \mathrm{~s}^{-1}\right)(\mathrm{b}, \mathrm{d}, \mathrm{f}, \mathrm{h})$ do vento. 


\subsection{ZCAS-99}

\subsubsection{Baixos níveis}

Observa-se a partir da imagem de satélite, já no dia 6 de janeiro de 1999 (Figura 9a), um padrão de nebulosidade típico da ZCAS se estendendo na direção noroeste-sudeste. Nota-se também nebulosidade com curvatura em formato de S clássica, como descrito em Kousky e Gan (1981), que caracteriza um Vórtice Ciclônico de Altos Níveis tropical, atuante sobre o NEB e Atlântico tropical. Este VCAN apresenta núcleo livre de nuvens, já que a maioria dos VCAN's é caracterizada por subsidência nessa região, segundo os últimos autores. O VCAN tropical é uma estrutura associada ao escoamento do $\mathrm{CN}$, cuja persistência é característica durante episódios de ZCAS, se desenvolvendo a partir da intensificação da crista em 200 hPa a sudeste da $\mathrm{AB}$ corrente abaixo e do $\mathrm{CN}$ sobre o oceano. A nebulosidade se apresenta intensa e bem distribuída ao longo de toda ZCAS, desde o Brasil central até o Atlântico Sul. Há intensos núcleos de precipitação ao longo de toda zona de convergência logo no início de seu desenvolvimento (Figura 10a), com destaque para o Atlântico Sul e para um núcleo entre os estados de São Paulo e Minas Gerais, que abrangem áreas extensas e nos quais a quantidade de precipitação acumulada é elevada. Observa-se também precipitação associada ao VCAN no Atlântico tropical, principalmente ao longo de sua porção oeste, onde normalmente há atividade convectiva intensa quando o vórtice se desloca de leste para oeste (KOUSKY; GAN, 1981).

Há forte convergência do fluxo horizontal de umidade no Atlântico Sul (Figura 10b) e também intensa convergência no Sudeste do Brasil, na Zona de Convergência Intertropical (ZCIT) e no sul do Maranhão, esta última associada ao VCAN. Nos lados equatorial e polar da ZCAS há divergência de umidade. 
(a)

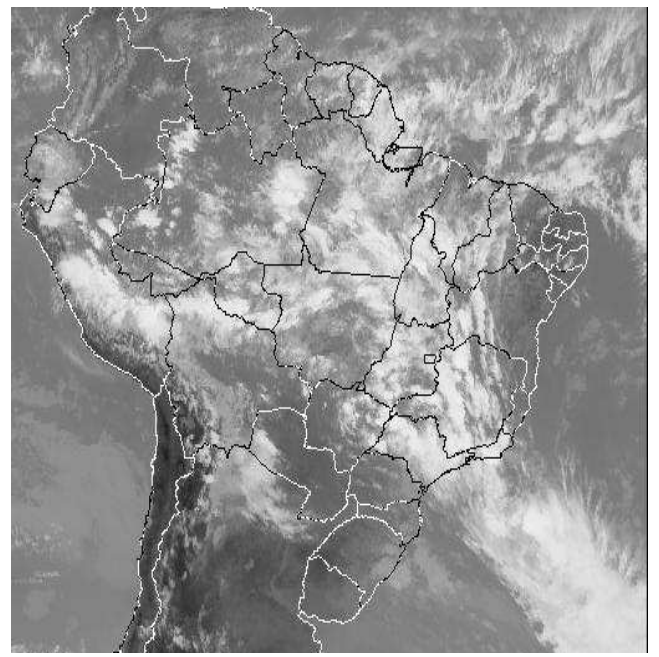

(c)

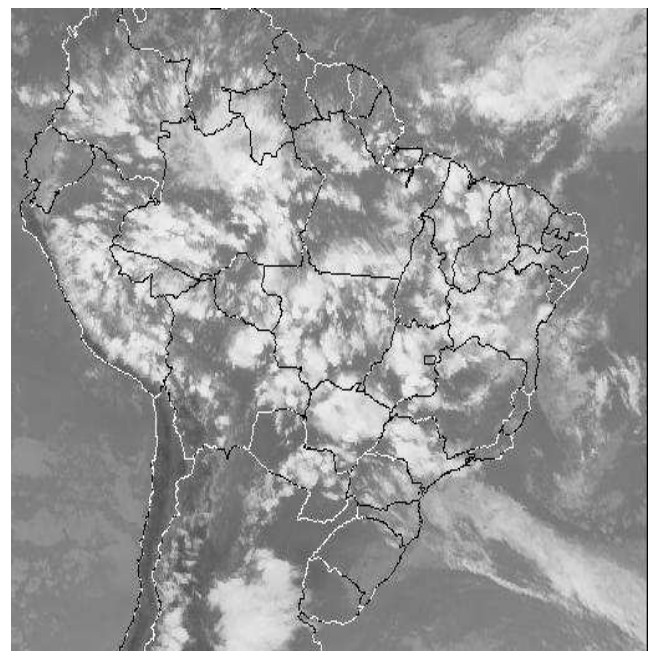

(b)

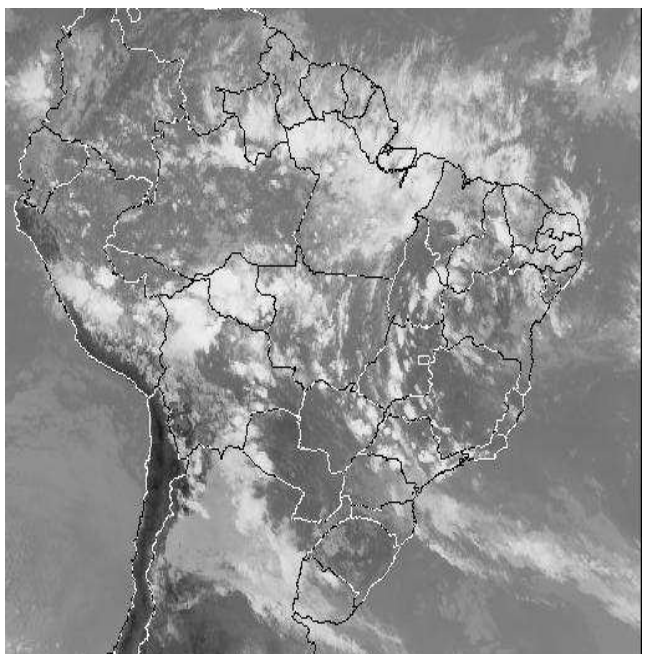

(d)

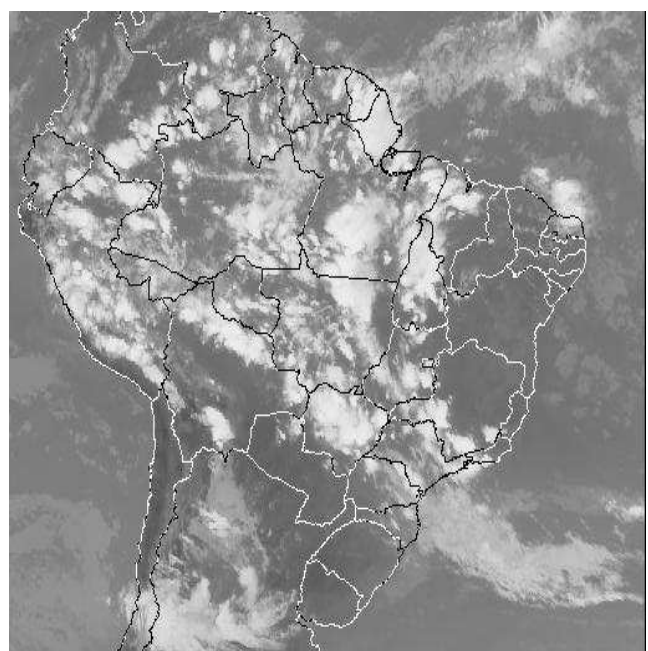

Figura 9. Imagens do satélite GOES-8 no canal do infravermelho para os dias (a) 06/01/99 às 18Z, (b) 09/01/99 às 18Z, (c) 12/01/99 às $21 \mathrm{Z}$ e (d) 17/01/99 às 21Z. Fonte: DSA/INPE.

Na Figura 11a observa-se a convergência do escoamento horizontal orientada na direção noroeste-sudeste. Ao longo da ZCAS oceânica identifica-se a fronteira entre o ar mais frio das latitudes mais altas e o mais quente das regiões tropicais, o que caracteriza um sistema frontal. Ao longo da porção continental da zona de convergência (aproximadamente ao longo da linha tracejada) a temperatura do ar em baixos níveis é menor relativamente às regiões adjacentes (lados equatorial e polar), pois a nebulosidade associada à ZCAS faz com que chegue menor quantidade de radiação solar à superfície para aquecê-la. A precipitação também desempenha um papel importante no abaixamento da temperatura em baixos níveis, visto que umedece o 
solo, fazendo com que mais radiação seja utilizada para evaporar a água da superfície do que para aquecer o ar adjacente.

Na Figura 11b, distingue-se o importante papel da ASAS de transportar umidade do Atlântico em direção à zona de convergência. Na região equatorial os alísios transportam umidade do oceano para o continente, adentrando o último pelas costas norte e nordeste. Assim como no caso ZCAS-98, é possível identificar que a zona de convergência se localiza no limite polar da massa tropical úmida com intenso gradiente de umidade, conforme Ninomiya (2007). Há destaque para um núcleo sobre Rondônia com intensa quantidade de umidade e para a região periférica oeste do VCAN (Figura 11b), onde também há maior quantidade de umidade, que se associa ao sistema frontal das latitudes mais altas.

No dia 9 de janeiro, nota-se que a nebulosidade associada à zona de convergência se desintensifica (Figura 9b), sendo que a orientação da ZCAS oceânica se torna mais zonal. Entretanto, sobre as costas norte e nordeste do Brasil, por onde os alísios penetram no continente transportando umidade proveniente do oceano Atlântico tropical, há intensa nebulosidade associada à ZCIT. A precipitação associada à ZCAS neste estágio do sistema é menos intensa do que no seu início (Figura 10c). A zona de convergência é predominantemente continental, havendo núcleos mais intensos de precipitação no oeste do estado de São Paulo, Mato Grosso, Rondônia e Bolívia. Há destaque para a costa norte e região Norte do Brasil, onde há grande quantidade de precipitação acumulada, associada à nebulosidade identificada na Figura 9b. A partir do campo de divergência de umidade (Figura 10d), identifica-se majoritariamente convergência na costa norte do Brasil e divergência ao sul do Atlântico Sul, desta forma a precipitação é intensa no Atlântico equatorial e não há precipitação acumulada na porção oceânica da ZCAS. 
(a)

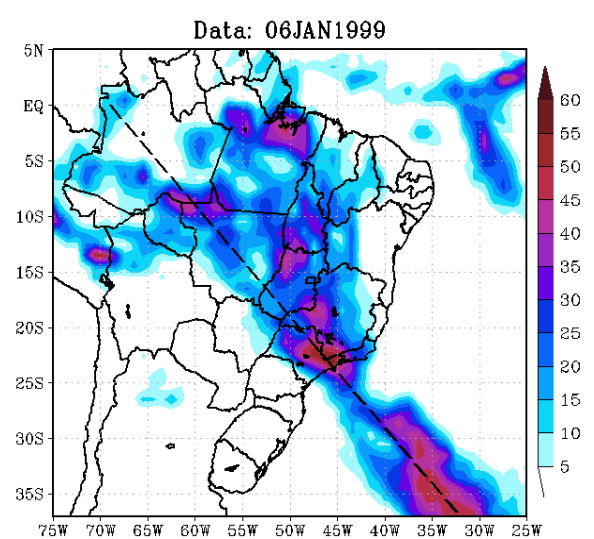

(c)

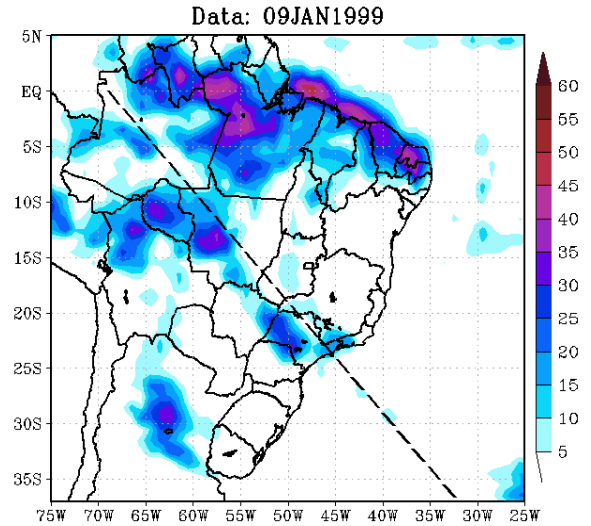

(e)

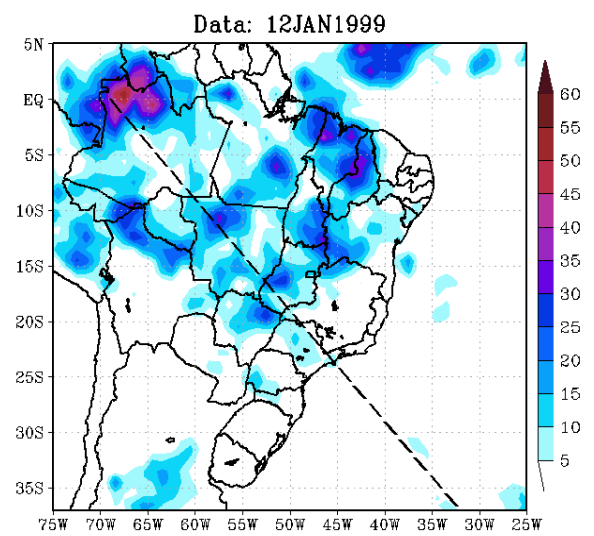

$(\mathrm{g})$

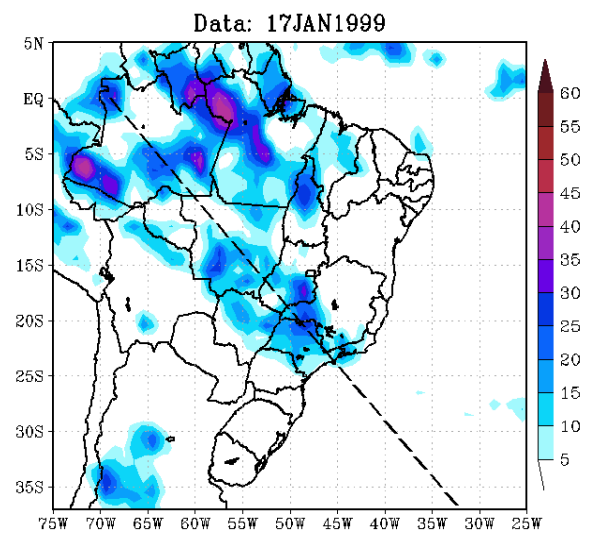

(b)

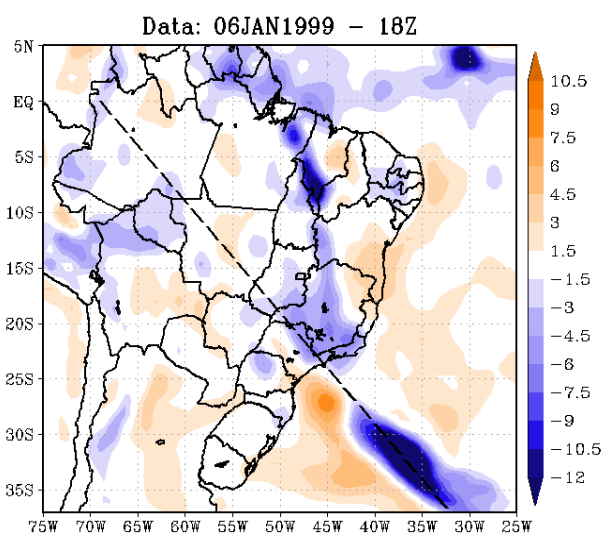

(d)

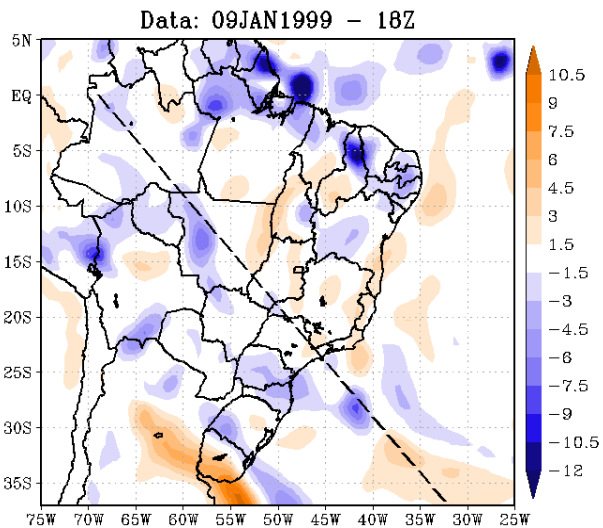

(f)

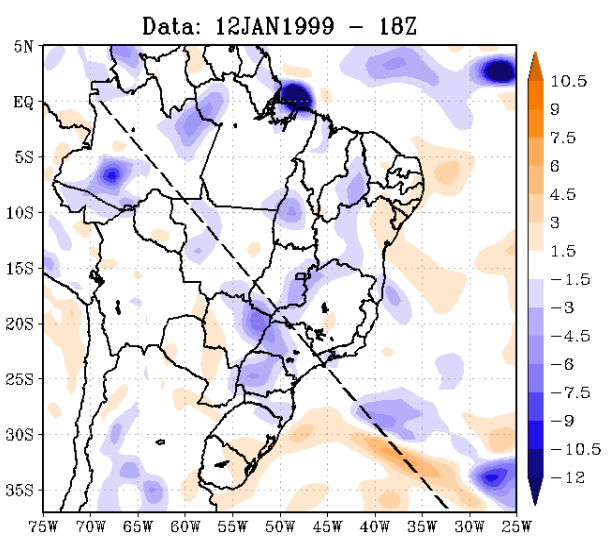

(h)

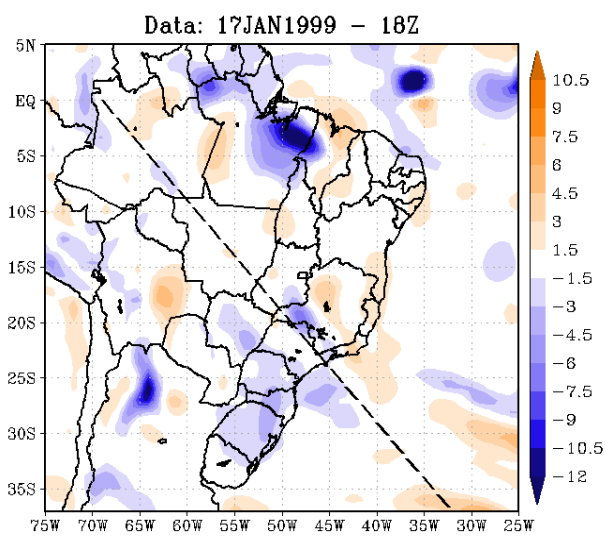

Figura 10. Precipitação diária acumulada pelo GPI (intervalo de $5 \mathrm{~mm} \mathrm{dia}^{-1}$ ) nos dias (a) 06/01/99, (c) 09/01/99, (e) 12/01/99 e (g) 17/01/99. Divergência do fluxo horizontal de umidade integrado na atmosfera, da pressão reduzida ao nível médio do mar ao nível de $100 \mathrm{hPa}$ (intervalo de $1,5 \times 10^{-4} \mathrm{~kg} \mathrm{~kg}^{-1} \mathrm{~s}^{-1}$ ), para as $18 \mathrm{Z}$ dos dias (b) 06/01/99, (d) 09/01/99, (f) 12/01/99 e (h) 17/01/99. O tracejado em preto representa a localização das seções verticais das Figuras 14 e 15. 
(a)

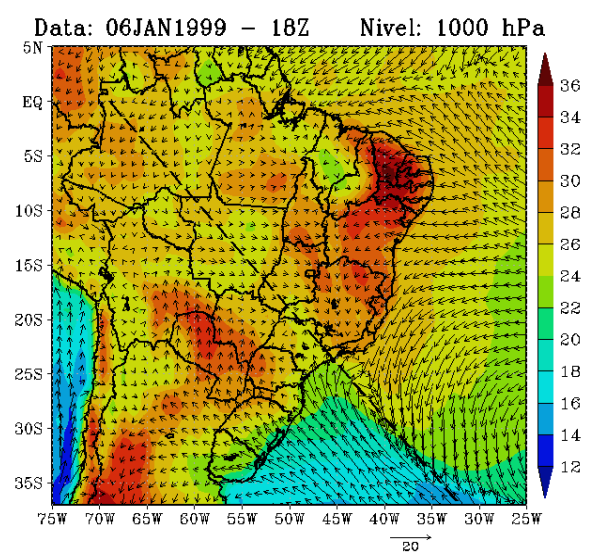

(c)

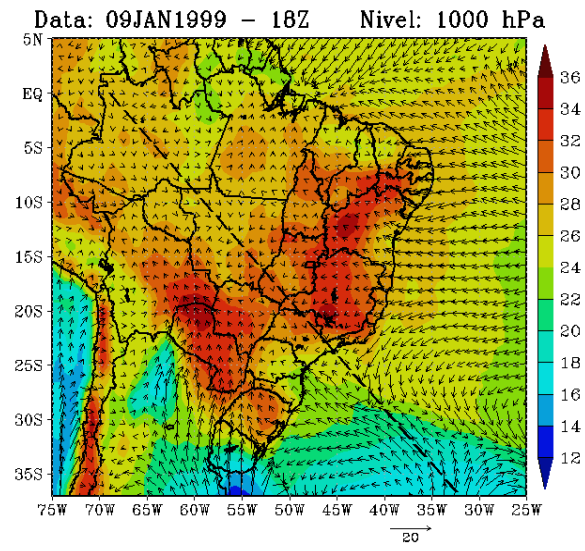

(e)

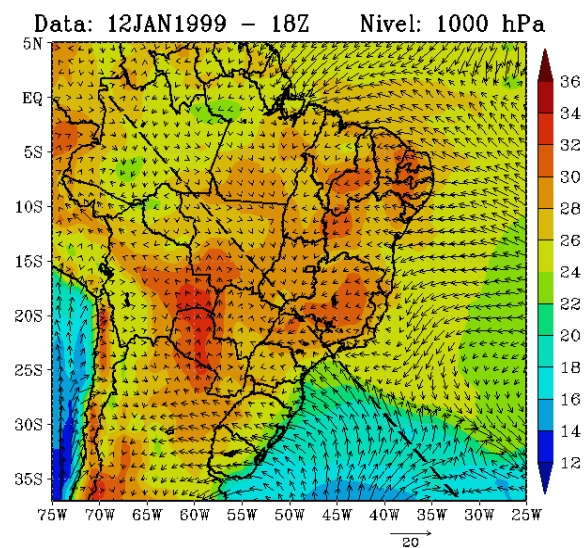

(g)

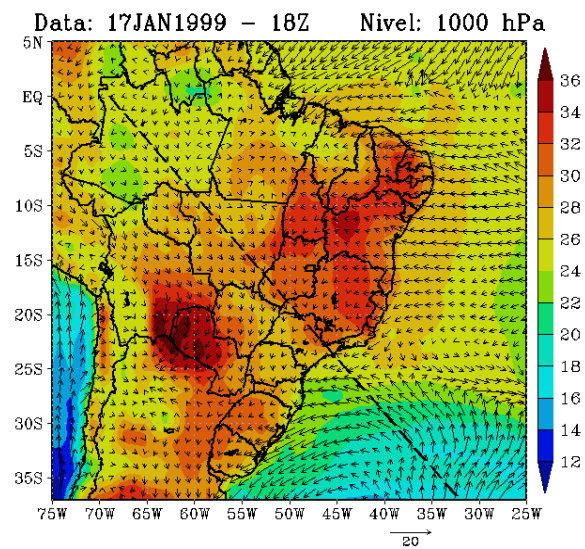

(b)

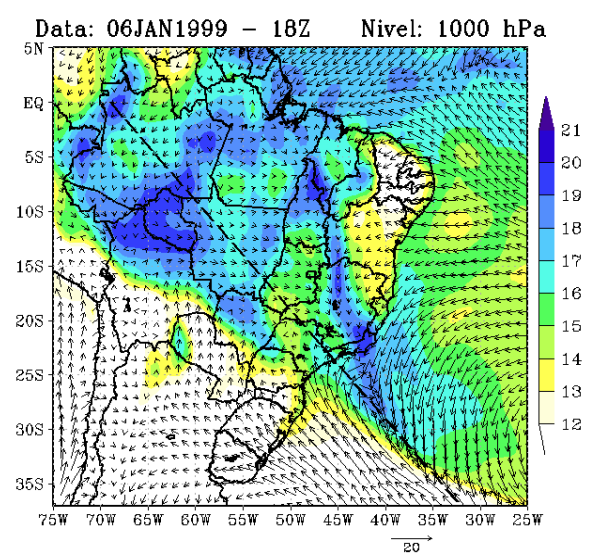

(d)

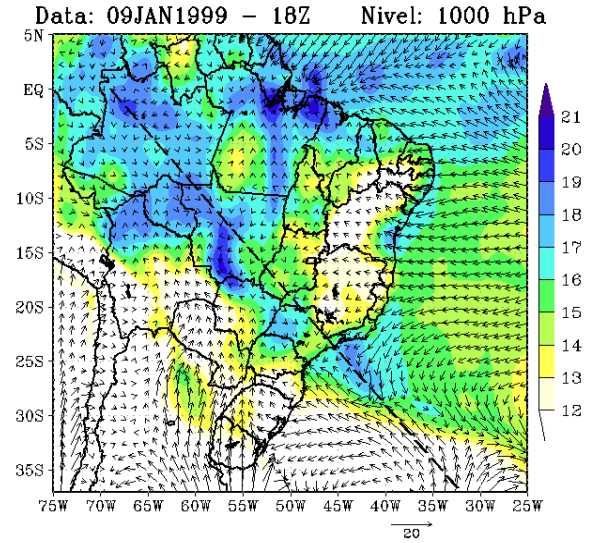

(f)

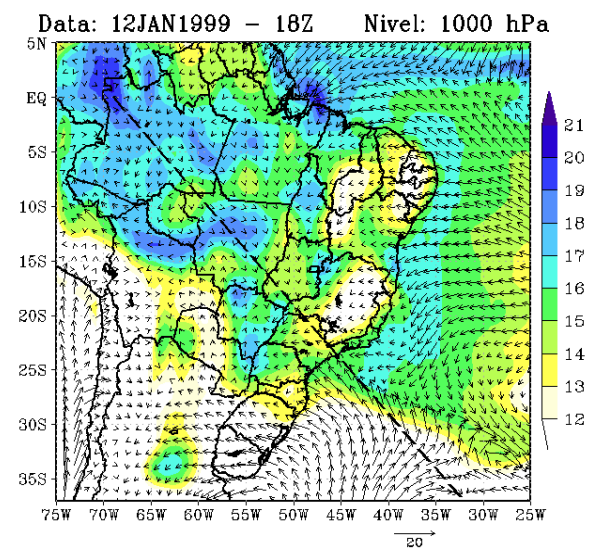

(h)

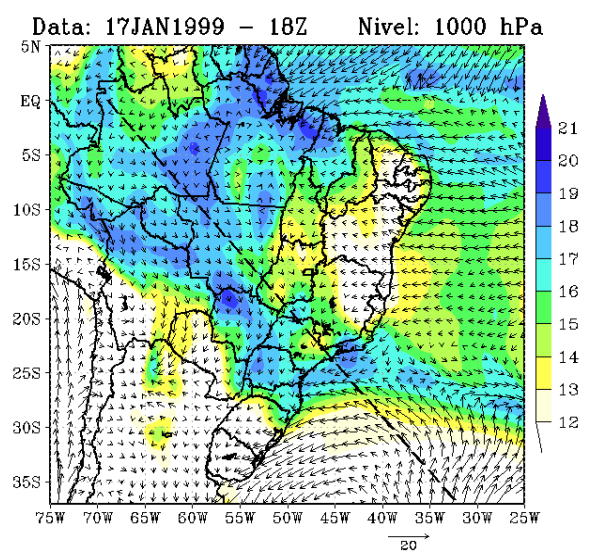

Figura 11. Idem à Figura 10 mas para escoamento horizontal $\left(\mathrm{m} \mathrm{s}^{-1}\right)$ e temperatura do ar (sombreado com intervalo de $\left.2{ }^{\circ} \mathrm{C}\right)$ em $1000 \mathrm{hPa}(\mathrm{a}, \mathrm{c}, \mathrm{e}, \mathrm{g})$ e para escoamento horizontal $\left(\mathrm{m} \mathrm{s}^{-1}\right)$ e umidade específica (sombreado com intervalo de $1 \mathrm{~g} \mathrm{~kg}^{-1}$ ) em $1000 \mathrm{hPa}(\mathrm{b}, \mathrm{d}, \mathrm{f}, \mathrm{h}$ ). 
A partir do campo de escoamento horizontal (Figura 11c), observa-se que a convergência em baixos níveis se desintensifica sobre o Atlântico Sul neste estágio do sistema. Há descaracterização da zona de convergência e o aporte de umidade para a ZCAS também se desintensifica (Figura 11d). A quantidade de umidade a oeste do VCAN também diminui com relação ao início do desenvolvimento da ZCAS no dia 6. Ocorre deformação da ASAS (Figuras 11c e 11d), sendo que seu escoamento se torna mais zonal transportando menos umidade do oceano para a ZCAS. Observa-se convergência do escoamento, à qual há intensa nebulosidade e precipitação associadas, na região da Ilha de Marajó.

A partir do campo de temperatura do ar (Figura 11c) identifica-se que o sistema frontal se tornou mais zonal, pois a fronteira entre o ar mais quente proveniente das regiões equatoriais e o ar mais frio das porções polares se apresenta mais zonalmente. Desta forma, o VCAN já não apresenta claramente a configuração clássica de $S$ neste estágio (Figura 9b), pois já não está mais tão combinado à nebulosidade associada à frente fria. Na região do Chaco, observam-se temperaturas mais elevadas com relação ao dia 6. Nesta região (Figura 11c), o intenso aquecimento superficial do altiplano boliviano e a intensificação da convecção sobre a Amazônia contribuem para a intensificação de um ciclone térmico à superfície (Baixa do Chaco), conforme Andrade (2007). Na região da ZCAS, predominantemente continental, observam-se ainda as temperaturas mais frias com relação às regiões vizinhas, como no dia 6 de janeiro. Identifica-se ainda uma correspondência entre as regiões mais secas (Figura 11d) e mais quentes (Figura 11c).

No dia 12 de janeiro, observa-se certa intensificação da nebulosidade na região de ZCAS oceânica (Figura 9c) com relação ao dia 9, no entanto menos intensa do que no dia 6. Sobre o continente, observa-se nebulosidade bem distribuída, principalmente sobre todo Brasil, e no Atlântico tropical a nebulosidade está associada à ZCIT. No Brasil central e noroeste da América do Sul encontram-se alguns núcleos de precipitação mais intensa (Figura 10e) 
associados à nebulosidade observada nessas regiões, com destaque para o noroeste do Amazonas. A partir do campo de precipitação nota-se que a zona de convergência se descaracteriza neste estágio, tornando-se mais continental e não apresentando configuração noroeste-sudeste típica (Figura 10e). No Atlântico Sul não é observada quantidade significativa de precipitação acumulada, já que as nuvens identificadas na Figura 9c sobre essa região são mais baixas, portanto estratiformes.

As regiões com convergência de umidade mais intensa (Figura 10f) são a ZCIT e uma porção oceânica próxima à Ilha de Marajó. No Atlântico Sul há destaque para o sul do Atlântico Sul aproximadamente em $33^{\circ} \mathrm{S}$ e entre $25^{\circ} \mathrm{W}$ e $30^{\circ} \mathrm{W}$, nesta região há convergência de umidade e observa-se certa circulação ciclônica na Figura 11e, porém não há grande quantidade de precipitação associada (Figura 10e). Essa circulação ciclônica em superfície caracteriza o núcleo de baixa pressão associado ao escoamento do cavado em altos níveis (Figura 13c). Ainda no Atlântico Sul ocorre divergência de umidade (Figura 10f) na região onde se observava convergência intensa de umidade logo no início do estabelecimento do sistema (dia 6), desta forma a ZCAS sobre o oceano se enfraquece com relação ao dia 6 . No Brasil central há convergência de umidade ao longo do interior das Regiões Nordeste, Sudeste e Centro-Oeste, nessas regiões há núcleos de precipitação associada apresentados na Figura 10e.

Com relação ao dia 9, a ZCAS se apresenta mais característica, a convergência do vento em baixos níveis volta a se apresentar mais claramente sobre o Atlântico Sul neste estágio (Figura 11e). Há diminuição da temperatura em 1000 hPa no interior do Nordeste e Sudeste do Brasil e na região do Chaco (Figura 11e) no dia 12. O abaixamento da temperatura nesta última região pode caracterizar uma desintensificação da Baixa do Chaco, o que, por sua vez, pode representar também a desintensificação da Alta da Bolívia, cuja intensidade está intimamente ligada à desse ciclone térmico à superfície, segundo Andrade (2007). A 
desintensificação da $\mathrm{AB}$ pode significar o enfraquecimento da ZCAS, pois a primeira é uma estrutura à qual os sistemas frontais que penetram na América do Sul se associam e permanecem semi-estacionários, amplificando a atividade convectiva na região e assim gerando a ZCAS, de acordo com Molion, Bernardo e Oliveira (2004). Neste dia, a frente fria penetra mais nas latitudes mais baixas. Quanto à umidade (Figura 11f), não são observadas alterações significativas com relação ao dia 9, apenas destaca-se que há menor quantidade de umidade na região da ZCAS próximo à costa de São Paulo e do Rio de Janeiro.

No dia 17 de janeiro a ZCAS está no final de seu ciclo de vida, porém a nebulosidade associada a ela ainda se mantém na configuração típica, isto é, na direção noroeste-sudeste (Figura 9d). Sobre o continente ainda há nebulosidade intensa e sobre o Atlântico Sul a ZCAS se mantém mais zonal. A ZCIT se apresenta menos intensa neste dia. No Atlântico Sul não há precipitação acumulada significativa no dia 17 (Figura 10g). A ZCAS em quase todo seu ciclo de vida se apresentou majoritariamente continental (Figuras 10c, 10e e 10g), como esperado durante anos de La Niña (fase fria no ENOS), e assim como proposto por Carvalho, Jones e Liebmann (2004). Observam-se alguns núcleos de precipitação mais intensa sobre a região norte do Brasil e outros menos intensos no Brasil central. A convergência de umidade é mais intensa no nordeste do Pará e no Atlântico tropical (Figura 10h). Na região da ZCAS já não ocorre mais convergência significativa.

Através do campo de escoamento horizontal (Figuras 11g e 11h), observa-se que a zona convergência se desintensifica novamente, tornando-se novamente mais zonal. O escoamento da ASAS se apresenta bem zonal e se desintensifica, assim o aporte de umidade realizado por essa estrutura para a região da ZCAS deve diminuir. As temperaturas na região do Chaco e no interior do Nordeste e Sudeste do Brasil se elevam (Figura 11g) com relação ao dia 12. A fronteira entre ar quente dos trópicos e ar mais frio dos polos se encontra mais a leste no Atlântico Sul, assim o último sistema frontal que passou pela região já se deslocou para o 
oceano neste período. Na região da ZCAS sobre o continente as temperaturas se apresentam menores com relação às regiões vizinhas, conforme já discutido. Observa-se secamento no interior do Nordeste e na região do Chaco (Figura 11h) com relação ao dia 12, associado ao aumento da temperatura nessas regiões (Figura 11g). Na costa da Bahia observa-se menos umidade disponível para ser transportada pela ASAS com relação aos demais dias. Portanto, considerando as condições em baixos níveis, havendo menos umidade disponível, com a ASAS desintensificada e o sistema frontal deslocado para o oceano, a ZCAS está em fase de enfraquecimento e deve se dissipar completamente no dia 18 de janeiro (não mostrado).

\subsubsection{Níveis médios}

No dia 6, observa-se um cavado sobre o Sul do Brasil, cujo eixo possui inclinação para oeste (Figuras 12a e 12b). Também é possível identificar a assinatura da ASAS sobre o Atlântico, sendo que o escoamento em sua porção sudoeste é mais intenso do que no restante, já que é fortalecido pelo escoamento de oeste em níveis médios. É possível identificar a circulação ciclônica do VCAN próxima à costa do NEB também no nível de 500 hPa a partir da Figura 12a.

No dia 9 de janeiro, nota-se que ocorre desintensificação do cavado de latitudes médias (Figura 12c) e que a ASAS sofre certa deformação se alongando mais para oeste (Figura 12d). O escoamento ao longo da ZCAS oceânica se enfraquece então, resultando na desintensificação da zona de convergência sobre o Atlântico, assim como observado nas Figuras 9b, 10c, 10d, 11c e 11d. É também possível identificar a assinatura ciclônica do VCAN sobre o NEB em 500 hPa (Figura 12c). 
(a)

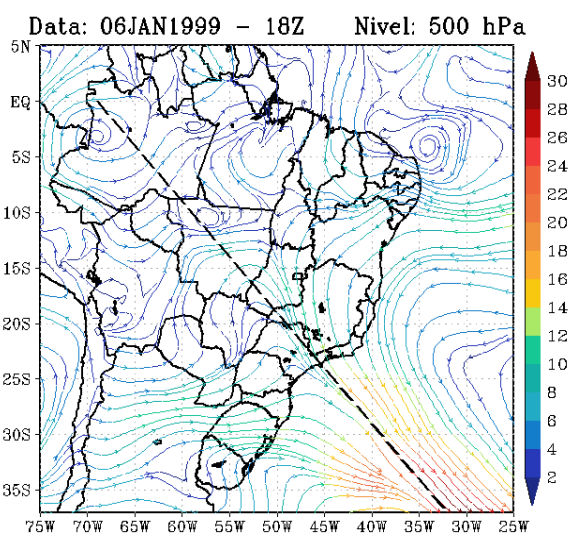

(c)

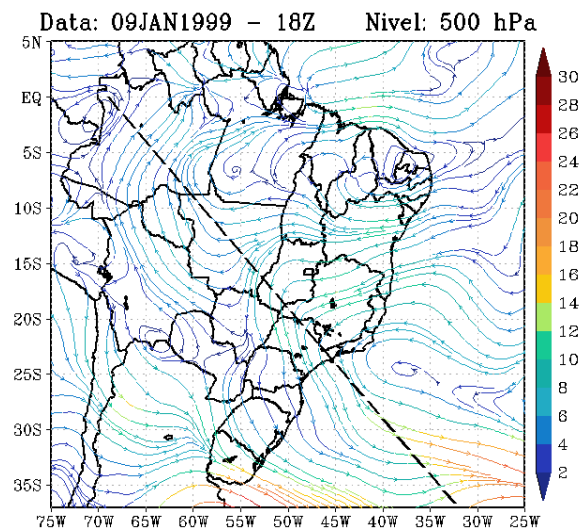

(e)

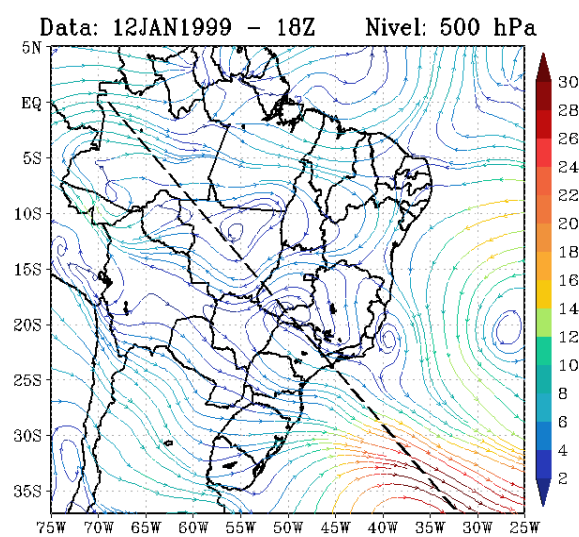

$(\mathrm{g})$

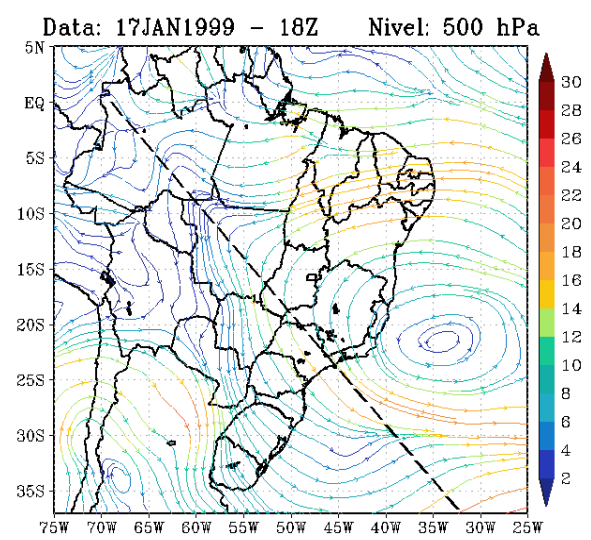

(b)

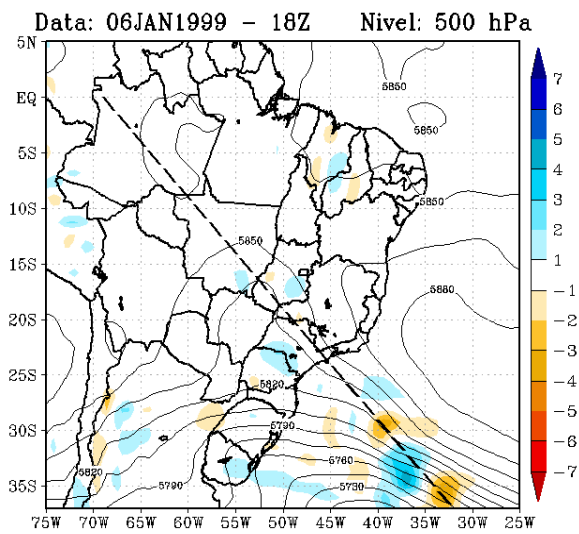

(d)

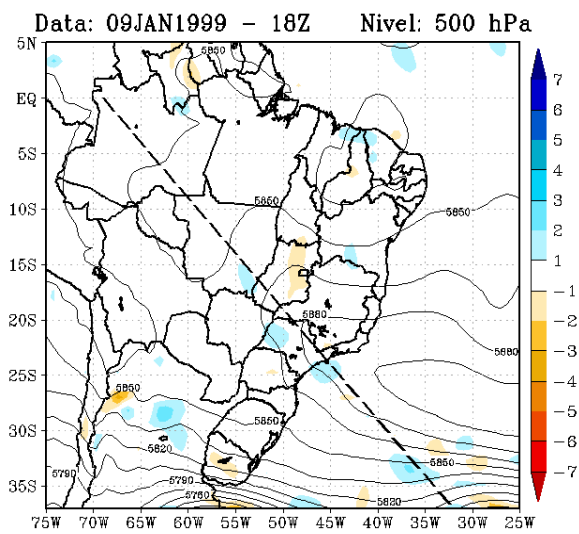

(f)

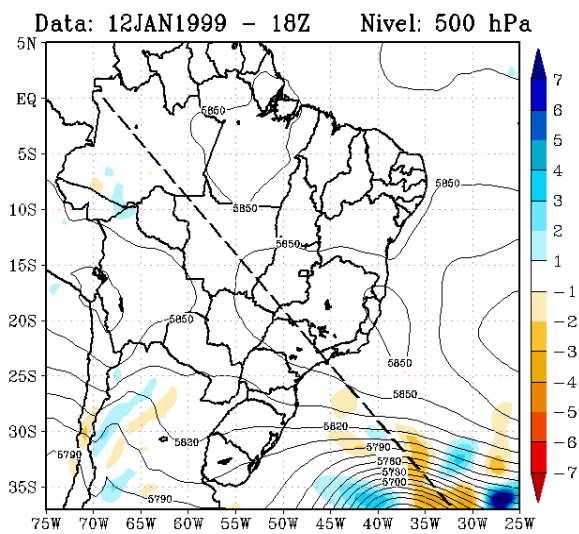

(h)

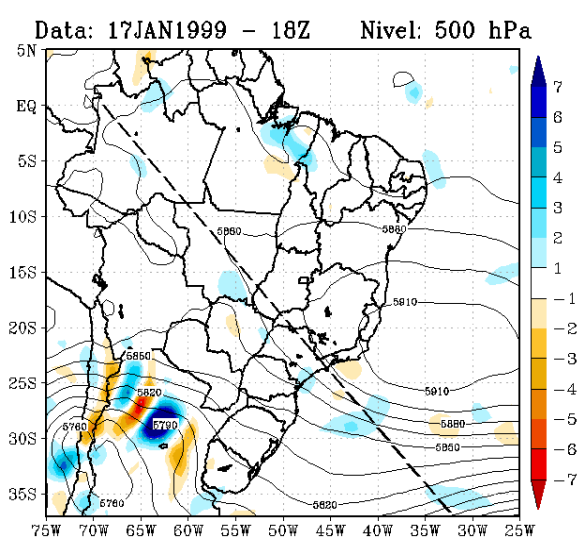

Figura 12. Idem à Figura 10 mas para linhas de corrente e magnitude do escoamento horizontal (intervalo de 2 $\mathrm{m} \mathrm{s}^{-1}$ ) em $500 \mathrm{hPa}(\mathrm{a}, \mathrm{c}, \mathrm{e}, \mathrm{g})$ e para altura geopotencial (contorno com intervalo de $15 \mathrm{~m}$ ) e advecção de vorticidade relativa (sombreado com intervalo de $1 \times 10^{-9} \mathrm{~s}^{-2}$ ) em $500 \mathrm{hPa}(\mathrm{b}, \mathrm{d}, \mathrm{f}, \mathrm{h})$. 
Já no dia 12 observa-se aproximação de um novo cavado, com inclinação do eixo para oeste, da região da zona de convergência (Figura 12e). A ASAS se desloca mais para o oceano e se intensifica com relação ao dia 9 de janeiro. A leste do cavado observa-se advecção de vorticidade ciclônica, mais a oeste há uma região de advecção de vorticidade anticiclônica (Figura 12f), o que indica que a tendência do sistema de cristas e cavados é se deslocar para leste.

No final do ciclo de vida da ZCAS, observa-se que o cavado de latitudes médias já se deslocou em direção ao oceano (Figuras 12g e 12h), assim o sistema frontal já está em estágio de dissipação não havendo mais o suporte da frente fria para a manutenção da zona de convergência. A ASAS se apresenta mais alongada em direção à costa do Brasil (Figura 12g) e sobre o norte da Argentina há um novo cavado se aproximando do Sul do Brasil, a leste do qual há nebulosidade associada (Figura 9d).

\subsubsection{Altos níveis}

Já no dia 6 de janeiro, observa-se a assinatura do CN bem acentuada com circulação ciclônica fechada (VCAN) e centro sobre as costas da Paraíba e de Pernambuco (Figura 13a). Do lado equatorial do jato subtropical a ZCAS deve se desenvolver, segundo Kodama (1992, 1993), sendo que o núcleo do jato em altos níveis encontra-se do lado leste do cavado de latitudes médias. Observa-se também uma região extensa de escoamento anticiclônico centrada sobre o sul de Minas Gerais.

No dia 9 observa-se outro cavado, cujo escoamento é menos intenso do que o associado ao cavado anterior, se aproximando da região de atuação da zona de convergência (Figura 
13b). Diante da passagem do sistema frontal, a ZCAS sofre enfraquecimento, entretanto o novo sistema frontal se aproxima da região de atuação do sistema e deve se associar à $A B$, fortalecendo então a ZCAS nos próximos dias. O VCAN, embebido no escoamento do CN se apresenta sobre o continente, centrado sobre o interior do NEB (Figura 13b), tendo se deslocado para sudoeste com relação ao dia 6. O deslocamento do VCAN se deu na forma preferencial deste tipo de sistema, que é no sentido leste-oeste após ter se formado sobre o Atlântico. Observa-se também circulação anticiclônica centrada sobre o oeste do Mato Grosso, que nos próximos dias deverá evoluir para uma circulação anticiclônica fechada em altos níveis, a Alta da Bolívia.

(a)

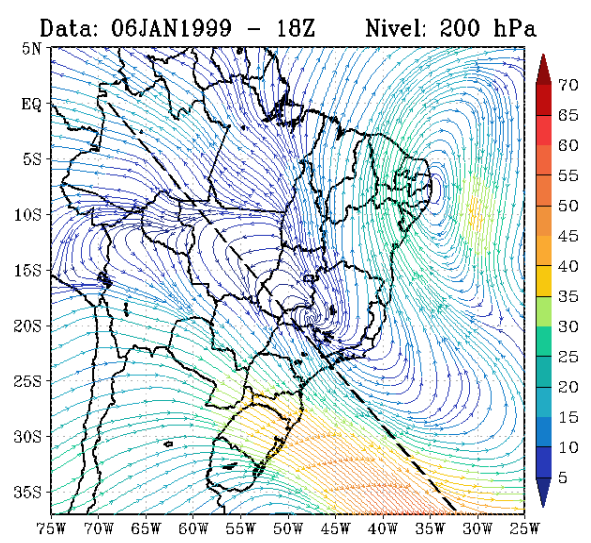

(c)

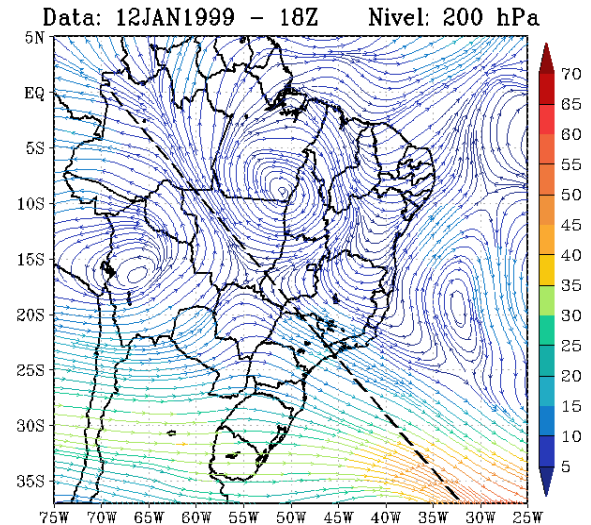

(b)

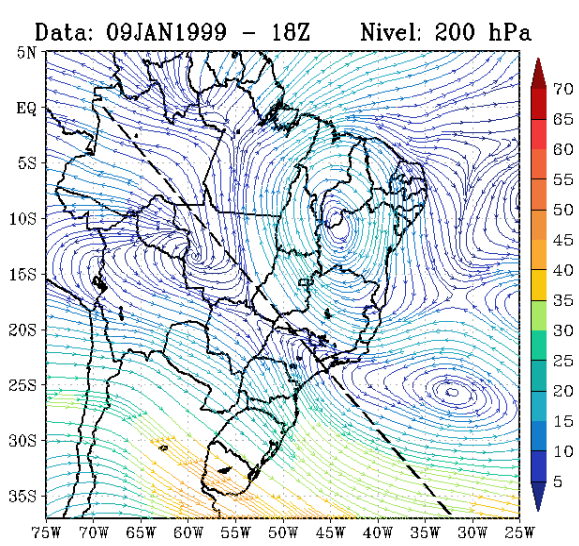

(d)

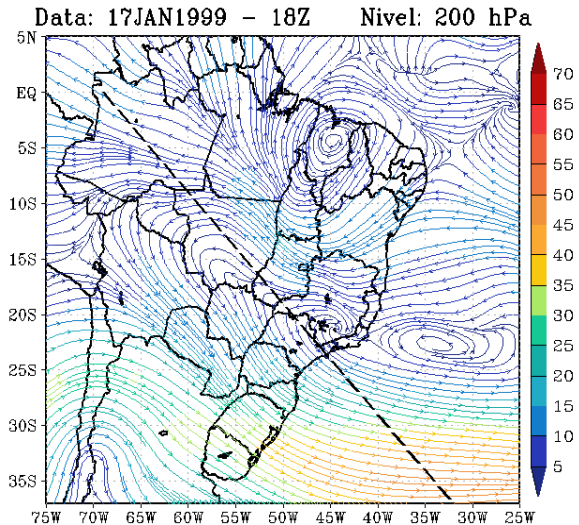

Figura 13. Idem à Figura 10 mas para linhas de corrente e magnitude do escoamento horizontal (intervalo de 5 $\mathrm{m} \mathrm{s}^{-1}$ ) em $200 \mathrm{hPa}$. 
No dia 12 o escoamento associado à corrente de jato se torna mais zonal (Figura 13c). O lado leste do cavado em altos níveis, ao qual está associado um sistema frontal em baixos níveis, se encontra sobre a área em que atua a zona de convergência. A AB apresenta circulação mais fechada e centrada sobre a Bolívia, e o VCAN, embebido no escoamento do $\mathrm{CN}$, encontra-se sobre o continente, com centro no sudeste do Pará. O mecanismo AB-CN é padrão de circulação típico na região do SMAS durante o verão.

Já no final do ciclo de vida da ZCAS, o sistema frontal se deslocou em direção ao oceano e observa-se outro cavado se aproximando do oeste da Argentina (Figura 13d). O escoamento em altos níveis sobre o Atlântico Sul se apresenta mais zonalmente. Sobre o NEB é possível identificar um novo VCAN que se formou sobre o oceano e se encontra centrado sobre o Maranhão neste período, entretanto a $\mathrm{AB}$ já se descaracterizou. Diante disso, a ZCAS está em estágio de dissipação.

\subsubsection{Seções verticais}

No dia 6 de janeiro destaca-se intensa convergência do fluxo horizontal de umidade sobre o Atlântico Sul (Figura 14a), existindo intensa precipitação associada a essa forte convergência sobre o oceano, conforme é possível verificar a partir da Figura 10a. A convergência de umidade se estende desde os níveis mais baixos aos níveis médios. Há um máximo secundário de convergência de umidade próximo à costa do Sudeste, associado também a um forte núcleo de precipitação. O aporte de umidade sobre o Atlântico Sul para a região da ZCAS (Figura 11b) está sendo promovido principalmente pela ASAS, cujo escoamento conflui com ventos de componente sul, associados ao sistema frontal que penetra 
no sul do Brasil. Assim, no início da evolução da ZCAS, grande quantidade de umidade está sendo advectada para a zona de convergência, contribuindo para o desenvolvimento do sistema. Sobre o Atlântico Sul, ainda no dia 6, destaca-se intenso movimento ascendente (Figura 14b), claramente associado à convergência de umidade em níveis baixos e médios (Figura 14a) e, consequentemente, à precipitação nesta região (Figura 10a). As demais porções com movimento ascendente intenso sobre o continente estão associadas aos demais núcleos de chuva localizados ao longo da ZCAS.

O corte vertical da componente zonal do vento (Figura 15a), revela a corrente de jato subtropical, com núcleo em torno de $200 \mathrm{hPa}$, se estendendo dos níveis mais altos aos baixos níveis sobre a porção oceânica. $\mathrm{O}$ vento meridional é de norte em toda coluna troposférica sobre o Atlântico (Figura 15b), associado ao escoamento do lado leste do cavado e à porção sudoeste da ASAS.

Não há convergência ou divergência intensa ao longo da seção vertical para o dia 9 de janeiro (Figura 14c), sendo assim, a convergência se desintensifica neste estágio do sistema, da mesma forma que mostrado através do escoamento horizontal na Figura 11d. Destacam-se apenas algumas regiões pouco extensas onde ocorre convergência do fluxo de umidade, às quais há significativo movimento ascendente associado (Figura 14d). Essas porções de movimento ascendente estão associadas a núcleos de precipitação ao longo da linha tracejada em preto mostrada na Figura 10c.

Na Figura 15c é possível identificar o jato subtropical sobre o oceano entre os níveis médios e altos. Como o escoamento se torna mais zonal no dia 9, a componente meridional (Figura 15d) é pouco intensa, sendo ligeiramente mais intensa na região da frente fria, onde se apresenta de sul. 
(a)

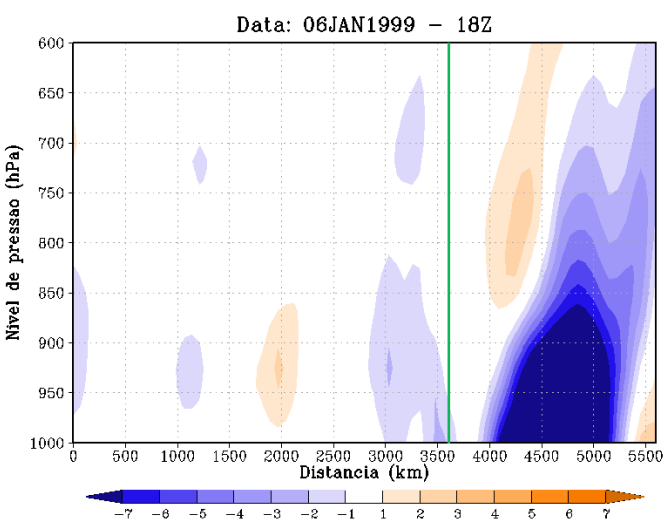

(c)

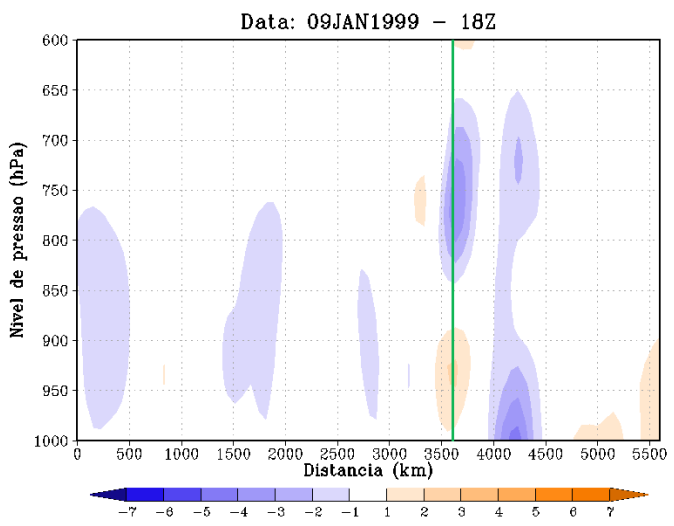

(e)

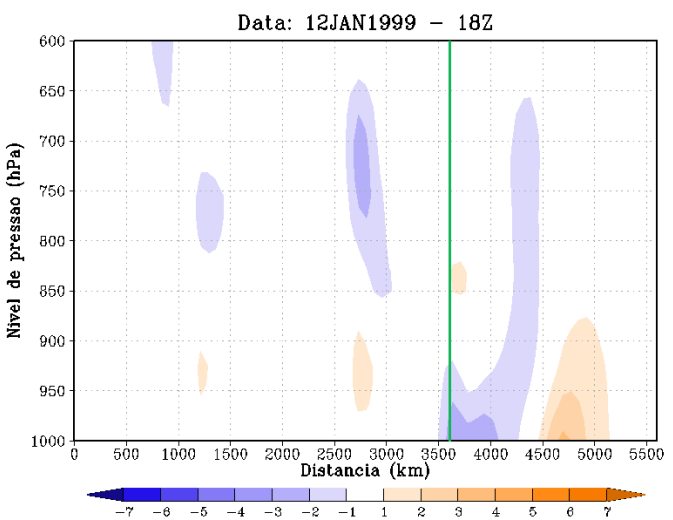

(g)

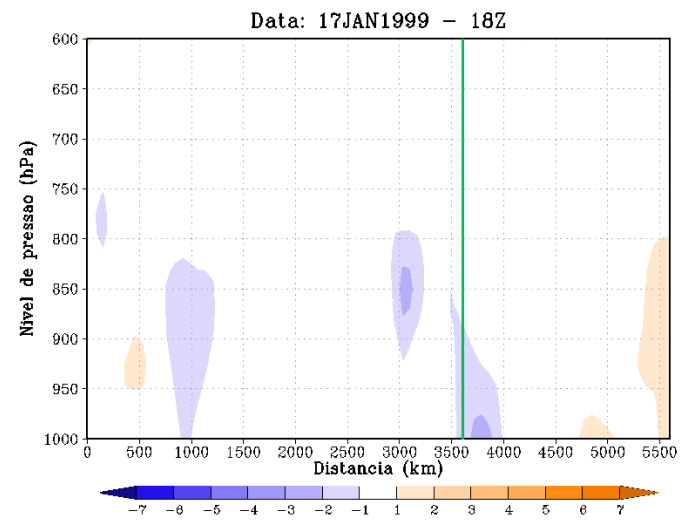

(b)

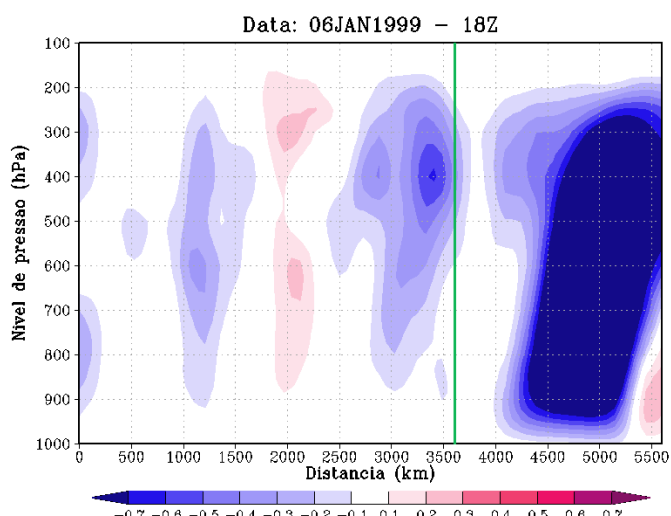

(d)

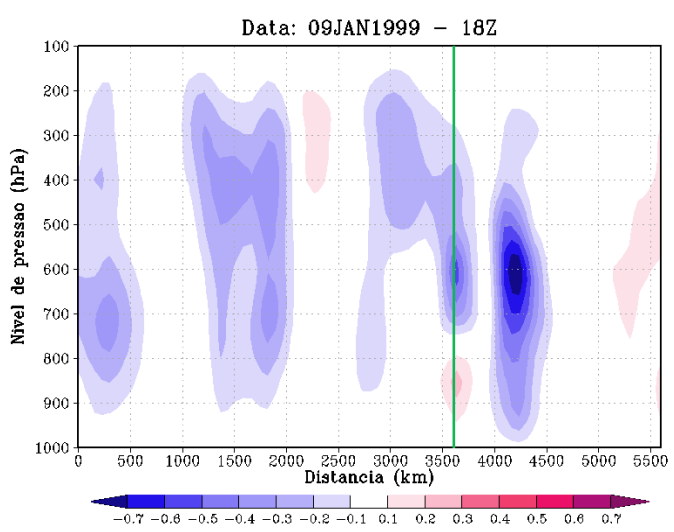

(f)

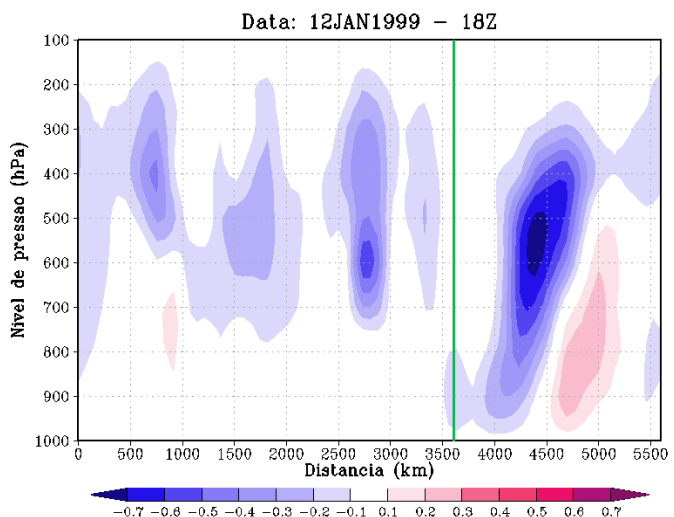

(h)

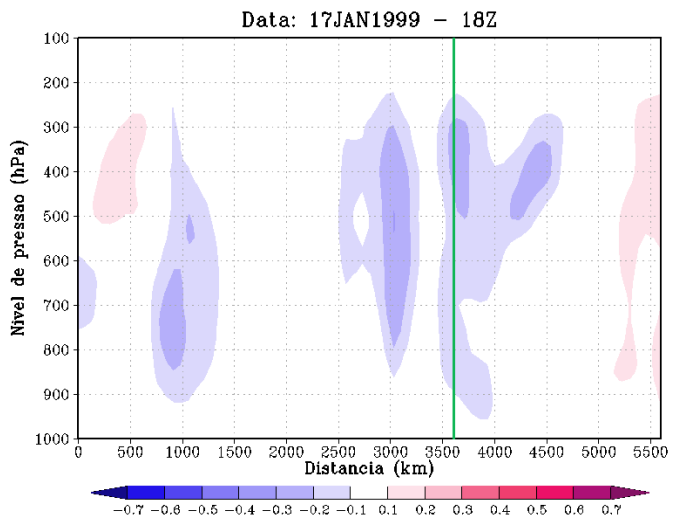

Figura 14. Seções verticais da divergência do fluxo horizontal de umidade (intervalo de $1 \times 10^{-0.7} \mathrm{~kg} \mathrm{~kg}^{-1} \mathrm{~s}^{-1}$ ) para as $18 \mathrm{Z}$ dos dias (a) 06/01/99, (c) 09/01/99, (e) 12/01/99 e (g) 17/01/99. Seções verticais da velocidade vertical omega (intervalo de $0,1 \times 10^{-2} \mathrm{hPa} \mathrm{s}^{-1}$ ) para as $18 \mathrm{Z}$ dos dias (b) 06/01/99, (d) 09/01/99, (f) 12/01/99 e (h) 17/01/99. No eixo das abscissas está representada a distância em km, a partir do ponto mais ao norte, ao longo da linha tracejada em preto nas Figuras anteriores. A linha em verde representa, aproximadamente, o limite entre continente e oceano, que se localizam à esquerda e à direita da mesma, respectivamente. No eixo das ordenadas estão representados os níveis de pressão em hPa. 
No dia 12 de janeiro, também não se observa forte convergência ao longo do corte vertical, sendo que o máximo de convergência se dá próximo à costa, havendo certa divergência sobre o Atlântico Sul em baixos níveis (Figura 14e). Todavia, há regiões de velocidade vertical omega negativa sobre o oceano (Figura 14f), se estendendo desde a superfície aos altos níveis, existindo também movimento subsidente sobre o Atlântico Sul. Apesar de certo movimento ascendente não há precipitação associada sobre o oceano (Figura 10e). Sobre o continente há movimento ascendente entre os níveis médios e altos, associado aos núcleos de precipitação sobre o Brasil mostrados na Figura 10e.

Na Figura 15e identifica-se o escoamento zonal de oeste associado ao jato subtropical se estendendo ao longo da troposfera. Já o vento meridional sobre o oceano (Figura 15f) é de norte em altos níveis, associado também ao escoamento da corrente de jato, considerando que a seção vertical foi feita sobre o lado leste do cavado de latitudes médias, cujo escoamento é de noroeste.

Nos estágios finais da zona de convergência não há convergência significante (Figura 14g). O movimento ascendente se restringe a poucos pontos localizados sobre a costa e o continente (Figura 14h), onde há precipitação associada (Figura 10g). A componente zonal do vento na Figura $15 \mathrm{~g}$ caracteriza o escoamento de oeste da corrente de jato sobre o Atlântico Sul. A componente meridional é de norte sobre a costa (Figura 15h), associada ao escoamento da porção sudoeste da ASAS (Figuras 12g e 13d), e de sul sobre o Atlântico Sul em níveis mais baixos (Figura 11g). 
(a)

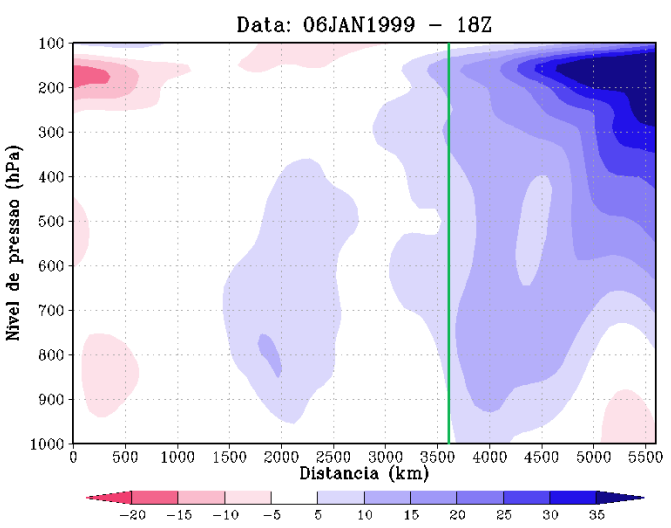

(c)

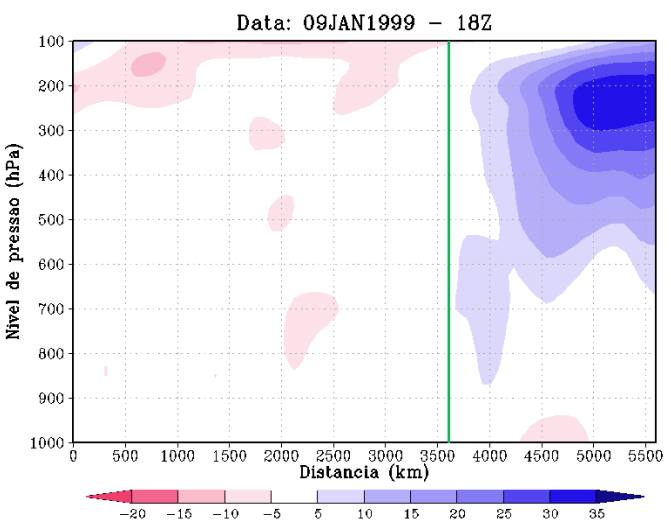

(e)

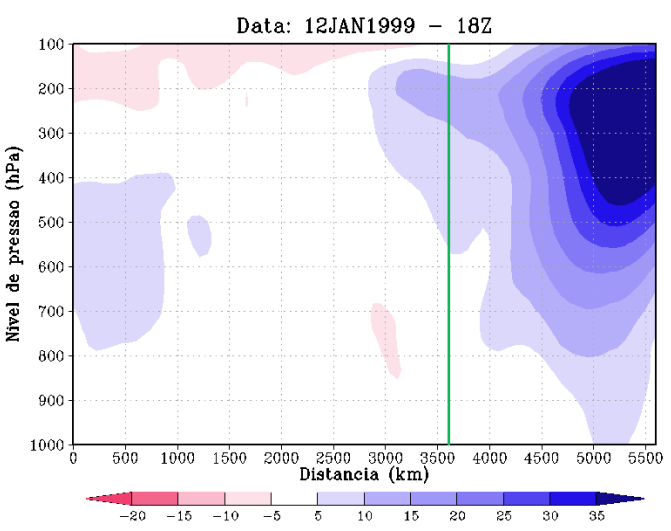

(g)

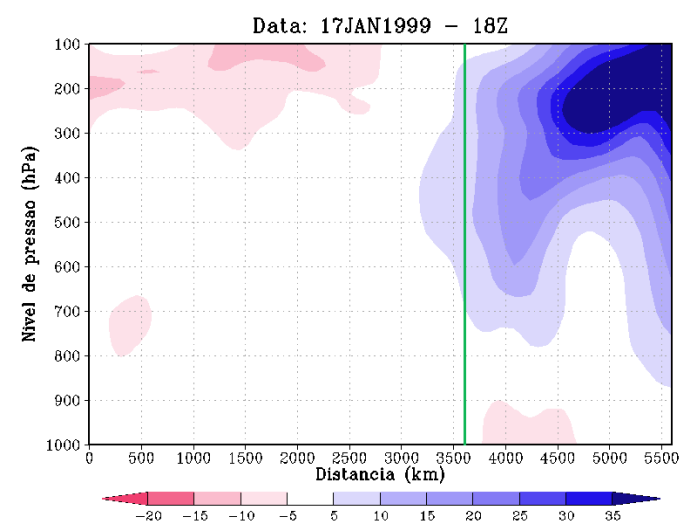

(b)

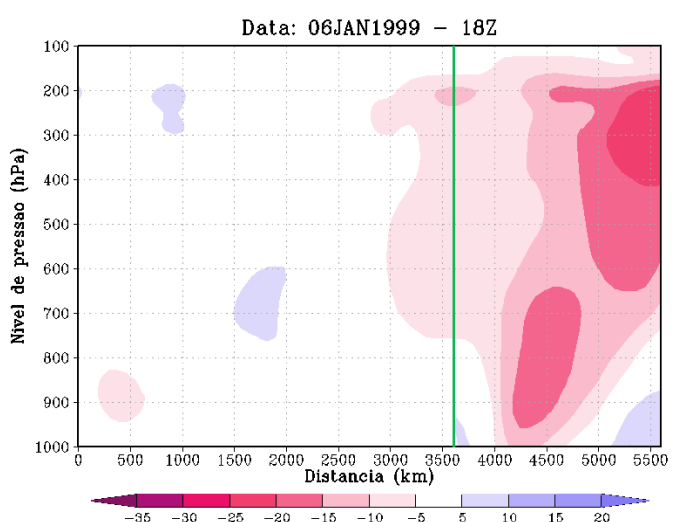

(d)

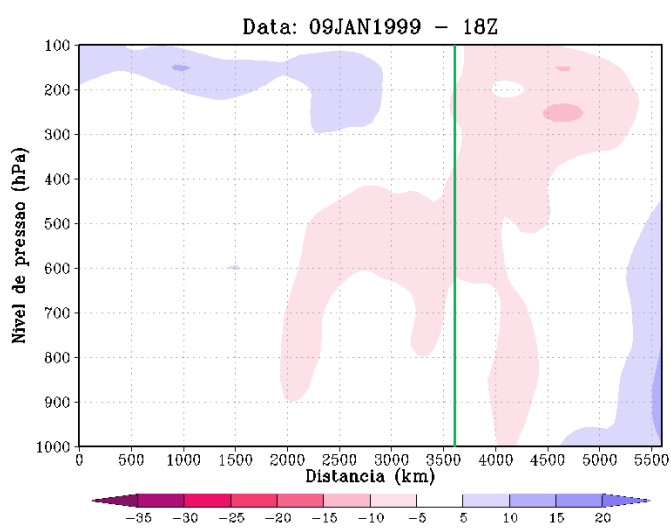

(f)

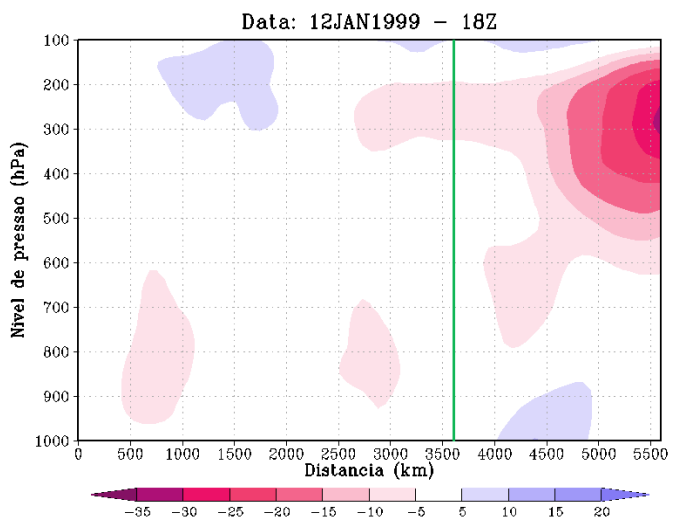

(h)

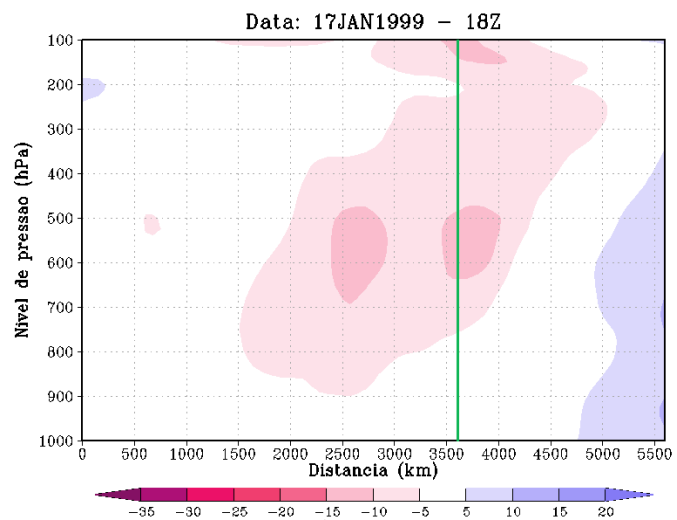

Figura 15. Idem à Figura 14 mas para as componentes zonal (intervalo de $\left.5 \mathrm{~m} \mathrm{~s}^{-1}\right)(\mathrm{a}, \mathrm{c}, \mathrm{e}, \mathrm{g})$ e meridional (intervalo de $5 \mathrm{~m} \mathrm{~s}^{-1}$ ) (b, d, f, h) do vento. 


\subsection{Considerações}

Em síntese, o caso ZCAS-99 se mantém ativo por 13 dias sofrendo sucessivas intensificações e desintensificações, uma vez que durante sua atuação ocorre a penetração de diferentes sistemas frontais, que quando se associam à $\mathrm{AB}$ em altos níveis intensificam a atividade da ZCAS, enfraquecendo-a quando se deslocam para o oceano. A ZCAS se manteve durante todo o período, pois apesar da dissipação dos sistemas frontais, o sistema AB-CN permanece ativo. Já o caso ZCAS-98 teve tempo de duração inferior (5 dias), visto que o mecanismo $\mathrm{AB}-\mathrm{CN}$ se mantém por menos tempo, não sendo observada a clara "gangorra" entre intensificação e desintensificação da atividade da ZCAS, assim como em ZCAS-99.

Outra característica clara, quando da comparação dos dois casos de ZCAS estudados no presente trabalho, é que ZCAS-99 é predominantemente continental enquanto que ZCAS-98 se apresenta mais alongada em direção ao Atlântico Sul. Essa diferença com relação à localização da nebulosidade e precipitação associadas à ZCAS pode ser consequência do ENOS, uma vez que os períodos de DJF de 1997-98 e de 1998-99 correspondem às fases quente e fria do El Niño mais intenso do século XX (LAU; ZHOU, 2003), respectivamente, e, conforme destacado por Nogués-Paegle e Mo (1997) e também por Carvalho, Jones e Liebmann (2004), a fase quente do ENOS (El Niño) favorece a ocorrência de ZCAS oceânica enquanto que a fase fria (La Niña) e neutra favorece ZCAS continental.

Essa modulação da ZCAS pelo ENOS pode ocorrer pois o enfraquecimento dos alísios, a consequente diminuição da ressurgência e o aumento da temperatura das águas no Pacífico leste equatorial, que ocorrem durante sua fase quente, causam abaixamento da pressão em baixos níveis no Pacífico. A célula térmica zonal de Walker sofre então um deslocamento, fazendo com que ocorra ascendência sobre o Pacífico leste e movimento subsidente sobre o 
norte do Brasil, assim como descrito por Liebmann e Marengo (2001). Desta forma, há um escoamento de baixos níveis de leste anômalo sobre o norte do Brasil que é defletido pelos Andes e segue na direção sudeste (LAU; ZHOU, 2003). A subsidência no norte do Brasil inibe a formação de nuvens, enquanto que o escoamento noroeste-sudeste intensificado carrega umidade para o Sudeste e Atlântico Sul e fortalece o escoamento associado à ASAS; a ZCAS então se apresenta mais oceânica quando da ocorrência de El Niño, concordando com o apresentado no estudo de Nogués-Paegle e Mo (1997). Durante períodos de La Niña há fortalecimento dos alísios, aumento da ressurgência e consequente aumento da pressão em baixos níveis no Pacífico leste. Sendo assim, ocorre ascendência sobre o norte do Brasil e desintensificação do escoamento noroeste-sudeste climatológico do SMAS; com essa configuração a ZCAS é predominantemente continental. 
Capítulo 4

\section{Influências da temperatura da superfície do mar na ZCAS}

A influência das características da superfície oceânica na variabilidade da precipitação sobre a América do Sul, especialmente na porção oceânica dos sistemas que atuam na região, foi estudada em muitos trabalhos. Barreiro, Chang e Saravanan (2002), por exemplo, argumentam que a variabilidade da precipitação sobre o oceano é mais influenciada pela TSM do que por variabilidades internas da atmosfera, e que a condição limite de superfície, ou seja a TSM, pode influenciar na estabilidade atmosférica e no suprimento de umidade para a convecção profunda, desempenhando assim um importante papel na variabilidade da ZCAS oceânica, não influenciando de maneira significativa as porções continentais.

No que concerne ao posicionamento da ZCAS, Barros et al. (2000) concluíram que anomalias quentes (frias) de TSM na região entre $40^{\circ} \mathrm{S}$ e $20^{\circ} \mathrm{S}$ e a oeste de $30^{\circ} \mathrm{W}$ são, na maioria dos casos, acompanhadas por um deslocamento da ZCAS para sul (norte). Além desta relação entre ZCAS e TSM, os autores indicaram que anomalias quentes (frias) de TSM no Atlântico adjacente ao continente não apenas contribuem para aumentar (diminuir) a precipitação sobre o sudeste da América do Sul (nordeste da Argentina, Uruguai e sul do Brasil), mas também estão associadas a deslocamento da ZCAS para sul (norte), diferentemente de Barreiro, Chang e Saravanan (2002), que apontaram que a TSM influencia de forma relevante apenas na ZCAS oceânica. 
Outros estudos ainda exploraram aspectos relativos ao acoplamento entre a ZCAS e a TSM do Atlântico, como Chaves e Nobre (2004) e Chaves e Satyamurty (2006). No primeiro trabalho, por exemplo, os autores mostraram que a intensificação da ZCAS tende a causar abaixamento da TSM na região sob o sistema devido à diminuição da incidência solar na superfície oceânica, causando anomalias negativas ou a desintensificação de anomalias positivas pré-existentes. Sendo assim, os autores observaram uma resposta oceânica à forçante atmosférica, no caso a nebulosidade associada à ZCAS. Essa interação entre oceano e atmosfera pode levar à desconfiguração dos processos que mantêm a ZCAS oceânica ativa, sendo que sem a diminuição da TSM, a ZCAS se manteria por mais tempo ativa, segundo Jorgetti (2008).

Diversos trabalhos focaram na representação da ZCAS por modelos numéricos da atmosfera. Recentemente, simulações da ZCAS e de outra importante zona de convergência atuante no globo, a Zona Frontal de Baiu (ZFB), foram realizadas com um modelo de circulação geral da atmosfera por Ninomiya (2007). O autor destaca que em muitos meses a ZCAS simulada aparece como uma banda de precipitação estreita e alongada, enquanto em outros meses como uma região larga de precipitação. O mesmo autor, em trabalhos anteriores (NINOMIYA et al., 2002, 2003), já havia apontado que simulações insatisfatórias da ZFB se dão principalmente devido à simulação insatisfatória das circulações de grande escala, como o anticiclone e os ventos de oeste das monções indianas.

A questão da simulação insatisfatória das circulações de grande escala destacada por Ninomiya (2007) está de acordo com Beljaars et al. (1996), que apontou que o tratamento de processos de superfície, que influenciam fortemente no estabelecimento dessas circulações, em modelos de grande escala é sempre um difícil problema devido às complicadas interações entre atmosfera, solo e vegetação. Desta forma, modelos numéricos regionais, tais como o RAMS e o BRAMS, têm diversas características que possibilitam explorar e determinar a 
influência das características da superfície, continental e oceânica, nessas circulações e por consequência na precipitação associada à ZCAS.

Alguns trabalhos realizaram simulações da ZCAS com o uso desses modelos numéricos. Calderon (2000), utilizando o RAMS, indicou que a TSM do Atlântico controla significativamente a precipitação sobre o oceano, ao longo da costa brasileira e também no interior do continente, sugerindo uma possível influência dos padrões de TSM na estrutura, intensidade e posicionamento da ZCAS. Em trabalho mais atual, Jorgetti (2008) realizou simulações com o BRAMS, acoplado a um modelo de camada de mistura oceânica, a fim de obter um melhor entendimento da relação entre ZCAS e Atlântico. Encontrou que as anomalias de TSM no Atlântico tropical e subtropical influenciam principalmente no transporte de umidade associado à ASAS e ao JBN, que por sua vez influenciam fortemente no posicionamento e intensidade da ZCAS. As simulações de Jorgetti (2008) representaram bem as circulações associadas ao SMAS, porém tenderam a subestimar a precipitação na região da ZCAS. Jorgetti (2008) ainda encontrou resultados semelhantes aos de Chaves e Nobre (2004) com respeito ao acoplamento entre ZCAS e TSM.

O presente trabalho, ao invés de investigar a influência de anomalias de TSM na ZCAS diretamente, enfatizou a verificação do impacto das resoluções espacial e temporal dos dados de TSM na precipitação associada ao sistema. As diferenças (positivas e negativas) entre as TSM's de diferentes conjuntos de dados representam, de certa forma, anomalias de TSM, mesmo que de pouca magnitude. Este estudo foi realizado com base em experimentos numéricos efetuados com o BRAMS e será apresentado neste Capítulo. 


\subsection{Características específicas dos testes de sensibilidade a TSM}

Com a finalidade de verificar o impacto das resoluções espacial e temporal dos dados de TSM nas características da ZCAS simulada, mais especificamente na precipitação associada ao sistema, foram realizados três experimentos numéricos distintos (SEM025, SEM1 e DIA025) para cada caso de ZCAS abordado no presente estudo. As diferenças entre os experimentos estão apresentadas na Tabela 2.

Tabela 2 - Diferenças entre os experimentos numéricos realizados com o BRAMS para verificação do impacto das resoluções espacial e temporal dos dados de TSM.

\begin{tabular}{cccc} 
& SEM025 & SEM1 & DIA025 \\
\hline resolução espacial & $0,25^{\circ} \times 0,25^{\circ}$ & $1^{\circ} \times 1^{\circ}$ & $0,25^{\circ} \times 0,25^{\circ}$ \\
resolução temporal & semanal & semanal & diária \\
\hline
\end{tabular}

Vale ressaltar que o conjunto de dados de TSM semanal com resolução espacial de $0,25^{\circ}$ (empregado no experimento SEM025) foi construído a partir do conjunto de TSM diária da NOAA com o mesmo espaçamento horizontal (empregado em DIA025), através de médias de sete dias, e ainda que a distribuição de umidade inicial do solo nos experimentos numéricos foi horizontalmente heterogênea, com base nos dados de Gevaerd e Freitas (2006), e é ilustrada na Figura 16.

As comparações realizadas entre os experimentos numéricos, bem como o impacto de qual resolução (espacial ou temporal) está sendo verificado em cada comparação estão apresentados na Tabela 3. 
(a)

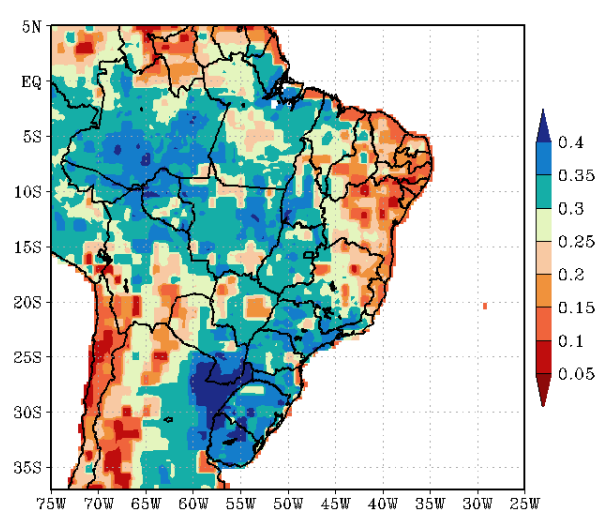

(b)

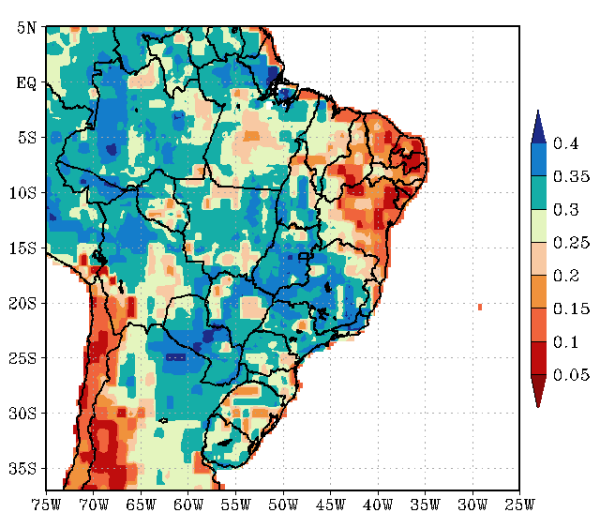

Figura 16. Umidade inicial do solo no nível de solo mais próximo à superfície $(0,10 \mathrm{~m}$ abaixo da superfície) nos três experimentos realizados com o BRAMS (SEM025, SEM1 e DIA025) para (a) ZCAS-98 e para (b) ZCAS-99 (intervalo de $0,05 \mathrm{~m}^{3} \mathrm{~m}^{-3}$ ).

Tabela 3 - Comparações entre os experimentos numéricos realizados com o BRAMS e impacto de qual resolução está sendo verificado em cada comparação.

\begin{tabular}{cc}
\hline Comparação entre os experimentos & Verificação do impacto da resolução \\
\hline DIA025 X SEM025 & temporal \\
SEM1 X SEM025 & espacial \\
\hline
\end{tabular}

As análises dos experimentos numéricos basearam-se nas diferenças de médias (calculadas para todo o período de integração) das seguintes variáveis: TSM, temperatura e umidade específica em baixos níveis $(1000 \mathrm{hPa})$ e fluxos de calor sensível e latente à superfície entre SEM025 e os demais experimentos. Também analisaram-se as diferenças da divergência média do fluxo horizontal de umidade integrado na atmosfera, sendo que a umidade específica, $q$, também necessária para esse cálculo foi calculada a partir da razão de mistura de vapor, $r_{v}$, segundo a seguinte equação (WALLACE; HOBBS, 2006):

$$
q=\frac{r_{v}}{1+r_{v}} \quad\left[k g ~ k g^{-1}\right]
$$

As análises ainda se basearam na inspeção das diferenças dos campos precipitação acumulada no final do período de integração (levando em conta ambas as parametrizações convectiva e microfísica do modelo) entre os experimentos. 


\subsubsection{Verificação das simulações de precipitação}

O conhecimento dos erros de previsão auxilia os previsores a lidarem com os problemas do modelo utilizado e proporciona melhora da previsão numérica do tempo. Variáveis como pressão, temperatura e componentes do vento são mais importantes para garantir uma previsão de qualidade, porém a precipitação é uma das variáveis mais utilizadas na previsão (CHOU; JUSTI DA SILVA, 1999) já que possui diversas aplicações, na sociedade acima de tudo. Além disso, como as simulações numéricas do presente trabalho foram realizadas para casos de ZCAS, sistema associado com precipitação, será verificada em especial a previsão dessa variável.

A primeira etapa para verificar as previsões de precipitação realizadas pelo modelo foi transportar as grades tanto dos dados diários de precipitação do GPI quanto das saídas do modelo para o mesmo espaçamento horizontal, a fim de possibilitar a comparação dos pontos de grade simulados e observados correspondentes. Neste procedimento, ambas as grades foram transformadas em uma nova grade com resolução espacial de 0,3 x 0,3 graus de latitude-longitude. Sendo assim, as saídas do modelo, cuja resolução espacial era de 0,255 x 0,274 graus de latitude-longitude originalmente foram "degradadas" através do método box averaging, intrínseco do software de visualização gráfica Grid Analysis and Display System (GrADS), e os dados de precipitação, cuja resolução espacial original é de 1 x 1 grau de latitude-longitude, tiveram sua resolução espacial aumentada através de interpolação bilinear, método também intrínseco do GrADS. Em seguida calcularam-se as acumulações diárias (das $00 Z$ de um dia às $00 Z$ do dia seguinte) da precipitação simulada para cada experimento.

Desta forma, com os dados das observações e as análises de precipitação diária acumulada do modelo na mesma grade, foi possível calcular índices estatísticos, tais como 
Erro Médio (EM), Raiz Quadrada do Erro Médio Quadrático - Root Mean Square Error (RMSE) em inglês, Raiz Quadrada do Erro Médio Quadrático com remoção do viés ou bias Root Mean Square Error Unbiased (RMSE $\left.E_{U B}\right)$ em inglês e Bias-Adjusted Threat Score (TSA) para cada simulação numérica. Também foram calculados Desvio Padrão da Observação (DPO) e Desvio Padrão da Simulação (DPS), este último também para cada experimento numérico.

Os índice estatístico EM pode ser definido como (FREITAS, 2003; FREITAS et al., 2007):

$$
E M=\frac{1}{n} \sum_{i=1}^{n}\left(y_{i}-o_{i}\right)
$$

E os índices RMSE, RMSE ${ }_{U B}$, DPO e DPS podem ser definidos como (PIELKE, 2002):

$$
\begin{gathered}
R M S E=\sqrt{\frac{1}{n} \sum_{i=1}^{n}\left(y_{i}-o_{i}\right)^{2}} \\
R M S E_{U B}=\sqrt{\frac{1}{n} \sum_{i=1}^{n}\left[\left(y_{i}-\bar{y}\right)-\left(o_{i}-\bar{o}\right)\right]^{2}} \\
D P O=\sqrt{\frac{1}{n} \sum_{i=1}^{n}\left(o_{i}-\bar{o}\right)^{2}} \\
D P S=\sqrt{\frac{1}{n} \sum_{i=1}^{n}\left(y_{i}-\bar{y}\right)^{2}}
\end{gathered}
$$

onde $n$ é o número de instantes da análise/observação, $y_{i}$ e $o_{i}$ são os valores simulados e observados, respectivamente, e $\bar{y}$ e $\bar{o}$ são as médias no tempo dos valores simulados e observados, respectivamente, para cada ponto de grade.

O EM fornece uma medida do desvio da simulação, permitindo que se identifique se a simulação está superestimando ou subestimando determinada variável com relação à 
observação, sendo que valores positivos (negativos) indicam superestimativa (subestimativa) (MENDONÇA, 1999).

O RMSE é uma medida da acurácia ou exatidão, que é o quanto o resultado de uma previsão é próximo do valor verdadeiro, e possibilita verificar a magnitude média do erro da simulação; ao elevar-se o erro ao quadrado os maiores erros são realçados (MENDONÇA, 1999), sendo que quanto maior o valor de RMSE menor é a acurácia da previsão numérica da quantidade de chuva. O RMSE $E_{U B}$ fornece a mesma informação que o RMSE, entretanto desconsidera os erros devidos ao viés do modelo numérico, possibilitando identificar quanto da acurácia de uma simulação está ligada a esse viés.

O Desvio Padrão fornece uma medida de quanto determinado valor está distante do valor médio, assim, quanto maior o Desvio Padrão maior é a dispersão dos valores em torno da média.

O EM e o RMSE foram utilizados por Jorgetti (2008), por exemplo, para verificar a performance das previsões de precipitação, associada a episódios de ocorrência de ZCAS, realizadas pelo BRAMS acoplado a um modelo de camada de mistura oceânica. Além do EM e do RMSE, Freitas (2003), por exemplo, também utilizou RMSE $E_{U B}$, DPO e DPS a fim de comparar simulações do modelo RAMS acoplado ao esquema Town Energy Budget (TEB) e ao Land Ecosystem-Atmosphere Feedback Model 2 (LEAF-2).

Finalmente o TSA é um índice que mede a habilidade do modelo em prever e sua acurácia em localizar eventos classificados em categorias, quanto mais próximo de 1 melhor é a previsão de precipitação do modelo e é definido como (BALDWIN; KAIN, 2006):

$$
T S A=\frac{(a+c)^{1 / B}-c^{1 / B}}{(a+c)^{1 / B}+c^{1 / B}}
$$

onde $B$ é o bias ou viés dado por:

$$
B=\frac{a+b}{a+c}
$$


e $a, b$ e $c$ são obtidos a partir da tabela de contingência 2 X 2 sim/não (Tabela 4), sendo que $a$ é o número de pontos previstos corretamente pelo modelo - hits $(H)$ - acima de determinado limiar.

Tabela 4 - Tabela de contingência 2 X 2 sim/não para dado evento.

\begin{tabular}{|c|c|c|c|c|}
\hline & \multicolumn{4}{|c|}{ Observado } \\
\hline & & Sim & Não & Total \\
\hline \multirow{3}{*}{ Previsto } & Sim & $\mathrm{a}$ & $\mathrm{b}$ & $a+b$ \\
\hline & Não & $\mathrm{c}$ & d & $c+d$ \\
\hline & Total & $a+c$ & $b+d$ & 1 \\
\hline
\end{tabular}

Com base na Tabela 4 tem-se que $a+b$ e $a+c$ são os números de pontos previstos (F) e observados $(\mathrm{O})$ acima de determinado limiar, respectivamente. Então $c=O-H$ e TSA pode ser calculado a partir de:

$$
T S A=\frac{1-\left(\frac{O-H}{O}\right)^{O / F}}{1+\left(\frac{O-H}{O}\right)^{O / F}}
$$

É importante salientar que os índices estatísticos apresentados anteriormente levam em conta uma distribuição de frequência aproximadamente normal (gaussiana), o que não é o caso da variável precipitação, assim devem ser calculados para precipitação dividida em categorias ou limiares. As categorias de precipitação para a utilização destes índices foram classificadas com base nos limiares, que correspondem a aproximadamente múltiplos de uma polegada de chuva $(25,4 \mathrm{~mm})$ acumulada diária, utilizados para avaliação de previsão de chuva do National Centers for Environmental Prediction (NCEP) (Tabela 5).

Alguns trabalhos já utilizaram esses limiares para análise do desempenho de modelos na previsão de chuva, tais como Chou e Justi da Silva (1999), que avaliaram o desempenho do 
modelo regional ETA sobre a América do Sul, e Mendonça (1999), que verificou o desempenho do modelo global CPTEC/COLA durante episódios de ZCAS, o que coincide com o sistema meteorológico estudado neste trabalho.

Tabela 5 - Classificação da intensidade da precipitação e limiares de precipitação acumulada diária $\left(\mathrm{mm}^{-1} \mathrm{dia}^{-1}\right)$.

\begin{tabular}{cll}
\hline Classificação da intensidade da precipitação & Limiar $\left(\mathbf{m m ~ d i a} \mathbf{~}^{-\mathbf{1}}\right)$ \\
\hline chuva-não chuva & 0,3 & \\
fraca & 2,$5 ; \quad 6,3$ \\
moderada & 12,$7 ; 19,0$ \\
forte & 25,$4 ; 38,1 ; 50,8$ \\
\hline
\end{tabular}

Uma vez que a precipitação ao longo da ZCAS apresenta grande variabilidade espacial, calcularam-se os índices estatísticos médios, através de sub-rotinas em FORTRAN, para cada uma das três regiões distintas que compõem a ZCAS (Figura 1), para todo o domínio do modelo, para cada categoria de precipitação (Tabela 5) e para cada simulação numérica separadamente. No caso do índice TSA foi calculado um valor para cada dia de simulação. Eventuais valores iguais a -9999 indicam que não foi possível calcular o índice.

\subsection{Testes de sensibilidade a TSM}

\subsubsection{ZCAS-98}

Comparando-se as simulações SEM025 e SEM1 com relação à TSM, observa-se, através da Figura 17, que no Pacífico e no Atlântico Sul, próximo às costas do Uruguai e Rio Grande do Sul, com alguns pontos também na região do Equador, a TSM em SEM1 é maior do que em SEM025. As diferenças, principalmente no Atlântico próximo ao sul do Brasil e no 
Pacífico são da ordem de até $2,5^{\circ} \mathrm{C}$, no Atlântico mais ao norte as diferenças entre as duas simulações são menores, sendo da ordem de $1{ }^{\circ} \mathrm{C}$. Apenas observam-se dois pontos no Atlântico Sul onde a TSM em SEM1 é menor do que em SEM025, sendo a diferença entre 0,5 e $1{ }^{\circ} \mathrm{C}$. Assim, de uma forma geral e na média, a TSM no experimento SEM1 é maior do que em SEM025.

Com relação à temperatura do ar em 1000 hPa (Figura 18), as maiores diferenças entre SEM1 e SEM025 estão na região oceânica, sendo, porém, de menor magnitude do que as diferenças de TSM. Como a TSM média do período de integração é maior em SEM1, o aquecimento do ar adjacente (baixos níveis) também é maior em SEM1 do que em SEM025. Não foram calculadas as diferenças de TSM e temperatura entre os experimentos SEM025 e DIA025, pois o conjunto de dados de TSM semanal com resolução espacial de 0,25 x 0,25 graus de latitude-longitude (utilizado em SEM025) foi criado a partir do conjunto de dados de TSM diária com a mesma resolução espacial (utilizado em DIA025).

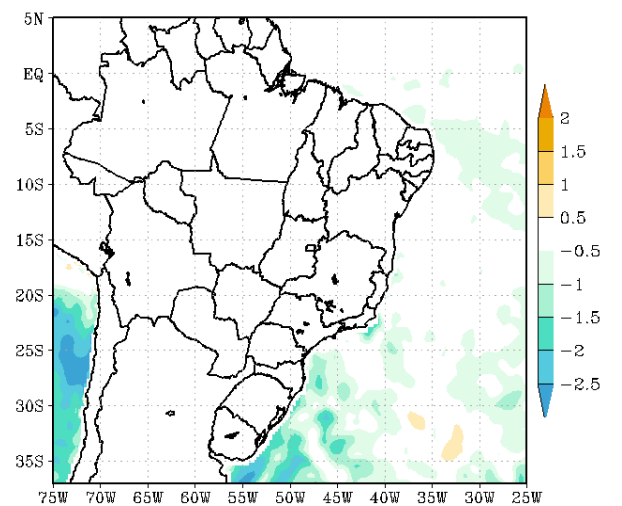

Figura 17. Diferença da média de TSM de todo o período de integração do modelo (08/02/98 às $00 \mathrm{Z}$ a 19/02/98 às 00Z) entre os experimentos numéricos SEM025 e SEM1 (SEM025-SEM1) (intervalo de $\left.0,5^{\circ} \mathrm{C}\right)$.

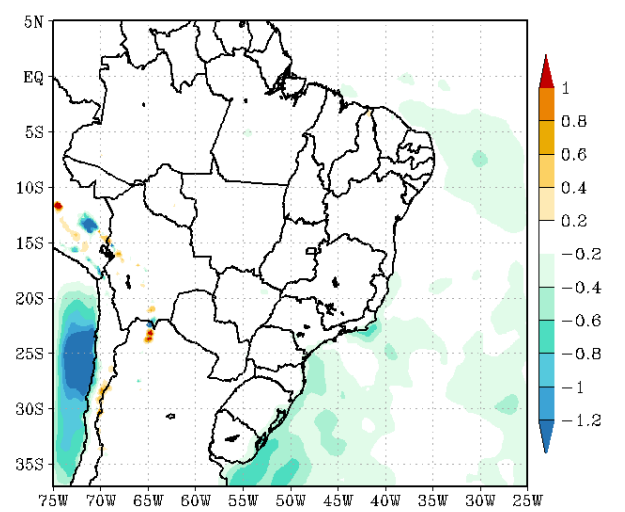

Figura 18. Idem à Figura 17 mas para temperatura do ar em $1000 \mathrm{hPa}$ (intervalo de $0,2^{\circ} \mathrm{C}$ ).

As diferenças com relação à umidade específica em 1000 hPa são muito pequenas, da ordem de $3 \times 10^{-3} \mathrm{~g} \mathrm{~kg}^{-1}$, concentrando-se mais no Atlântico Sul próximo à costa do Uruguai, 
sendo que há mais umidade em SEM1 do que em SEM025 (Figura 19a), observa-se o mesmo no Pacífico. A maior umidade em SEM1 reflete a maior TSM neste experimento já que nessas condições pode ocorrer mais evaporação e, portanto, maior suprimento de umidade em baixos níveis. Entre SEM025 e DIA025 não há diferenças significativas (Figura 19b), com exceção do Atlântico na direção da costa da Bahia, onde SEM1 apresenta TSM superior a SEM025.

Em ambas as Figuras observa-se que as maiores diferenças se encontram ao longo dos Andes. Com relação à divergência do fluxo de umidade, observa-se que as maiores diferenças tanto entre SEM025 e SEM1 quanto entre SEM025 e DIA025 encontram-se na região oceânica da ZCAS, na porção oceânica da ZCIT e nos Andes (Figuras 19c e 19d), que estão próximas às regiões onde as TSM's tiveram as maiores diferenças (Figura 17).

(a)

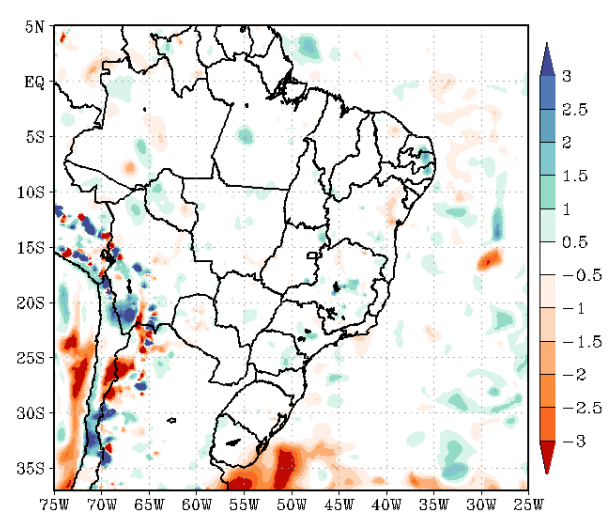

(c)

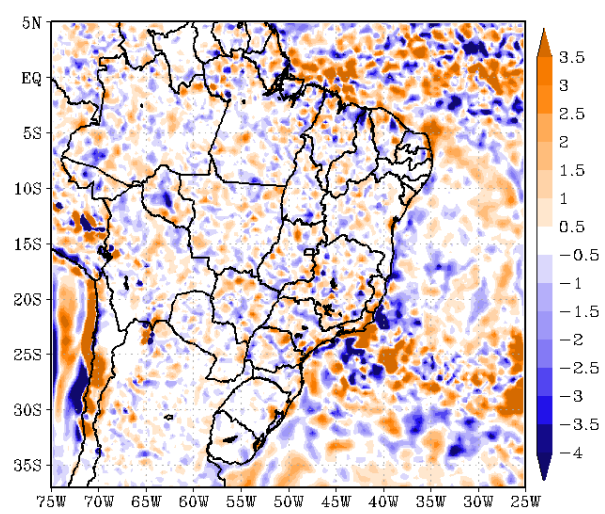

(b)

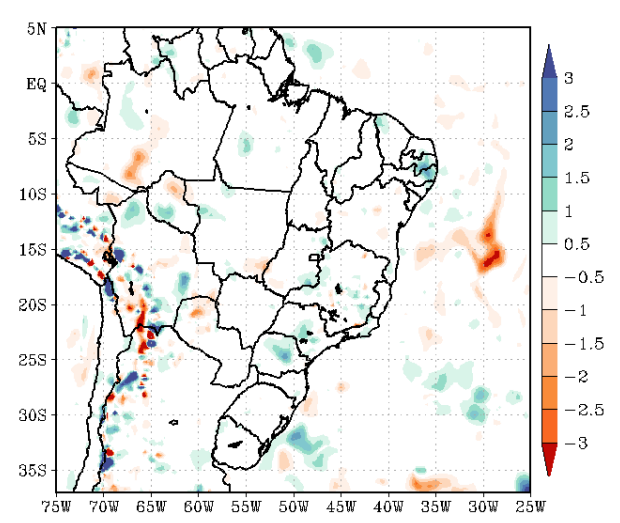

(d)

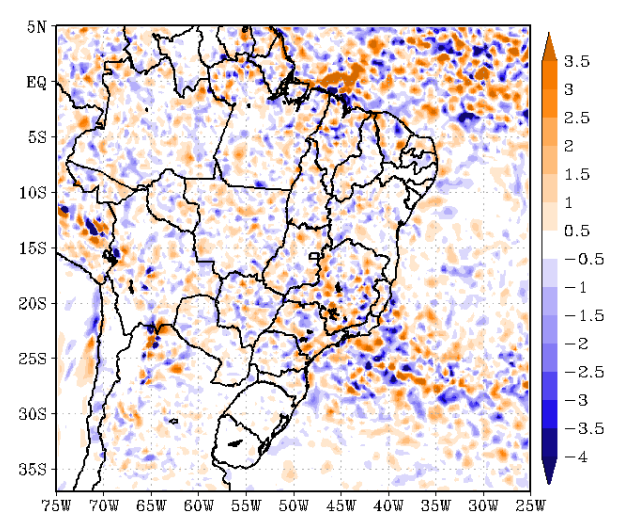

Figura 19. Diferença da média de umidade específica de todo o período de integração do modelo (08/02/98 às 00Z a 19/02/98 às 00Z) entre os experimentos numéricos (a) SEM025 e SEM1 (SEM025-SEM1) e (b) SEM025 e DIA025 (SEM025-DIA025) (intervalo de $0,5 \times 10^{-3} \mathrm{~g} \mathrm{~kg}^{-1}$ ) e diferença da divergência média do fluxo horizontal de umidade, do mesmo período de integração, integrado na atmosfera, da pressão reduzida ao nível médio do mar ao nível de $100 \mathrm{hPa}$ entre os experimentos numéricos (c) SEM025 e SEM1 (SEM025SEM1) e (d) SEM025 e DIA025 (SEM025-DIA025) (intervalo de $0,5 \times 10^{-4} \mathrm{~kg} \mathrm{~kg}^{-1} \mathrm{~s}^{-1}$ ). 
Já com respeito ao fluxo de calor sensível, observa-se que é maior em SEM1 do que em SEM025 na região oceânica (Figura 20a). Na região continental, principalmente no noroeste da Amazônia o fluxo de calor sensível é maior em SEM025 do que em SEM1. O maior fluxo de calor sensível no oceano é consistente com a maior TSM em SEM1 nessa região, já que devido a essa maior temperatura, o aquecimento por calor sensível do ar adjacente à superfície do mar será maior neste experimento. Destacam-se duas regiões no Atlântico Sul onde o fluxo de calor sensível é maior em SEM025 do que em SEM1, coincidindo com as regiões onde a TSM em SEM025 é maior do que em SEM1.

As diferenças entre SEM025 e DIA025 concentram-se sobre o continente (Figura 20b), porém também não se observam padrões claros. Apenas no noroeste da Amazônia e em poucos pontos do Atlântico Sul observa-se que o fluxo de calor sensível é ligeiramente maior em SEM025 do que em DIA025, o que significa que o aquecimento nessas regiões é ligeiramente maior em SEM025. Em ambas as comparações (Figuras 20a e 20b), notam-se grandes diferenças também na encosta dos Andes, a leste da Cordilheira. As diferenças observadas sobre o continente se dão devido às diferentes quantidades de precipitação entre os experimentos, conforme será mostrado adiante. A precipitação irá determinar a umidade do solo, que por sua vez definirá a partição do saldo de radiação entre os fluxos de calor sensível e latente à superfície.

As diferenças entre os fluxos de calor latente em SEM1 e em SEM025 (Figura 20c) podem ser maiores do que $56 \mathrm{~W} \mathrm{~m}^{-2}$ (escala da Figura 20c deve ser multiplicada por 4) majoritariamente sobre as regiões oceânicas, sendo maiores em SEM1. Assim a evaporação em SEM1 é mais eficiente do que em SEM025, o que pode indicar que em SEM1 há maior suprimento de umidade para a formação de precipitação associada à ZCAS.

Destacam-se os mesmos dois pontos sobre o Atlântico Sul, onde o fluxo de calor latente em SEM025 é maior do que em DIA025. Sobre o continente é possível observar apenas que 
na região amazônica há alguns pontos onde o fluxo de calor latente em DIA025 é maior do que em SEM025, desta forma pode ocorrer maior evaporação nesta região em DIA025, o que pode significar suprimento de umidade para a convecção amazônica (Figura 20d). Comparando-se SEM025 com DIA025, notam-se dois padrões claros na Figura 20d, no Atlântico Sul e no Pacífico o fluxo de calor latente é maior em SEM025, na região da ZCIT a situação se inverte, isto é, no Atlântico Sul possivelmente há maior evaporação e, como consequência, maior suprimento de umidade para a zona de convergência em SEM025, já na ZCIT o maior suprimento de umidade deve se dar em DIA025.

(a)

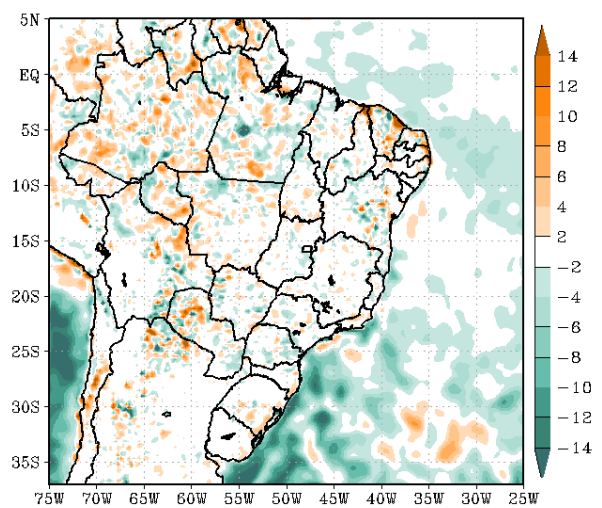

(c)

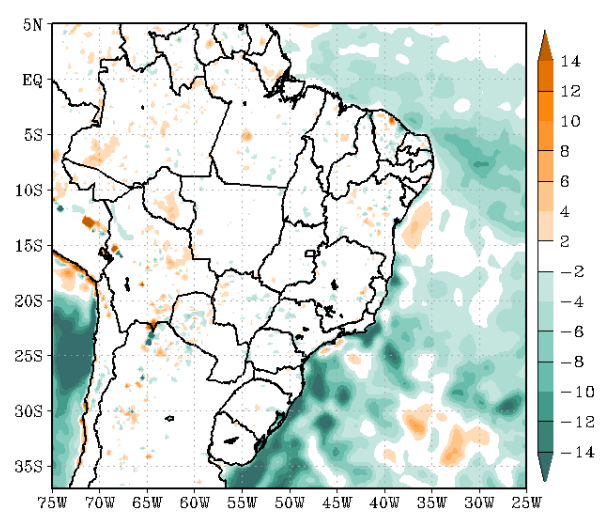

(b)

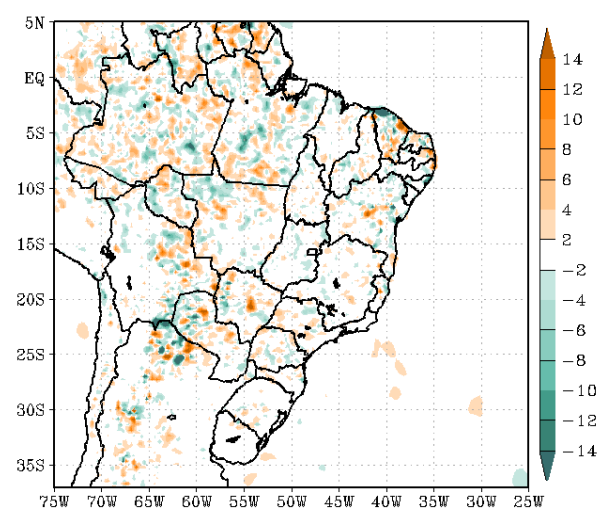

(d)

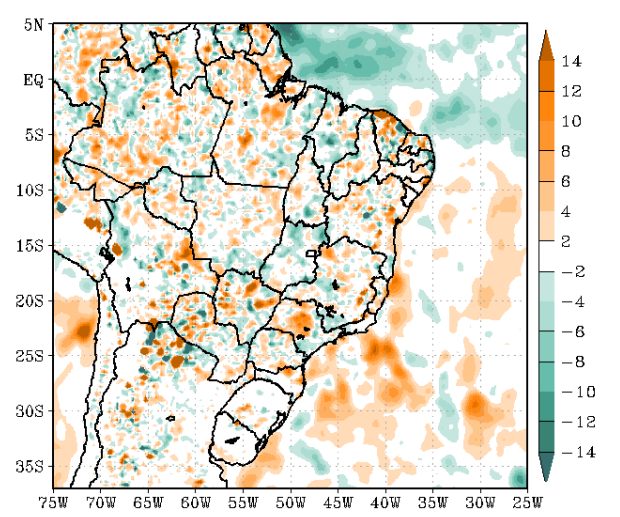

Figura 20. Diferença da média do fluxo de calor sensível à superfície de todo o período de integração do modelo (08/02/98 às 00Z a 19/02/98 às 00Z) entre os experimentos numéricos (a) SEM025 e SEM1 (SEM025SEM1) e (b) SEM025 e DIA025 (SEM025-DIA025) (intervalo de $2 \mathrm{~W} \mathrm{~m}^{-2}$ ) e diferença da média do fluxo de calor latente à superfície, do mesmo período de integração, entre os experimentos numéricos (c) SEM025 e SEM1 (SEM025-SEM1) e (d) SEM025 e DIA025 (SEM025-DIA025) (intervalo de $2 \mathrm{~W} \mathrm{~m}^{-2}$ ). Os valores em (c) devem ser multiplicados por 4 . 
As diferenças de precipitação acumulada entre SEM025 e SEM1 mostram que na região da ZCAS, majoritariamente em SEM1 há maior quantidade de chuva do que em SEM025 (Figura 21a), sendo que ocorre o oposto nos lados equatorial e polar do sistema, havendo mais chuva em SEM025 do que em SEM1 nessas regiões. Assim como no trabalho de Barreiro, Chang e Saravanan (2002), a maior quantidade de precipitação em SEM1 na região da ZCAS oceânica se dá devido à maior TSM que induz maior evaporação e, portanto, maior fornecimento de umidade para a zona de convergência principalmente nos níveis mais baixos. O fato de SEM025 apresentar mais precipitação acumulada do que SEM1 nos lados polar e equatorial da ZCAS pode ser devido a SEM025 distribuir melhor a precipitação sobre a região oceânica do que SEM1. Na porção da ZCIT mais próxima à costa do Brasil (Figura 21a) também observa-se que em SEM1 há mais precipitação do que em SEM025.

Um padrão claro ao longo da ZCAS na Figura 21a é que as maiores diferenças se concentram na porção oceânica e as menores na região amazônica, sendo que a região costeira é intermediária. Os maiores impactos nas regiões oceânica e mais próximas ao oceano (costeira) se devem ao fato da diferença entre as simulações numéricas ser exatamente a TSM.

As diferenças entre os experimentos SEM025 e DIA025 são menores do que entre SEM1 e SEM025 (Figura 21b), até porque as TSM's de SEM025 foram construídas a partir das TSM's utilizadas em DIA025. O padrão observado na Figura 21a, quanto às maiores diferenças se darem na porção oceânica e as menores na amazônica, também é identificado na Figura 21b. Neste caso, a quantidade de precipitação acumulada na região de ZCAS oceânica é em geral maior em SEM1 e SEM025 do que em DIA025. Desta forma, DIA025 é o experimento que apresenta menor quantidade de precipitação na região da ZCAS oceânica, entretanto este experimento apresenta mais chuva nas porções polar e equatorial da ZCAS, distribuindo mais a precipitação horizontalmente do que SEM1 e SEM025. 
(a)

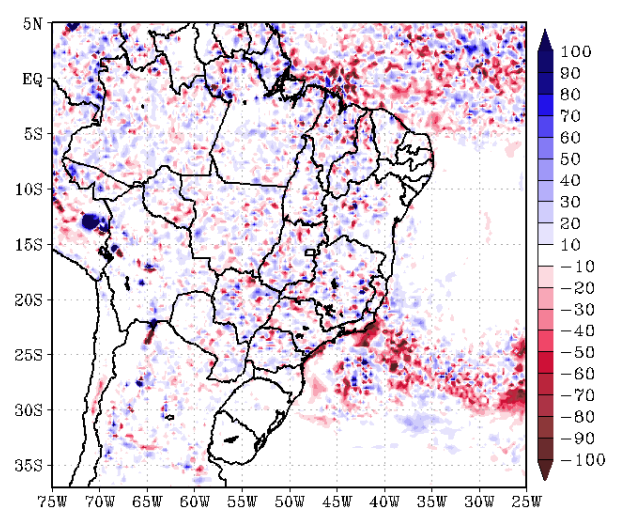

(b)

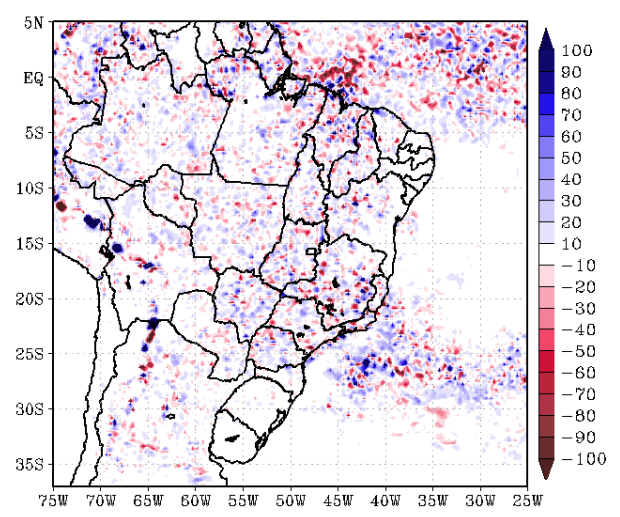

Figura 21. Diferença da precipitação acumulada no final do período de integração do modelo (08/02/98 às 00Z a 19/02/98 às 00Z) entre os experimentos numéricos (a) SEM025 e SEM1 (SEM025-SEM1) e (b) SEM025 e DIA025 (SEM025-DIA025) (intervalo de $10 \mathrm{~mm} \mathrm{dia}^{-1}$ ).

\subsubsection{ZCAS-99}

Comparando-se as simulações SEM025 e SEM1 com relação à TSM média, observa-se, na Figura 22, que a TSM em SEM1 é maior do que em SEM025, principalmente no Pacífico Sul e no Atlântico Sul, assim como ocorre em ZCAS-98 (Figura 17). No entanto, a magnitude da diferença de TSM entre os experimentos é menor em ZCAS-99 do que em ZCAS-98. Observa-se apenas uma pequena porção onde a TSM é maior em SEM025 do que SEM1 próxima à costa de São Paulo (Figura 22).

A temperatura em 1000 hPa é maior em SEM1 do que em SEM025 (Figura 23), também com destaque para o Pacífico e Atlântico Sul. Assim como em ZCAS-98, a maior TSM em SEM1 faz com que o ar adjacente sofra maior aquecimento. Não foram calculadas as diferenças de TSM e temperatura entre SEM025 e DIA025 pelas razões já apresentadas na seção anterior. 


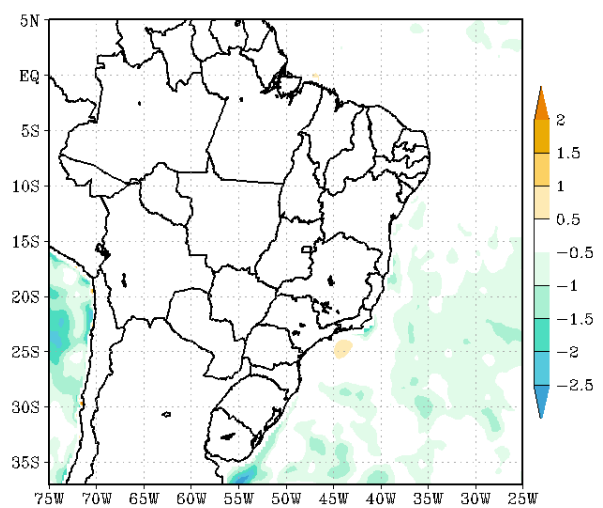

Figura 22. Diferença da média de TSM de todo o período de integração do modelo (02/01/99 às 00Z a $18 / 01 / 99$ às $00 Z$ ) entre os experimentos numéricos SEM025 e SEM1 (SEM025-SEM1) (intervalo de $\left.0,5^{\circ} \mathrm{C}\right)$.

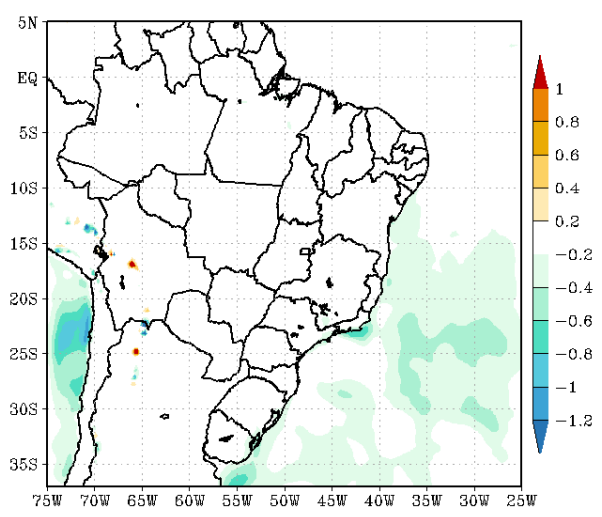

Figura 23. Idem à Figura 22 mas para temperatura do ar em $1000 \mathrm{hPa}$ (intervalo de $0,2^{\circ} \mathrm{C}$ ).

Com relação à umidade específica média em baixos níveis, SEM025 apresenta maior quantidade de umidade disponível do que SEM1 de um modo geral (Figura 24a), sendo que apesar da pequena magnitude as maiores diferenças encontram-se ao longo da Cordilheira dos Andes, no Atlântico Sul e no oceano na direção da costa da Bahia. Entre SEM025 e DIA025 (Figura 24b) observam-se poucas diferenças, mais concentradas ao longo dos Andes, no Pacífico e pequenas porções no Atlântico. No sul do Atlântico Sul há mais umidade em SEM025 do que em DIA025 majoritariamente.

As maiores diferenças entre SEM025 e SEM1 e entre SEM025 e DIA025 com relação à divergência do fluxo horizontal de umidade integrado na atmosfera (Figuras $24 \mathrm{c}$ e 24d) encontram-se ao longo da ZCAS oceânica, ao longo da ZCIT e dos Andes, similarmente ao que ocorre em ZCAS-98 (Figuras 19c e 19d).

O fluxo de calor sensível médio em SEM1 é maior do que em SEM025 na maior parte da região oceânica (Figura 25a), refletindo a maior TSM em SEM1, semelhantemente ao que ocorre em ZCAS-98 (Figura 20a). Nota-se um núcleo com fluxo de calor sensível mais intenso em SEM025 próximo à costa do estado de São Paulo, coincidindo com a pequena porção onde a TSM em SEM025 é maior do que em SEM1 (Figura 22). Sobre o continente as 
diferenças entre os dois experimentos são de menor magnitude, não sendo possível observar um padrão claro. As diferenças entre o fluxo de calor sensível em SEM025 e DIA025 concentram-se sobre o continente (Figura 25b), já que os dados de TSM que alimentaram o modelo no experimento SEM025 foram construídos a partir dos utilizados em DIA025, desta forma, sobre o oceano é de se esperar que não haja discrepâncias significativas.

(a)

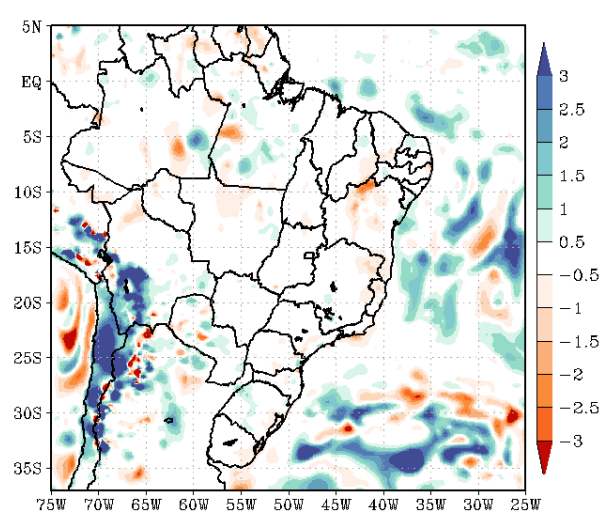

(c)

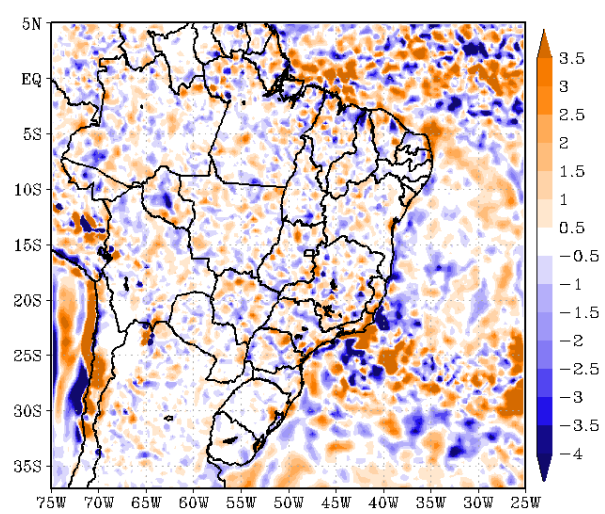

(b)

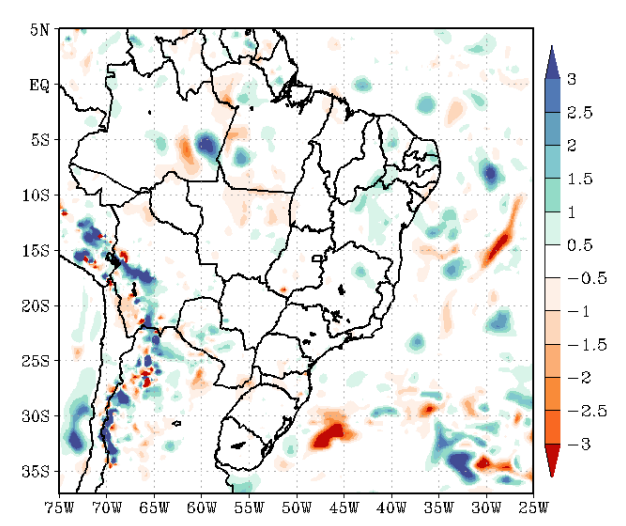

(d)

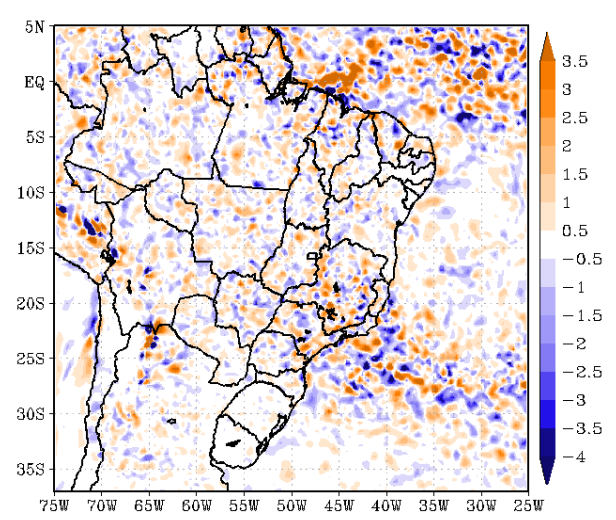

Figura 24. Diferença da média de umidade específica de todo o período de integração do modelo (02/01/99 às 00Z a 18/01/99 às 00Z) entre os experimentos numéricos (a) SEM025 e SEM1 (SEM025-SEM1) e (b) SEM025 e DIA025 (SEM025-DIA025) (intervalo de $0,5 \times 10^{-3} \mathrm{~g} \mathrm{~kg}^{-1}$ ) e diferença da divergência média do fluxo horizontal de umidade, do mesmo período de integração, integrado na atmosfera, da pressão reduzida ao nível médio do mar ao nível de $100 \mathrm{hPa}$ entre os experimentos numéricos (c) SEM025 e SEM1 (SEM025SEM1) e (d) SEM025 e DIA025 (SEM025-DIA025) (intervalo de $0,5 \times 10^{-4} \mathrm{~kg} \mathrm{~kg}^{-1} \mathrm{~s}^{-1}$ ).

No que tange ao fluxo de calor latente (Figura 25c), as diferenças entre SEM1 e SEM025 se dão majoritariamente sobre o oceano, sendo que podem ser da ordem de $56 \mathrm{~W} \mathrm{~m}^{-2}$ (escala da Figura 25c deve ser multiplicada por 4), assim há razoavelmente maior fluxo de calor latente em SEM1 com relação a SEM025, o que pode significar maior evaporação e assim 
maior suprimento de umidade para a formação de nebulosidade e precipitação associada em SEM1, similarmente a ZCAS-98 (Figura 20c). Na pequena porção oceânica próxima à costa de São Paulo, já citada anteriormente, há maior fluxo de calor latente em SEM025, consistentemente com a maior TSM nessa região. Sobre o continente não são encontradas diferenças significativas. A partir da Figura 25d observa-se maior fluxo de calor latente em SEM025 do que em DIA025 na região do Atlântico Sul, já na região da ZCIT a situação se inverte assim como em ZCAS-98 (Figura 20d), sugerindo maior evaporação em SEM025 do que em DIA025 na região de ZCAS oceânica.

(a)

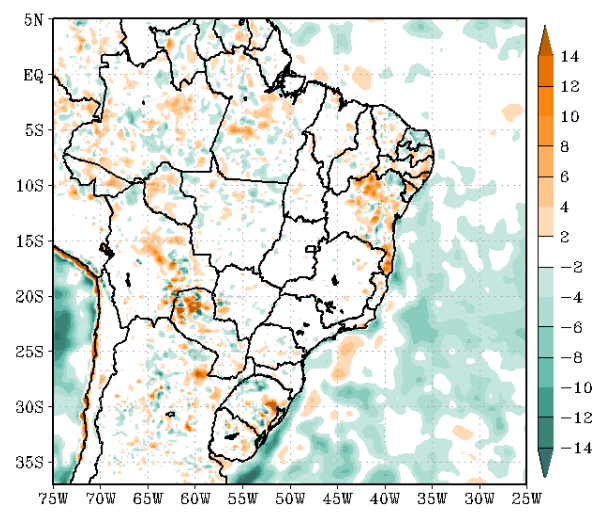

(c)

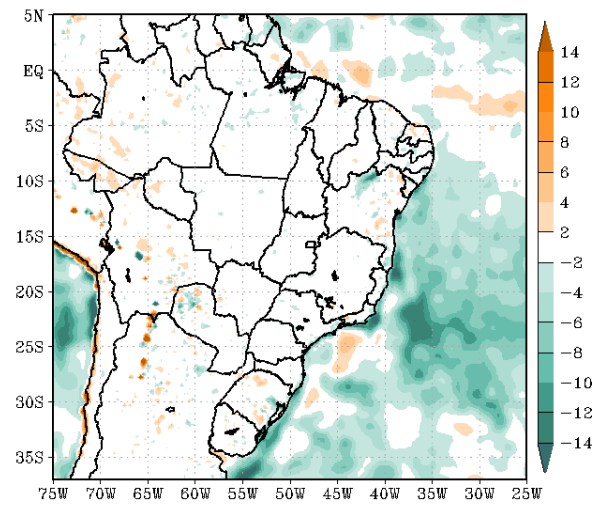

(b)

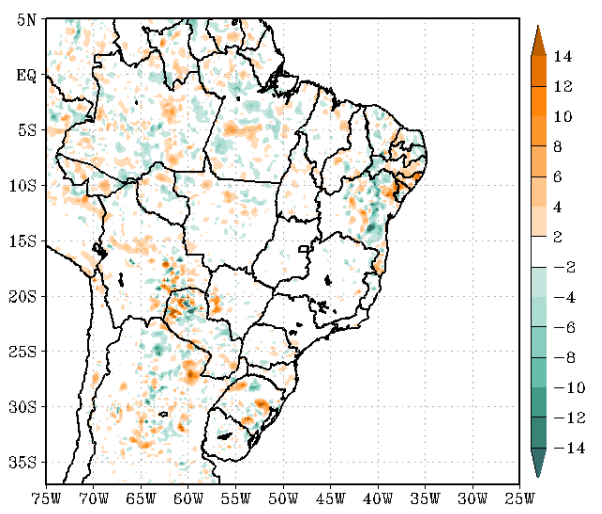

(d)

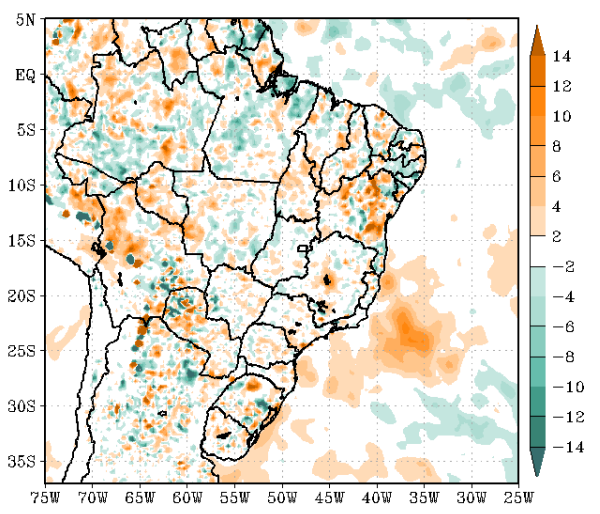

Figura 25. Diferença da média do fluxo de calor sensível à superfície de todo o período de integração do modelo (02/01/99 às 00Z a 18/01/99 às 00Z) entre os experimentos numéricos (a) SEM025 e SEM1 (SEM025SEM1) e (b) SEM025 e DIA025 (SEM025-DIA025) (intervalo de $2 \mathrm{~W} \mathrm{~m}^{-2}$ ) e diferença da média do fluxo de calor latente à superfície, do mesmo período de integração, entre os experimentos numéricos (c) SEM025 e SEM1 (SEM025-SEM1) e (d) SEM025 e DIA025 (SEM025-DIA025) (intervalo de $2 \mathrm{~W} \mathrm{~m}^{-2}$ ). Os valores em (c) devem ser multiplicados por 4. 
As diferenças de precipitação acumulada entre SEM025 e SEM1 e entre SEM025 e DIA025 encontram-se majoritariamente ao longo da ZCAS e da ZCIT (Figuras 26a e 26b). A partir da Figura 26a observa-se que há maior quantidade de precipitação acumulada em SEM1 do que em SEM025, principalmente na região oceânica, assim como ocorre para ZCAS-98 (Figura 21a). Em SEM025 há maior quantidade de precipitação nas porções polar e equatorial da ZCAS do que em SEM1. As maiores diferenças estão sobre o oceano nas duas comparações, uma vez que a única diferença entre as simulações são os dados de TSM. Sendo assim, esta variável tende a impactar principalmente as regiões sobre o oceano. Observa-se também certo impacto ao longo da região costeira do Brasil (Figuras 26a e 26b). Na Figura 26b é possível notar que há principalmente mais precipitação acumulada na ZCAS oceânica em SEM025 do que em DIA025.

Em síntese, o experimento com menor quantidade de precipitação acumulada na ZCAS oceânica é DIA025, sendo seguido por SEM025 e por SEM1, nesta ordem, assim como ocorre em ZCAS-98 (Figuras 21a e 21b).

(a)

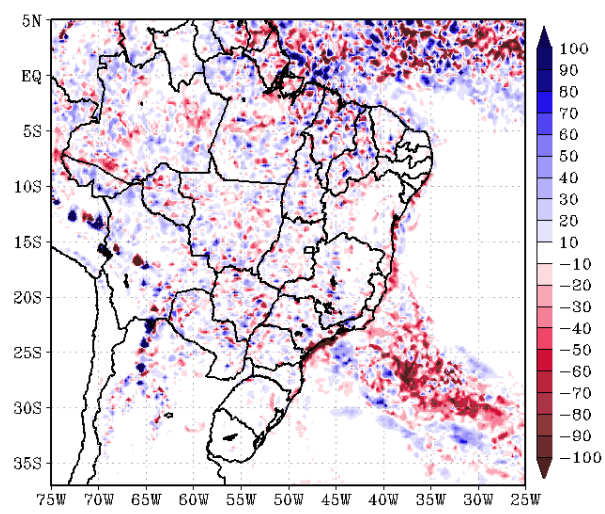

(b)

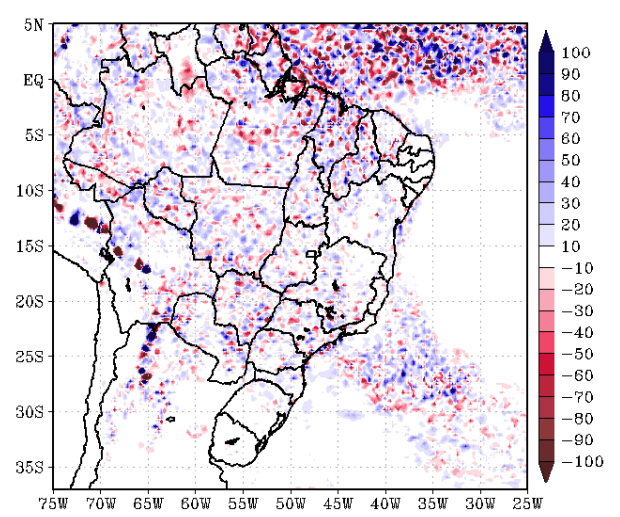

Figura 26. Diferença da precipitação acumulada no final do período de integração do modelo (02/01/99 às 00Z a 18/01/99 às 00Z) entre os experimentos numéricos (a) SEM025 e SEM1 (SEM025-SEM1) e (b) SEM025 e DIA025 (SEM025-DIA025) (intervalo de $10 \mathrm{~mm} \mathrm{dia}^{-1}$ ). 


\subsection{Verificação das simulações de precipitação}

\subsubsection{ZCAS-98}

Com base na Tabela 6 observa-se que o DPS é maior do que DPO em todos os experimentos numéricos em todas as regiões e limiares de chuva, o que indica que os valores simulados estão mais dispersos em relação ao valor médio do que os observados. Observa-se também que de uma forma geral DPO e DPS são menores à medida que se aumenta o limiar, uma vez que há menor flutuação dos valores em torno da média quanto maior for o limiar. Das regiões que compõem a ZCAS, a amazônica é a que apresenta menores DPS's em todos os experimentos.

Observando-se os valores de EM, nota-se que o modelo, nos três experimentos, superestima a precipitação para os limiares mais baixos, subestimando para os limiares maiores ou iguais a $12,7 \mathrm{~mm} \mathrm{dia}^{-1}$, com exceção da região costeira, na qual a subestimativa ocorre a partir do limiar de 19,0 $\mathrm{mm} \mathrm{dia}^{-1}$. O viés depende do limiar de chuva, sendo que a superestimativa (subestimativa) é maior para o limiar mais baixo (alto). Desta forma, o modelo BRAMS apresenta uma melhor performance para os limiares intermediários (fraca e moderada) e os maiores vieses se dão para limiares altos de chuva e para o experimento SEM1.

Com base em RMSE pode-se observar que a acurácia da previsão de chuva é maior para ao limiares mais baixos, decrescendo gradativamente para os mais limiares mais altos. Com relação às diferentes regiões, a acurácia é menor quando considera-se todo o domínio e é maior para as limiares mais baixos na região amazônica.

Quando remove-se o viés de RMSE é possível notar que grande parte do erro do BRAMS na previsão da quantidade de precipitação é devido ao próprio viés do modelo. A redução no 
valor de $\mathrm{RMSE}_{\mathrm{UB}}$ com relação a RMSE mostra que o modelo posiciona a precipitação corretamente, e o RMSE $E_{U B}$ revela que o modelo erra de forma sistemática para limiares de chuva intensa, pois o mesmo é mais acurado na previsão de chuva para os limiares mais altos quando não é levado em conta o viés

Tabela 6 - DPO para cada limiar de precipitação do NCEP $\left(\mathrm{mm} \mathrm{dia}^{-1}\right)$, para todo domínio e cada região que compõe a ZCAS (oceânica, costeira e amazônica) separadamente. DPS, EM, RMSE e RMSE UB $_{\text {para cada limiar }}$ de precipitação do NCEP $\left(\mathrm{mm} \mathrm{dia}^{-1}\right)$, para todo domínio e cada região que compõe a ZCAS (oceânica, costeira e amazônica) separadamente e para cada um dos experimentos numéricos (SEM025, SEM1 e DIA025) realizados com o BRAMS para ZCAS-98.

\begin{tabular}{|c|c|c|c|c|c|c|c|c|c|c|c|c|c|c|}
\hline \multirow[b]{2}{*}{ Região } & \multirow{2}{*}{$\begin{array}{c}\text { Limiar } \\
\left(\mathrm{mm}^{-1}\right. \\
\left.\mathrm{dia}^{-1}\right)\end{array}$} & \multirow[b]{2}{*}{ DPO } & \multicolumn{4}{|c|}{ SEM025 } & \multicolumn{4}{|c|}{ SEM1 } & \multicolumn{4}{|c|}{ DIA025 } \\
\hline & & & DPS & EM & RMSE & $\mathrm{RMSE}_{\mathbf{B}}$ & DPS & EM & RMSE & $\mathrm{RMSE}_{\mathbf{B}}$ & DPS & EM & RMSE & $\mathrm{RMSE}_{\mathrm{B}}$ \\
\hline \multirow{8}{*}{ 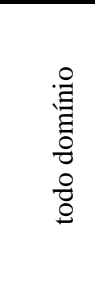 } & 0,3 & 5,887 & 8,660 & 6,764 & 15,053 & 9,937 & 8,725 & 6,875 & 15,208 & 10,022 & 8,568 & 6,686 & 14,951 & 9,860 \\
\hline & 2,5 & 5,801 & 8,844 & 4,102 & 15,162 & 10,149 & 8,888 & 4,149 & 15,234 & 10,191 & 8,721 & 3,992 & 15,003 & 10,045 \\
\hline & 6,3 & 5,001 & 8,186 & 1,522 & 15,421 & 9,452 & 8,216 & 1,551 & 15,455 & $\begin{array}{r}9,472 \\
\end{array}$ & 8,010 & 1,394 & 15,231 & 9,296 \\
\hline & 12,7 & 3,278 & 6,261 & $-2,127$ & 16,335 & 7,068 & 6,308 & $-2,071$ & 16,324 & 7,118 & 6,140 & $-2,229$ & 16,144 & 6,960 \\
\hline & 19,0 & 1,850 & 3,830 & $-6,352$ & 18,281 & 4,267 & 3,824 & $-6,277$ & 18,281 & 4,278 & 3,776 & $-6,453$ & 18,119 & 4,234 \\
\hline & 25,4 & 0,720 & 2,131 & $-10,080$ & 21,805 & 2,289 & 2,116 & $-10,033$ & 21,877 & 2,280 & 2,083 & $-10,235$ & 21,761 & 2,243 \\
\hline & 38,1 & 0,046 & 0,403 & $-21,190$ & 31,469 & 0,434 & 0,383 & $-21,647$ & 31,290 & 0,413 & 0,394 & $-21,538$ & 31,480 & 0,425 \\
\hline & 50,8 & 0,000 & 0,000 & $-45,832$ & 45,832 & 0,000 & 0,000 & $-46,050$ & 46,050 & 0,000 & 0,000 & $-45,148$ & 45,148 & 0,000 \\
\hline \multirow{8}{*}{ 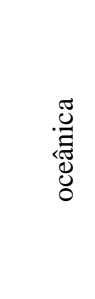 } & 0,3 & 5,851 & 10,843 & 5,023 & 14,019 & 11,647 & 11,050 & 5,122 & 14,415 & 12,022 & 10,601 & 4,927 & 13,845 & 11,428 \\
\hline & 2,5 & 5,433 & 11,385 & 4,599 & 15,721 & 12,960 & 11,602 & 4,486 & 16,020 & 13,245 & 11,018 & 4,378 & 15,392 & 12,629 \\
\hline & 6,3 & 4,488 & 10,085 & 1,911 & 16,517 & 11,622 & 10,460 & 1,619 & 16,740 & 11,996 & 9,716 & 1,718 & 16,214 & 11,341 \\
\hline & 12,7 & 2,381 & 6,799 & $-2,268$ & 17,867 & 7,420 & 7,183 & $-2,327$ & 18,140 & 7,873 & 6,563 & $-2,423$ & 17,573 & 7,223 \\
\hline & 19,0 & 0,627 & 2,274 & $-8,067$ & 18,363 & 2,270 & 2,536 & $-8,253$ & 18,679 & 2,520 & 2,363 & $-8,326$ & 17,801 & 2,350 \\
\hline & 25,4 & 0,069 & 0,243 & $-12,627$ & 18,126 & 0,247 & 0,379 & $-12,564$ & 19,079 & 0,380 & 0,299 & $-12,748$ & 17,486 & 0,304 \\
\hline & 38,1 & 0,000 & 0,000 & $-18,749$ & 21,310 & 0,000 & 0,000 & $-20,917$ & 21,293 & 0,000 & 0,000 & $-18,877$ & 20,743 & 0,000 \\
\hline & 50,8 & -9999 & -9999 & -9999 & -9999 & -9999 & -9999 & -9999 & -9999 & -9999 & -9999 & -9999 & -9999 & -9999 \\
\hline \multirow{8}{*}{$\begin{array}{l}\frac{\pi}{0} \\
\frac{0}{0} \\
0 \\
0\end{array}$} & 0,3 & 7,526 & 10,801 & 9,226 & 16,300 & 12,311 & 11,157 & 9,618 & 16,758 & 12,625 & 10,534 & 9,015 & 16,049 & 12,099 \\
\hline & 2,5 & 7,078 & 10,452 & 7,307 & 15,324 & 11,771 & 10,773 & 7,736 & 15,768 & 12,077 & 10,268 & 7,130 & 15,157 & 11,621 \\
\hline & 6,3 & 5,859 & 9,591 & 4,555 & 14,174 & 10,422 & 9,886 & 5,021 & 14,618 & 10,728 & 9,347 & 4,283 & 13,915 & 10,158 \\
\hline & 12,7 & 3,209 & 6,703 & 0,569 & 13,605 & 6,960 & 6,955 & 0,888 & 13,744 & 7,186 & 6,534 & 0,215 & 13,294 & 6,779 \\
\hline & 19,0 & 1,327 & 3,487 & $-2,302$ & 14,323 & 3,345 & 3,635 & $-1,678$ & 14,466 & 3,505 & 3,321 & $-2,650$ & 14,021 & 3,232 \\
\hline & 25,4 & 0,334 & 0,990 & $-4,385$ & 16,291 & 0,818 & 1,004 & $-3,721$ & 16,169 & 0,851 & 0,958 & $-4,837$ & 15,947 & 0,802 \\
\hline & 38,1 & 0,000 & 0,000 & $-13,606$ & 20,489 & 0,000 & 0,000 & $-13,508$ & 20,584 & 0,000 & 0,000 & $-14,764$ & 20,667 & 0,000 \\
\hline & 50,8 & -9999 & -9999 & -9999 & -9999 & -9999 & -9999 & -9999 & -9999 & -9999 & -9999 & -9999 & -9999 & -9999 \\
\hline \multirow{8}{*}{ 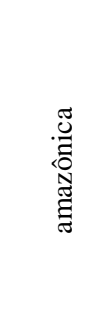 } & 0,3 & 5,989 & 8,092 & 5,056 & 11,955 & 9,668 & 8,026 & 5,078 & 11,920 & 9,614 & 8,024 & 5,090 & 11,961 & 9,643 \\
\hline & 2,5 & 5,523 & 7,720 & 4,145 & 11,609 & 9,325 & 7,660 & 4,102 & 11,508 & 9,265 & 7,642 & 4,073 & 11,496 & 9,284 \\
\hline & 6,3 & 4,913 & 7,313 & 1,802 & 10,947 & 8,966 & 7,246 & 1,742 & 10,791 & 8,904 & 7,222 & 1,676 & 10,779 & 8,883 \\
\hline & 12,7 & 3,591 & 5,630 & $-4,143$ & 10,313 & 6,647 & 5,512 & $-4,103$ & 10,231 & 6,586 & 5,539 & $-4,177$ & 10,252 & 6,583 \\
\hline & 19,0 & 1,650 & 2,200 & $-10,068$ & 12,507 & 2,866 & 2,092 & $-10,092$ & 12,428 & 2,782 & 2,240 & $-10,030$ & 12,601 & 2,873 \\
\hline & 25,4 & 0,270 & 0,595 & $-15,960$ & 16,486 & 0,652 & 0,511 & $-16,021$ & 16,528 & 0,594 & 0,509 & $-16,044$ & 16,591 & 0,578 \\
\hline & 38,1 & 0,000 & 0,000 & $-30,694$ & 30,694 & 0,000 & 0,000 & $-31,278$ & 31,278 & 0,000 & 0,000 & $-31,563$ & 31,563 & 0,000 \\
\hline & 50,8 & 0,000 & 0,000 & $-41,810$ & 41,810 & 0,000 & 0,000 & $-42,593$ & 42,593 & 0,000 & 0,000 & $-42,146$ & 42,146 & 0,000 \\
\hline
\end{tabular}

Comparando-se as regiões, o modelo apresenta melhor desempenho para a região de ZCAS amazônica. Já comparando-se os três experimentos numéricos com base nos índices 
estatísticos da Tabela 6, de uma forma geral, SEM1 é o experimento de pior desempenho e DIA025 é o de melhor skill, que é muito semelhante ao de SEM025, já que as TSM's deste são construídas a partir das utilizadas em DIA025.

Com base em TSA (Tabelas 7, 8 e 9) observa-se que, de maneira geral e para cada região, os melhores valores se dão para os limiares mais baixos nos três experimentos, principalmente para o limiar de chuva-não chuva, decrescendo gradativamente para os limiares subsequentes. Assim, o modelo BRAMS possui um melhor desempenho em prever a ocorrência/não ocorrência de chuva do que em localizar os núcleos mais intensos de chuva - assim como apontado por Mendonça (1999), que obteve conclusão similar para o modelo global CPTEC/COLA - porém quando localiza os núcleos o BRAMS apresenta grande skill na previsão da quantidade de chuva intensa, conforme pôde ser visto a partir de RMSE $\mathrm{UB}_{\text {. }}$

Comprando-se as três regiões que compõem a ZCAS, o pior desempenho do modelo se deu para a região oceânica e o melhor para a amazônica, na qual os valores de TSA são iguais ou próximos de 1 , principalmente para o limiar de $0,3 \mathrm{~mm} \mathrm{dia}^{-1}$. Observa-se também destaque para a região costeira, na qual o modelo apresenta desempenho razoável para os limiares de chuva fraca e moderada. 
Tabela 7 - TSA para cada dia de simulação para os limiares de precipitação do NCEP (mm dia ${ }^{-1}$ ), para todo o domínio e cada região que compõe a ZCAS (oceânica, costeira e amazônica) separadamente para SEM025 para ZCAS-98. Os valores destacados em vermelho e sombreados em cinza representam os cinco melhores valores de TSA em cada limiar e os cinco melhores valores de TSA em cada região, respectivamente.

\begin{tabular}{|c|c|c|c|c|c|c|c|c|c|c|c|c|}
\hline Região & $\begin{array}{c}\text { Limiar } \\
\left(\mathbf{m m}^{-1}\right. \\
\left.\mathbf{d i a}^{-1}\right)\end{array}$ & $\begin{array}{c}\text { dia } \\
8\end{array}$ & $\begin{array}{c}\text { dia } \\
9\end{array}$ & $\begin{array}{c}\text { dia } \\
10\end{array}$ & $\begin{array}{c}\text { dia } \\
11\end{array}$ & $\begin{array}{c}\text { dia } \\
12\end{array}$ & $\begin{array}{c}\text { dia } \\
13\end{array}$ & $\begin{array}{c}\text { dia } \\
14\end{array}$ & $\begin{array}{c}\text { dia } \\
15\end{array}$ & $\begin{array}{c}\text { dia } \\
16\end{array}$ & $\begin{array}{c}\text { dia } \\
17\end{array}$ & $\begin{array}{c}\text { dia } \\
18\end{array}$ \\
\hline \multirow{8}{*}{ 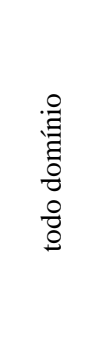 } & 0,3 & 0,636 & 0,666 & 0,702 & 0,698 & 0,736 & 0,624 & 0,646 & 0,566 & 0,498 & 0,503 & 0,604 \\
\hline & 2,5 & 0,449 & 0,456 & 0,537 & 0,631 & 0,591 & 0,511 & 0,517 & 0,457 & 0,372 & 0,361 & 0,442 \\
\hline & 6,3 & 0,326 & 0,311 & 0,372 & 0,481 & 0,464 & 0,389 & 0,255 & 0,247 & 0,228 & 0,238 & 0,285 \\
\hline & 12,7 & 0,162 & 0,139 & 0,196 & 0,233 & 0,279 & 0,189 & 0,087 & 0,083 & 0,087 & 0,127 & 0,123 \\
\hline & 19,0 & 0,072 & 0,059 & 0,134 & 0,111 & 0,143 & 0,052 & 0,028 & 0,030 & 0,032 & 0,076 & 0,051 \\
\hline & 25,4 & 0,030 & 0,025 & 0,122 & 0,053 & 0,089 & 0,009 & 0,004 & 0,008 & 0,008 & 0,054 & 0,028 \\
\hline & 38,1 & 0,003 & 0,009 & 0,017 & 0,009 & 0,021 & -9999 & -9999 & -9999 & 0,000 & 0,023 & 0,006 \\
\hline & 50,8 & 0,000 & -9999 & -9999 & 0,000 & -9999 & -9999 & -9999 & -9999 & -9999 & -9999 & 0,000 \\
\hline \multirow{8}{*}{ 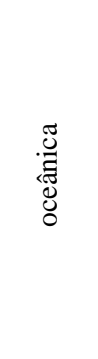 } & 0,3 & 0,675 & 0,143 & 0,690 & 0,715 & 0,687 & 0,644 & 0,721 & 0,601 & 0,492 & 0,750 & 0,764 \\
\hline & 2,5 & 0,168 & 0,015 & 0,499 & 0,752 & 0,588 & 0,707 & 0,669 & 0,565 & 0,330 & 0,588 & 0,560 \\
\hline & 6,3 & 0,053 & 0,000 & 0,262 & 0,617 & 0,546 & 0,473 & 0,521 & 0,460 & 0,175 & 0,471 & 0,413 \\
\hline & 12,7 & 0,000 & -9999 & 0,077 & 0,385 & 0,513 & 0,109 & 0,233 & 0,251 & 0,088 & 0,357 & 0,164 \\
\hline & 19,0 & 0,000 & -9999 & 0,020 & 0,031 & 0,471 & 0,043 & 0,015 & 0,077 & 0,005 & 0,310 & 0,012 \\
\hline & 25,4 & -9999 & -9999 & -9999 & -9999 & 0,153 & -9999 & -9999 & -9999 & 0,000 & 0,190 & 0,000 \\
\hline & 38,1 & -9999 & -9999 & -9999 & -9999 & -9999 & -9999 & -9999 & -9999 & -9999 & 0,029 & -9999 \\
\hline & 50,8 & -9999 & -9999 & -9999 & -9999 & -9999 & -9999 & -9999 & -9999 & -9999 & -9999 & -9999 \\
\hline \multirow{8}{*}{$\begin{array}{l}\frac{\pi}{0} \\
\frac{0}{0} \\
0 \\
0\end{array}$} & 0,3 & 0,946 & 0,982 & 0,930 & 0,866 & 0,869 & 0,917 & 0,930 & 0,961 & 0,933 & 0,834 & 0,974 \\
\hline & 2,5 & 0,913 & 0,803 & 0,901 & 0,781 & 0,811 & 0,702 & 0,615 & 0,879 & 0,745 & 0,623 & 0,794 \\
\hline & 6,3 & 0,700 & 0,575 & 0,701 & 0,662 & 0,702 & 0,719 & 0,366 & 0,394 & 0,523 & 0,264 & 0,358 \\
\hline & 12,7 & 0,194 & 0,120 & 0,312 & 0,377 & 0,556 & 0,392 & 0,070 & 0,135 & 0,278 & 0,074 & 0,138 \\
\hline & 19,0 & 0,058 & 0,028 & 0,194 & 0,188 & 0,344 & 0,115 & 0,011 & 0,027 & 0,145 & 1,000 & 0,038 \\
\hline & 25,4 & 0,000 & 0,007 & 0,188 & 0,105 & 0,225 & 0,017 & 0,000 & -9999 & 0,047 & -9999 & 0,007 \\
\hline & 38,1 & -9999 & -9999 & 0,017 & 0,038 & 0,018 & -9999 & -9999 & -9999 & 0,000 & -9999 & -9999 \\
\hline & 50,8 & -9999 & -9999 & -9999 & -9999 & -9999 & -9999 & -9999 & -9999 & -9999 & -9999 & -9999 \\
\hline \multirow{8}{*}{ 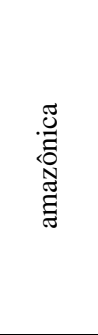 } & 0,3 & 0,921 & 0,977 & 0,977 & 0,993 & 0,965 & 1,000 & 0,974 & 0,906 & 0,952 & 0,819 & 0,782 \\
\hline & 2,5 & 0,755 & 0,861 & 0,785 & 0,890 & 0,879 & 0,772 & 0,841 & 0,746 & 0,895 & 0,547 & 0,608 \\
\hline & 6,3 & 0,527 & 0,618 & 0,471 & 0,606 & 0,701 & 0,439 & 0,442 & 0,518 & 0,719 & 0,353 & 0,436 \\
\hline & 12,7 & 0,340 & 0,224 & 0,076 & 0,258 & 0,287 & 0,189 & 0,170 & 0,162 & 0,226 & 0,140 & 0,132 \\
\hline & 19,0 & 0,081 & 0,027 & 0,004 & 0,130 & 0,121 & 0,086 & 0,077 & 0,038 & 0,067 & 0,039 & 0,016 \\
\hline & 25,4 & 0,000 & 0,000 & -9999 & 0,056 & 0,063 & 0,060 & 0,002 & 0,000 & -9999 & 0,016 & 0,000 \\
\hline & 38,1 & -9999 & 0,000 & -9999 & 0,000 & 0,000 & -9999 & -9999 & -9999 & -9999 & -9999 & -9999 \\
\hline & 50,8 & -9999 & -9999 & -9999 & 0,000 & -9999 & -9999 & -9999 & -9999 & -9999 & -9999 & -9999 \\
\hline
\end{tabular}


Tabela 8 - Idem à Tabela 7 mas para SEM1.

\begin{tabular}{|c|c|c|c|c|c|c|c|c|c|c|c|c|}
\hline Região & $\begin{array}{c}\text { Limiar } \\
\left(\mathbf{m m}^{-1}\right. \\
\left.\text { dia }^{-1}\right)\end{array}$ & $\begin{array}{c}\text { dia } \\
\mathbf{8} \\
\end{array}$ & $\begin{array}{c}\text { dia } \\
9 \\
\end{array}$ & $\begin{array}{c}\text { dia } \\
10\end{array}$ & $\begin{array}{c}\text { dia } \\
11 \\
\end{array}$ & $\begin{array}{c}\text { dia } \\
12 \\
\end{array}$ & $\begin{array}{c}\text { dia } \\
13 \\
\end{array}$ & $\begin{array}{l}\text { dia } \\
14 \\
\end{array}$ & $\begin{array}{c}\text { dia } \\
15 \\
\end{array}$ & $\begin{array}{l}\text { dia } \\
16 \\
\end{array}$ & $\begin{array}{c}\text { dia } \\
17 \\
\end{array}$ & $\begin{array}{c}\text { dia } \\
18 \\
\end{array}$ \\
\hline \multirow{8}{*}{ 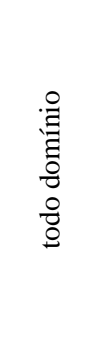 } & 0,3 & 0,643 & 0,669 & 0,716 & 0,696 & 0,732 & 0,626 & 0,652 & 0,562 & 0,497 & 0,504 & 0,605 \\
\hline & 2,5 & 0,439 & 0,453 & 0,529 & 0,631 & 0,601 & 0,513 & 0,516 & 0,451 & 0,375 & 0,359 & 0,441 \\
\hline & 6,3 & 0,318 & 0,307 & 0,372 & 0,484 & 0,462 & 0,407 & 0,255 & 0,245 & 0,231 & 0,234 & 0,276 \\
\hline & 12,7 & 0,158 & 0,134 & 0,194 & 0,235 & 0,288 & 0,194 & 0,083 & 0,081 & 0,089 & 0,127 & 0,120 \\
\hline & 19,0 & 0,067 & 0,059 & 0,133 & 0,107 & 0,144 & 0,051 & 0,023 & 0,029 & 0,036 & 0,072 & 0,053 \\
\hline & 25,4 & 0,028 & 0,023 & 0,113 & 0,054 & 0,091 & 0,008 & 0,001 & 0,009 & 0,008 & 0,049 & 0,032 \\
\hline & 38,1 & 0,002 & 0,005 & 0,016 & 0,009 & 0,018 & -9999 & -9999 & -9999 & 0,000 & 0,019 & 0,006 \\
\hline & 50,8 & 0,000 & -9999 & -9999 & 0,000 & -9999 & -9999 & -9999 & -9999 & -9999 & -9999 & 0,000 \\
\hline \multirow{8}{*}{ 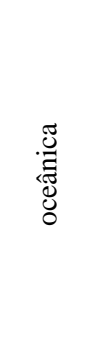 } & 0,3 & 0,696 & 0,147 & 0,715 & 0,724 & 0,680 & 0,610 & 0,703 & 0,579 & 0,490 & 0,734 & 0,779 \\
\hline & 2,5 & 0,142 & 0,007 & 0,478 & 0,769 & 0,604 & 0,711 & 0,667 & 0,546 & 0,325 & 0,579 & 0,559 \\
\hline & 6,3 & 0,049 & 0,000 & 0,230 & 0,620 & 0,558 & 0,541 & 0,518 & 0,459 & 0,176 & 0,463 & 0,390 \\
\hline & 12,7 & 0,000 & -9999 & 0,120 & 0,452 & 0,570 & 0,136 & 0,221 & 0,263 & 0,085 & 0,347 & 0,136 \\
\hline & 19,0 & 0,000 & -9999 & 0,016 & 0,030 & 0,457 & 0,068 & 0,008 & 0,089 & 0,006 & 0,278 & 0,007 \\
\hline & 25,4 & -9999 & -9999 & -9999 & -9999 & 0,261 & -9999 & -9999 & -9999 & 0,000 & 0,167 & 0,000 \\
\hline & 38,1 & -9999 & -9999 & -9999 & -9999 & -9999 & -9999 & -9999 & -9999 & -9999 & 0,012 & -9999 \\
\hline & 50,8 & -9999 & -9999 & -9999 & -9999 & -9999 & -9999 & -9999 & -9999 & -9999 & -9999 & -9999 \\
\hline \multirow{8}{*}{$\begin{array}{l}\frac{\pi}{0} \\
\frac{\pi}{0} \\
0 \\
0\end{array}$} & 0,3 & 0,928 & 0,977 & 0,931 & 0,867 & 0,859 & 0,899 & 0,945 & 0,963 & 0,938 & 0,826 & 0,976 \\
\hline & 2,5 & 0,915 & 0,820 & 0,893 & 0,789 & 0,800 & 0,716 & 0,627 & 0,896 & 0,744 & 0,620 & 0,772 \\
\hline & 6,3 & 0,694 & 0,583 & 0,700 & 0,677 & 0,717 & 0,713 & 0,440 & 0,404 & 0,531 & 0,265 & 0,332 \\
\hline & 12,7 & 0,210 & 0,135 & 0,311 & 0,389 & 0,564 & 0,380 & 0,085 & 0,129 & 0,286 & 0,063 & 0,140 \\
\hline & 19,0 & 0,059 & 0,029 & 0,207 & 0,193 & 0,357 & 0,117 & 0,009 & 0,024 & 0,161 & 0,001 & 0,047 \\
\hline & 25,4 & 0,003 & 0,006 & 0,185 & 0,108 & 0,228 & 0,018 & 0,000 & -9999 & 0,047 & -9999 & 0,007 \\
\hline & 38,1 & -9999 & -9999 & 0,020 & 0,023 & 0,024 & -9999 & -9999 & -9999 & 0,000 & -9999 & -9999 \\
\hline & 50,8 & -9999 & -9999 & -9999 & -9999 & -9999 & -9999 & -9999 & -9999 & -9999 & -9999 & -9999 \\
\hline \multirow{8}{*}{ 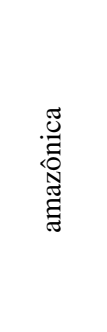 } & 0,3 & 0,923 & 0,993 & 0,970 & 0,997 & 0,952 & 1,000 & 0,979 & 0,904 & 0,953 & 0,824 & 0,784 \\
\hline & 2,5 & 0,757 & 0,886 & 0,762 & 0,882 & 0,865 & 0,753 & 0,843 & 0,731 & 0,906 & 0,563 & 0,595 \\
\hline & 6,3 & 0,539 & 0,637 & 0,459 & 0,597 & 0,681 & 0,477 & 0,488 & 0,490 & 0,715 & 0,357 & 0,426 \\
\hline & 12,7 & 0,340 & 0,233 & 0,083 & 0,253 & 0,286 & 0,185 & 0,171 & 0,151 & 0,229 & 0,151 & 0,132 \\
\hline & 19,0 & 0,096 & 0,034 & 0,004 & 0,122 & 0,145 & 0,084 & 0,063 & 0,032 & 0,069 & 0,031 & 0,018 \\
\hline & 25,4 & 0,000 & 0,002 & -9999 & 0,063 & 0,058 & 0,056 & 0,000 & 1,000 & -9999 & 0,010 & 0,000 \\
\hline & 38,1 & -9999 & 0,000 & -9999 & 0,000 & 0,000 & -9999 & -9999 & -9999 & -9999 & -9999 & -9999 \\
\hline & 50,8 & -9999 & -9999 & -9999 & 0,000 & -9999 & -9999 & -9999 & -9999 & -9999 & -9999 & -9999 \\
\hline
\end{tabular}


Tabela 9 - Idem à Tabela 7 mas para DIA025.

\begin{tabular}{|c|c|c|c|c|c|c|c|c|c|c|c|c|}
\hline Região & $\begin{array}{c}\text { Limiar } \\
\left(\mathbf{m m}^{-1}\right) \\
\left.\text { dia }^{-1}\right)\end{array}$ & $\begin{array}{c}\text { dia } \\
8\end{array}$ & $\begin{array}{c}\text { dia } \\
9\end{array}$ & $\begin{array}{c}\text { dia } \\
10\end{array}$ & $\begin{array}{l}\text { dia } \\
11\end{array}$ & $\begin{array}{c}\text { dia } \\
12\end{array}$ & $\begin{array}{c}\text { dia } \\
13\end{array}$ & $\begin{array}{l}\text { dia } \\
14\end{array}$ & $\begin{array}{c}\text { dia } \\
15\end{array}$ & $\begin{array}{c}\text { dia } \\
16\end{array}$ & $\begin{array}{c}\text { dia } \\
17\end{array}$ & $\begin{array}{c}\text { dia } \\
18\end{array}$ \\
\hline \multirow{8}{*}{ 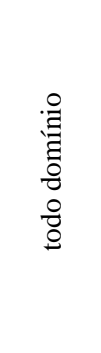 } & 0,3 & 0,638 & 0,665 & 0,712 & 0,698 & 0,732 & 0,627 & 0,652 & 0,561 & 0,499 & 0,502 & 0,602 \\
\hline & 2,5 & 0,449 & 0,459 & 0,540 & 0,632 & 0,589 & 0,516 & 0,521 & 0,454 & 0,373 & 0,362 & 0,444 \\
\hline & 6,3 & 0,326 & 0,311 & 0,378 & 0,484 & 0,464 & 0,394 & 0,257 & 0,245 & 0,231 & 0,233 & 0,283 \\
\hline & 12,7 & 0,162 & 0,134 & 0,202 & 0,239 & 0,281 & 0,187 & 0,086 & 0,080 & 0,088 & 0,127 & 0,126 \\
\hline & 19,0 & 0,069 & 0,058 & 0,138 & 0,112 & 0,140 & 0,051 & 0,026 & 0,030 & 0,031 & 0,077 & 0,051 \\
\hline & 25,4 & 0,030 & 0,022 & 0,121 & 0,052 & 0,089 & 0,010 & 0,003 & 0,007 & 0,007 & 0,054 & 0,029 \\
\hline & 38,1 & 0,002 & 0,006 & 0,015 & 0,009 & 0,018 & -9999 & -9999 & -9999 & 0,000 & 0,022 & 0,005 \\
\hline & 50,8 & 0,000 & -9999 & -9999 & 0,000 & -9999 & -9999 & -9999 & -9999 & -9999 & -9999 & 0,000 \\
\hline \multirow{8}{*}{ 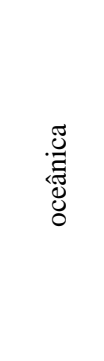 } & 0,3 & 0,639 & 0,144 & 0,699 & 0,718 & 0,646 & 0,612 & 0,738 & 0,583 & 0,492 & 0,747 & 0,763 \\
\hline & 2,5 & 0,155 & 0,014 & 0,494 & 0,754 & 0,591 & 0,679 & 0,654 & 0,557 & 0,329 & 0,587 & 0,573 \\
\hline & 6,3 & 0,051 & 0,000 & 0,251 & 0,620 & 0,552 & 0,440 & 0,492 & 0,461 & 0,173 & 0,461 & 0,401 \\
\hline & 12,7 & 0,000 & -9999 & 0,125 & 0,436 & 0,528 & 0,112 & 0,229 & 0,242 & 0,085 & 0,357 & 0,172 \\
\hline & 19,0 & 0,000 & -9999 & 1,000 & 0,031 & 0,455 & 0,064 & 0,015 & 0,072 & 0,008 & 0,321 & 0,018 \\
\hline & 25,4 & -9999 & -9999 & -9999 & -9999 & 0,202 & -9999 & -9999 & -9999 & 0,000 & 0,201 & 0,000 \\
\hline & 38,1 & -9999 & -9999 & -9999 & -9999 & -9999 & -9999 & -9999 & -9999 & -9999 & 0,025 & -9999 \\
\hline & 50,8 & -9999 & -9999 & -9999 & -9999 & -9999 & -9999 & -9999 & -9999 & -9999 & -9999 & -9999 \\
\hline \multirow{8}{*}{$\begin{array}{l}\frac{\pi}{0} \\
\frac{0}{0} \\
0\end{array}$} & 0,3 & 0,945 & 0,960 & 0,927 & 0,858 & 0,864 & 0,922 & 0,934 & 0,959 & 0,933 & 0,832 & 0,971 \\
\hline & 2,5 & 0,913 & 0,820 & 0,889 & 0,773 & 0,809 & 0,731 & 0,621 & 0,889 & 0,774 & 0,619 & 0,782 \\
\hline & 6,3 & 0,704 & 0,561 & 0,711 & 0,664 & 0,712 & 0,748 & 0,410 & 0,419 & 0,528 & 0,270 & 0,361 \\
\hline & 12,7 & 0,200 & 0,122 & 0,310 & 0,389 & 0,550 & 0,375 & 0,065 & 0,126 & 0,274 & 0,072 & 0,125 \\
\hline & 19,0 & 0,053 & 0,036 & 0,194 & 0,188 & 0,336 & 0,103 & 0,010 & 0,024 & 0,135 & 1,000 & 0,036 \\
\hline & 25,4 & 0,000 & 0,007 & 0,195 & 0,109 & 0,221 & 0,027 & 0,000 & -9999 & 0,041 & -9999 & 0,007 \\
\hline & 38,1 & -9999 & -9999 & 0,016 & 0,029 & 0,019 & -9999 & -9999 & -9999 & 0,000 & -9999 & -9999 \\
\hline & 50,8 & -9999 & -9999 & -9999 & -9999 & -9999 & -9999 & -9999 & -9999 & -9999 & -9999 & -9999 \\
\hline \multirow{8}{*}{ 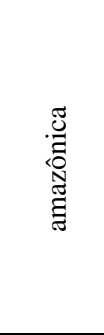 } & 0,3 & 0,933 & 0,985 & 0,967 & 1,000 & 0,947 & 1,000 & 0,983 & 0,905 & 0,954 & 0,821 & 0,767 \\
\hline & 2,5 & 0,769 & 0,886 & 0,773 & 0,914 & 0,868 & 0,804 & 0,846 & 0,735 & 0,897 & 0,550 & 0,588 \\
\hline & 6,3 & 0,534 & 0,630 & 0,468 & 0,615 & 0,685 & 0,436 & 0,465 & 0,495 & 0,764 & 0,335 & 0,424 \\
\hline & 12,7 & 0,336 & 0,202 & 0,086 & 0,265 & 0,288 & 0,190 & 0,168 & 0,150 & 0,235 & 0,144 & 0,125 \\
\hline & 19,0 & 0,081 & 0,025 & 0,000 & 0,137 & 0,143 & 0,095 & 0,059 & 0,035 & 0,072 & 0,038 & 0,022 \\
\hline & 25,4 & 0,000 & 0,000 & -9999 & 0,048 & 0,056 & 0,063 & 0,000 & 0,002 & -9999 & 0,013 & 0,000 \\
\hline & 38,1 & -9999 & 0,000 & -9999 & 0,000 & 0,000 & -9999 & -9999 & -9999 & -9999 & -9999 & -9999 \\
\hline & 50,8 & -9999 & -9999 & -9999 & 0,000 & -9999 & -9999 & -9999 & -9999 & -9999 & -9999 & -9999 \\
\hline
\end{tabular}

\subsubsection{ZCAS-99}

A partir da Tabela 10 observa-se que DPS é maior do que DPO nas regiões de ZCAS oceânica e costeira e para o domínio todo em todos os experimentos e para todos os limiares 
de precipitação, entretanto na região costeira os valores de DPS e DPO são mais próximos. Na região amazônica DPS apresenta valores inferiores a DPO para os limiares de chuva-não chuva e chuva fraca em todas as simulações, o que revela excelente skill do modelo em prever chuvas dessa intensidades nessa região, com base em um dos critérios de Pielke (2002) para avaliação de modelos. Observa-se também que, de modo geral, DPO e DPS são menores à medida que se aumenta o limiar, da mesma forma e pelo mesmo motivo que ocorre para ZCAS-98.

Tabela 10 - Idem à Tabela 6 mas para ZCAS-99.

\begin{tabular}{|c|c|c|c|c|c|c|c|c|c|c|c|c|c|c|}
\hline & & & & SEM & 1025 & & & SE & I1 & & & DIA & 025 & \\
\hline Região & $\underset{(\mathrm{mm}}{\operatorname{Limiar}}$ & DPO & DPS & EM & RMSE & $\mathrm{RMSE}_{\mathbf{B}}$ & DPS & EM & RMSE & $\mathrm{RMSE}_{\mathbf{B}}$ & DPS & EM & RMSE & $\mathrm{RMSE}_{\mathrm{B}}$ \\
\hline & 0,3 & 7,367 & 9,249 & 4,362 & 14,483 & 11,387 & 9,401 & 4,588 & 14,679 & 11,503 & 9,266 & 4,380 & 14,509 & 11,413 \\
\hline & 2,5 & 6,977 & 9,180 & 2,492 & 15,350 & 11,214 & 9,288 & 2,730 & 15,508 & 11,303 & 9,227 & 2,514 & 15,399 & 11,266 \\
\hline & 6,3 & 6,424 & 9,008 & 0,133 & 16,176 & 10,781 & 9,070 & 0,387 & 16,298 & 10,846 & 9,025 & 0,162 & 16,238 & 10,819 \\
\hline & 12,7 & 5,334 & 8,539 & $-3,834$ & 17,542 & 9,879 & 8,558 & $-3,538$ & 17,582 & 9,897 & 8,533 & $-3,801$ & 17,580 & 9,883 \\
\hline T & 19,0 & 4,133 & 7,979 & $-7,645$ & 19,490 & 8,852 & 8,005 & $-7,332$ & 19,478 & 8,895 & 8,021 & $-7,640$ & 19,517 & 8,880 \\
\hline F & 25,4 & 2,497 & 6,071 & $-11,010$ & 21,892 & 6,473 & 6,106 & $-10,751$ & 21,740 & 6,500 & 6,096 & $-11,012$ & 21,841 & 6,451 \\
\hline & 38,1 & 0,487 & 1,932 & $-14,255$ & 28,544 & 2,054 & 1,951 & $-13,954$ & 28,266 & 2,072 & 1,915 & $-14,281$ & 28,340 & 2,063 \\
\hline & 50,8 & 0,011 & 0,309 & $-18,262$ & 45,729 & 0,315 & 0,185 & $-17,831$ & 44,798 & 0,191 & 0,206 & $-19,298$ & 45,390 & 0,212 \\
\hline & 0,3 & 8,148 & 12,066 & 1,315 & 14,305 & 12,867 & 2,479 & 2,023 & 14,849 & 13,198 & 11,898 & 1,185 & 14,158 & 12,713 \\
\hline & 2,5 & 7,584 & 13,179 & $-0,619$ & 16,793 & 13,955 & 13,368 & $-0,050$ & 16,942 & 13,998 & 13,054 & $-0,777$ & 16,693 & 13,819 \\
\hline$\widetilde{J}$ & 6,3 & 6,684 & 14,657 & $-2,186$ & 19,466 & 15,037 & 14,588 & $-1,673$ & 19,148 & 14,849 & 14,443 & $-2,312$ & 19,305 & 14,852 \\
\hline 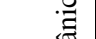 & 12,7 & 5,293 & 15,488 & $-3,448$ & 23,308 & 15,732 & 15,387 & $-2,798$ & 22,789 & 15,557 & 15,480 & $-3,468$ & 23,311 & 15,739 \\
\hline & 19,0 & 4,140 & 15,201 & $-5,146$ & 25,965 & 15,366 & 15,137 & $-4,368$ & 25,435 & 15,258 & 15,349 & $-4,888$ & 26,152 & 15,537 \\
\hline & 25,4 & 2,313 & 11,614 & $-5,662$ & 30,863 & 11,367 & 11,815 & $-4,774$ & 30,074 & 11,628 & 11,623 & $-5,439$ & 30,973 & 11,412 \\
\hline & 38,1 & 0,465 & 3,632 & $-2,914$ & 40,158 & 3,552 & 3,647 & $-1,755$ & 40,039 & 3,574 & 3,640 & $-3,420$ & 39,830 & 3,577 \\
\hline & 50,8 & 0,000 & 0,000 & 28,075 & 66,103 & 0,000 & 0,000 & 27,384 & 62,308 & 0,000 & 0,000 & 28,975 & 67,183 & 0,000 \\
\hline & 0,3 & 8,526 & 8,683 & 5,661 & 14,145 & 11,124 & 8,964 & 6,072 & 14,525 & 11,349 & 8,745 & 5,602 & 14,129 & 11,173 \\
\hline & 2,5 & 8,194 & 8,440 & 3,851 & 13,958 & 10,808 & 8,691 & 4,297 & 14,354 & 11,065 & 8,518 & 3,786 & 13,965 & 10,872 \\
\hline & 6,3 & 7,455 & 7,759 & 1,025 & 13,607 & 10,105 & 7,983 & 1,424 & 13,920 & 10,304 & 7,821 & 1,010 & 32 & 10,116 \\
\hline & 12,7 & 5,509 & 6,556 & $-4,062$ & 13,742 & 7,948 & 6,684 & $-3,576$ & 13,848 & 8,092 & 6,595 & $-4,024$ & 13,684 & 7,965 \\
\hline $\bar{n}$ & 19,0 & 3,558 & 4,915 & $-8,582$ & 14,944 & 5,586 & 5,052 & $-8,082$ & 15,070 & 5,786 & 4,933 & $-8,541$ & 14,938 & 5,589 \\
\hline & 25,4 & 2,046 & 3,208 & $-12,108$ & 16,612 & 3,471 & 3,232 & $-11,737$ & 16,779 & 3,578 & 3,197 & $-12,095$ & 16,538 & 3,464 \\
\hline & 38,1 & 0,256 & 0,695 & $-20,414$ & 21,857 & 0,667 & 0,609 & $-20,368$ & 22,043 & 0,662 & 0,658 & $-20,580$ & 22,094 & 0,696 \\
\hline & 50,8 & 0,000 & 0,000 & $-23,096$ & 23,736 & 0,000 & 0,000 & $-23,712$ & 24,301 & 0,000 & 0,000 & $-25,061$ & 25,949 & 0,000 \\
\hline & 0,3 & 9,389 & 8,327 & 3,145 & 12,960 & 11,563 & 8,271 & 3,155 & 12,886 & 11,502 & 8,259 & 3,143 & 12,964 & 11,592 \\
\hline & 2,5 & 9,088 & 8,239 & 2,086 & 12,623 & 11,344 & 8,197 & 2,114 & 12,564 & 11,305 & 8,186 & 2,080 & 12,633 & 11,383 \\
\hline$\widetilde{J}$ & 6,3 & 8,449 & 8,084 & $-0,176$ & 12,341 & 10,931 & 8,009 & $-0,166$ & 12,223 & 10,847 & 8,014 & $-0,213$ & 12,337 & 10,947 \\
\hline ชี & 12,7 & 7,227 & 7,622 & $-5,044$ & 12,972 & 9,698 & 7,525 & $-5,015$ & 12,815 & 9,575 & 7,528 & $-5,099$ & 12,950 & 9,719 \\
\hline$\varepsilon$ & 19,0 & 5,285 & 6,332 & $-9,823$ & 14,609 & 7,473 & 6,239 & $-9,758$ & 14,437 & 7,348 & 6,299 & $-10,038$ & 14,624 & 7,385 \\
\hline & 25,4 & 2,702 & 3,971 & $-13,973$ & 16,955 & 4,219 & 3,989 & $-13,953$ & 16,791 & 4,073 & 3,951 & $-14,329$ & 16,973 & 3,986 \\
\hline & 38,1 & 0,366 & 0,743 & $-22,145$ & 23,340 & 0,885 & 0,853 & $-21,539$ & 22,707 & 0,984 & 0,775 & $-22,166$ & 22,915 & 0,902 \\
\hline & 50,8 & 0,068 & 0,444 & $-41,418$ & 41,454 & 0,497 & 0,511 & $-40,890$ & 40,934 & 0,564 & 0,482 & $-40,924$ & 40,964 & 0,535 \\
\hline
\end{tabular}


Com base em EM (Tabela 10), observa-se que na região oceânica o modelo BRAMS subestima a precipitação para todos os limiares, com exceção dos limiares de chuva-não chuva e de forte de 50,8 $\mathrm{mm} \mathrm{dia}^{-1}$. Para a região costeira o modelo superestima a chuva para os limiares mais baixos, subestimando para os mais altos em todos os experimentos. Já na região amazônica o modelo superestima a precipitação para os dois limiares mais baixos e subestima para os demais, sendo que a subestimativa é maior quanto maior é o limiar. Desta forma, observa-se que o viés depende do limiar de chuva e que o BRAMS apresenta uma melhor performance para os limiares fraca e moderada, uma vez que os maiores vieses, positivos ou negativos, se dão para limiares de chuva-não chuva e chuva forte.

O RMSE demonstra que a acurácia do modelo numérico é maior para limiares mais baixos, decrescendo gradativamente para os mais altos, visto que os valores de RMSE aumentam à medida que se aumenta o limiar. Assim, a acurácia da previsão também é dependente do limiar de intensidade de chuva. A região de ZCAS amazônica é a que apresenta maior acurácia dentre as regiões estudadas, assim como ocorre para ZCAS-98.

Ao remover-se o viés é possível identificar que ocorre grande redução no valor de RMSE, sendo assim grande parte do erro do modelo na simulação da quantidade de precipitação acumulada é devido ao viés (ou bias) do modelo. Os valores de $\mathrm{RMSE}_{\mathrm{UB}}$ revelam que se o viés não for levado em consideração, o modelo é melhor em prever a quantidade de chuva acumulada em eventos mais intensos; sendo assim o modelo erra sistematicamente para limiares altos de precipitação.

De modo geral, o modelo BRAMS apresenta melhor performance para as regiões costeira e amazônica e desempenho semelhante nos três experimentos numéricos (SEM025, SEM1 e DIA025) para ZCAS-99.

Nas Tabelas 11, 12 e 13 observa-se que os melhores valores de TSA, ou seja os mais próximos de 1, ocorrem para os limiares mais baixos de chuva, principalmente para o de 
chuva-não chuva, decrescendo gradativamente para os demais. O modelo tem então um melhor skill em simular a ocorrência ou não de chuva do que localizar eventos de precipitação mais intensa, da mesma forma que ocorre para a simulação do caso ZCAS-98. No entanto, quando o modelo localiza estas chuvas, o erro é sistemático sendo praticamente proveniente do viés.

Tabela 11 - Idem à Tabela 7 mas para SEM025 para ZCAS-99.

\begin{tabular}{|c|c|c|c|c|c|c|c|c|c|c|c|c|c|c|c|c|c|}
\hline 0 & $\begin{array}{l}\operatorname{miar} \\
\mathrm{nm}^{-1} \\
\left.\mathbf{a}^{-1}\right)\end{array}$ & $\begin{array}{c}\text { dia } \\
2 \\
\end{array}$ & $\begin{array}{c}\text { dia } \\
\mathbf{3} \\
\end{array}$ & $\begin{array}{c}\text { dia } \\
4\end{array}$ & $\begin{array}{c}\text { dia } \\
5\end{array}$ & $\begin{array}{c}\text { dia } \\
6\end{array}$ & $\begin{array}{c}\text { dia } \\
7\end{array}$ & $\begin{array}{c}\text { dia } \\
8 \\
\end{array}$ & $\begin{array}{c}\text { dia } \\
9\end{array}$ & $\begin{array}{c}\text { dia } \\
10\end{array}$ & $\begin{array}{r}\text { dia } \\
11 \\
\end{array}$ & $\begin{array}{c}\text { dia } \\
12\end{array}$ & $\begin{array}{c}\text { dia } \\
13\end{array}$ & $\begin{array}{l}\text { dia } \\
14 \\
\end{array}$ & $\begin{array}{l}\text { dia } \\
15\end{array}$ & $\begin{array}{c}\text { dia } \\
16 \\
\end{array}$ & $\begin{array}{c}\text { dia } \\
17\end{array}$ \\
\hline \multirow{8}{*}{ 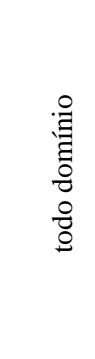 } & & 686 & 3 & 0 , & 0 & 3 & 0 & 33 & 0 & 0 & 0 & 2 & 5 & 4 & 9 & 7 & 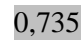 \\
\hline & & 52 & 0,589 & 0 & 0 & 631 & 0 , & 52 & 43 & 0 & 52 & 36 & 91 & 0,557 & 544 & 679 & 46 \\
\hline & 6,3 & 0,487 & 0,466 & 0,456 & 0,507 & 0,528 & 0,493 & 0,385 & 0,376 & 0,507 & 0,531 & 0,442 & 0,417 & 0,442 & 0,477 & 0,485 & 0,463 \\
\hline & 12,7 & 0,265 & 0,293 & 0,271 & 0,310 & 0,332 & 0,308 & 0,207 & 0,263 & 0,249 & 0,318 & 0,206 & 0,192 & 0,290 & 0,270 & 0,272 & 0,208 \\
\hline & 19,0 & 0,182 & 0,182 & 0,155 & 0,205 & 0,191 & 0,201 & 0,113 & 0,152 & 0,103 & 0,141 & 0,108 & 0,067 & 0,161 & 0,183 & 0,162 & 0,065 \\
\hline & 25,4 & 0,220 & 0,094 & 0,094 & 0,131 & 0,121 & 0,137 & 0,055 & 0,076 & 0,036 & 0,059 & 0,050 & 0,019 & 0,097 & 0,108 & 0,075 & 0,018 \\
\hline & 38,1 & 0,203 & 0,011 & 0,015 & 0,090 & 0,092 & 0,038 & 0,001 & 0,029 & 0,001 & 0,016 & 0,000 & 0,000 & 0,026 & 0,023 & 0,010 & 0,000 \\
\hline & 50,8 & 118 & 0,000 & 0,000 & 19 & 002 & 0,000 & -9999 & -9999 & 0,000 & 0,000 & 0,000 & -9999 & 0,000 & 0,000 & 0,000 & -9999 \\
\hline \multirow{8}{*}{ 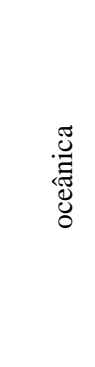 } & 0 & 564 & 0,661 & 0,639 & 0,715 & 0,639 & 0,503 & 0,168 & 0,162 & 0,098 & 0,059 & 0,227 & 0,494 & 0,314 & 0,798 & 0,720 & 0,392 \\
\hline & 2,5 & 0,578 & 0,577 & 0,432 & 0,558 & 0,684 & 0,550 & 0,087 & 0,200 & 0,001 & 0,010 & 0,064 & 0,147 & 0,180 & 0,633 & 0,789 & 0,484 \\
\hline & 6,3 & 0,542 & 0,570 & 0,305 & 0,439 & 0,676 & 0,435 & 0,058 & 0,010 & -9999 & -9999 & 0,000 & 0,074 & 0,161 & 0,307 & 0,807 & 1,000 \\
\hline & 12,7 & 0,532 & 0,472 & 0,168 & 0,161 & 0,633 & 0,156 & 1,000 & -9999 & -9999 & -9999 & -9999 & -9999 & 0,236 & 0,144 & 0,552 & -9999 \\
\hline & 19,0 & 0,533 & 0,358 & 0,068 & 0,074 & 0,529 & 0,052 & -9999 & -9999 & -9999 & -9999 & -9999 & -9999 & 0,087 & 0,058 & 0,252 & -9999 \\
\hline & 25,4 & 0,536 & 0,152 & 0,019 & 0,027 & 0,418 & 0,010 & -9999 & -9999 & -9999 & -9999 & -9999 & -9999 & 0,002 & 0,000 & 0,062 & -9999 \\
\hline & 38,1 & 0,300 & 0,000 & -9999 & -9999 & 0,237 & 0,000 & -9999 & -9999 & -9999 & -9999 & -9999 & -9999 & -9999 & -9999 & -9999 & -9999 \\
\hline & 50,8 & 1,000 & 0,000 & -9999 & -9999 & -9999 & -9999 & -9999 & -9999 & -9999 & -9999 & -9999 & -9999 & -9999 & -9999 & -9999 & -9999 \\
\hline \multirow{8}{*}{$\frac{\overrightarrow{0}}{0}$} & 0 & 0,905 & 0,878 & 0,906 & 0,996 & 0,865 & 0,821 & 0,824 & 0,847 & 0,902 & 0,908 & 0,940 & 0,965 & 0,896 & 0,791 & 0,905 & 0,875 \\
\hline & 2,5 & 0,787 & 0,823 & 0,878 & 0,951 & 0,807 & 0,696 & 0,728 & 0,747 & 0,741 & 0,807 & 0,912 & 0,781 & 0,796 & 0,810 & 0,813 & 0,854 \\
\hline & 6,3 & 0,603 & 0,620 & 0,748 & 759 & 0,699 & 0,546 & 0,617 & 0,533 & 0,558 & 0,639 & 0,658 & 0,481 & 0,633 & 0,697 & 0,547 & 0,747 \\
\hline & 12,7 & 8 & 0,422 & 0 , & 33 & 14 & 0 , & 0,377 & 0,223 & 0,069 & 13 & 65 & 0,105 & 0,224 & 0,324 & 0,225 & 0,372 \\
\hline & 19,0 & 0,087 & 0,213 & 0,316 &, 375 & 0,357 & 0,242 & 0,204 & 0,085 & 0,001 & 0,022 & 0,025 & 0,035 & 0,031 & 0,159 & 0,136 & 0,056 \\
\hline & 25,4 & 0,024 & 0,105 & 0,186 & 0,226 & 0,250 & 0,157 & 0,071 & 0,004 & 0,000 & 0,000 & 0,011 & -9999 & 0,000 & 0,104 & 0,068 & 0,007 \\
\hline & 38,1 & -9999 & 0,031 & 0,086 & 0,022 & 0,181 & 0,000 & -9999 & -9999 & -9999 & -9999 & -9999 & -9999 & -9999 & 0,029 & 1,000 & -9999 \\
\hline & 50,8 & -9999 & -9999 & 0,000 & -9999 & 0,015 & -9999 & -9999 & -9999 & -9999 & -9999 & -9999 & -9999 & -9999 & -9999 & -9999 & -9999 \\
\hline \multirow{8}{*}{ 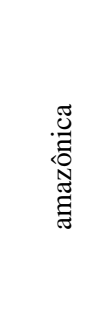 } & 0,3 & 1,000 & 90 & 992 & 1,000 & 998 & 1,000 & 0,968 & 1,000 & 0,994 & 0,999 & 1,000 & 0,945 & 1,000 & 1,000 & 1,000 & 1,000 \\
\hline & 2 , & 0,997 & 0,935 & 0,831 & 0,839 & 0,874 & 0,952 & 0,870 & 0,944 & 0,937 & 0,900 & 0,923 & 0,878 & 0,941 & 0,964 & 0,965 & 0,939 \\
\hline & 6,3 & 0,786 & 0,767 & 0,533 & 0,582 & 0,735 & 0,646 & 0,619 & 0,724 & 0,698 & 0,737 & 0,596 & 0,738 & 0,786 & 0,852 & 0,641 & 0,725 \\
\hline & 12,7 & 0,246 & 0,520 & 0,252 & 0,159 & 0,441 & 0,218 & 0,356 & 0,464 & 0,294 & 0,554 & 0,163 & 0,356 & 0,474 & 0,670 & 0,295 & 0,259 \\
\hline & 19,0 & 0,023 & 0,414 & 0,098 & 0,015 & 0,199 & 0,079 & 0,166 & 0,259 & 0,104 & 0,295 & 0,076 & 0,097 & 0,277 & 0,473 & 0,163 & 0,078 \\
\hline & 25,4 & 0,000 & 0,313 & 0,058 & 0,000 & 0,072 & 0,000 & 0,078 & 0,103 & 0,041 & 0,236 & 0,027 & 0,039 & 0,157 & 0,247 & 0,065 & 0,028 \\
\hline & 38 & 0,000 & 0,086 & 0,000 & 0,000 & 0,010 & -9999 & 0,000 & 0,000 & 0,000 & 0,128 & -9999 & 0,000 & 0,005 & 0,097 & 1,000 & -9999 \\
\hline & 50,8 & -9999 & -9999 & -9999 & -9999 & -9999 & -9999 & -9999 & -9999 & 0,000 & -9999 & -9999 & -9999 & 0,000 & 0,000 & -9999 & -9999 \\
\hline
\end{tabular}


Tabela 12 - Idem à Tabela 7 mas para SEM1 para ZCAS-99.

\begin{tabular}{|c|c|c|c|c|c|c|c|c|c|c|c|c|c|c|c|c|c|}
\hline & $\begin{array}{c}\left(\mathrm{mm}^{-1}\right. \\
\left.\mathrm{dia}^{-1}\right)\end{array}$ & $\begin{array}{c}\text { dia } \\
2\end{array}$ & $\begin{array}{c}\text { dia } \\
\mathbf{3}\end{array}$ & $\begin{array}{c}\text { dia } \\
4\end{array}$ & $\begin{array}{c}\text { dia } \\
5\end{array}$ & $\begin{array}{c}\text { dia } \\
6\end{array}$ & $\begin{array}{c}\text { dia } \\
7\end{array}$ & $\begin{array}{c}\text { dia } \\
8\end{array}$ & $\begin{array}{c}\text { dia } \\
9\end{array}$ & $\begin{array}{c}\text { dia } \\
10\end{array}$ & $\begin{array}{c}\text { dia } \\
11\end{array}$ & $\begin{array}{c}\text { dia } \\
12\end{array}$ & $\begin{array}{c}\text { dia } \\
13\end{array}$ & $\begin{array}{c}\text { dia } \\
14\end{array}$ & $\begin{array}{r}\text { dia } \\
15\end{array}$ & $\begin{array}{l}\text { dia } \\
16\end{array}$ & $\begin{array}{c}\text { dia } \\
17\end{array}$ \\
\hline \multirow{8}{*}{ 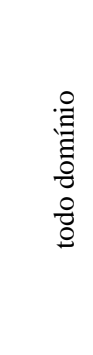 } & 0 & 0,687 & 0,689 & 0,733 & 0,727 & 0,709 & 0,689 & 0,669 & 0,693 & 0,697 & 0,701 & 0,722 & 0,724 & 0,661 & 0,732 & 0,756 & 0,734 \\
\hline & 2,5 & 52 & 95 & 0,626 & 643 & 0,633 & 0,635 & 560 & 0,546 & 0,677 & 0,649 & 0,638 & 594 & 558 & 640 & 683 &, 646 \\
\hline & 6,3 & 0,494 & 0,477 & 0,456 & 0,505 & 0,529 & 0,497 & 0,384 & 0,383 & 0,503 & 0,529 & 0,441 & 0,420 & 0,434 & 0,466 & 0,491 & 0,463 \\
\hline & 12,7 & 0,275 & 0,308 & 0,269 & 0,302 & 0,332 & 0,316 & 0,207 & 0,268 & 0,252 & 0,312 & 0,201 & 0,200 & 0,288 & ,264 & 274 & 0,200 \\
\hline & 19,0 & 0,188 & 0,194 & 0,156 & 0,208 & 0,190 & 0,201 & 0,111 & 0,150 & 0,096 & 0,139 & 0,102 & 0,070 & 0,161 & 0,173 & 0,167 & 0,061 \\
\hline & 25,4 & 0,226 & 0,108 & 0,094 & 0,134 & 0,122 & 0,136 & 0,057 & 0,079 & 0,034 & ,059 & 0,050 & 0,023 & 0,092 & 0,114 & 0,075 & 0,017 \\
\hline & 38,1 & 0,206 & 0,011 & 0,017 & 0,097 & 0,091 & 0,042 & 0,002 & 0,028 & 0,000 & 0,016 & 0,000 & 0,001 & 0,027 & 0,025 & 0,011 & 0,001 \\
\hline & 50, & 0,117 & 0,000 & 0,000 & 020 & 0,002 & 0,000 & -9999 & -9999 & 0,000 & 0,000 & 0,000 & -9999 & 0,000 & 0,000 & 0,001 & -9999 \\
\hline \multirow{8}{*}{ 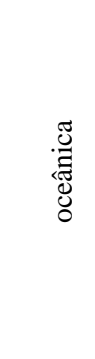 } & & & & 21 & & & & 62 & & & & & 87 & 32 & 802 & 764 & 396 \\
\hline & 2,5 & 0,577 & 0,580 & 0,418 & 0,556 & 0,685 & 0,555 & 0,079 & 0,191 & 0,001 & 0,006 & 0,065 & 0,163 & 0,192 & 0,625 & 0,791 & 0,499 \\
\hline & 6,3 & 0,551 & 0,598 & 0,286 & 0,424 & 0,677 & 0,449 & 0,063 & 0,011 & -9999 & -9999 & 0,000 & 0,078 & 0,169 & 0,277 & 0,771 & 1,000 \\
\hline & 12,7 & 0,541 & 0,523 & 0,143 & 0,094 & 0,637 & 0,179 & 1,000 & -9999 & -9999 & -9999 & -9999 & -9999 & 0,205 & 0,130 & 0,528 & 9999 \\
\hline & 19,0 & 2 & 0 & 055 & c & 0 & 55 & -9999 & -9 & 99 & 99 & 9 & -9999 & 86 & 042 & 0,264 & -9999 \\
\hline & 25,4 & 0,526 & 0,236 & 0,019 & 0,017 & 0,426 & 0,013 & -9999 & -9999 & -9999 & -9999 & -9999 & -9999 & 0,006 & 0,000 & 0,095 & -9999 \\
\hline & 38,1 & 0,302 & 0,000 & -9999 & -9999 & 0,239 & 0,000 & -9999 & -9999 & -9999 & -9999 & -9999 & -9999 & -9999 & -9999 & -9999 & -9999 \\
\hline & 50,8 & 1,000 & 0,000 & -9999 & -9999 & -9999 & -9999 & -9999 & -9999 & -9999 & -9999 & -9999 & -9999 & -9999 & -9999 & -9999 & -9999 \\
\hline \multirow{8}{*}{$\frac{\pi}{\omega}$} & 0, & 0,914 & & 0,913 & 0,995 & 0,869 & 0,829 & 0,831 & 0,846 & 0,905 & 0,918 & 0,939 & 0,954 & 0,904 & 0,793 & 0,899 & 0,877 \\
\hline & 2,5 & 0,786 & 0,856 & 0,878 & 0,935 & 0,813 & 0,740 & 0,724 & 0,788 & 0,749 & 0,809 & 0,905 & 0,772 & 0,806 & 0,804 & 0,803 & 0,852 \\
\hline & 6,3 & 0,603 & 0,637 & 0,748 & 0,745 & 0,691 & 0,562 & 0,615 & 0,577 & 0,544 & 0,662 & 0,671 & 0,467 & 0,635 & 0,674 & 0,548 & 0,769 \\
\hline & 12,7 & 0,276 & 0,425 & 0,535 & 0,528 & 0,483 & 0,380 & 0,378 & 0,210 & 0,077 & 0,213 & 0,167 & 0,116 & 0,258 & 0,322 & 0,221 & 0,367 \\
\hline & 19,0 & 0,091 & 0,217 & 0,324 & 0,386 & 0,320 & 0,244 & 0,204 & 0,091 & 0,001 & 0,022 & 20 & 0,030 & 0,029 & 0,152 & 0,127 & 0,061 \\
\hline & 25,4 & 0,026 & 0,102 & 0,182 & 0,240 & 0,213 & 0,153 & 0,087 & 0,011 & 0,000 & 0,000 & 0,009 & -9999 & 0 , & 0,101 & 0,070 & 0,008 \\
\hline & 38,1 & -9999 & 0,026 & 0,075 & 0,032 & 0,152 & 0,010 & -9999 & -9999 & -9999 & -9999 & -9999 & -9999 & -9999 & 0,050 & 1,000 & -9999 \\
\hline & 50,8 & -9999 & -9999 & 0,000 & -9999 & 0,013 & -9999 & -9999 & -9999 & -9999 & -9999 & -9999 & -9999 & -9999 & -9999 & -9999 & -9999 \\
\hline \multirow{8}{*}{ 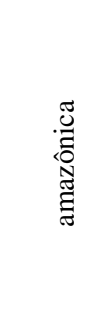 } & 0,3 & 1,000 & 0,992 & & 1,000 & 0,999 & 1,000 & 0,968 & 1,000 & 0,996 & 0,992 & 1,000 & 0,947 & 1,000 & 1,000 & 1,000 & 1,000 \\
\hline & 2,5 & 0,995 & 0,940 & 0,809 & 0,836 & 0,887 & 0,946 & 0,867 & 0,965 & 0,943 & 0,909 & 0,929 & 0,888 & 0,922 & 0,978 & 0,967 & 0,953 \\
\hline & 6,3 & 0,799 & 0,762 & 0,532 & 0,598 & 0,747 & 0,653 & 0,627 & 0,766 & 0,710 & 0,745 & 0,606 & 0,746 & 0,759 & 0,866 & 0,647 & 0,742 \\
\hline & 12,7 & 0,253 & 0,519 & 0,243 & 0,156 & 0,452 & 0,233 & 0,366 & 0,487 & 0,295 & 0,526 & 0,157 & 0,366 & 0,471 & 0,654 & 0,275 & 0,260 \\
\hline & 19,0 & 0,026 & 0,426 & 0,096 & 0,024 & 0,210 & 0,070 & 0,168 & 0,258 & 0,096 & 0,280 & 0,067 & 0,105 & 0,259 & 0,472 & 0,160 & 0,065 \\
\hline & 25,4 & 0,000 & 0,317 & 0,052 & 0,000 & 0,070 & 0,000 & 0,081 & 0,103 & 0,037 & 0,240 & 0,017 & 0,043 & 0,151 & 0,281 & 0,058 & 0,028 \\
\hline & 38,1 & 0,000 & 0,066 & 0,000 & 0,000 & 0,000 & -9999 & 0,008 & 0,000 & 0,000 & 0,133 & -9999 & 0,000 & 0,039 & 0,104 & 0,000 & -9999 \\
\hline & 50,8 & -9999 & -9999 & -9999 & -9999 & -9999 & -9999 & -9999 & -9999 & 0,000 & -9999 & -9999 & -9999 & 0,000 & 0,000 & -9999 & -999 \\
\hline
\end{tabular}

Dentre as regiões que compõem a ZCAS, o melhor desempenho do BRAMS nos três experimentos se dá na região amazônica, havendo diversas ocorrências de TSA igual a 1 para o limiar de chuva-não chuva, e o pior desempenho se dá para a oceânica, similarmente a ZCAS-98. 
Tabela 13 - Idem à Tabela 7 mas para DIA025 para ZCAS-99.

\begin{tabular}{|c|c|c|c|c|c|c|c|c|c|c|c|c|c|c|c|c|c|}
\hline o & $\begin{array}{c}\text { Limiar } \\
\left(\mathbf{d i a}^{-1}\right)\end{array}$ & $\begin{array}{c}\text { dia } \\
2\end{array}$ & $\begin{array}{c}\text { dia } \\
\mathbf{3} \\
\end{array}$ & $\begin{array}{c}\text { dia } \\
4\end{array}$ & $\begin{array}{c}\text { dia } \\
5\end{array}$ & $\begin{array}{c}\text { dia } \\
6\end{array}$ & $\begin{array}{c}\text { dia } \\
7\end{array}$ & $\begin{array}{c}\text { dia } \\
8\end{array}$ & $\begin{array}{c}\text { dia } \\
9\end{array}$ & $\begin{array}{c}\text { dia } \\
10\end{array}$ & $\begin{array}{c}\text { dia } \\
11\end{array}$ & $\begin{array}{c}\text { dia } \\
12\end{array}$ & $\begin{array}{c}\text { dia } \\
13\end{array}$ & $\begin{array}{r}\text { dia } \\
14 \\
\end{array}$ & $\begin{array}{c}\text { dia } \\
15\end{array}$ & $\begin{array}{c}\text { dia } \\
16\end{array}$ & $\begin{array}{c}\text { dia } \\
17\end{array}$ \\
\hline \multirow{8}{*}{ 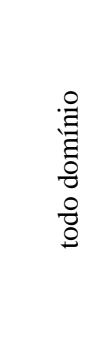 } & 0,3 & 0,687 & 0,687 & 0,733 & 0,722 & 0,704 & 0,679 & 0,668 & 0,687 & 0,695 & 0,696 & 0,717 & 0,719 & 0,653 & 0,726 & 0,742 & 0,731 \\
\hline & 2,5 & 0,654 & 0,585 & 0,629 & 0,643 & 0,632 & 0,633 & 0,559 & 0,547 & 0,682 & 0,654 & 0,633 & 0,589 & 0,552 & 0,644 & 0,681 & 0,646 \\
\hline & 6,3 & 0,488 & 0,466 & 0,457 & 0,506 & 0,532 & 0,492 & 0,384 & 0,383 & 0,507 & 0,527 & 0,437 & 0,421 & 0,432 & 0,486 & 0,493 & 0,465 \\
\hline & 12,7 & 0,267 & 0,293 & 0,277 & 0,304 & 0,340 & 0,311 & 0,211 & 0,265 & 0,249 & 0,309 & 0,198 & 0,188 & 0,287 & 0,271 & 0,272 & 0,205 \\
\hline & 19,0 & 0,185 & 0,174 & 0,154 & 0,205 & 0,189 & 0,207 & 0,108 & 0,146 & 0,100 & 0,138 & 0,100 & 0,070 & 0,153 & 0,189 & 0,162 & 0,062 \\
\hline & 25,4 & 0,216 & 0,092 & 0,093 & 0,135 & 0,122 & 0,138 & 0,051 & 0,080 & 0,039 & 0,062 & 0,048 & 0,021 & 0,092 & 0,113 & 0,075 & 0,016 \\
\hline & 38,1 & 0,202 & 0,014 & 0,013 & 0,082 & 0,096 & 0,044 & 0,002 & 0,031 & 0,000 & 0,018 & 0,000 & 0,001 & 0,030 & 0,024 & 0,009 & 0,000 \\
\hline & 50,8 & 0,125 & 0,000 & 0,000 & 0,012 & 0,002 & 0,000 & -9999 & -9999 & 0,000 & 0,000 & 0,000 & -9999 & 0,000 & 0,000 & 0,000 & -9999 \\
\hline \multirow{8}{*}{ 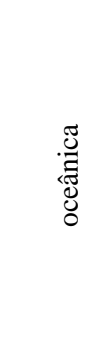 } & 0,3 & 0,571 & 0,666 & 0,639 & 0,696 & 0,633 & 0,491 & 0,168 & 0,154 & 0,099 & 0,063 & 0,226 & 0,493 & 0,327 & 0,802 & 0,695 & 0,378 \\
\hline & 2,5 & 0,578 & 0,559 & 0,442 & 0,548 & 0,683 & 0,543 & 0,079 & 0,204 & 0,001 & 0,010 & 0,064 & 0,147 & 0,184 & 0,621 & 0,750 & 0,559 \\
\hline & 6,3 & 0,540 & 0,575 & 0,297 & 0,452 & 0,673 & 0,432 & 0,056 & 0,009 & -9999 & -9999 & 0,000 & 0,076 & 0,158 & 0,299 & 0,766 & 1,000 \\
\hline & 12,7 & 0,534 & 0,487 & 0,164 & 0,131 & 0,634 & 0,152 & 1,000 & -9999 & -9999 & -9999 & -9999 & -9999 & 0,211 & 0,153 & 0,550 & -9999 \\
\hline & 19,0 & 0,534 & 0,346 & 0,072 & 0,062 & 0,530 & 0,050 & -9999 & -9999 & -9999 & -9999 & -9999 & -9999 & 0,084 & 0,066 & 0,281 & -9999 \\
\hline & 25,4 & 0,526 & 0,143 & 0,025 & 0,009 & 0,414 & 0,010 & -9999 & -9999 & -9999 & -9999 & -9999 & -9999 & 0,002 & 0,000 & 0,081 & -9999 \\
\hline & 38,1 & 0,295 & 0,000 & -9999 & -9999 & 0,240 & 0,000 & -9999 & -9999 & -9999 & -9999 & -9999 & -9999 & -9999 & -9999 & -9999 & -9999 \\
\hline & 50,8 & 1,000 & 0,000 & -9999 & -9999 & -9999 & -9999 & -9999 & -9999 & -9999 & -9999 & -9999 & -9999 & -9999 & -9999 & -9999 & -9999 \\
\hline \multirow{8}{*}{$\begin{array}{l}\frac{\pi}{0} \\
\frac{\pi}{0} \\
0 \\
0\end{array}$} & 0,3 & 0,906 & 0,883 & 0,906 & 0,996 & 0,868 & 0,803 & 0,845 & 0,854 & 0,905 & 0,900 & 0,938 & 0,952 & 0,894 & 0,794 & 0,897 & 0,870 \\
\hline & 2,5 & 0,787 & 0,825 & 0,880 & 0,939 & 0,817 & 0,705 & 0,741 & 0,750 & 0,745 & 0,801 & 0,906 & 0,771 & 0,797 & 0,808 & 0,802 & 0,854 \\
\hline & 6,3 & 0,598 & 0,633 & 0,754 & 0,745 & 0,712 & 0,542 & 0,620 & 0,541 & 0,539 & 0,625 & 0,640 & 0,481 & 0,649 & 0,691 & 0,535 & 0,751 \\
\hline & 12,7 & 0,275 & 0,422 & 0,535 & 0,526 & 0,530 & 0,372 & 0,390 & 0,230 & 0,076 & 0,220 & 0,168 & 0,111 & 0,240 & 0,307 & 0,227 & 0,377 \\
\hline & 19,0 & 0,093 & 0,209 & 0,312 & 0,375 & 0,359 & 0,261 & 0,187 & 0,097 & 0,002 & 0,024 & 0,031 & 0,032 & 0,037 & 0,165 & 0,148 & 0,059 \\
\hline & 25,4 & 0,026 & 0,109 & 0,174 & 0,247 & 0,253 & 0,155 & 0,059 & 0,007 & 0,000 & 0,000 & 0,009 & -9999 & 0,000 & 0,107 & 0,072 & 0,011 \\
\hline & 38,1 & -9999 & 0,037 & 0,079 & 0,019 & 0,166 & 0,005 & -9999 & -9999 & -9999 & -9999 & -9999 & -9999 & -9999 & 0,036 & 1,000 & -9999 \\
\hline & 50,8 & -9999 & -9999 & 0,000 & -9999 & 0,016 & -9999 & -9999 & -9999 & -9999 & -9999 & -9999 & -9999 & -9999 & -9999 & -9999 & -9999 \\
\hline \multirow{8}{*}{ 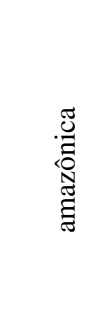 } & 0, & 1,000 & 0,993 & 0,992 & 1,000 & 0,997 & 1,000 & 0,965 & 1,000 & 0,996 & 0,995 & 0,998 & 0,950 & 1,000 & 1,000 & 1,000 & 1,000 \\
\hline & 2,5 & 0,997 & 0,937 & 0,824 & 0,834 & 0,881 & 0,950 & 0,872 & 0,968 & 0,950 & 0,913 & 0,925 & 0,887 & 0,916 & 0,974 & 0,987 & 0,946 \\
\hline & 6,3 & 0,806 & 0,756 & 0,526 & 0,580 & 0,746 & 0,654 & 0,623 & 0,755 & 0,701 & 0,733 & 0,597 & 0,753 & 0,756 & 0,886 & 0,627 & 0,757 \\
\hline & 12,7 & 0,248 & 0,506 & 0,260 & 0,163 & 0,458 & 0,228 & 0,380 & 0,473 & 0,276 & 0,527 & 0,159 & 0,353 & 0,470 & 0,679 & 0,281 & 0,261 \\
\hline & 19,0 & 0,028 & 0,414 & 0,098 & 0,027 & 0,182 & 0,082 & 0,168 & 0,249 & 0,091 & 0,285 & 0,053 & 0,107 & 0,229 & 0,502 & 0,149 & 0,062 \\
\hline & 25,4 & 0,000 & 0,342 & 0,057 & 0,012 & 0,070 & 0,000 & 0,075 & 0,099 & 0,038 & 0,242 & 0,006 & 0,029 & 0,143 & 0,256 & 0,058 & 0,017 \\
\hline & 38,1 & 0,000 & 0,047 & 0,000 & 0,000 & 0,030 & -9999 & 0,009 & 0,000 & 0,000 & 0,156 & -9999 & 0,000 & 0,014 & 0,084 & 1,000 & -9999 \\
\hline & 50,8 & -9999 & -9999 & -9999 & -9999 & -9999 & -9999 & -9999 & -9999 & 0,000 & -9999 & -9999 & -9999 & 0,000 & 0,000 & -9999 & -9999 \\
\hline
\end{tabular}

\subsection{Conclusões}

Foi realizada uma série de simulações com o modelo BRAMS (Tabela 1) com três configurações diferentes para dois casos de ZCAS, simulações estas que diferiam com relação 
aos dados de TSM (Tabela 2). Procurou-se explorar aspectos relativos à influência das resoluções espacial e temporal desses dados (Tabela 3) sobre algumas características da ZCAS, principalmente sobre a precipitação associada ao sistema. Além disso, foi realizada uma análise estatística com a finalidade de verificar o desempenho do modelo numérico em simular a precipitação associada à ZCAS em cada região que a compõe (Figura 1), em cada experimento (Tabela 2) e para diferentes limiares de chuva (Tabela 5).

Para ambos os casos ZCAS-98 e ZCAS-99, conclui-se que os maiores impactos das resoluções espacial e temporal dos dados de TSM se dão nas regiões oceânica e mais próximas ao oceano (costeiras), já que a diferença entre as simulações numéricas é exatamente a TSM. Porém, assim como em Calderon (2000), observou-se que, mesmo de forma mais suave, a TSM influencia também no interior do continente.

O experimento com maior quantidade de precipitação acumulada foi SEM1 em ambos os casos, pois neste a TSM média é superior à dos demais experimentos (Figuras 17 e 22), induzindo maior evaporação e instabilidade em baixos níveis, favorecendo o desenvolvimento de precipitação. No entanto, a magnitude da diferença de TSM entre os experimentos em ZCAS-99 é menor do que em ZCAS-98. O experimento com menor quantidade de precipitação acumulada na ZCAS oceânica nos dois casos foi DIA025, sendo seguido de SEM025 e de SEM1, nesta ordem (Figuras 21a, 21b, 26a e 26b).

Com relação ao estudo estatístico das simulações de precipitação para os casos de ZCAS, obteve-se que o viés do modelo é dependente do limiar de chuva e que grande parte do erro na previsão de chuva realizada pelo BRAMS é devida ao viés do próprio modelo, sendo que o mesmo erra de forma sistemática para limiares de chuva mais intensa (Tabelas 6 e 10).

Para ZCAS-98, o BRAMS, de maneira geral, superestima a precipitação para limiares mais baixos, subestimando para os mais altos (Tabela 6). O trabalho de Jorgetti (2008), por 
exemplo, mostrou que o BRAMS acoplado a um modelo de camada de mistura oceânica tendeu a subestimar a precipitação na região da ZCAS.

O experimento de melhor skill para ZCAS-98 foi o que utilizou o conjunto de dados de TSM com resoluções espacial e temporal mais refinadas (DIA025), sendo que o que utilizou TSM's com resoluções espacial e temporal mais baixas (SEM1) apresentou pior desempenho. Para ZCAS-99 os três experimentos numéricos (SEM025, SEM1 e DIA025) apresentaram performances semelhantes (Tabela 10), diferentemente de ZCAS-98 (Tabela 6), pois em ZCAS-99 as diferenças de TSM entre as simulações (Figura 22) são menores do que em ZCAS-98 (Figura 17), não afetando significativamente o desempenho do modelo.

Com relação à localização da chuva, o modelo é melhor em identificar a ocorrência/não ocorrência de chuva do que em localizar os núcleos de chuva mais intensos (Tabelas 7, 8, 9, 11, 12 e 13), todavia, quando localizados, o BRAMS possui alto skill em simular a quantidade de precipitação. No que tange às regiões que compõem a ZCAS, o melhor e o pior desempenhos do modelo se deram para as regiões amazônica e oceânica, respectivamente. 
Capítulo 5

\section{Influências das condições inicias de umidade do solo na ZCAS}

A CLP é fator crítico na produção de circulações e de sistemas atmosféricos de mesoescala e, segundo Zhang e Anthes (1982), é mais sensível à disponibilidade de umidade no solo do que ao albedo, rugosidade da superfície e capacidade térmica do solo. As condições de umidade do solo, e principalmente fortes descontinuidades no fluxo de calor sensível geradas por contrastes de umidade na superfície, desempenham importante papel no estabelecimento de circulações intensas (AVISSAR; PIELKE, 1989). Diante disso, muitos trabalhos investigaram os impactos das condições de umidade no estabelecimento dessas circulações.

Ookouchi et al. (1984), por exemplo, indicaram que em um terreno plano, com disponibilidade de umidade do solo não homogênea, a intensidade das circulações térmicas de mesoescala se aproxima à de brisa marítima na presença de grandes contrastes e também que mesmo pequenas quantidades de água no solo, adjacentes a áreas secas, podem resultar em escoamento de mesoescala significante.

Outros estudos verificaram o impacto da umidade do solo no desenvolvimento de precipitação. Beljaars et al. (1996), por exemplo, com o uso de um modelo global, verificaram a sensibilidade de previsões numéricas de precipitação a anomalias de umidade do solo para os Estados Unidos central durante extremos de chuva. Os autores realizaram um teste com solo muito seco (25\% de umidade com relação à saturação do solo) como condição inicial e 
um segundo teste com solo muito úmido (100\% de umidade com relação à saturação do solo), sendo que seus resultados apontaram que com solo muito úmido há maior produção de precipitação quando compara-se a condições de solo seco, mostrando assim que a evaporação influencia significativamente na precipitação. O aumento da evaporação e diminuição do aquecimento devido à alta umidade do solo resultam em ausência de inversão térmica suficiente, havendo então menos inibição da atividade convectiva (BELJAARS et al., 1996).

Já para a América do Sul, e similarmente a Beljaars et al. (1996), Candido, Gan e Manzi (2006) estudaram o impacto da condição inicial de água no solo na precipitação e circulação atmosférica associadas a um evento de ZCAS, conduzindo, com um modelo de área limitada, três testes de sensibilidade com três condições iniciais de umidade do solo distintas: controle (condição climatológica), solo úmido (em capacidade de campo) e solo seco (em ponto de murcha permanente). O maior impacto da mudança de umidade do solo se deu no balanço de energia à superfície devido à alteração na partição de energia disponível já apontada por Beljaars et al. (1996).

Os resultados de Candido, Gan e Manzi (2006) indicaram que alterações na condição hídrica do solo na Amazônia podem ser importantes no transporte de umidade para outras áreas, tanto durante eventos de ZCAS quanto em ocorrências de JBN, sendo que o mecanismo é de feedback positivo entre o conteúdo de água no solo e a precipitação associada à ZCAS. Concluíram também que o aumento da umidade do solo promove aumento da Energia Potencial Convectiva Disponível, Convective Available Potential Energy (CAPE) em inglês, ocorrendo o oposto quando há redução da umidade.

O desmatamento de porções da Amazônia também causa grande impacto intensificando as circulações de meso e grande escalas, visto que causa secamento do solo na região desmatada (BAIDYA ROY; AVISSAR, 2002; GASH; NOBRE, 1997). Desta forma, intensa convergência seria observada sobre a área mais seca, e umidade seria transportada das regiões 
vizinhas para a região desmatada, favorecendo o desenvolvimento de precipitação sobre a mesma.

Alguns autores, entretanto, exploraram o impacto do desmatamento de áreas de diferentes tamanhos na precipitação. Durieux, Machado e Laurent (2003), sugeriram que desmatamento de $10 \%$ da Amazônia não traz alterações significativas na precipitação com relação à região não desmatada. Todavia, com uma porcentagem maior de desmatamento durante a estação seca, há diminuição na convecção e aumento da formação de nuvens baixas. Com $20 \%$ ou mais de área desmatada as alterações são mais evidentes na estação chuvosa, com aumento da convecção. Concluíram então que o desmatamento pode aumentar a sazonalidade. Já o desmatamento completo da Amazônia causaria diminuição da precipitação na região (AVISSAR et al., 2002; WERTH; AVISSAR, 2004), pois não haveria nem contrastes de temperatura na superfície suficientes para promover convergência de massa sobre a região, nem umidade disponível no solo para tal processo.

As circulações geradas a partir de descontinuidades na paisagem têm um impacto significante no ciclo hidrológico, no tempo e no clima. Esses processos, no entanto, não são bem representados em modelos atmosféricos de grande escala, já que estes não têm uma resolução apropriada para este fim (AVISSAR, 1991). Assim, Avissar e Chen (1993) simularam um domínio que consistia em uma área muito irrigada e outra muito seca com o modelo regional RAMS. Na área seca, grande parte da radiação solar incidente foi usada para aquecer a atmosfera e a superfície. Entretanto, na área irrigada, grande parte da energia radiativa foi usada para evapotranspiração. $\mathrm{O}$ aquecimento mais rápido da superfície seca gera mistura turbulenta intensa e uma CLP instável e estratificada. Já o aquecimento mais lento da área úmida limita o desenvolvimento da CLP, que permanece rasa sobre esta área.

Outro estudo, que utilizou um modelo regional, o ETA acoplado ao modelo de superfície continental Simplified Simple Biosphere (SSiB), foi o de De Gonçalves et al. (2006). Nesse 
trabalho verificaram o impacto das condições iniciais de umidade do solo nos sistemas de tempo da América do Sul. Concluíram que o uso de dados de umidade inicial do solo melhora o desempenho das simulações.

Já Grimm, Pal e Giorgi (2007) realizaram simulações com um modelo climático regional e observaram que se a umidade do solo for reduzida no centro-leste do Brasil ocorre aumento da temperatura da superfície e produção de anomalia ciclônica sobre o Sudeste do Brasil, tendendo assim a aumentar a precipitação no centro-leste do país. Os autores sugerem ainda que a influência da umidade do solo na variação da precipitação monçônica é um exemplo de impacto de forçante local, entretanto, no caso do centro-leste brasileiro, a umidade do solo não tem um impacto local na precipitação. Anomalias de umidade do solo induzem a anomalias de circulação que são modificadas por efeitos topográficos e geram transporte de umidade, produzindo então anomalias de precipitação (GRIMM; PAL; GIORGI, 2007).

No presente trabalho, através de experimentos numéricos com o modelo regional BRAMS, procurou-se verificar as influências da condição de solo mais seca possível aplicada às regiões de ZCAS continental nas características do sistema, principalmente com relação à precipitação. Este estudo será apresentado neste Capítulo.

\subsection{Características específicas dos testes de sensibilidade a US}

Com a finalidade de verificar a sensibilidade do modelo BRAMS à umidade inicial do solo e o impacto desse parâmetro nas características da ZCAS simulada, mais especificamente na precipitação associada ao sistema, foram realizados três experimentos numéricos distintos (AMAZ, COST e CTRL) para cada um dos casos de ZCAS. A fração inicial de umidade do 
solo (com relação à saturação de cada tipo de solo - Tabela 14) empregada nos experimentos foi horizontalmente homogênea e conforme a Tabela 15, sendo que as simulações numéricas diferiam apenas com relação à US inicial em determinadas regiões do domínio. Vale ressaltar que as TSM's empregadas nos testes de sensibilidade do modelo a US foi o conjunto de dados de TSM diária da NOAA com espaçamento horizontal de 0,25 x 0,25 graus de latitudelongitude, as mesmas da simulação DIA025 do Capítulo anterior.

Tabela 14 - Tipos de solo disponíveis no modelo BRAMS e respectivos pontos de saturação $\left(\mathrm{m} \mathrm{m}^{-3}\right)$ e pontos de murcha permanente $\left(\mathrm{m} \mathrm{m}^{-3}\right)$.

\begin{tabular}{ccc}
\hline $\begin{array}{c}\text { Tipo de solo } \\
\text { (BRAMS) }\end{array}$ & $\begin{array}{c}\text { Ponto de saturação } \\
\left(\mathbf{m ~ m}^{-3}\right)\end{array}$ & $\begin{array}{c}\text { Ponto de murcha } \\
\text { permanente }\left(\mathbf{m ~ m}^{-3}\right)\end{array}$ \\
\hline 1 - sandy & 0,3950 & 0,0321 \\
2 - loamy sand & 0,4100 & 0,0356 \\
3 - sandy loam & 0,4350 & 0,0440 \\
4 - silt loam & 0,4850 & 0,0601 \\
5 - loam & 0,4510 & 0,0580 \\
6 - sandy clay loam & 0,4200 & 0,0545 \\
7 - silty clay loam & 0,4770 & 0,0755 \\
8 - clay loam & 0,4760 & 0,0664 \\
9 - sandy clay & 0,4260 & 0,0650 \\
10 - silty clay & 0,4920 & 0,0790 \\
11 - clay & 0,4820 & 0,0825 \\
12 - peat & 0,8630 & 0,0860 \\
\hline
\end{tabular}

Em AMAZ e em COST, considerados como experimentos "secos" e similares a um dos experimentos de Candido, Gan e Manzi (2006), aplicou-se como condição inicial de umidade do solo a quantidade de umidade mínima aceitável pelo modelo numérico para cada tipo de solo, que seria o ponto de murcha permanente (PMP) (Tabela 14), nas regiões amazônica (Figura 27a) e costeira (Figura 27b), respectivamente, sendo que estas regiões coincidem com aquelas que compõem a ZCAS definidas na Figura 1. Vale ressaltar que o PMP é o ponto a 
partir do qual o sistema radicular da maioria das plantas não é mais apto a extrair água do solo. Assim, mesmo havendo certa porção de água no solo, a mesma não está disponível para as plantas.

Tabela 15 - Níveis do solo (metros abaixo da superfície) e fração inicial de umidade do solo em cada nível com relação à saturação de cada tipo solo (Tabela 14).

\begin{tabular}{cc}
\hline $\begin{array}{c}\text { Níveis do solo } \\
\text { (metros abaixo da } \\
\text { superfície) }\end{array}$ & $\begin{array}{c}\text { Fração inicial de } \\
\text { umidade do solo com } \\
\text { relação à saturação de } \\
\text { cada tipo de solo }\end{array}$ \\
\hline$-0,10$ & 0,25 \\
$-0,20$ & 0,30 \\
$-0,30$ & 0,35 \\
$-0,50$ & 0,40 \\
$-0,75$ & 0,45 \\
$-1,00$ & 0,50 \\
$-1,25$ & 0,55 \\
$-1,50$ & 0,60 \\
$-1,75$ & 0,65 \\
$-2,00$ & 0,70 \\
$-3,00$ & 0,75 \\
$-4,00$ & 0,80 \\
\hline
\end{tabular}

No experimento controle (CTRL) a umidade inicial do solo horizontalmente homogênea (Tabela 15) não foi alterada em nenhuma porção do domínio (Figura 27c). As regiões de ZCAS amazônica e costeira serão consideradas como regiões "secas" nos experimentos AMAZ e COST, respectivamente.

A condição inicial de umidade do solo representada pelo PMP em AMAZ e COST foi aplicada a todos os níveis de solo apresentados na Tabela 15, assim como é possível observar nas Figuras 28a e 28b, que apresentam o perfil vertical da umidade inicial do solo em AMAZ 
e COST, respectivamente. As seções verticais em AMAZ e COST foram feitas em latitudes constantes ao longo de $7^{\circ} \mathrm{S}$ e $20^{\circ} \mathrm{S}$, respectivamente.

(a)

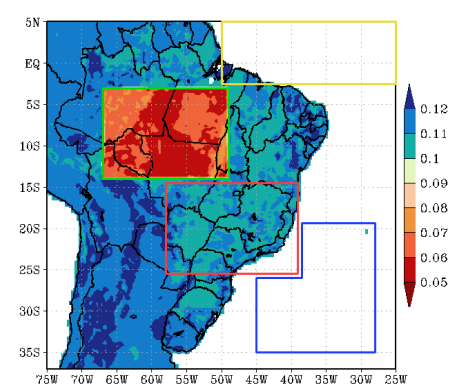

(b)

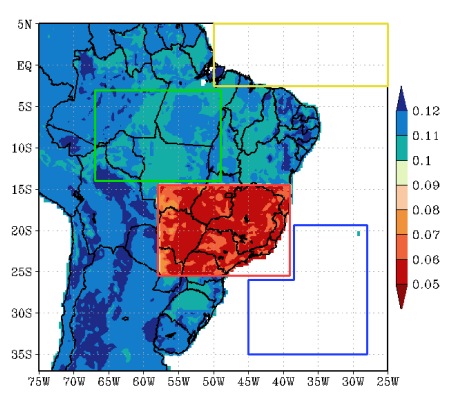

(c)

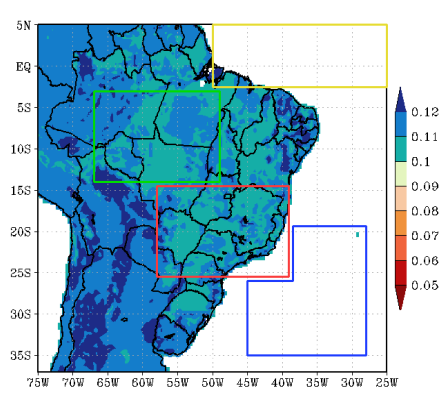

Figura 27. Umidade inicial do solo no nível de solo mais próximo à superfície $(0,10 \mathrm{~m}$ abaixo da superfície) nos três experimentos realizados com o BRAMS (a) AMAZ, (b) COST e (c) CTRL (intervalo de 0,01 $\mathrm{m}^{3} \mathrm{~m}^{-3}$ ). Os retângulos verde, vermelho e azul representam as regiões que compõem a ZCAS (vide Figura 1). O retângulo amarelo representa a região equatorial.

Com a finalidade de apenas ilustrar o perfil da distribuição de umidade no solo no final do período de integração do modelo numérico, são apresentadas as Figuras 28c e 28d (28e e 28f) para o caso ZCAS-98 (ZCAS-99), nas quais é possível identificar umidade proveniente da precipitação que penetrou no solo, principalmente nos níveis superiores. Para o caso ZCAS-98 a quantidade de umidade no solo no final da integração na região costeira em COST (Figura 28d) é maior e penetra mais nos níveis mais profundos do solo do que na região amazônica em AMAZ (Figura 28c). Para ZCAS-99 a umidade proveniente da chuva atinge níveis mais profundos do solo na região costeira no experimento COST (Figura 28f) em comparação com os experimentos para ZCAS-98 e a quantidade de água nos níveis mais próximos à superfície na região amazônica em AMAZ (Figura 28e) é maior se comparada ao que é observado nas demais Figuras.

As análises dos experimentos numéricos basearam-se nas diferenças de médias (calculadas para todo o período de integração), entre CTRL e os demais experimentos, das seguintes variáveis: temperatura do ar, umidade específica em baixos níveis (1000 hPa) e fluxos de calor sensível e latente à superfície. Também analisaram-se as mesmas diferenças 
para a precipitação acumulada no final do período de integração e para a divergência média do fluxo horizontal de umidade integrado na atmosfera, sendo que a umidade específica, utilizada também neste cálculo, foi calculada a partir de (1).

(a)

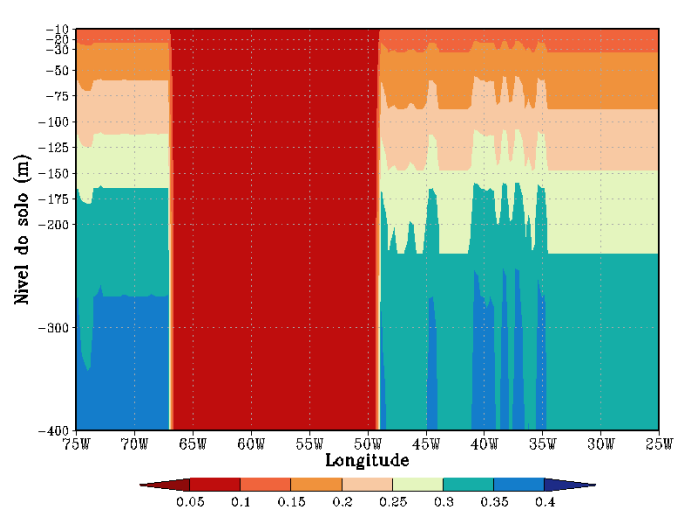

(c)

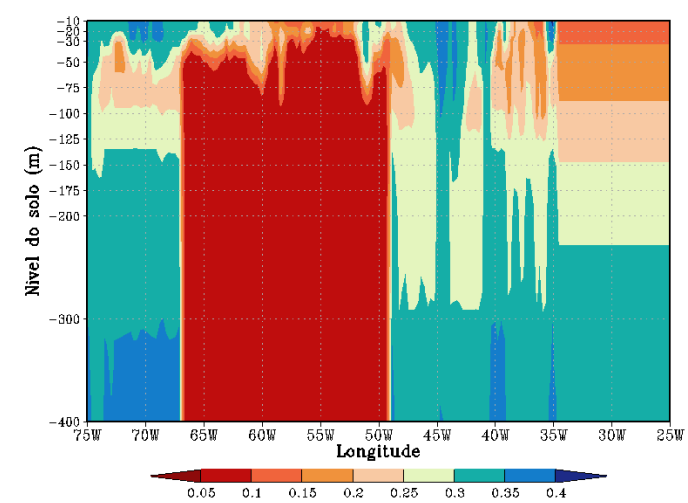

(e)

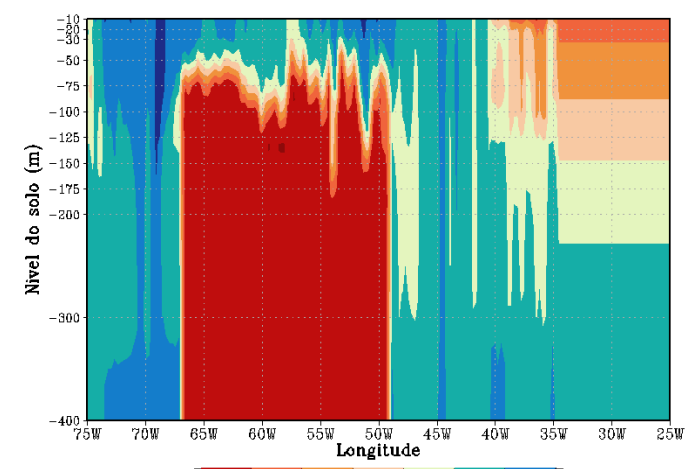

(b)

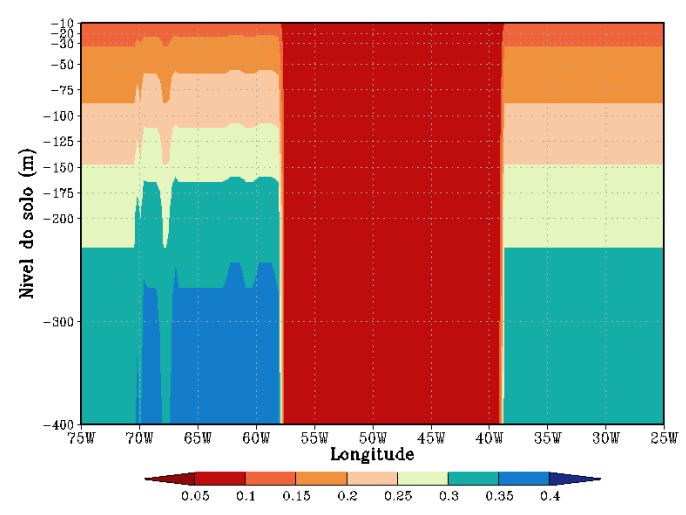

(d)

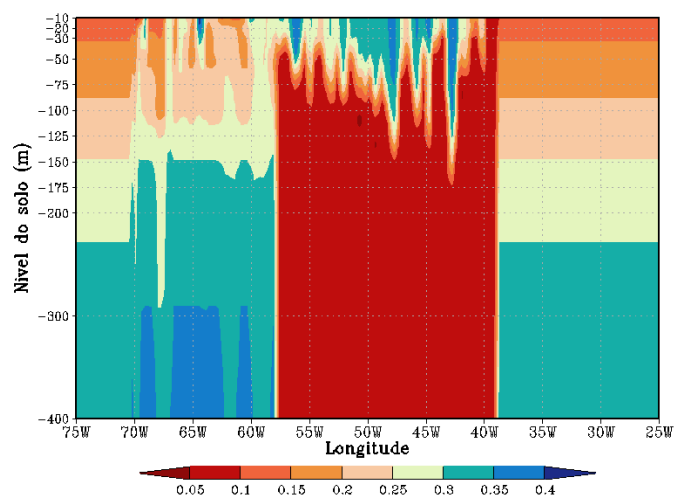

(f)

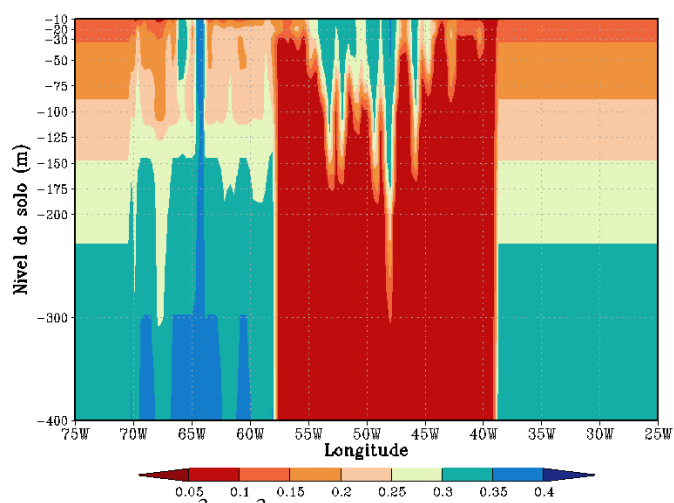

Figura 28. Seção vertical da umidade inicial do solo (intervalo de $0,05^{0.05} \mathrm{~m}^{3.1} \mathrm{~m}^{-3}$ ) em (a) AMAZ e (b) COST. Umidade do solo no final do período de integração (intervalo de $0,05 \mathrm{~m}^{3} \mathrm{~m}^{-3}$ ) em (c) AMAZ para ZCAS-98, (d) COST para ZCAS-98, (e) AMAZ para ZCAS-99 e (f) COST para ZCAS-99. As seções foram realizadas em latitudes constantes, $7^{\circ} \mathrm{S}$ e $20^{\circ} \mathrm{S}$ em AMAZ e COST, respectivamente. No eixo das ordenadas estão representados os níveis do solo abaixo da superfície (m) definidos no modelo numérico.

Considerando-se as diferenças entre os experimentos com relação a CTRL, AMAZCTRL e COST-CTRL, ainda foi realizado o cálculo do volume de precipitação "positivo" 
(levando em conta apenas os pixels nos quais a diferença é positiva) e "negativo" (levando em conta apenas os pixels nos quais a diferença é negativa) e a contagem do número de pixels "positivos" e "negativos" (de acordo com o mesmo critério) no final do período de integração do modelo para cada região que compõe a ZCAS e para a região equatorial, definida nas Figuras 27a, 27b e 27c. Essa última região foi determinada com base na precipitação acumulada no final do período de integração do modelo nos diferentes experimentos numéricos realizados para os dois casos de ZCAS, sendo que abrange o máximo possível a porção equatorial onde há precipitação e que corresponde aproximadamente com a posição oceânica atlântica da ZCIT. A contagem do número de pixels "positivos" e "negativos" permite identificar se na maior parte de determinada região ocorreu mais precipitação no experimento "seco" (AMAZ ou COST) ou em CTRL.

As análises das simulações, além disso, basearam-se na inspeção dos perfis verticais das médias, para todo o período de integração do modelo e para cada uma das regiões definidas nas Figuras 27a, 27b e 27c, para temperatura do ar e do ponto de orvalho, temperatura potencial e componente vertical do vento, e perfis verticais da divergência média do fluxo horizontal de umidade e da divergência média horizontal. Apenas serão apresentadas as Figuras cujas diferenças entre os perfis verticais forem significativas, quando da comparação dos experimentos AMAZ e COST a CTRL. 


\subsection{Testes de sensibilidade a US}

\subsubsection{ZCAS-98}

Comparando-se a temperatura média de ambos os experimentos "secos", AMAZ e COST, à de CTRL (Figuras 29a e 29b), observa-se que o secamento de ambas as regiões para o PMP causa aumento da temperatura em baixos níveis nas mesmas, conforme o esperado. Com menor quantidade de água no solo a capacidade térmica do mesmo diminui, facilitando assim seu aquecimento, e, por consequência, o aquecimento do ar adjacente e o abaixamento da pressão em baixos níveis. A presença de ar mais quente nos níveis mais próximos à superfície gera uma condição de instabilidade na atmosfera sobre as regiões de ZCAS amazônica e ZCAS costeira nos experimentos AMAZ e COST, respectivamente.

(a)

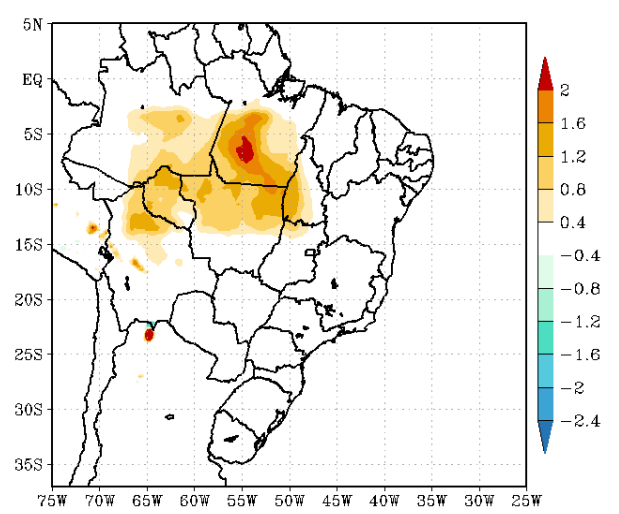

(b)

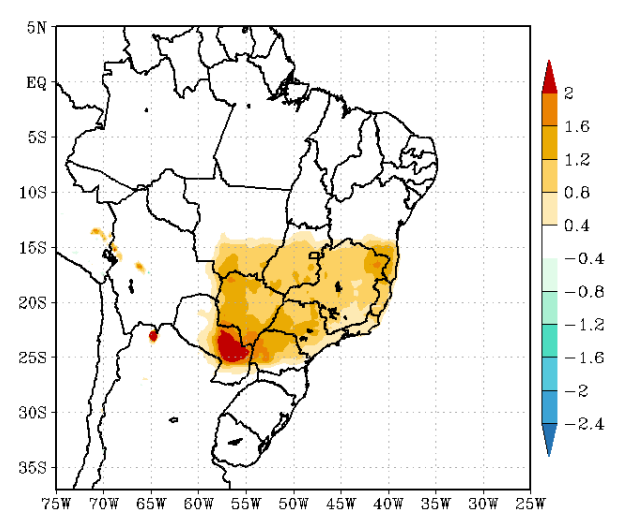

Figura 29. Diferença da média de temperatura do ar de todo o período de integração do modelo (08/02/98 às 00Z a 19/02/98 às 00Z) em $1000 \mathrm{hPa}$ entre os experimentos numéricos (a) AMAZ e CTRL (AMAZ-CTRL) e (b) COST e CTRL (COST-CTRL) (intervalo de $0,4^{\circ} \mathrm{C}$ ).

Sendo assim, com base na temperatura do ar, observa-se que a condições iniciais de US apenas afetam a região na qual foi aplicada a condição de umidade mínima aceitável, não havendo impacto significativo nas demais regiões do domínio. Nas áreas sombreadas das 
Figuras 29a e 29b ainda destacam-se as porções nordeste e sudoeste, respectivamente, nas quais a diferença de temperatura entre os experimentos "secos" e CTRL é maior.

Na Figura 30a observa-se diferença significante entre AMAZ e CTRL sobre a porção nordeste da região de ZCAS amazônica coincidindo com aquela destacada na Figura 29a. Nesta região, a condição de US inicial, representada pelo PMP, causou impacto significativo quando da comparação com o experimento CTRL, havendo mais umidade disponível em CTRL. Não há diferenças significativas de umidade específica média entre COST e CTRL (Figura 30b).

(a)

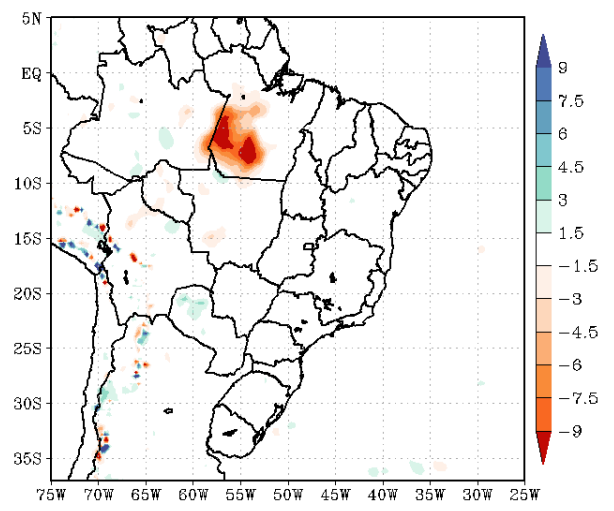

(c)

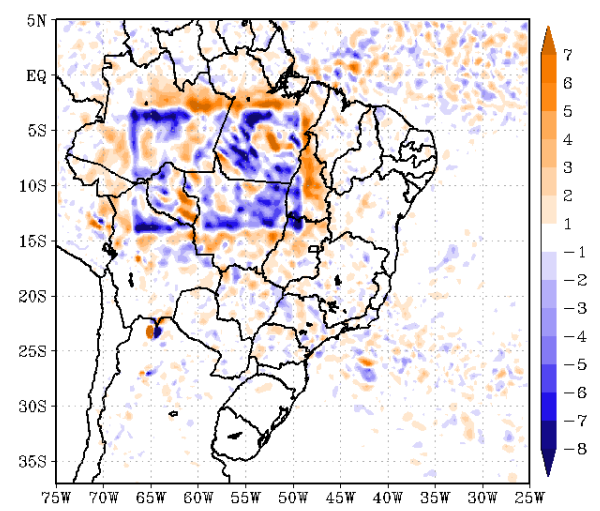

(b)

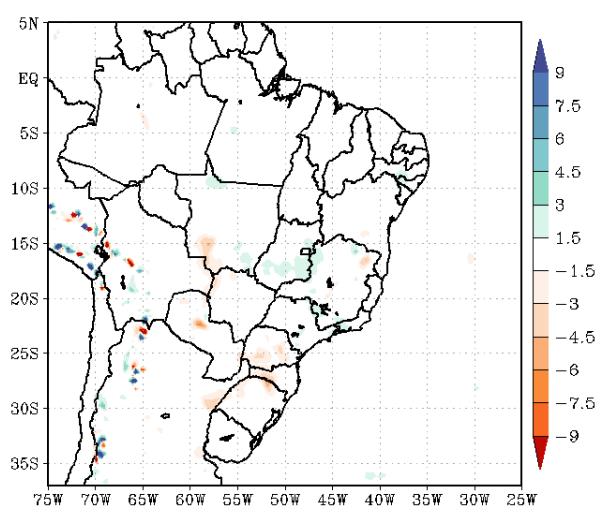

(d)

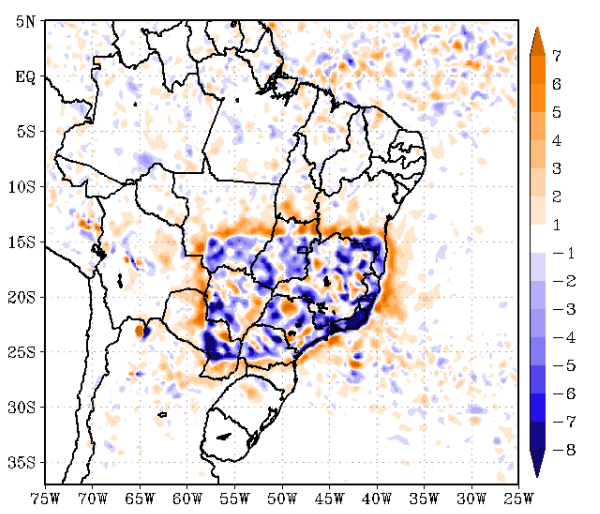

Figura 30. Diferença da média de umidade específica, em $1000 \mathrm{hPa}$, de todo o período de integração do modelo (08/02/98 às 00Z a 19/02/98 às 00Z) entre os experimentos numéricos (a) AMAZ e CTRL (AMAZCTRL) e (b) COST e CTRL (COST-CTRL) (intervalo de $1,5 \times 10^{-3} \mathrm{~g} \mathrm{~kg}^{-1}$ ) e diferença da divergência média do fluxo horizontal de umidade, do mesmo período de integração, integrado na atmosfera, da pressão reduzida ao nível médio do mar ao nível de $100 \mathrm{hPa}$ entre os experimentos numéricos (c) AMAZ e CTRL (AMAZCTRL) e (d) COST e CTRL (COST-CTRL) (intervalo de $1 \times 10^{-4} \mathrm{~kg} \mathrm{~kg}^{-1} \mathrm{~s}^{-1}$ ). 
O fato de haver temperaturas mais elevadas em baixos níveis em AMAZ e COST com relação a CTRL faz com que haja maior instabilidade atmosférica nos dois primeiros experimentos, conforme já discutido. Diante disso, a parametrização convectiva do modelo numérico utilizado é mais acionada nas regiões mais quentes, havendo maior movimento vertical e maior formação de precipitação convectiva. Com o abaixamento da pressão ocorre, de uma maneira geral, maior convergência de umidade em baixos níveis nos experimentos "secos", ou seja, AMAZ (Figura 30c) e COST (Figura 30d), sendo que a umidade que converge sobre as regiões de ZCAS amazônica em AMAZ e ZCAS costeira em COST é proveniente das regiões adjacentes a elas. Conforme pode ser observado nas Figuras 30c e 30d, nas regiões circunvizinhas ocorre divergência maior em AMAZ e COST do que em CTRL, confirmando que a umidade das fronteiras é transportada e converge mais nas regiões de ZCAS amazônica e costeira nos experimentos "secos".

É possível observar que AMAZ e COST apresentam fluxo de calor sensível à superfície (Figuras 31a e 31b) mais intenso do que CTRL, assim como o esperado, pois com a US inicial menor do que a de CTRL esses experimentos tendem a apresentar maior aquecimento do solo.

De maneira geral, o fluxo de calor latente à superfície (Figuras 31c e 31d) também é mais intenso nos experimentos "secos". Após a precipitação, formada pela convergência de umidade trazida das fronteiras da região, há maior quantidade de umidade disponível no solo para evaporação, sendo que esta quantidade deve ser maior do que a de CTRL, já que, como poderá ser visto nas Figuras seguintes, em CTRL chove menos do que nos experimentos "secos".

Entretanto, nas fronteiras das regiões mais secas observa-se que o fluxo de calor latente é maior em CTRL do que nos demais experimentos (Figuras 31c e 31d), já que nessas regiões a divergência de umidade é menor também em CTRL (Figuras 30c e 30d), permitindo que haja mais umidade disponível para evaporação no último experimento. Na Figura 31c destaca-se 
uma porção no sudoeste do Pará onde o fluxo de calor latente também é mais intenso em CTRL do que em AMAZ, coincidindo com a porção onde há maior quantidade de umidade disponível em CTRL (Figura 30a).

(a)

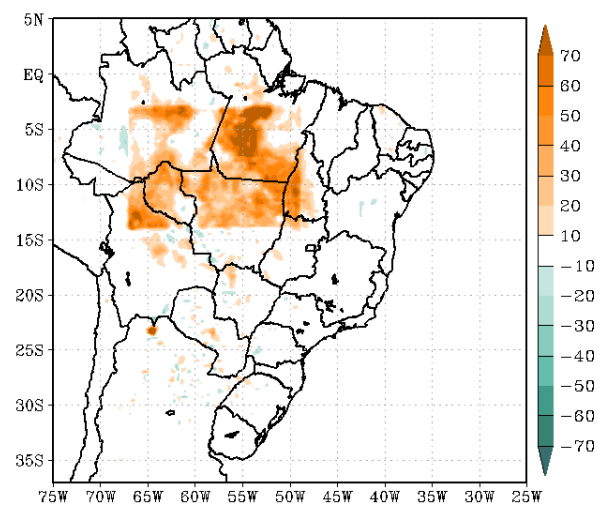

(c)

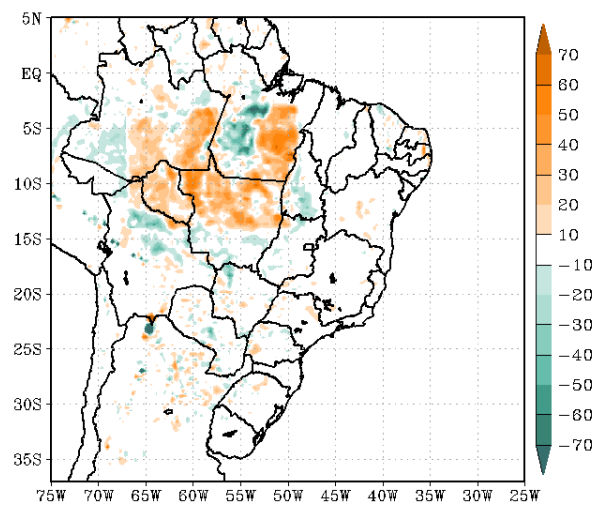

(b)

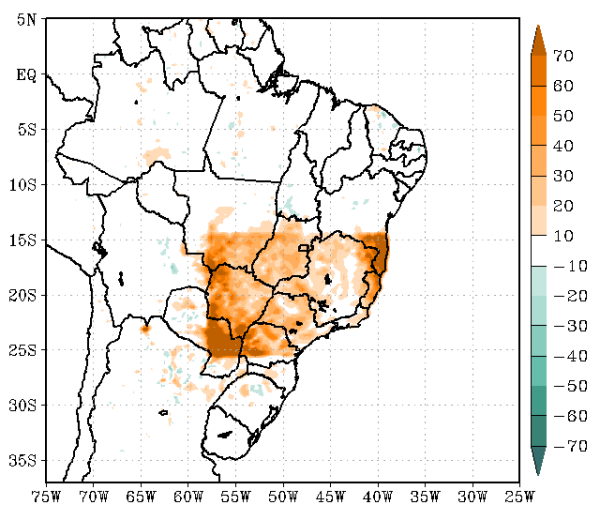

(d)

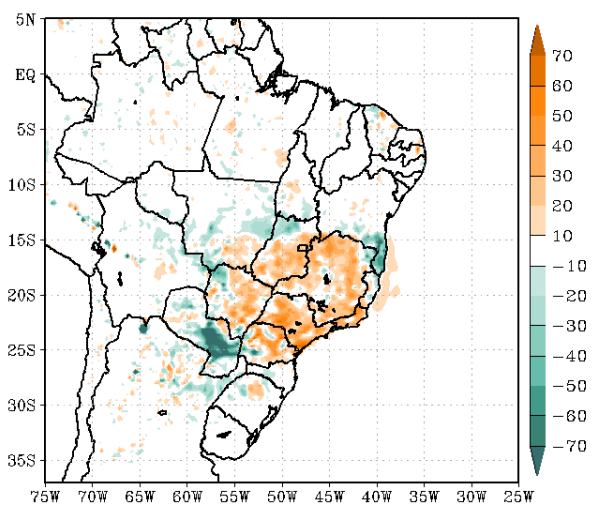

Figura 31. Diferença da média do fluxo de calor sensível à superfície de todo o período de integração do modelo (08/02/98 às 00Z a 19/02/98 às 00Z) entre os experimentos numéricos (a) AMAZ e CTRL (AMAZCTRL) e (b) COST e CTRL (COST-CTRL) (intervalo de $10 \mathrm{~W} \mathrm{~m}^{-2}$ ) e diferença da média do fluxo de calor latente à superfície, do mesmo período de integração, entre os experimentos numéricos (c) AMAZ e CTRL (AMAZ-CTRL) e (d) COST e CTRL (COST-CTRL) (intervalo de $10 \mathrm{~W} \mathrm{~m}^{-2}$ ).

Com relação à precipitação, a variável de maior interesse nesse estudo, observa-se nas Figuras 32a e 32b que a maior quantidade acumulada se dá nos experimentos AMAZ e COST se comparados ao CTRL, ao contrário dos resultados de experimentos semelhantes realizados por Beljaars et al. (1996) e por Candido, Gan e Manzi (2006). Em síntese, a aplicação da mínima quantidade de umidade aceitável no solo como condição inicial faz com que a temperatura do ar em baixos níveis nesses experimentos seja mais elevada e ocorra 
instabilização da atmosfera, movimento ascendente e convergência em baixos níveis, assim como discutido anteriormente.

O secamento de uma região intensifica as circulações de mesoescala, geradas devido a heterogeneidades na superfície do solo, assim como é destacado nos trabalhos de Baidya Roy e Avissar (2002) e Gash e Nobre (1997). No último estudo, por exemplo, os autores apontam que o desmatamento de parte de uma floresta, o que implicaria em redução da umidade do solo no local desmatado, resultaria no desenvolvimento de circulações de mesoescala, sendo que o escoamento deve se dar da região mais úmida à mais seca, devido ao maior abaixamento de pressão induzido pelo aquecimento na primeira. Desta forma, apesar da menor quantidade de água disponível para evaporação nas regiões "secas" em AMAZ e COST, a umidade que é trazida das porções circunvizinhas por circulações de mesoescala e converge sobre essas regiões serve como mecanismo de compensação. Assim sendo, o efeito da convergência acaba sendo mais eficiente no processo de formação de chuva do que a quantidade de água inicialmente disponível no solo para evaporação.

Esse efeito da condição de US inicial (mínima aceitável pelo modelo) sobre a precipitação poderia não ser o mesmo se a área da região "seca" fosse bastante aumentada, pois não haveria heterogeneidades na superfície e, portanto, contrastes de temperaturas suficientes para gerar uma circulação de meso ou de grande escala eficiente em transportar umidade para a região em questão. Essa ideia foi apontada por Avissar et al. (2002) e Werth e Avissar (2004), por exemplo, sendo que no último trabalho os autores destacam que o desmatamento completo da Amazônia resultaria em diminuição da precipitação, evaporação e nebulosidade na região. O desmatamento da Floresta Amazônica do trabalho de Werth e Avissar (2004) pode ser representado, neste estudo, pelo secamento da região amazônica realizado no experimento AMAZ, pois a remoção da floresta resultaria em diminuição da 
umidade disponível no solo, uma vez que a vegetação, através do processo de evapotranspiração, é a principal responsável pela manutenção da umidade na região.

É possível também identificar porções ao longo da região de ZCAS amazônica nas quais a quantidade de precipitação acumulada em CTRL é maior do que em AMAZ (Figura 32a), sendo que elas coincidem com aquelas onde CTRL possui maior quantidade de umidade (Figura 30a).

Ao longo das fronteiras das regiões de ZCAS amazônica e costeira há mais chuva em CTRL do que em AMAZ e COST (Figuras 32a e 32b), uma vez que a intensa convergência de umidade, devido ao abaixamento da pressão em baixos níveis nos dois últimos experimentos, faz com que a chuva seja menos distribuída e mais concentrada sobre as regiões de solo mais seco com relação ao CTRL.

O impacto das condições iniciais de umidade do solo na precipitação (Figuras 32a e 32b), ao contrário das variáveis analisadas anteriormente, não se dá somente sobre a região na qual foi realizada a alteração da US inicial (ZCAS amazônica e ZCAS costeira), mas também sobre as demais regiões que compõem a ZCAS e sobre a região equatorial (Figuras 27a, 27b e 27c).

(a)

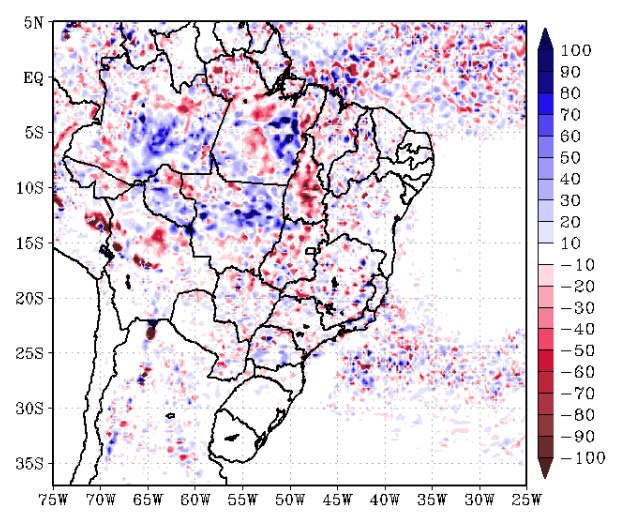

(b)

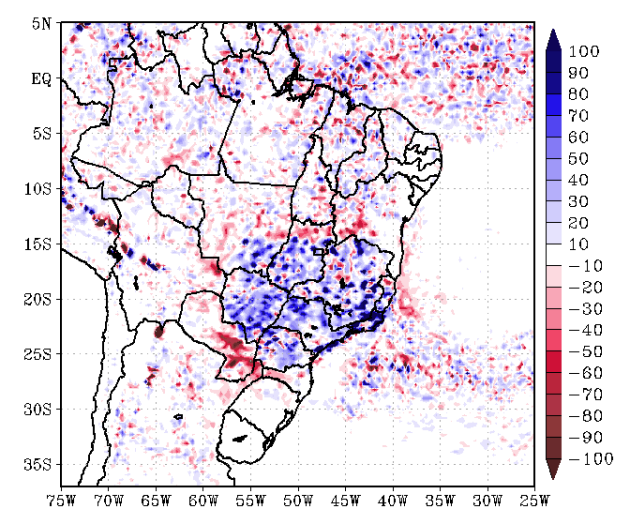

Figura 32. Diferença da precipitação acumulada no final do período de integração do modelo (08/02/98 às $00 Z$ a 19/02/98 às 00Z) entre os experimentos numéricos (a) AMAZ e CTRL (AMAZ-CTRL) e (b) COST e CTRL (COST-CTRL) (intervalo de $10 \mathrm{~mm} \mathrm{dia}^{-1}$ ). 
Através da Tabela 16 é possível notar que o maior impacto das condições iniciais de US sobre a chuva se dá mais localmente, ou seja, na região onde foi feita a alteração com relação ao CTRL, conforme o esperado; e também que o volume de precipitação acumulada, considerando apenas os pixels nos quais chove mais em AMAZ e COST com relação a CTRL nas regiões amazônica e costeira em AMAZ e COST, respectivamente, é aproximadamente três vezes maior do que quando chove mais em CTRL nas mesmas regiões. O número de pixels na região amazônica nos quais ocorre mais chuva em AMAZ do que em CTRL é aproximadamente o dobro do número de pixels nos quais ocorre o oposto. O mesmo ocorre na região costeira em COST.

Observa-se também a partir da Tabela 16 que o volume de chuva acumulada em pontos onde chove mais em CTRL é maior na região costeira em AMAZ, ocorrendo o mesmo na região amazônica em COST. Assim, parte da umidade da região costeira (amazônica) em AMAZ (COST) pode ter sido transportada e ter convergido na região onde há intenso abaixamento de pressão devido ao secamento, contribuindo para o aumento do volume de chuva na região amazônica (costeira) e para ocorrência de menos precipitação na região costeira (amazônica) em AMAZ (COST), semelhantemente ao que foi sugerido por Candido, Gan e Manzi (2006) com relação ao transporte de umidade quando de alterações hídricas no solo.

Com relação à região oceânica, em AMAZ o impacto não é significativo, já em COST observa-se menos precipitação acumulada (quando a diferença COST-CTRL é positiva) do que em CTRL (quando a diferença COST-CTRL é negativa), pois parte da umidade disponível na porção de ZCAS oceânica pode ter convergido sobre a região costeira. Sobre a região equatorial o impacto é pouco significativo, havendo maior quantidade de precipitação acumulada quando as diferenças AMAZ-CTRL e COST-CTRL são negativas. 
De uma forma geral, há maior volume de precipitação acumulada sobre as regiões onde é aplicado o PMP como condição inicial de US e menor quantidade nas demais regiões quando contrasta-se com o experimento CTRL, pelas razões discutidas anteriormente.

Tabela 16 - Volume de precipitação (mm) e número de pixels "positivos" e "negativos" para as diferenças AMAZ-CTRL e COST-CTRL para cada região que compõe a ZCAS e para a região equatorial. Os valores se referem à precipitação acumulada no final do período de integração do modelo (08/02/98 às 00Z a 19/02/98 às 00Z) para ZCAS-98.

\begin{tabular}{cccccc}
\cline { 3 - 6 } \multicolumn{2}{c}{} & \multicolumn{2}{c}{ AMAZ-CTRL } & \multicolumn{2}{c}{ COST-CTRL } \\
\hline região & sinal & volume $(\mathbf{m m})$ & $\mathbf{n}^{\mathbf{0}}$.pixels & volume $(\mathbf{m m})$ & $\mathbf{n}^{\mathbf{0}}$.pixels \\
\hline \multirow{2}{*}{ amazônica } & - & 22417,1 & 1107 & 24254,5 & 1682 \\
& + & 59272,8 & 1953 & 17302,4 & 1378 \\
\multirow{2}{*}{ costeira } & - & 31350,5 & 1700 & 27284,8 & 1186 \\
& + & 25628,6 & 1495 & 79598,7 & 2009 \\
\multirow{2}{*}{ cceânica } & - & 17854,6 & 1707 & 22018,4 & 1864 \\
& + & 18328,1 & 1781 & 17193,7 & 1624 \\
equatorial & - & 39238,2 & 1530 & 39562,3 & 1566 \\
\hline
\end{tabular}

A partir dos perfis verticais de temperatura do ar e do ponto de orvalho médios na região amazônica em AMAZ e em CTRL (Figura 33a) e na região costeira em COST e CTRL (Figura 33b) é possível identificar que a condição de US aplicada nos experimentos "secos" faz com que a umidade relativa da atmosfera seja mais baixa, visto que as temperaturas do ar e do ponto de orvalho são mais distantes nesses experimentos. Assim, em CTRL o ar está mais próximo da saturação e a altura da base das nuvens, que coincide com o Nível de Condensação por Levantamento (NCL), deverá ser menor. Pode-se observar nas Figuras 33a e $33 \mathrm{~b}$ que a temperatura do ponto de orvalho em AMAZ e COST, respectivamente, se torna maior do que em CTRL acima de $880 \mathrm{hPa}$ aproximadamente, isso pode se dar devido a possível transporte de vapor verticalmente para cima realizado pelo movimento vertical mais intenso induzido pelo maior aquecimento da superfície nos experimentos "secos". 
(a)

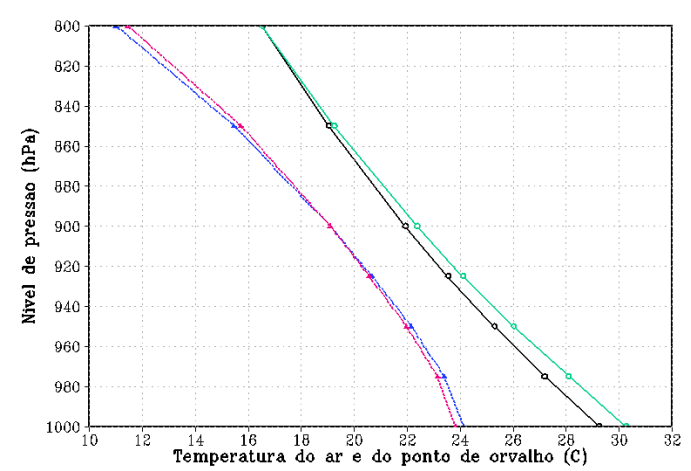

(b)

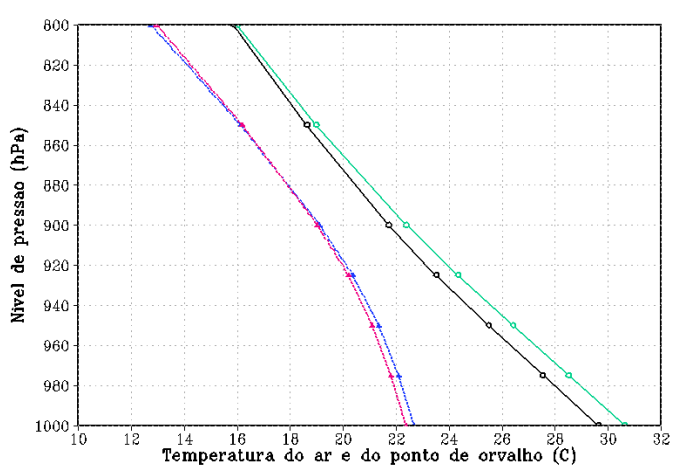

Figura 33. Perfis verticais da média da temperatura do ar e do ponto de orvalho (intervalo de $2{ }^{\circ} \mathrm{C}$ ) de todo o período de integração do modelo (08/02/98 às $00 \mathrm{Z}$ a 19/02/98 às 00Z) e das regiões (a) amazônica e (b) costeira, sendo que as linhas preta e azul representam a temperatura do ar e do ponto de orvalho em CTRL, respectivamente, e as linhas verde e magenta representam as mesmas variáveis em AMAZ (a) e em COST (b). No eixo da ordenadas estão representados os níveis de pressão em hPa.

Em CTRL a temperatura potencial nas regiões amazônica (Figura 34a) e costeira (Figura 34b) é menor quando comparada às mesmas regiões em AMAZ e COST, respectivamente, devido ao maior aquecimento do ar adjacente à superfície gerado pelo secamento do solo nesses últimos experimentos. Próximo à superfície a atmosfera é quase estaticamente neutra, principalmente nos experimentos mais secos, o que mostra que neles a atmosfera é menos estável do que em CTRL, estando assim mais próxima da instabilidade. Esse resultado é semelhante ao de Candido (2002).

(a)

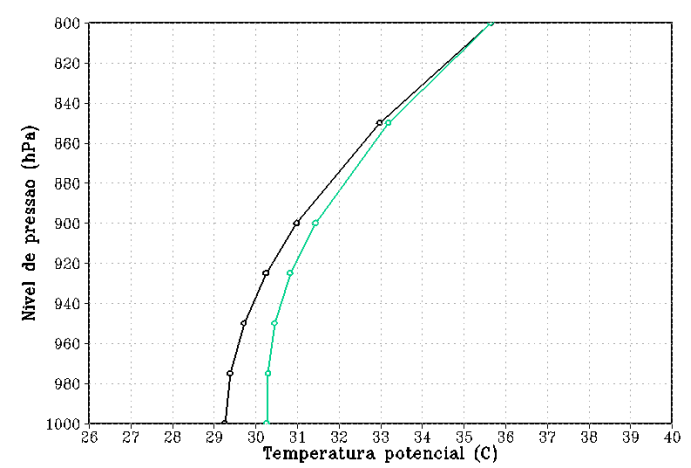

(b)

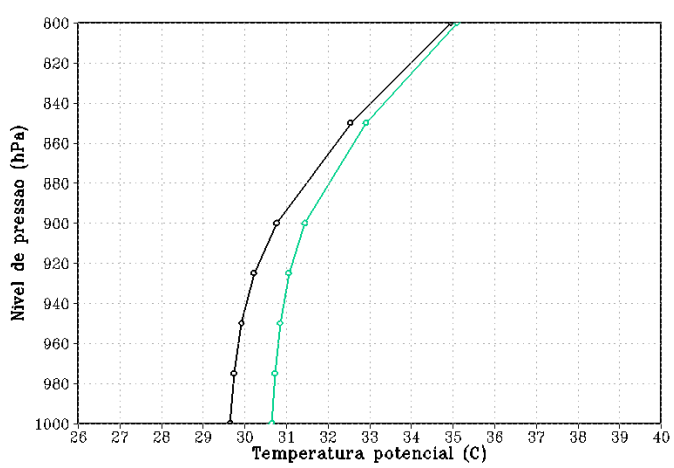

Figura 34. Perfis verticais da média da temperatura potencial (intervalo de $1{ }^{\circ} \mathrm{C}$ ) de todo o período de integração do modelo (08/02/98 às 00Z a 19/02/98 às 00Z) e das regiões (a) amazônica e (b) costeira, sendo que a linha preta representa a temperatura potencial em CTRL e a linha verde representa a mesma variável em AMAZ (a) e em COST (b). No eixo da ordenadas estão representados os níveis de pressão em hPa. 
O perfil do movimento vertical apenas complementa a conclusão obtida a partir dos campos analisados anteriormente. Em ambos os experimentos AMAZ e COST sobre as respectivas regiões nas quais foi aplicado o PMP como US inicial, a velocidade vertical (Figuras 35a e 35b) é maior se comparada à observada em CTRL sobre as mesmas regiões, sendo que esse padrão se dá dos baixos aos altos níveis da troposfera. O movimento ascendente mais intenso nos experimentos "secos" é induzido pelo aquecimento do ar adjacente ao solo mais seco, que se aquece mais rapidamente do que o solo mais úmido e causa instabilidade.

Uma das características da parametrização convectiva do modelo é o aquecimento na média troposfera, que induz movimento ascendente provocando um pico na velocidade vertical em altos níveis. Com as maiores temperaturas nos experimentos "secos", a parametrização convectiva do modelo é acionada mais vezes, havendo mais precipitação e então maior liberação de calor latente na média troposfera, justificando-se assim as diferenças entre movimento vertical em AMAZ/COST e CTRL, que aumentam com a altura e são maiores em torno de 300 e $250 \mathrm{hPa}$ (Figuras 35a e 35b).

(a)

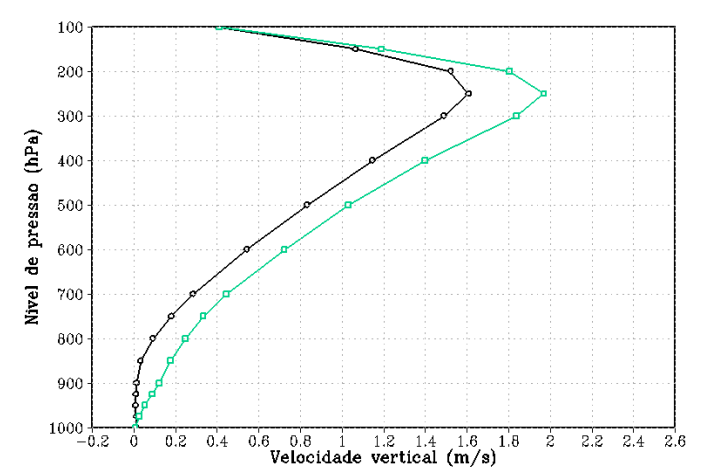

(b)

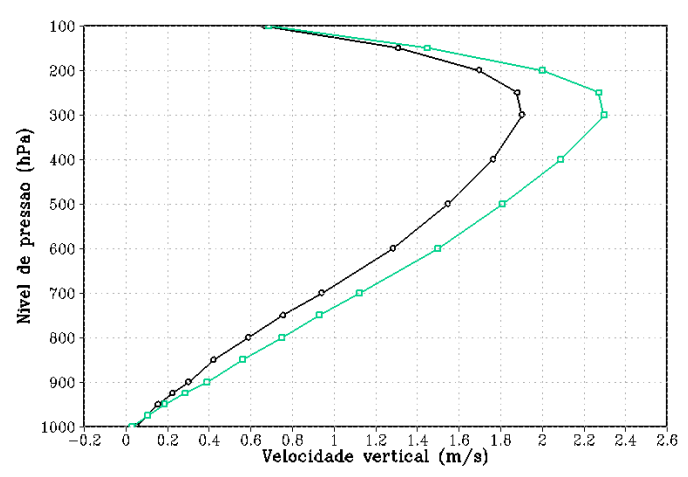

Figura 35. Idem à Figura 34 mas para componente vertical do vento (intervalo de $0,2 \times 10^{-2} \mathrm{~m} \mathrm{~s}^{-1}$ ).

Vale enfatizar ainda que a velocidade vertical na região costeira em COST (Figura 35b) é mais intensa do que na região amazônica em AMAZ (Figura 35a), de um modo geral, e que 
no primeiro caso a quantidade de precipitação acumulada no final do período de integração do modelo é maior do que no segundo (Tabela 16). Desta forma, destaca-se o importante papel da convergência em baixos níveis no desenvolvimento de convecção, uma vez que o movimento ascendente é induzido por ela.

É importante lembrar também que o caso ZCAS-98 ocorre durante a fase quente do ENOS, ou seja, quando há maior subsidência sobre a Amazônia e fortalecimento do escoamento de baixos níveis noroeste-sudeste, que carrega umidade da Bacia Amazônica ao Sudeste. Assim, o movimento ascendente na região de ZCAS amazônica em AMAZ pode ter sido atenuado devido ao efeito do ENOS sobre a região, sendo que este último pode ainda ter contribuído para maior quantidade de precipitação acumulada na região de ZCAS costeira em COST, uma vez que o escoamento de baixos níveis intensificado na direção da Região Sudeste carrega umidade proveniente da Amazônia.

A partir dos perfis verticais da divergência do fluxo de umidade (Figuras 36a e 36b), é possível observar que o secamento do solo favorece a convergência principalmente nos níveis mais próximos à superfície. Inclusive, em AMAZ (Figura 36a) ocorre convergência e em CTRL divergência de umidade próximo à superfície. Os maiores impactos se dão até $800 \mathrm{hPa}$ aproximadamente, acima deste nível os perfis dos experimentos "secos" e CTRL são semelhantes, sendo que dos médios aos altos níveis observa-se fraca divergência. Isto se dá uma vez que a convergência de umidade ocorre majoritariamente nos níveis mais próximo à superfície, onde está concentrada a maior parte da umidade da atmosfera.

$\mathrm{O}$ aquecimento intenso do solo causa abaixamento da umidade relativa (Figuras 33a e 33b), que por sua vez causa mais aumento de temperatura (similarmente ao observado no estudo de Segal et al., 1989), diminuição da estabilidade em baixos níveis (Figuras 34a e 34b), que leva ao favorecimento do movimento vertical ascendente (Figuras 35a e 35b). Com movimento vertical intensificado e aumento de temperatura há favorecimento da convecção e 
precipitação, o que leva a maior liberação de calor latente, intensificando novamente o movimento vertical. Com isso a convergência em baixos níveis é favorecida, ocorrendo também intensificação da divergência em altos níveis induzida pelo movimento vertical (Figuras 36c e 36d), principalmente nos experimentos “secos”. Nos níveis médios observa-se o NND, no qual a divergência é nula (Figuras 36c e 36d).

(a)

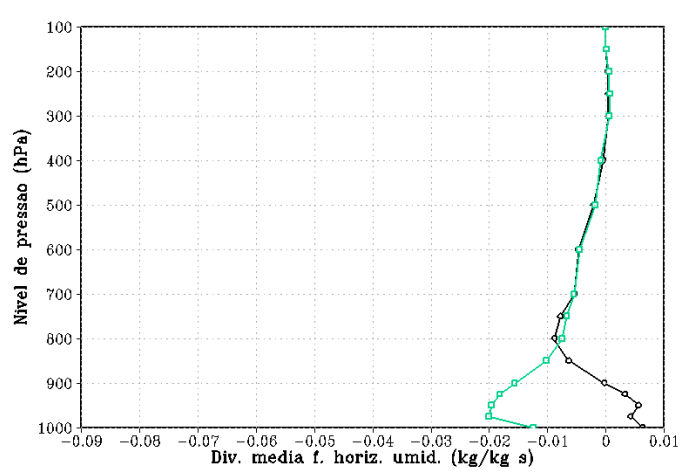

(c)

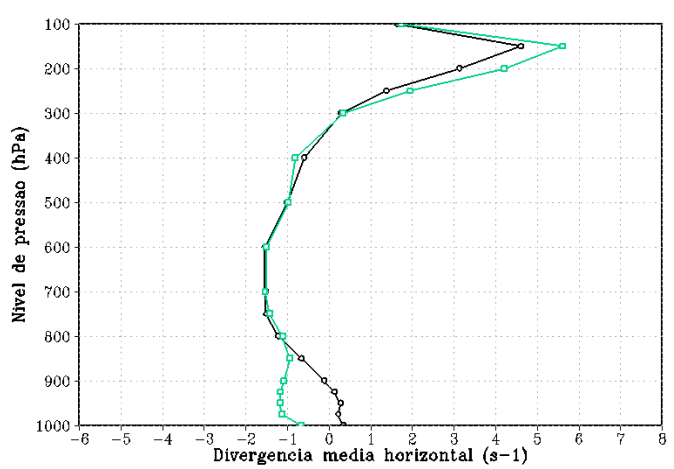

(b)

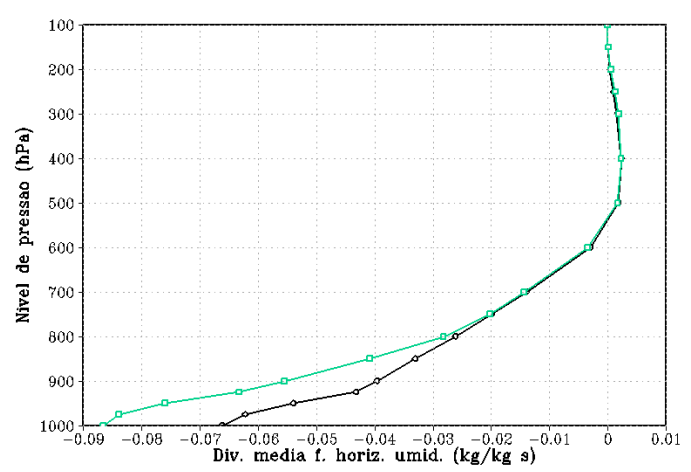

(d)

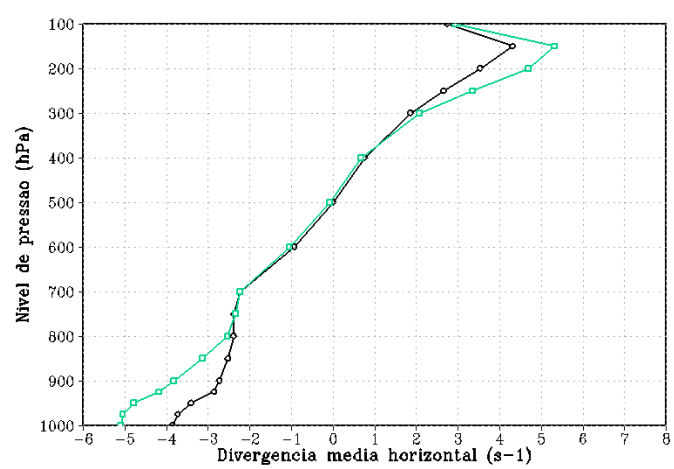

Figura 36. Perfis verticais da divergência média do fluxo horizontal de umidade (intervalo de $0,01 \times 10^{-6} \mathrm{~kg}$ $\left.\mathrm{kg}^{-1} \mathrm{~s}^{-1}\right)$ de todo o período de integração do modelo (08/02/98 às $00 \mathrm{Z}$ a 19/02/98 às $00 \mathrm{Z}$ ) e para as regiões (a) amazônica e (b) costeira e perfis verticais da divergência média horizontal (intervalo de $1 \times 10^{-6} \mathrm{~s}^{-1}$ ), do mesmo período de integração, para as regiões (c) amazônica e (d) costeira. A linha preta representa a variável em CTRL e a linha verde representa a variável em AMAZ (a, c) e em COST (b, d). No eixo da ordenadas estão representados os níveis de pressão em hPa. 


\subsubsection{ZCAS-99}

Da mesma forma que para ZCAS-98, nos experimentos "secos" para ZCAS-99 observase maior temperatura em baixos níveis com relação a CTRL. O maior aquecimento do solo mais seco faz com que a atmosfera fique menos instável, com ar mais quente abaixo do ar mais frio. Conforme é possível observar nas Figuras 37a e 37b, as diferenças significativas de temperatura entre AMAZ e COST e o experimento CTRL se dão sobre as regiões nas quais foi empregada a condição de US inicial seca. Em COST (Figura 37b) as diferenças são mais expressivas do que em AMAZ (Figura 37a), havendo destaque para as porções nordeste e sudoeste da região costeira em COST.

(a)

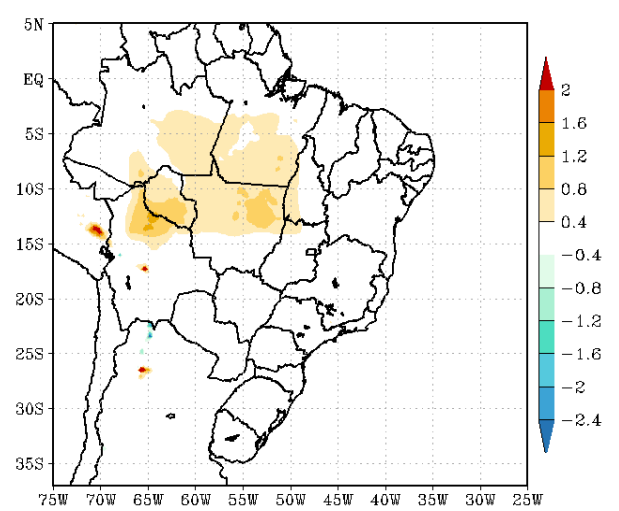

(b)

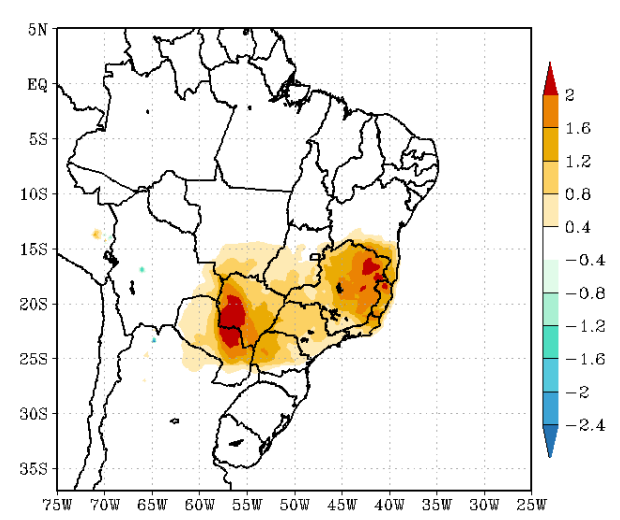

Figura 37. Diferença da média de temperatura do ar de todo o período de integração do modelo (02/01/99 às 00Z a 18/01/99 às 00Z) em $1000 \mathrm{hPa}$ entre os experimentos numéricos (a) AMAZ e CTRL (AMAZ-CTRL) e (b) COST e CTRL (COST-CTRL) (intervalo de $0,4^{\circ} \mathrm{C}$ ).

Com relação à umidade específica, as diferenças entre AMAZ e CTRL não são significativas (Figura 38a). Já as diferenças entre COST e CTRL (Figura 38b) são significativas em porções que coincidem com aquelas destacadas na Figura 37b, assim como em ZCAS-98. A diferença de temperatura de grande magnitude entre COST e CTRL nessas regiões aponta para solo muito seco em COST com relação ao de CTRL. Assim, em CTRL a 
quantidade de umidade disponível em baixos níveis é significativamente maior do que em COST (Figura 38b).

De forma semelhante ao caso de ZCAS-98, a instabilização da atmosfera sobre as regiões de secamento do solo em AMAZ e COST faz com que movimento vertical seja induzido sobre a região, e com o abaixamento da pressão em superfície ocorre convergência de umidade mais intensa nesses experimentos do que em CTRL (Figuras 38c e 38d). Semelhantemente a ZCAS-98, nas fronteiras das regiões amazônica e costeira ocorre maior divergência em AMAZ e COST, respectivamente, do que em CTRL, pois a umidade que converge essas regiões é proveniente dessas fronteiras.

(a)

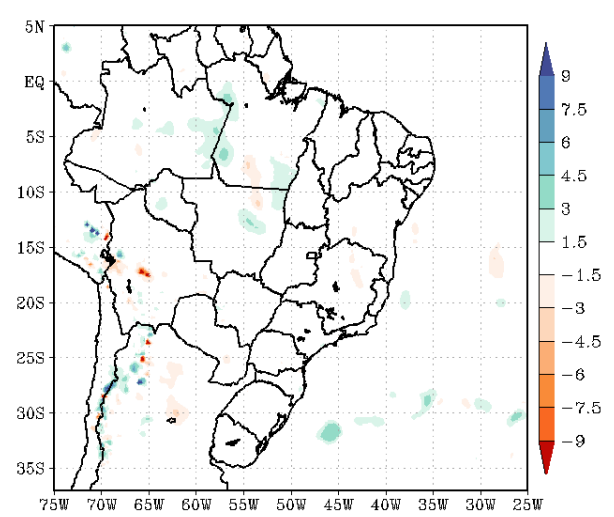

(c)

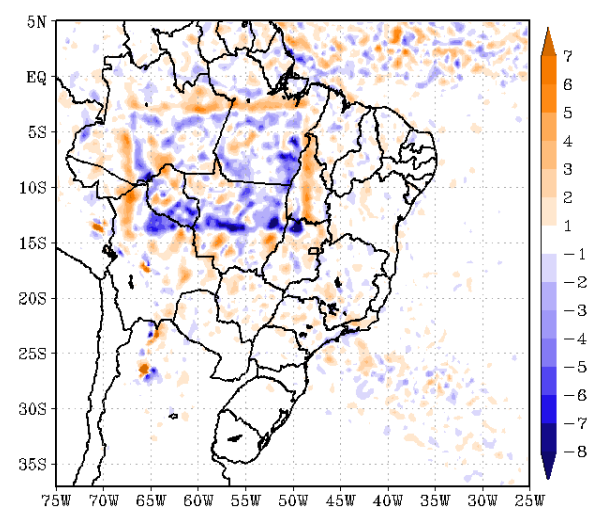

(b)

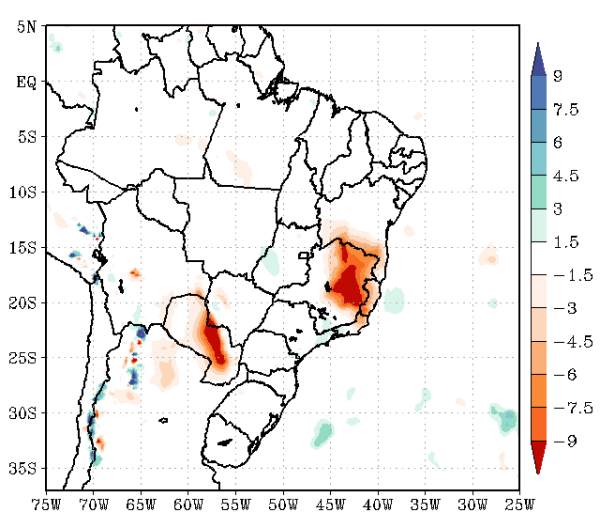

(d)

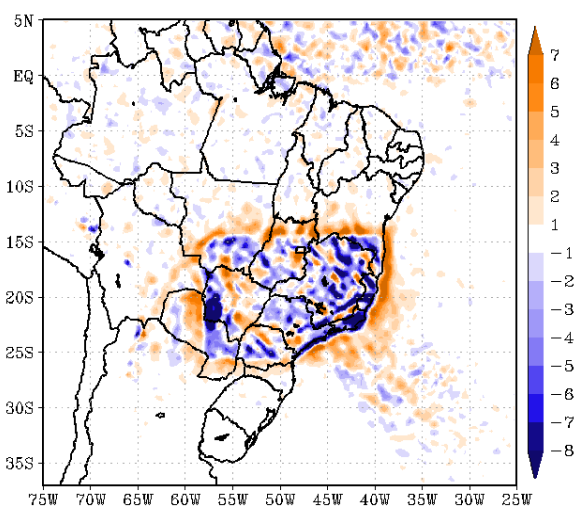

Figura 38. Diferença da média de umidade específica de todo o período de integração do modelo (02/01/99 às 00Z a 18/01/99 às 00Z) entre os experimentos numéricos (a) AMAZ e CTRL (AMAZ-CTRL) e (b) COST e CTRL (COST-CTRL) (intervalo de $1,5 \times 10^{-3} \mathrm{~g} \mathrm{~kg}^{-1}$ ) e diferença da divergência média do fluxo horizontal de umidade, do mesmo período de integração, integrado na atmosfera, da pressão reduzida ao nível médio do mar ao nível de $100 \mathrm{hPa}$ entre os experimentos numéricos (c) AMAZ e CTRL (AMAZ-CTRL) e (d) COST e CTRL (COST-CTRL) (intervalo de $1 \times 10^{-4} \mathrm{~kg} \mathrm{~kg}^{-1} \mathrm{~s}^{-1}$ ). 
Os experimentos AMAZ e COST apresentam fluxo de calor sensível à superfície mais intenso do que CTRL (Figuras 39a e 39b) nas regiões amazônica e costeira, respectivamente, já que os primeiros experimentos apresentam solo mais seco nessa regiões. As diferenças entre AMAZ e CTRL são menores se comparadas às entre COST e CTRL, sendo que se concentram nas porções sudeste e sudoeste da região amazônica (Figura 39a). Entre COST e CTRL as diferenças mais significativas se concentram nas porções nordeste e sudoeste na região costeira (Figura 39b), coincidindo com as regiões onde o fluxo de calor latente é mais intenso em CTRL (Figura 39d). Ou seja, CTRL, nestas regiões, apresenta mais umidade disponível para evaporação, assim como já confirmado através da Figura 38b, e o ar em COST se aquece mais devido à pouca US.

O fluxo de calor latente médio em AMAZ é mais intenso do que em CTRL em toda a região amazônica (Figura 39c), pois, como é possível observar na Figura 40a, em AMAZ há mais precipitação acumulada do que em CTRL, devido à intensa instabilidade e à umidade proveniente das fronteiras da região. Assim, a precipitação sobre a região contribui para maior fluxo de calor latente, já que no final do período de integração há mais água disponível para evaporação no solo.

É importante destacar na Figura 39b que ao longo da uma faixa central na direção noroeste-sudeste sobre a região costeira as diferenças entre COST e CTRL não são significativas, isso se dá devido ao posicionamento da ZCAS, cuja nebulosidade associada faz diminuir a incidência de raios solares na superfície nos dois experimentos. O posicionamento da ZCAS nessa região contribui para o fluxo de calor latente ser maior em COST, pois a precipitação associada ao sistema, que é mais intensa em COST (Figura 40b) fornece umidade ao solo para evaporação. 
(a)

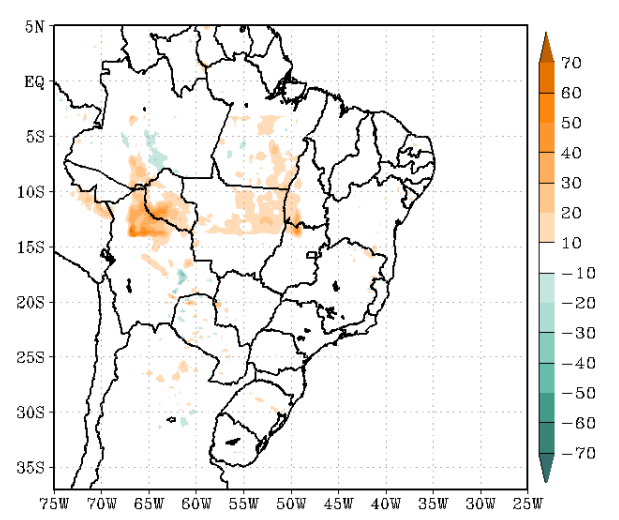

(c)

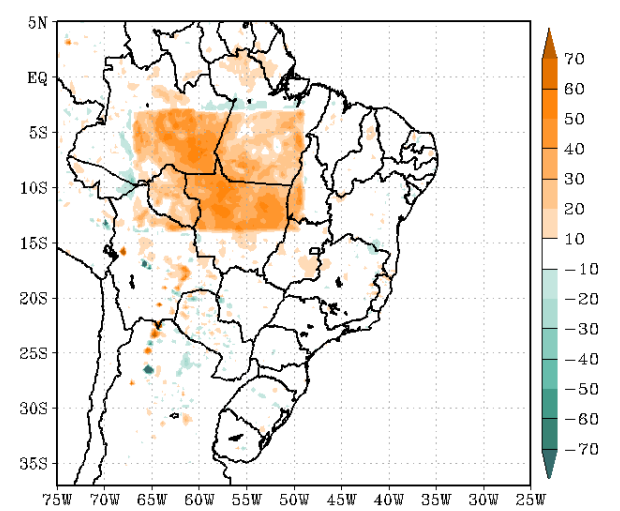

(b)

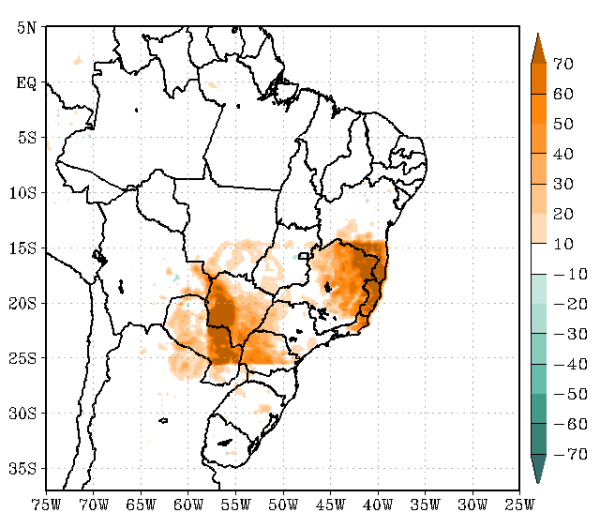

(d)

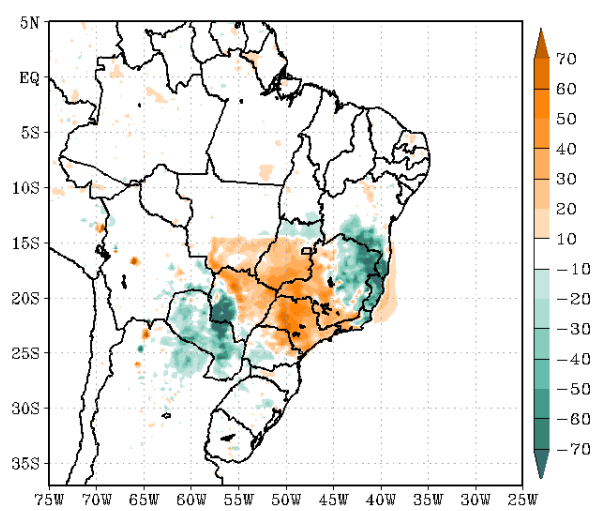

Figura 39. Diferença da média do fluxo de calor sensível à superfície de todo o período de integração do modelo (02/01/99 às 00Z a 18/01/99 às 00Z) entre os experimentos numéricos (a) AMAZ e CTRL (AMAZCTRL) e (b) COST e CTRL (COST-CTRL) (intervalo de $10 \mathrm{~W} \mathrm{~m}^{-2}$ ) e diferença da média do fluxo de calor latente à superfície, do mesmo período de integração, entre os experimentos numéricos (c) AMAZ e CTRL (AMAZ-CTRL) e (d) COST e CTRL (COST-CTRL) (intervalo de $10 \mathrm{~W} \mathrm{~m}^{-2}$ ).

Observa-se, de maneira geral, que AMAZ e COST apresentam maior quantidade de precipitação acumulada do que CTRL (Figuras 40a e 40b) nas regiões amazônica e costeira, respectivamente. Pelo mesmo motivo que em ZCAS-98, a instabilidade gerada pelo maior aquecimento do solo nos experimentos "secos" faz com que se desenvolvam circulações de meso e grande escalas e, portanto, maior convergência de umidade e consequente desenvolvimento vertical. A convergência, então, acaba sendo mais eficiente no processo de formação de chuva do que a quantidade de água disponível no solo para evaporação (que é maior em CTRL).

Similarmente a ZCAS-98, ao longo das fronteiras das regiões de ZCAS amazônica e costeira há mais chuva em CTRL do que em AMAZ e COST (Figuras 40a e 40b), 
respectivamente. A chuva é menos distribuída e mais concentrada sobre as regiões mais "secas" em AMAZ e COST, tendo em vista que a convergência para essas regiões é mais intensa nesses experimentos do que em CTRL.

Assim como observado a partir da diferença do fluxo de calor latente entre COST e CTRL, a maior quantidade de precipitação em COST com relação a CTRL (Figura 40b) se dá ao longo da ZCAS, cuja nebulosidade deve se apresentar mais concentrada sobre a região devido à intensa convergência de umidade.

A influência da US inicial na precipitação se dá sobre todas as regiões que compõem a ZCAS e sobre a região equatorial (Figuras 27a, 27b e 27c), porém é mais intensa sobre a região na qual foi realizada a alteração da US inicial para o PMP (Figuras 40a e 40b).

(a)

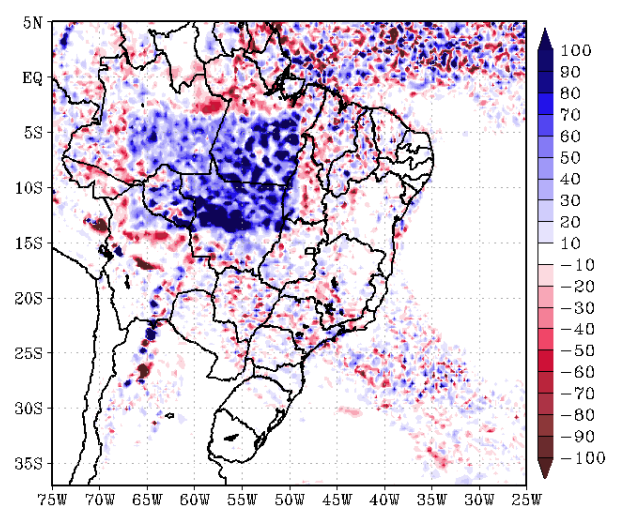

(b)

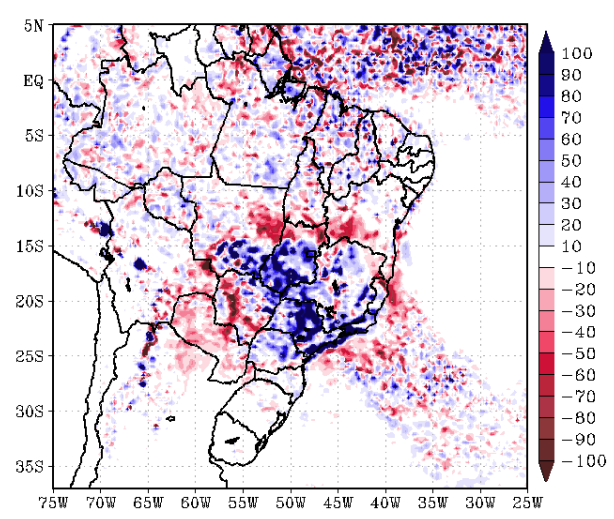

Figura 40. Diferença da precipitação acumulada no final do período de integração do modelo (02/01/99 às 00Z a 18/01/99 às 00Z) entre os experimentos numéricos (a) AMAZ e CTRL (AMAZ-CTRL) e (b) COST e CTRL (COST-CTRL) (intervalo de $10 \mathrm{~mm} \mathrm{dia}^{-1}$ ).

A partir da Tabela 17, observa-se que o volume de precipitação acumulada (considerando os pixels cuja diferença COST-CTRL é positiva) na região costeira em COST é maior do que o dobro da precipitação acumulada em CTRL (quando a diferença COST-CTRL é negativa) na mesma região. Já em AMAZ (quando a diferença AMAZ-CTRL é positiva) esse volume é cerca de 14 vezes o acumulado em CTRL (quando a diferença AMAZ-CTRL é negativa). O número de pixels nos quais a chuva acumulada em AMAZ é maior do que CTRL na região 
amazônica é expressivamente maior do que os número de pixels nos quais ocorre o oposto, sendo assim, o impacto na região amazônica é bastante significativo, principalmente no que diz respeito ao volume de chuva acumulada.

Nota-se também na Tabela 17 certo impacto da US inicial nas regiões onde este parâmetro foi mantido como horizontalmente homogêneo. Nas regiões costeira, oceânica e equatorial em AMAZ (para a diferença AMAZ-CTRL positiva) e amazônica, oceânica e equatorial em COST (para a diferença COST-CTRL positiva) há menor quantidade de precipitação com relação a CTRL (para as diferenças negativas). Desta forma, parte da umidade dessas regiões pode ser sido advectada para as regiões "secas", devido à forte convergência induzida pelo abaixamento de pressão em superfície já discutido anteriormente, fazendo com que houvesse menor quantidade de umidade disponível para formação de precipitação nessas regiões.

Tabela 17 - Idem à Tabela 16 mas para ZCAS-99 e período de integração do modelo de 02/01/99 às 00Z a $18 / 01 / 99$ às $00 Z$.

\begin{tabular}{ccrrrr} 
& & \multicolumn{2}{c}{ AMAZ-CTRL } & \multicolumn{2}{c}{ COST-CTRL } \\
\hline região & sinal & volume $(\mathbf{m m})$ & $\mathbf{n}^{\mathbf{0}}$.pixels & volume $(\mathbf{m m})$ & $\mathbf{n}^{\mathbf{0}}$.pixels \\
\hline \multirow{2}{*}{ amazônica } & - & 10395,9 & 452 & 32331,3 & 1669 \\
& + & 140757,0 & 2608 & 22988,0 & 1391 \\
\multirow{2}{*}{ costeira } & - & 28171,4 & 1639 & 40516,0 & 1459 \\
& + & 27965,2 & 1556 & 94456,1 & 1736 \\
\multirow{2}{*}{ oceânica } & - & 21344,8 & 1837 & 24555,3 & 1942 \\
& + & 17498,9 & 1651 & 18920,5 & 1546 \\
equatorial & - & 60584,5 & 1539 & 63566,8 & 1530 \\
\hline
\end{tabular}

Os perfis verticais de temperatura e de temperatura do ponto de orvalho (Figuras 41a e 41b) levam a conclusões semelhantes às do caso de ZCAS-98, revelando que nos experimentos "secos" a umidade relativa é menor. 
(a)

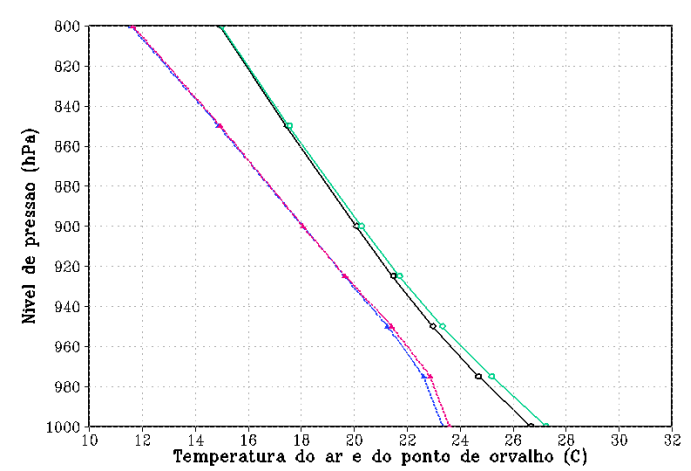

(b)

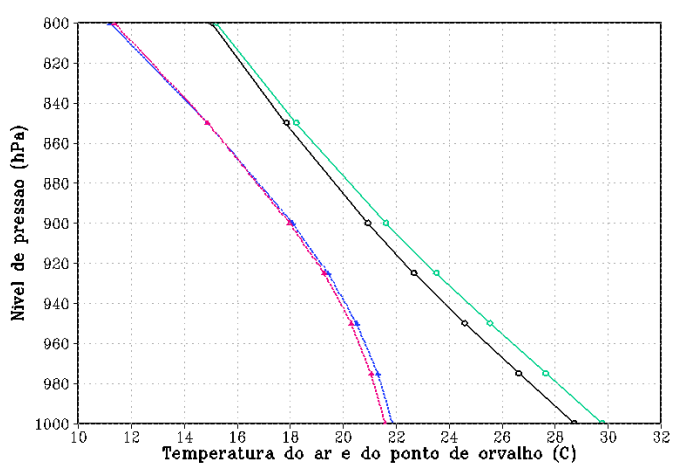

Figura 41. Perfis verticais da média da temperatura do ar e do ponto de orvalho (intervalo de $2{ }^{\circ} \mathrm{C}$ ) de todo o período de integração do modelo (02/01/99 às $00 \mathrm{Z}$ a 18/01/99 às $00 \mathrm{Z})$ e das regiões (a) amazônica e (b) costeira, sendo que as linhas preta e azul representam a temperatura do ar e do ponto de orvalho em CTRL, respectivamente, e as linhas verde e magenta representam as mesmas variáveis em AMAZ (a) e em COST (b). No eixo da ordenadas estão representados os níveis de pressão em hPa.

O secamento do solo provoca um aumento da temperatura potencial em baixos níveis (Figuras 42a e 42b), já que devido a ele ocorre um aumento da temperatura na superfície. Da mesma forma que para ZCAS-98, nos experimentos mais secos a atmosfera é menos estável do que em CTRL, estando assim mais próxima da instabilidade, e nos níveis adjacentes à superfície é quase neutra, sendo menos estável do que nos níveis mais altos.

(a)

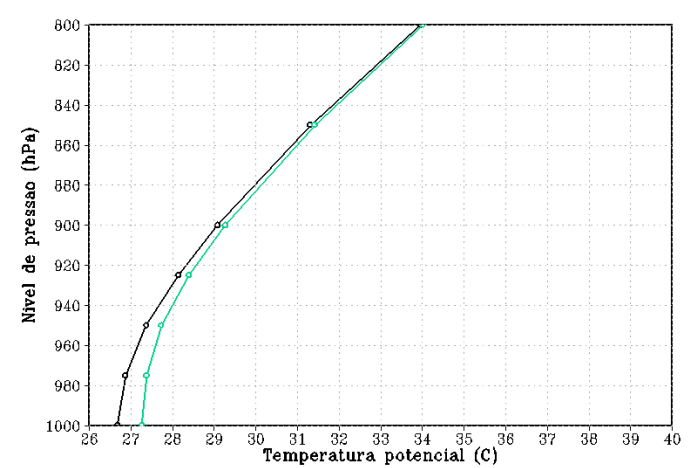

(b)

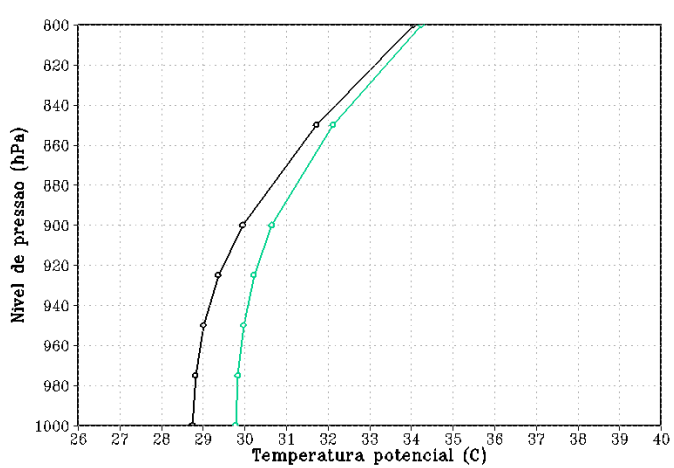

Figura 42. Perfis verticais da média da temperatura potencial (intervalo de $1{ }^{\circ} \mathrm{C}$ ) de todo o período de integração do modelo (02/01/99 às $00 \mathrm{Z}$ a 18/01/99 às $00 \mathrm{Z})$ e das regiões (a) amazônica e (b) costeira, sendo que a linha preta representa a temperatura potencial em CTRL e a linha verde representa a mesma variável em AMAZ (a) e em COST (b). No eixo da ordenadas estão representados os níveis de pressão em $\mathrm{hPa}$.

Assim como para ZCAS-98, o perfil do movimento vertical apenas complementa a conclusão obtida a partir dos campos analisados anteriormente. Em AMAZ e COST sobre as regiões amazônica e costeira, respectivamente, a velocidade vertical é maior se comparada à 
observada em CTRL sobre as mesmas regiões (Figuras 43a e 43b) dos baixos aos altos níveis. Nos experimentos "secos" o movimento ascendente é fortalecido pela convergência mais intensa, induzida pelo aquecimento mais elevado do solo com menor quantidade de umidade. As maiores diferenças entre AMAZ/COST e CTRL se dão em aproximadamente $300 \mathrm{hPa}$ (Figuras 43a e 43b), da mesma forma que em ZCAS-98 e pelas mesmas razões.

A velocidade vertical em AMAZ sobre a região amazônica (Figura 43a) é de maior magnitude do que em COST sobre a região costeira (Figura 43b), ao contrário do que ocorre em ZCAS-98. Isto pode ser devido ao ENOS, que durante o caso ZCAS-99 está em sua fase fria, isto é, quando há maior ascendência sobre a Amazônia e enfraquecimento do escoamento de baixos níveis anômalo de leste, que é defletido pelos Andes e advecta umidade para o Sudeste do Brasil. Diante disso, o movimento ascendente induzido pelo solo mais seco em AMAZ pode ter sido intensificado pela atuação do fenômeno La Niña.

(a)

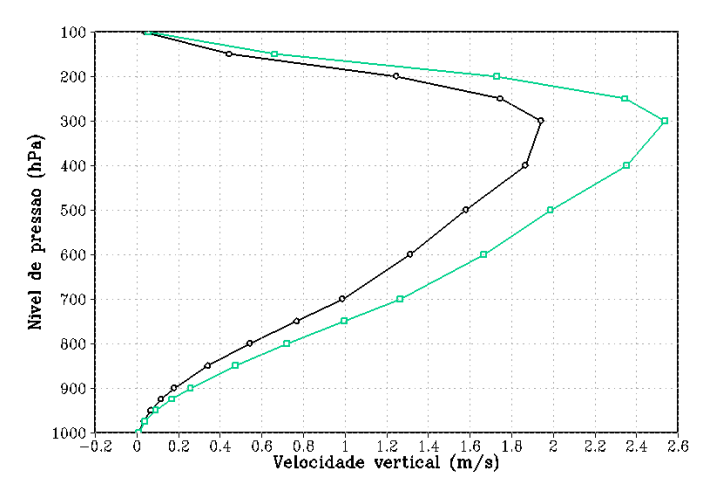

(b)

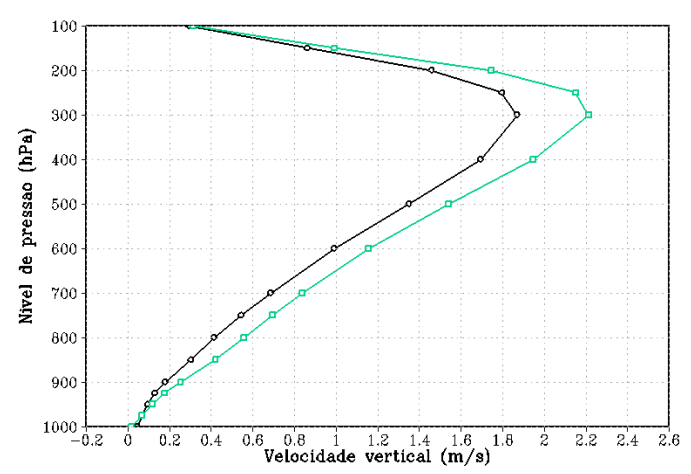

Figura 43. Idem à Figura 42 mas para componente vertical do vento (intervalo de $0,2 \times 10^{-2} \mathrm{~m} \mathrm{~s}^{-1}$ ).

Sobre a região de ZCAS amazônica em CTRL (Figura 44a) há convergência de umidade em baixos níveis, porém em AMAZ essa convergência é mais intensa, conforme esperado e já discutido com base em outros campos, ocorrendo o mesmo na região costeira em COST (Figura 44b). Já dos médios aos altos níveis é observada divergência de umidade pouco intensa em ambas as Figuras, já que nesses níveis da troposfera há pouca umidade. 
Nas Figuras 44c e 44d destaca-se o padrão de convergência em baixos níveis e divergência nos níveis mais altos, com convergência e divergência mais acentuada nos experimentos mais "secos", o que pode ser justificado da mesma forma que para ZCAS-98. Observa-se ainda que o NND está em torno de 450 hPa em AMAZ e de 400 hPa em COST.

(a)

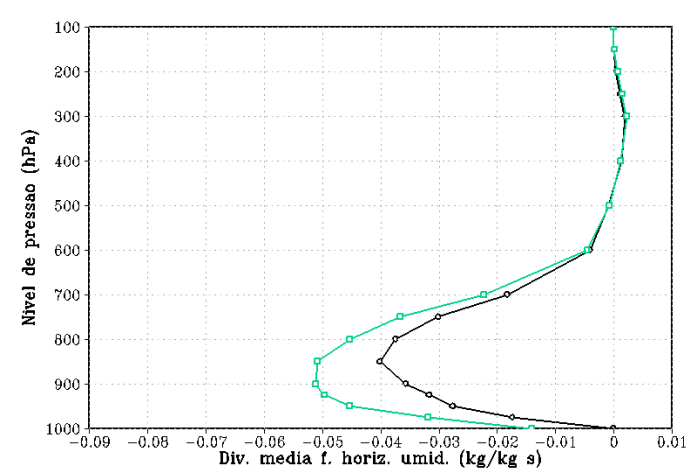

(c)

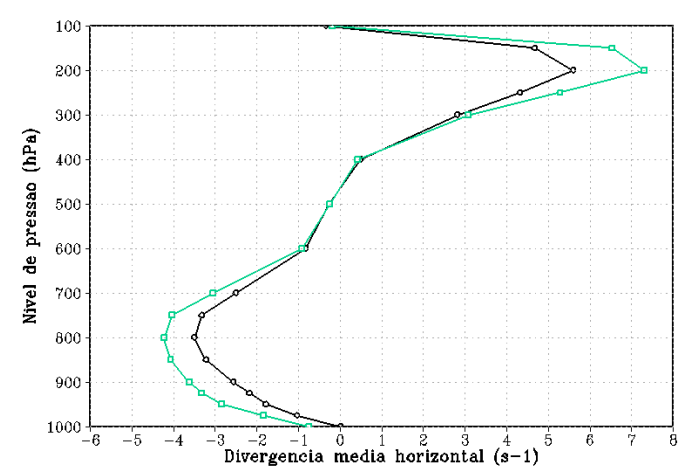

(b)

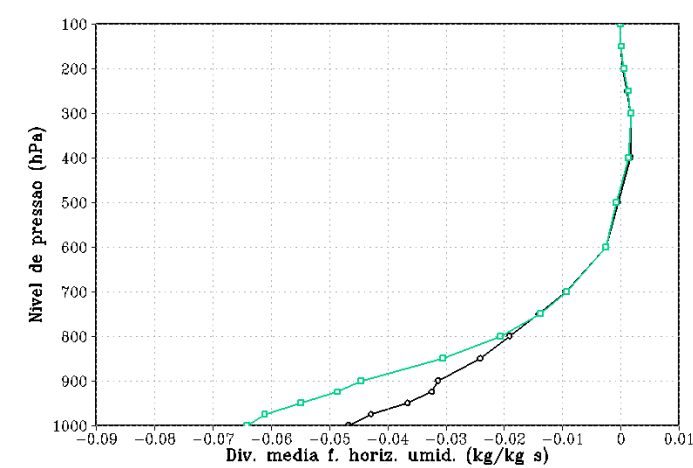

(d)

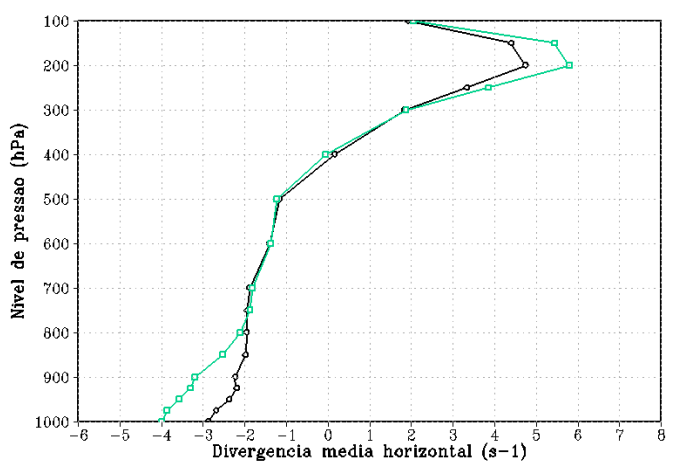

Figura 44. Perfis verticais da divergência média do fluxo horizontal de umidade (intervalo de $0,01 \times 10^{-6} \mathrm{~kg}$ $\left.\mathrm{kg}^{-1} \mathrm{~s}^{-1}\right)$ de todo o período de integração do modelo (02/01/99 às 00Z a 18/01/99 às 00Z) e para as regiões (a) amazônica e (b) costeira e perfis verticais da divergência média horizontal (intervalo de $1 \times 10^{-6} \mathrm{~s}^{-1}$ ), do mesmo período de integração, para as regiões (c) amazônica e (d) costeira. A linha preta representa a variável em CTRL e a linha verde representa a variável em $\operatorname{AMAZ~(a,~c)~e~em~COST~(b,~d).~No~eixo~da~ordenadas~}$ estão representados os níveis de pressão em $\mathrm{hPa}$. 


\subsection{Conclusões}

Foi realizada uma série de simulações com o modelo BRAMS (Tabela 1) com três condições iniciais de umidade do solo distintas (Figuras 27a, 27b e 27c) para dois casos de ZCAS (ZCAS-98 e ZCAS-99). Para cada caso foi realizada uma simulação controle (CTRL), na qual a US inicial foi mantida horizontalmente homogênea em todo domínio do modelo, e duas simulações com a aplicação da condição inicial de umidade do solo mais seca possível (ponto de murcha permanente) em duas regiões que compõem a ZCAS (costeira e amazônica) separadamente. Procurou-se investigar a influência dessas condições do solo em aspectos como fluxos de calor à superfície, convergência de umidade e principalmente a precipitação associada à ZCAS em cada região que a compõe (Figura 1).

As condições iniciais de US, nos dois casos de ZCAS, apenas afetaram a região na qual foi aplicada a condição de umidade mínima aceitável, não havendo impacto significativo nas demais regiões do domínio no que diz respeito à temperatura e umidade em baixos níveis, e fluxos de calor à superfície. Com relação à precipitação o impacto da US inicial se deu em todas as regiões que compõem a ZCAS e sobre a região equatorial, porém foi mais intenso sobre a região na qual foi aplicado o PMP como US inicial (Figuras 32a, 32b, 40a e 40b).

De forma geral, a quantidade de precipitação acumulada na região amazônica em AMAZ e costeira em COST foi maior do que em CTRL (Figuras 32a, 32b, 40a e 40b). A aplicação do PMP como condição inicial de US fez com que a temperatura do ar em baixos níveis nesses experimentos fosse mais elevada, ocorrendo diminuição da estabilidade da atmosfera, movimento ascendente e convergência de umidade, que é trazida das fronteiras da região por circulações de meso e grande escalas geradas pelas heterogeneidade na superfície, em baixos níveis sobre a região mais seca. Com os movimentos verticais favorecidos, ocorre também 
favorecimento da convecção e precipitação, e a liberação de calor latente na média troposfera que ocorre devido à última, intensifica ainda mais os movimentos verticais.

Em ambos os casos de ZCAS foi possível também apontar um provável efeito do ENOS sobre o escoamento nas porções continentais do sistema, uma vez que a velocidade vertical em AMAZ sobre a região amazônica (Figura 35a) é de menor magnitude do que em COST sobre a região costeira (Figura 35b) em ZCAS-98, período de fase quente do ENOS. Em ZCAS-99 observou-se exatamente o oposto (Figuras 43a e 43b), visto que este caso ocorreu durante a La Niña. Isto porque durante a fase quente (fria) do ENOS há maior subsidência (ascendência) sobre a região amazônica, o que pode ter contribuído para enfraquecer (fortalecer) o movimento vertical sobre a região. 


\section{Capítulo 6}

\section{Conclusões}

O objetivo geral deste trabalho foi estudar as principais características da ZCAS e verificar as influências das condições de TSM e US, principalmente na precipitação associada ao sistema, através de experimentos numéricos com o modelo BRAMS (Tabela 1) para dois casos de ZCAS. Pretendeu-se ainda identificar diferenças nas características da ZCAS observada e simulada em condições de El Niño (ZCAS-98) e de La Niña (ZCAS-99).

O sistema do caso de ZCAS-99 apresentou sucessivas intensificações e desintensificações, visto que durante sua atuação ocorreu a penetração de diferentes sistemas frontais, que quando se associaram à $\mathrm{AB}$ intensificaram a atividade da ZCAS, enfraquecendoa quando se deslocaram para o oceano. Esse caso de ZCAS se manteve por 13 dias, pois apesar da dissipação dos sistemas frontais, o mecanismo $\mathrm{AB}-\mathrm{CN}$ permaneceu ativo. Já a nebulosidade e a precipitação associada ao caso ZCAS-98 não apresentaram tal oscilação, tendo ciclo de vida inferior ao caso de 1999 (5 dias), visto que o mecanismo AB-CN se manteve por menos tempo. Observa-se assim a importância da circulação de altos níveis atuante na região do SMAS como suporte para a manutenção da ZCAS.

Uma característica marcante dos casos de ZCAS estudados neste trabalho é que, enquanto a ZCAS-98 se apresenta mais alongada em direção ao Atlântico Sul, a ZCAS-99 é predominantemente continental. Isto pode ser consequência da atuação do ENOS, tendo em vista que o período de DJF de 1997-98 (1998-99) corresponde à fase quente (fria) do El Niño- 
Oscilação Sul, que favorece a ocorrência de ZCAS oceânica (continental), conforme Carvalho, Jones e Liebmann (2004) e Nogués-Paegle e Mo (1997).

Com relação à TSM, procurou-se explorar aspectos relativos à influência das resoluções espacial e temporal desses dados (Tabela 2) sobre características da ZCAS e, além disso, realizar uma verificação do desempenho do modelo numérico em simular a precipitação associada ao sistema em cada região que o compõe (Figura 1) através de índices estatísticos. SEM1 foi o experimento com maior TSM média (Figuras 17 e 22) e, devido à maior evaporação e instabilização da atmosfera em baixos níveis, foi também o experimento com maior quantidade de precipitação acumulada (Figuras 21a, 21b, 26a e 26b). O experimento com menor quantidade de precipitação acumulada na ZCAS oceânica (região mais afetada pelos dados de TSM) foi DIA025.

No que tange ao skill do modelo, para ZCAS-98, o melhor e o pior desempenhos se deram nas simulações que utilizaram dados de TSM com resoluções espacial e temporal mais refinadas (DIA025) e mais grosseiras (SEM1) (Tabela 6), respectivamente. Para ZCAS-99 não foi observada diferença de desempenho significativa entre as simulações (Tabela 10). Grande parte do erro na previsão de chuva do modelo BRAMS é devida ao viés do próprio modelo, que é melhor em identificar a ocorrência ou não de chuva do que em localizar os núcleos de chuva mais intensos (Tabelas 7, 8, 9, 11, 12 e 13). No entanto, o BRAMS apresenta alto skill no que diz respeito à quantidade de chuva. Com relação à simulação de precipitação nas diferentes regiões que compõem a ZCAS, o melhor e o pior desempenhos do modelo se deram nas regiões amazônica e oceânica, respectivamente.

Com a finalidade de estudar influências das condições de US inicial na ZCAS foram realizadas três simulações para cada caso de ZCAS, uma delas sendo o controle (CTRL) e outras duas utilizando o PMP como condição inicial nas regiões de ZCAS costeira e amazônica separadamente (Figuras 27a, 27b e 27c). De forma geral, a quantidade de 
precipitação acumulada nos experimentos "secos", isto é, na região amazônica em AMAZ e costeira em COST, foi maior do que em CTRL (Figuras 32a, 32b, 40a e 40b), ao contrário do feedback positivo entre conteúdo de umidade no solo e precipitação associada à ZCAS proposto por Candido, Gan e Manzi (2006).

A condição inicial de solo seco fez com que o mesmo se aquecesse mais do que o solo em CTRL, aquecendo mais o ar adjacente e causando instabilização da atmosfera nos níveis mais baixos. Com isso, foram induzidos movimento ascendente e convergência de umidade (trazida das fronteiras por circulações de meso e grande escalas geradas pela heterogeneidade na superfície). Desta forma, a parametrização convectiva do modelo foi mais acionada, e a liberação de calor latente na média troposfera, que é característica dessa parametrização, intensificou ainda mais os movimentos verticais, produzindo mais precipitação, tornando este mecanismo um feedback positivo.

No trabalho de Candido, Gan e Manzi (2006), o secamento do solo de todo o domínio fez com que o suprimento de umidade para a região da ZCAS diminuísse e o transporte para áreas subtropicais da América do Sul se intensificasse, fortalecendo eventos de JBN, causando então enfraquecimento da ZCAS. Em contrapartida, no presente estudo, o secamento, apenas das regiões de ZCAS continental, induziu o desenvolvimento de circulações de mesoescala, já referidas, que contribuíram para a convergência de umidade sobre a região "seca", aumentando assim a precipitação sobre a região de ZCAS continental em cujo solo foi aplicada a condição de US seca.

Nos testes de sensibilidade do modelo BRAMS à US foi observado provável efeito do ENOS sobre o escoamento ao longo da ZCAS continental. A velocidade vertical em AMAZ sobre a região amazônica (Figura 35a) foi de menor magnitude do que em COST sobre a região costeira (Figura 35b) em ZCAS-98, período de fase quente do ENOS, que favorece a subsidência sobre a Amazônia, podendo ter contribuído para enfraquecer o movimento 
vertical sobre a região. Em ZCAS-99, ocorrido durante a fase fria do ENOS, ocorreu exatamente o oposto (Figuras 43a e 43b).

\subsection{Sugestões para trabalhos futuros}

O JBN da América do Sul pode desempenhar um importante papel transportando umidade e ar quente das regiões tropicais e alimentando a convecção e precipitação nas regiões subtropicais da América do Sul. O JBN intensificado também contribui para o fortalecimento do escoamento de baixos níveis noroeste-sudeste climatológico do SMAS, influenciando fortemente no posicionamento e intensidade da ZCAS. A precipitação associada à ZCAS, por sua vez, pode causar diversos problemas sociais e econômicos nas regiões onde o sistema atua. Diante disso, sugere-se para trabalhos futuros a realização de uma análise dos padrões de transporte e de convergência de umidade realizado pelo Jato de Baixos Níveis da América do Sul, e a determinação e análise do balanço de vapor d'água sobre a região da ZCAS a fim de aprimorar o entendimento desses processos e assim melhorar suas representações em modelos atmosféricos.

Com relação ao conjunto de dados de precipitação utilizado na análise sinótica e também na validação do modelo, sugere-se o uso dos dados do TRMM (Tropical Rainfall Measuring Mission) produto 3B42 versão 6 (HUFFMAN et al., 2007). Este é um conjunto de dados quase global, cobrindo de $50^{\circ} \mathrm{S}$ a $50^{\circ} \mathrm{N}$ e de $180^{\circ} \mathrm{W}$ a $180^{\circ} \mathrm{E}$, e suas resoluções espacial ( $0,25 \times$ x 0,25 graus de latitude-longitude) e temporal (três em três horas) são superiores às do GPI, utilizado neste trabalho, e mais compatíveis com a resolução do modelo BRAMS, evitando-se, assim, interpolações mais grosseiras quando da comparação observação X 
simulação. Além disso, a alta resolução temporal desse conjunto de dados poderia ser importante para estudos do desempenho da parametrização convectiva do modelo, em termos de ciclo diurno da precipitação.

Tendo em vista a melhora das simulações de precipitação realizadas pelo modelo regional empregado neste estudo, sugere-se a realização de testes com as diferentes parametrizações de convecção profunda disponíveis no BRAMS. E ainda visando o aprimoramento da representação da ZCAS pelo modelo numérico, sugere-se a realização de experimentos similares aos realizados neste trabalho, porém com a utilização do conjunto de dados MERRA (Modern Era Retrospective-Analysis for Research and Applications) (BOSILOVICH, 2008) como condições iniciais e de fronteira do modelo, e de conjunto de dados de umidade inicial heterogênea, uma vez que, conforme De Gonçalves et al. (2006), o uso deste tipo de dado melhora o desempenho do modelo numérico.

A fim de melhor estudar o impacto das condições de US de ambas as regiões continentais que compõem a ZCAS na precipitação associada ao sistema, propõe-se utilizar como umidade inicial não apenas a condição seca representada pelo PMP, mas também uma condição úmida, que pode ser representada, por exemplo, pelo ponto de saturação do solo. Para a realização de uma série de simulações ainda mais completa sugere-se, para trabalhos futuros, a aplicação do método de separação de fatores desenvolvido por Stein e Alpert (1993).

Visando melhor detalhar os processos de mesoescala envolvidos na representação da ZCAS bem como das circulações locais geradas por heterogeneidades na superfície (como nos testes de sensibilidade a US), sugere-se o aninhamento de grades de maior resolução sobre as diferentes regiões continentais que compõem a ZCAS (costeira e amazônica).

Além da temperatura da superfície do mar e das condições iniciais de umidade do solo, podem ser estudadas as influências de outras características da superfície na ZCAS, como a vegetação, testando-se, por exemplo, a sensibilidade do modelo a diferentes coberturas 
vegetais nas regiões de ZCAS costeira e amazônica, ou então simulando-se um desmatamento nessas regiões, semelhantemente aos trabalhos de Avissar et al. (2002), Gash e Nobre (1997) e Werth e Avissar (2004).

Ainda do ponto de vista de modelagem numérica, sugere-se a realização de testes de sensibilidade a US, similares aos efetuados neste trabalho, com o uso do modelo OLAM (Ocean-Land-Atmosphere Model), uma vez que é um modelo global capaz de representar simultaneamente fenômenos de escala global, no caso a ZCAS, e regional (RAMOS DA SILVA et al., 2009), neste caso as circulações de mesoescala geradas pelos contrastes de US. Além dessas vantagens com relação ao BRAMS, o OLAM não necessita de condições de fronteira lateral, não utilizando aninhamento de grades, o que elimina os problemas de trocas de energia entre as fronteiras. O OLAM ainda permite interações em duas direções entre todas as áreas do globo, possibilitando a realização de simulações climáticas que dependem dessas interações entre diferentes escalas espaciais (WALKO; AVISSAR, 2008). 


\section{Referências*}

ANDRADE, L. S. Variabilidade decadal da Zona de Convergência Intertropical e sua influência na pluviosidade da Região Norte do Brasil. 2007. 73 f. Dissertação (Mestrado em Meteorologia) - Instituto de Ciências Atmosféricas, Universidade Federal de Alagoas, Maceió, 2007.

ARAKAWA, A.; SCHUBERT, W. H. Interaction of a Cumulus cloud ensemble with the large-scale environment, Part I. Journal of Atmospheric Sciences, v. 31, p. 674-701, abr. 1974.

ARKIN, P. A.; MEISNER, B. N. The relationship between large-scale convective rainfall and cold cloud over the Western Hemisphere during 1982-84. Monthly Weather Review, v.115, p. 51-74, jan. 1987.

AVISSAR, R.; PIELKE, R. A. A parameterization of heterogeneous land surfaces for atmospheric numerical models and its impact on regional meteorology. Monthly Weather Review, v. 117, p. 2113-2136, out. 1989.

A statistical-dynamical approach to parameterize subgrid-scale land-surface heterogeneity in climate models. Surveys in Geophysics, v. 12, n. 1-3, p. 155-178, mar. 1991.

CHEN, F. Development and analysis of prognostic equations for mesoscale kinetic energy and mesoscale (subgrid scale) fluxes for large-scale atmospheric models. Journal of the Atmospheric Sciences, v. 50, n. 22, p. 3751-3774, nov. 1993.

; SILVA DIAS, P. L.; SILVA DIAS, M. A. F.; NOBRE, C. The Large-Scale Biosphere-Atmosphere Experiment in Amazonia (LBA): insights and future research needs. Journal of Geophysical Research, v. 107, n. D20, p. 54-1-6, out. 2002.

\footnotetext{
* De acordo com:

ASSOCIAÇÃO BRASILEIRA DE NORMAS TÉCNICAS. NBR 6023: informação e documentação: referências: elaboração. Rio de Janeiro, 2002.
} 
BAIDYA ROY, S.; AVISSAR, R. Impact of land use/land cover change on regional hydrometeorology in Amazonia. Journal of Geophysical Research, v. 107, n. D20, p. 4-112, ago. 2002.

BALDWIN, M. E.; KAIN, J. S. Sensitivity of several performance measures to displacement error, bias, and event frequency. Weather and Forecasting, v. 21, p. 636-648, ago. 2006.

BARREIRO, M.; CHANG, P.; SARAVANAN, R. Variability of the South Atlantic Convergence Zone simulated by an Atmospheric General Circulation Model. Journal of Climate, v. 15, p. 745-763, abr. 2002.

BARROS, V.; GONZALEZ, M.; LIEBMANN, B.; CAMILLONI, I. Influence of the South Atlantic Convergence Zone and South Atlantic sea surface temperature on interannual summer rainfall variability in Southeastern South America. Theoretical and Applied Climatology, v. 67, p. 123-133, 2000.

BELJAARS, A. C. M.; VITERBO, P.; MILLER, M. J.; BETTS, A. K. The anomalous rainfall over the United States during July 1993: sensitivity to land surface parameterization and soil moisture anomalies. Monthly Weather Review, v. 124, p. 362-383, mar. 1996.

BOSILOVICH, M. G. NASA's Modern Era Retrospective-analysis for Research and Applications: integrating Earth observations. Earthzine - Fostering Earth \& Global Awareness, 2008. Disponível em: <http://www.earthzine.org/2008/09/26/nasas-modern-eraretrospective-analysis/>. Acesso em: 29 jan. 2010.

BRANDÃO, R. S.; FISCH, G. F. A Zona de Convergência do Atlântico Sul e seus impactos nas enchentes em áreas de risco em Guaratinguetá - SP. Revista Biociências, UNITAU, v. 14, n. 2, p. 95-104, 2008. Disponível em: <http://periodicos.unitau.br/ojs2.2/index.php/biociencias>. Acesso em: 11 nov. 2009.

CALDERON, D. Influência da temperatura da superfície do mar e da convecção em simulações regionais para a Zona de Convergência do Atlântico Sul. 2000. 89 f. Dissertação (Mestrado em Meteorologia) - Instituto de Astronomia, Geofísica e Ciências Atmosféricas, Universidade de São Paulo, São Paulo, 2000.

CANDIDO, L. A. Impacto da condição inicial de água no solo na previsão de verão da América do Sul. 2002. 224 f. Tese (Doutorado em Meteorologia) - Instituto Nacional de Pesquisas Espaciais, São José dos Campos, 2002. 
; GAN, M. A.; MANZI, A. O. Sensibilidade da Zona de Convergência do Atlântico Sul (ZCAS) à condição hídrica do solo: um estudo de caso. Revista Brasileira de Meteorologia, v. 21, n. 3b, p. 387-397, dez. 2006.

CARVALHO, L. M. V.; JONES, C.; LIEBMANN, B. Extreme precipitation events in southeastern South America and large-scale convective patterns in the South Atlantic Convergence Zone. Journal of Climate, v. 15, p. 2377-2394, set. 2002.

The South Atlantic Convergence Zone: intensity, form, persistence, and relationships with intraseasonal to interannual activity and extreme rainfall. Journal of Climate, v. 17, p. 88-108, jan. 2004.

CASARIN, D. P.; KOUSKY, V. E. Anomalias de precipitação no sul do Brasil e variações na circulação atmosférica. Revista Brasileira de Meteorologia, v. 1, p. 83-90, 1986.

CAVALCANTI, I. F. A.; MARENGO, J. A.; SATYAMURTY, P.; NOBRE, C. A.; TROSNIKOV, I.; BONATTI, J. P.; MANZI, A. O.; TARASOVA, T.; PEZZI, L. P.; D'ALMEIDA, C.; SAMPAIO, G.; CASTRO, C. C.; SANCHES, M. B.; CAMARGO, H. Global climatological features in a simulation using the CPTEC-COLA AGCM. Journal of Climate, v. 15, n. 21, p. 2965-2988, nov. 2002.

CHAVES, R. R.; NOBRE, P. Interaction between sea surface temperature over the South Atlantic Ocean and the South Atlantic Convergence Zone. Geophysical Research Letters, v. 31, L03204, fev. 2004.

; SATYAMURTY, P. Estudo das condições regionais associadas a um evento de forte ZCAS em janeiro de 2003. Revista Brasileira de Meteorologia, v. 21, n. 1, p. 134-140, abr. 2006.

CHEN, C; COTTON, W. R. A one-dimensional simulation of the Stratocumulus-capped mixed layer. Boundary-Layer Meteorology, v. 25, n. 3, p. 289-321, mar. 1983.

CHINA será segundo maior importador da agroindústria brasileira em 2030, aponta estudo da Ernst \& Yo. Aditivos \& Ingredientes, São Paulo, 13 out. 2009. Disponível em: $<$ http://www.insumos.com.br/aditivos_e_ingredientes/noticias_ler.php?id_noticia=90>. Acesso em: 1 fev. 2010. 
CHOU, S. C.; JUSTI DA SILVA, M. G. A. Objective evaluation of ETA model precipitation forecasts over South America. Revista Climanálise, 1999. Disponível em: <http://www.cptec.inpe.br/products/climanalise/artigos/artcien2.shtml>. Acesso em: 27 fev. 2009.

CLARK, T. L. A small-scale dynamic model using a terrain-following coordinate transformation. Journal of Computational Physics, v. 24, p. 186-215, jun. 1977.

CLIMANÁLISE. Boletim de monitoramento e análise climática. CPTEC/INPE, Cachoeira Paulista, v. 13, n. 02, fev. 1998. Disponível em: <http://www.cptec.inpe.br/products/climanalise/capa1.html>. Acesso em: 28 set. 2008.

COHEN, C. A comparison of Cumulus parameterizations in idealized sea-breeze simulations. Montlhy Weather Review, v. 130, p. 2554-2571, nov. 2002.

COTTON, W. R.; PIELKE, R. A.; WALKO, R. L.; LISTON, G. E.; TREMBACK, C. J.; JIANG, H.; MCANELLY, R. L.; HARRINGTON, J. Y.; NICHOLLS, M. E.; CARRIO, G. G.; MCFADDEN, J. P. RAMS 2001: Current status and future directions. Meteorology and Atmospheric Physics, v. 82, n. 1-4, p. 5-29, jan. 2003.

CUNNINGHAM, C. A. C.; CAVALCANTI, I. F. A. Intraseasonal modes of variability affecting the South Atlantic Convergence Zone. International Journal of Climatology, v. 26, n. 9, p. 1165-1180, jul. 2006.

DE ALMEIDA, R. A. F.; NOBRE, P.; HAARSMA, R. J.; CAMPOS, E. J. D. Negative ocean-atmosphere feedback in the South Atlantic Convergence Zone. Geophysical Research Letters, v. 34, L18809, set. 2007.

DE GONÇALVES, L. G. G.; SHUTTLEWORTH, W. J.; CHOU, S. C.; XUE, Y.; HOUSER, P. R.; TOLL, D. L.; MARENGO, J.; RODELL, M. Impact of different initial soil moisture fields on ETA model weather forecasts for South America. Journal of Geophysical Research, v. 111, D17102, set. 2006.

DE SOUZA, E. B.; AMBRIZZI, T. Modulation of the intraseasonal rainfall over tropical Brazil by the Madden-Julian Oscillation. International Journal of Climatology, v. 26, n. 13, p. 1759-1776, abr. 2006.

DRUMOND, A. R. M. Anomalias de TSM no Hemisfério Sul e seu impacto na Monção Sul Americana. 2005. 99f. Tese (Doutorado em Meteorologia) - Instituto de Astronomia, Geofísica e Ciências Atmosféricas, Universidade de São Paulo, São Paulo, 2005. 
DURIEUX, L.; MACHADO, L. A. T.; LAURENT, H. The impact of deforestation on cloud cover over the Amazon arc of deforestation. Remote Sensing of Environment, v. 86, p. 132$140,2003$.

FERREIRA, N. J.; SANCHES, M.; SILVA DIAS, M. A. F. Composição da Zona de Convergência do Atlântico Sul em períodos de El Niño e La Niña. Revista Brasileira de Meteorologia, v. 19, n. 1, p. 89-98, jun. 2004.

FIGUEROA, S. N.; SATYAMURTY, P.; SILVA DIAS, P. L. Simulations of the summer circulation over the South American region with an ETA coordinate model. Journal of the Atmospheric Sciences, v. 52, n.10, p. 1573-1584, maio 1995.

FREITAS, E. D. Circulações locais em São Paulo e sua influência sobre a dispersão de poluentes. 2003. 157 f. Tese (Doutorado em Meteorologia) - Instituto de Astronomia, Geofísica e Ciências Atmosféricas, Universidade de São Paulo, São Paulo, 2003.

; ROZOFF, C. M.; COTTON, W. R.; SILVA DIAS, P. L. Interactions of an urban heat island and sea-breeze circulations during winter over the metropolitan area of São Paulo, Brazil. Boundary-Layer Meteorology, v. 122, n. 1, p. 43-65, jan. 2007.

GAN, M. A.; KOUSKY, V. E.; ROPELEWSKI, C. F. The South American monsoon circulation and its relationship to rainfall over West-central Brazil. Journal of Climate, v. 17, p. 47-66, jan. 2004.

GANDU, A. W.; SILVA DIAS, P. L. Impact of tropical heat sources on the South American tropospheric upper circulation and subsidence. Journal of Geophysical Research, v. 103, n. D6, p. 6001-6015, 1998.

; COHEN, J. C. P.; SOUZA, J. R. S. Simulation of deforestation in eastern Amazonia using a high-resolution model. Theoretical and Applied Climatology, v. 78, n. 1-3, p. 123135, abr. 2004.

GASH, J. H. C.; NOBRE, C. A. Climatic effects of amazonian deforestation: some results from ABRACOS. Bulletin of the American Meteorological Society, v. 78, n. 5, p. 823-830, maio 1997.

GEVAERD, R.; FREITAS, S. Estimativa operacional da umidade do solo para iniciação de modelos de previsão numérica da atmosfera. Parte I: Descrição da metodologia e validação. Revista Brasileira de Meteorologia, v. 21, n. 3, p. 1-15, dez. 2006. 
GRELL, G. A. Prognostic evaluation of assumptions used by Cumulus parameterizations. Monthly Weather Review, v.121, p. 764-787, mar. 1993.

GRIMM, A. M.; PAL, J. S.; GIORGI, F. Connection between spring conditions and peak summer monsoon rainfall in South America: role of soil moisture, surface temperature, and topography in Eastern Brazil. Journal of Climate, v. 20, p. 5929-5945, dez. 2007.

HERDIES, D. L.; DA SILVA, A.; SILVA DIAS, M. A. F.; NIETO FERREIRA, R. Moisture budget of the bimodal pattern of the summer circulation over South America. Journal of Geophysical Research, v. 107, n. D20, p. 42-1-10, set. 2002.

HUFFMAN, G. J.; ADLER, R. F.; MORRISSEY, M. M.; BOLVIN, D. T.; CURTIS, S.; JOYCE, R.; MCGAVOCK, B.; SUSSKIND, J. Global precipitation at one-degree daily resolution from multisatellite observations. Journal of Hydrometeorology, v. 2, p. 36-50, fev. 2001.

BOLVIN, D. T.; GU, G.; NELKIN, E. J.; BOWMAN, K. P.; HONG, Y.; STOCKER, E. F.; WOLFF, D. B. The TRMM Multisatellite Precipitation Analysis (TMPA): quasi-global, multiyear, combined-sensor precipitation estimates at fine scales. Journal of Hydrometeorology, v. 8, p. 38-55, fev. 2007.

INSTITUTO BRASILEIRO DE GEOGRAFIA E ESTATÍSTICA. Apresenta dados estatísticos, informações geográficas, econômicas e sociais do Brasil. Disponível em: <http://www.ibge.gov.br/home/default.php>. Acesso em: 3 dez. 2009.

JONES, C.; CARVALHO, L. M. V. Active and break phases in the South American Monsoon System. Journal of Climate, v. 15, p. 905-914, abr. 2002.

JORGetTI, T. A Zona de Convergência do Atlântico Sul e os processos oceânicos do Atlântico e do Pacífico. 2008. 169 f. Tese (Doutorado em Meteorologia) - Instituto de Astronomia, Geofísica e Ciências Atmosféricas, Universidade de São Paulo, São Paulo, 2008.

KODAMA, Y. Large-scale common features of subtropical precipitation zones (the Baiu Frontal Zone, the SPCZ, and the SACZ). Part I: Characteristics of the subtropical frontal zones. Journal of the Meteorological Society of Japan, v. 70, n. 4, p. 813-836, ago. 1992.

Large-scale common features of sub-tropical convergence zones (the Baiu Frontal Zone, the SPCZ, and the SACZ). Part II: Conditions of the circulations for generating the STCZs. Journal of the Meteorological Society of Japan, v. 71, n. 5, p. 581-610, out. 1993. 
KOUSKY, V. E.; GAN, M. A. Upper tropospheric cyclonic vortices in the tropical South Atlantic. Tellus, v. 33, p. 538-551, 1981.

LAU, K.-M.; ZHOU, J. Anomalies of the South American Summer Monsoon associated with the 1997-99 El Niño-Southern Oscillation. International Journal of Climatology, v. 23, n. 5, p 529-539, 2003.

LENTERS, J. D.; COOK, K H. Summertime precipitation variability over South America: role of the large-scale circulation. Monthly Weather Review, v. 127, p. 409-431, mar. 1999.

LIEBMANN, B.; KILADIS, G. N.; MARENGO, J. A.; AMBRIZZI, T.; GLICK, J. D. Submonthly convective variability over South America and the South Atlantic Convergence Zone. Journal of Climate, v. 12, p. 1877-1891, jul. 1999.

; JONES, C.; CARVALHO, L. M. V. Interannual variability of daily extreme precipitation events in the State of São Paulo, Brazil. Journal of Climate, v. 14, p. 208-218, jan. 2001.

; MARENGO, J. A. Interannual variability of the rainy season and rainfall in the Brazilian Amazon Basin. Journal of Climate, v. 14, p. 4308-4318, nov. 2001.

; KILADIS, G. N.; VERA, C. S.; SAULO, A. C.; CARVALHO, L. M. V. Subseasonal variations of rainfall in South America in the vicinity of the low-level jet East of the Andes and comparison to those in the South Atlantic Convergence Zone. Journal of Climate, v. 17, p. 3829-3842, out. 2004.

LISTON, G. E.; PIELKE, R. A. A climate version of the Regional Atmospheric Modeling System. Theoretical and Applied Climatology, v. 66, n. 1-2, p. 29-47, jun. 2000.

LU, L. X.; PIELKE, R. A.; LISTON, G. E.; PARTON, W. J.; OJIMA, D.; HARTMAN, M. Implementation of a two-way interactive atmospheric and ecological model and its application to the central United States. Journal of Climate, v. 14, p. 900-919, mar. 2001.

MENDONÇA, A. M. Desempenho do modelo global CPTEC/COLA durante episódios de ZCAS, utilizando os esquemas de convecção profunda tipo Kuo e Arakawa-Schubert relaxada. 1999. 166 f. Dissertação (Mestrado em Meteorologia) - Instituto Nacional de Pesquisas Espaciais, São José dos Campos, 1999. 
MOLION, L. C. B.; BERNARDO, S. O.; OLIVEIRA, C. P. Variabilidade da circulação de grande escala sobre o Atlântico Subtropical. In: CONGRESSO BRASILEIRO DE METEOROLOGIA, 13., 2004, Fortaleza. Anais... Rio de Janeiro: Sociedade Brasileira de Meteorologia, 2004.

NINOMIYA, K.; NISHIMURA, T. OHFUCHI, W.; SUZUKI, T.; MATSUMURA, S. Features of the Baiu Front simulated in an AGCM (T42L52). Journal of the Meteorological Society of Japan, v. 80, n. 4, p. 697-716, ago. 2002.

; ENOMOTO, T.; NISHIMURA, T.; SUZUKI, T.; MATSUMURA, S. Synoptic- and meso- $\alpha$-scale variation of the Baiu Front simulated in an AGCM. Journal of the Meteorological Society of Japan, v. 81, n. 6, p. 1387-1405, dez. 2003.

. Similarity and difference between the South Atlantic Convergence Zone and the Baiu Frontal Zone simulated by an AGCM. Journal of the Meteorological Society of Japan, v. 85, n. 3, p. 277-299, jun. 2007.

NOGUÉS-PAEGLE, J.; MO, K. C. Alternating wet and dry conditions over South America during summer. Monthly Weather Review, v. 125, p. 279-291, fev. 1997.

OOKOUCHI, Y.; SEGAL, M.; KESSLER, R. C.; PIELKE, R. A. Evaluation of soil moisture effects on the generation and modification of mesoscale circulations. Monthly Weather Review, v. 112, p. 2281-2292, nov. 1984.

PIELKE, R. A.; COTTON, W. R.; WALKO, R. L.; TREMBACK, C. J.; LYONS, W. A., GRASSO, L. D.; NICHOLLS, M. E.; MORAN, M. D.; WESLEY, D. A., LEE, T. J.; COPELAND, J. H. A comprehensive meteorological modeling system - RAMS. Meteorology and Atmospheric Physics, v. 49, p. 69-91, 1992.

Mesoscale Meteorological Modeling. 2. ed. Londres: Academic Press, 2002, 676 p.

QUADRO, M. F. L. Estudo de episódios de Zona de Convergência do Atlântico Sul (ZCAS) sobre a América do Sul. 1994. 89f. Dissertação (Mestrado em Meteorologia) Instituto Nacional de Pesquisas Espaciais, São José dos Campos, 1994.

RAMOS DA SILVA, R.; SILVA DIAS, P. L.; MOREIRA, D. S.; DE SOUZA, E. B. Modelo OLAM (Ocean-Land-Atmosphere-Model): descrição, aplicações, e perspectivas. Revista Brasileira de Meteorologia. v. 24, n. 2, p. 144-157, jun. 2009. 
RICKENBACH, T. M.; NIETO FERREIRA, R.; HALVERSON, J.; SILVA DIAS, M. A. F. Modulation of convection in the southwestern Amazon basin by extratropical stationary fronts. Journal of Geophysical Research, v. 107, n. D20, 8040, ago. 2002.

SECRETARIA DOS TRANSPORTES METROPOLITANOS. Regiões Metropolitanas. Apresenta informações geográficas, econômicas e sociais das regiões metropolitanas brasileiras. Disponível em: $<$ http://www.stm.sp.gov.br/index.php?option=com_content\&view=article\&id=2267\&Itemid= 310>. Acesso em: 3 dez. 2009.

SEGAL, M.; SHREIBER, W. E.; KALLOS, G.; GARRATT, J. R.; RODI, A.; WEAVER, J.; PIELKE, R. A. The impact of crop areas in Northeast Colorado on midsummer mesoscale thermal circulations. Monthly Weather Review, v. 117, p. 809-825, abr. 1989

STEIN, U.; ALPERT, P. Factor separation in numerical simulations. Journal of Atmospheric Sciences, v. 50, n. 14, p. 2107-2115, abr. 1993.

TREMBACK, C. J. Numerical simulation of a Mesoscale Convective Complex: model development and numerical results. 1990. 247 f. Tese (Doutorado) - Department of Atmospheric Science, Colorado State University, Fort Collins, 1990.

TRIPOLI, G. J.; COTTON, W. R. The Colorado State University three-dimensional cloud/mesoscale model - 1982, Part I: General theoretical framework and sensitivity experiments. Journal de Recherches Atmospheriques, v. 16, p. 185-220, 1982.

UPPALA, S. M.; KALLBERG, P. W.; SIMMONS, A. J.; ANDRAE, U.; BECHTOLD, V. C.; FIORINO, M.; GIBSON, J. K.; HASELER, J.; HERNANDEZ, A.; KELLY, G. A.; LI, X.; ONOGI, K.; SAARINEN, S.; SOKKA, N.; ALLAN, R. P.; ANDERSSON, E.; ARPE, K.; BALMASEDA, M. A.; BELJAARS, A. C. M.; VAN DE BERG, L.; BIDLOT, J.; BORMANN, N.; CAIRES, S.; CHEVALLIER, F.; DETHOF, A.; DRAGOSAVAC, M.; FISHER, M.; FUENTES, M.; HAGEMANN, S.; HÓLM, E.; HOSKINS, B. J.; ISAKSEN, L.; JANSSEN, P. A. E. M.; JENNE, R.; MCNALLY, A. P ; MAHFOUF, J.-F.; MORCRETTE, J.-J.; RAYNER, N. A.; SAUNDERS, R. W.; SIMON, P.; STERL, A.; TRENBERTH, K. E.; UNTCH, A.; VASILJEVIC, D.; VITERBO, P.; WOOLLEN, J. The ERA-40 re-analysis. Quarterly Journal of the Royal Meteorological Society, v. 131, n. 612, p. 2961-3012, out. 2005.

WALKO, R. L.; COTTON, W. R.; MEYERS, M. P.; HARRINGTON, J. Y. New RAMS cloud microphysics parameterization. Part I: The single-moment scheme. Atmospheric Research, v. 38, p. 29-62, 1995. 
; BAND, L. E.; BARON, J.; KITTEL, T. G. F.; LAMMERS, R.; LEE, T. J.; OJIMA, D.; PIELKE, R. A.; TAYLOR, C.; TAGUE, C.; TREMBACK, C. J.; VIDALE, P. L. Coupled atmosphere-biophysics-hydrology models for environmental modeling. Journal of Applied Meteorology, v. 39, p. 931-944, jun. 2000.

; AVISSAR, R. The Ocean-Land-Atmosphere Model (OLAM). Part I: shallow-water tests. Monthly Weather Review, v. 136, n. 11, p. 4033-4044, nov. 2008.

WALLACE, J. M.; HOBBS, P. V. Atmospheric Science: An introductory survey. 2. ed. San Diego: Academic Press, 2006, 483 p.

WERTH, D.; AVISSAR, R. The regional evapotranspiration of the Amazon. Journal of Hydrometeorology, v. 5, p. 100-109, fev. 2004.

ZHANG, D. L.; ANTHES, R. A. A high resolution model of the planetary boundary layersensitivity tests and comparisons with SESAME-79 data. Journal of Applied Meteorology, v. 21, p. 1594-1609, nov. 1982. 